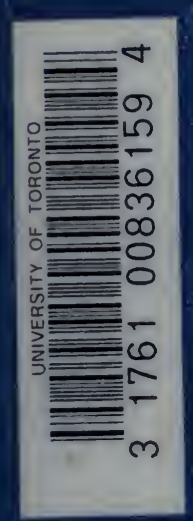


Digitized by the Internet Archive in 2008 with funding from Microsoft Corporation 


PUBLICATIONS OF THE UNIVERSITY OF MANCHESTER

-BIOLOGICAL SERIES

No. II

\section{THE QUANTITATIVE METHOD IN BIOLOGY}


Published by the University of Manchester at

THE UNIVERSITY PRESS (H. M. MCKechnie, Secretary)

12 Lime Grove, Oxford ROAd, MANCHESTER

LONGMANS, GREEN \& CO.

London : 39 Paternoster Row, E.C.4

New YORK : 443-449 Fourth Avenue and Thirtieth Street

Chicago : Prairie Avenue and Twenty-fifth Street

BOMBAX : 8 Hornby Road

Calcutta : 6 Old Court House Street

MADRAS : 167 Mount Road 


\section{THE QUANTITATIVE METHOD IN BIOLOGY}

BY

Julius Macleod, Dr Nat. Sc.

Professor of Botany in the University of Ghent

WITH 27 FIGURES

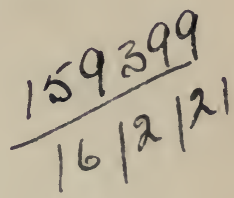

MANCHESTER :

AT THE UNIVERSITY PRESS

12 LIME GROVE, OXFORD ROAD

LONGMANS, GREEN \& CO.

LONDON, NEW YORK, BOMBAY, ETC 
PUBLICATIONS OF THE UNIVERSITY OF MANCHESTER No. $\operatorname{CXX}$

QU
307
$M 35$

All rights reserved 


\section{P R E F A C E}

IN Physics, Chemistry and Mineralogy the properties of the objects are measured and expressed by means of figures called constants. A constant is independent of any theory: it is the exact expression of a fact. The constants are in reality the material by means of which theories are built up, the explanation of the observed facts is found and the road opened for new discoveries.

In Botany and Zoology, on the contrary, the properties (characters) of the living things are usually described by means of terms. We say that a given object is long or short, broad or narrow, oblong or oval, etc. Much progress would be rendered possible if such terms as long, broad, short, etc., were replaced by figures. This would be simple enough if the properties of animals and plants were invariable. Unfortunately these properties are almost always variable, not only within the limits of one species, but also among the children of the same parents and even among the progeny of one parent. ${ }^{1}$ Variability has been hitherto the great obstacle which has rendered impossible the general use of quantitative data (figures) in Biological Sciences.

The object of the present book is to describe a method by which biological constants may be established.

In the first two chapters I have expounded certain theoretical views about the notion of species and variation. Those views afford us a guide for the discovery of the primordia (simple or elementary properties or characters) which are to be measured in order to find constants. The constants themselves are, however, entirely independent of any theory and of any

1 Parthenogenesis, apogamy, asexual multiplication in animals and plants. 
calculation whatsoever. Each constant is a direct expression of an observed fact.

I have been asked several times in what way the described method was to be applied to the investigation of certain given properties of certain animals or plants. My answer is that in each peculiar case a preliminary investigation is required in order to find the primordia which are to be measured and the way in which the measurements are to be carried out. This preliminary work may be a long one.

For example, I began in December I9I4 the study of the British species of the genus Mnium (Acrocarpic Mosses). I spent two months on the preparatory work before I had found a dozen of the primordia and established their exact definition and the method of measuring them. In a similar way it took me in 1916 about three months to determine exactly twenty-five primordia of the fertile stem of the Grasses. In 1907 I began the measurement of thirty-eight primordia of the species of the genus Carabus after a preparatory investigation of the simple properties of the Coleoptera and other insects which lasted several years. Such work is, I think, an excellent school for the biologist, because he becomes aware of the vagueness of many of our notions. As soon as we require to make measurements, we feel again and again compelled to replace approximations by exact definitions. It may be hoped that the preparatory work under consideration will become easier in proportion as the number of examples investigated becomes greater.

The work needed for the measurement of the primordia of animals and plants is rather lengthy, but biologists ought not to shrink from the idea of undertaking such a laborious task. It may be recalled that the physicists, the chemists and the mineralogists have already collected hundreds of thousands of constants at the cost of tremendous toil. They have persevered in spite of numerous difficulties. For example, in order to establish exactly the constants (atomic weight, specific gravity, melting-point, etc.) of a given metal, a pure specimen 
must be provided, and the preparation of a pure specimen may last several months. Moreover, many figures obtained by the measurement of inorganic objects are variable according to the external conditions, in the same way as the dimensions and other properties of living beings. For instance, the density of a given substance varies according to temperature; pressure has an influence on the boiling-point; etc. Therefore, in order to establish constants, certain conventions have been made; this renders the task still more laborious and delicate. Biologists should not allow themselves to be discouraged by the prospect of "such lengthy work"; they should always remember what the students of inorganic nature have already carried out.

When an index of refraction, a coefficient of expansion or a given angle of a crystal has been exactly measured, work and perseverance find their reward, because a precise notion has been acquired once for all. In Biology, on the contrary, especially in the descriptive (systematic) part of Zoology and Botany, ${ }^{1}$ numerous objects have been described again and again as new ; contradiction and hesitation prevail everywhere ; an enormous amount of labour has been wasted. We should follow the example given by physicists, chemists and mineralogists. Otherwise it may be feared that the work, like that of Penelope, will go on indefinitely.

It may be remarked that the present book is NOT in reality a treatise on mathematical biology: mathematical notions (Part VI.) are used only in order to find the primordia and the methods of measuring them. We may hope that when a sufficient number of constants have been collected the powerful machinery of mathematical science will become applicable to biological problems.

I have, in conclusion, the pleasant duty of acknowledging the assistance received from various friends.

To Professor F. E. Weiss, who has kindly read through the manuscript and has made numerous corrections in the language, and to Professor W. H. Lang, in whose laboratory

1 See on Embryology, § 50. 
I have been working for more than three years, I am indebted for the most cordial assistance. Both of them have given me bibliographical information of a most useful character.

I beg Professor G. Unwin, who kindly helped me with the language, to accept my most sincere thanks.

To Professor Niels Bohr, Copenhagen, I am indebted for useful remarks about the mathematical part.

Finally, I have to express my great obligation to $\mathrm{Mr} \mathrm{W}$. D. Evans, M.A., who has read through the manuscript and proofs of the mathematical part and who has assisted me in various ways.

JULIUS MACLEOD.

THE UNIVERSITY, Manchester. 21st December 1918. 


\section{CONTENTS}

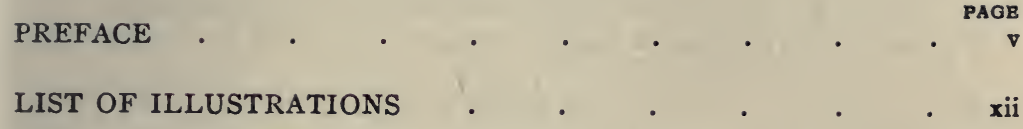

\section{PART I}

THE NOTION OF SPECIES IS A CHEMICAL NOTION . • I

The Living Substance of each Specific Form is a Mixture of a Number of Chemical Entities-Each Specific Mixture differs from all others by at least one Entity-Chemical Classification of Plants and AnimalsGroups and Series of Chemical Entities-Glycerides-Proteins-Natural Mixtures-Bioproteins-Biotic and Abiotic Chemical PropertiesHeredity-Individual Variation-Mutation-Lamarckism

\section{PART II}

THE OBSERVABLE PROPERTIES OF EACH SPECIES ARE PRODUCED BY REACTIONS OF ITS LIVING SUBSTANCE . . . . . . . .

Possible and Observable Properties-Range of Possibilities-PlasticityVariants-Complexity-Monotypic and Complex Species-Subspecies -Pure Lines-Bud-Variation-Bud-Species-Continuous and Discontinuous Variation-Adaptation-Accommodation-Variation under Cultivation-Latent Properties

\section{PART III}

\section{QUANTITATIVE METHOD AND PRIMORDIA . . . .}

Summary of Parts I. and II.-Use of the Quantitative Method in the Description and Classification of Species-Linnæus-Latreille-Bertillonage - Biometry - Quantitative Variation-Quetelet - Variation Curves-Galton-Weldon-Pearson-Davenport-Biometrika-Application of the Quantitative Method on the Study of HybridizationMendel-The Mendelian Experiments in Relation to the Notion of Species-Simple and Compound Properties-Primordia-Observable Properties and Hereditary Factors-Segregation (Dissociation) of Compound Properties into Primordia by Hybridization, Plasticity, Gradation and in the Course of Individual Development-The Mendelian Method of describing Hybrids is applicable on the Description of Species - Phyllotaxis - Quantitative Investigation of Physiological Functions 


\section{PART IV}

THE PRIMORDIA

The Adult State is a State of Equilibrium-Each Primordium represents a State of Equilibrium-Individual Adaptation (Accommodation) is Equilibrium-Classification of the Primordia with reference to their Development-Sensitive Period-Correlation-Independence of the Primordia-Pædogenesis-Measurement of a State of EquilibriumCurves of Development-Leading Property-Variation in Embryology

\section{PART V}

\section{ATTEMPT AT A CLASSIFICATION OF THE PRIMORDIA}

Numerous Primordia mentioned in existing Descriptive LiteratureClassification of the Primordia (Bateson)-Spirogyra (Primordia, Sensitive Period)-Uniaxial System-Radial System-PediastrumMorphological Homology and Mechanical Concordance-Volvox, Hydrodictyon-Systems of Segmentation derived from the Uniaxial System-Ramification-Pseudochete-Complicated Cases - Primordia of Trees, Cuttings, Grafts, etc. - The Notion of Individual-Series of Subordinate Biological Units-Secondary Segmentation-Rectangular Biaxial System (Chess-board System)-Alterations of the Chess-board System-Intermediate Units-Vexillary Marks-Gradation-Differentiation-Simple and Compound Axes-Curved Axes-DisorderFalse (Oblique) Axes-Second Secondary Segmentation: Rectangular Triaxial System-Shell of the Molluscs

\section{PART VI}

THE MEASUREMENT OF VARIABLE PROPERTIES OF ANIMALS AND PLANTS. SIMPLE NOTIONS OF PROBABILITY (FREQUENCY).

Position of Equilibrium of a Sphere on a Horizontal Plane-ChanceSpecific Energy - One Coin (Head or Tail)-A System of Two CoinsThree Coins-An Unlimited Number of Coins-An Urn containing Two Sorts of Balls, Three Sorts of Balls-One Die, Two Dice-Coexistence of Simple Events-Various Ways in which they may be combined into Compound Events-Diversity of the Effects

Application of the Principles of Frequency on the Hereditary Transmission of Primordia in the Mendelian Hybrids-Segregation

Measurement of the Density of a Solid Body-Curve of ErrorsMeasurement of a given Weight of a certain Substance-A Mixture of Two Volumes of Water-A Mixture of an Acid and an Alkaline Liquid -Continuous and Discontinuous Variation-Unilateral VariationInfluence of Growth-Embryological Curves

An Urn containing Two Sorts of Prisms-Variation Curve-Extreme Values and Mean Value-Experiments with Cards-Biological and Inorganic Variation Curves-Conditions of Existence-Components of Chance-Optimal Values-Values $m-0 . M$-Significance of a Mean Value-The Highest Value of a Variable Primordium is a Specific Constant-Minimal Value-Conventions-Usefulness of Mean Values for Comparing Two or More Series of Measurements 


\section{PART VII}

\section{VARIATION STEPS}

Examples-Diverse Series of Variation Steps-Variation Steps of the First, Second and Third Degree-Symmetry and Variation StepsRelation between Mean Value and Variation Steps-Transformation of a Monomorphic Curve into a Dimorphic or a Polymorphic one by External Causes-Influence of Selection upon Variation Steps-Discontinuous Variation, Variation Steps and Specific Difference-Relation between Variation Steps and Phyllotaxis-Methods for the Discovery of Variation Steps-Embryological Series-Parallel Variation: Mechanical Concordance, Embryological Parallelism, Parallel Variation Steps

\section{PART VIII}

\section{GRADATION}

Comparison between Living Beings and Crystals-The Axes of the Crystals are Lines of Stability - The Axes of the Living Beings are also Lines of Stability-Difference between both Sorts of Axes-Examples of Gradation-Independence of the Primordia in Respect of Gradation -Comparison between Gradation Curves and Embryological CurvesThe Axes of the Living Beings are Lines of Equilibrium, Ordonnance, Gradation, Segmentation and Differentiation-Various Effects of Gradation

\section{PART IX}

APPLICATION OF THE QUANTITATIVE METHOD - THE DESCRIPTION OF SPECIES . . . . .

Various Applications of the Quantitative Method-Breach of Continuity in the Development of Biological Science-Vagueness and Incompleteness of Specific and Generic Descriptions-Importance of Systematics -Comparative Method-Morphology-Palæontology-Importance of Collections-Minute Details-The Notion of Species-Independence of Species-Quantitative Description and Identification of GramineaConstants of Alopecurus pratensis-Tables of Constants-ExamplesMethods for using Tables of Identification-Bertillonage 


\section{LIST OF ILLUSTRATIONS}

FIGURE

I. Variation Curve of the Disc-breadth of Ophiocoma nigra $\quad$ - $\quad 29$

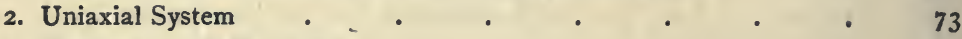

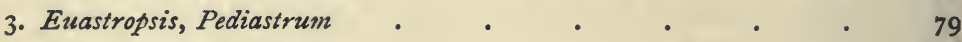

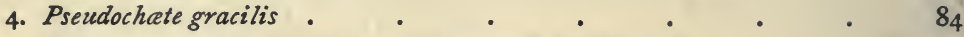

5. A Hair consisting of Four Cells (Erodium moschatum) . . 87

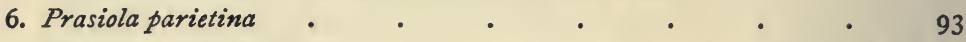

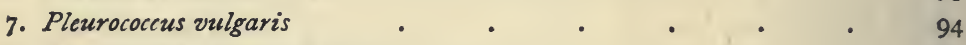

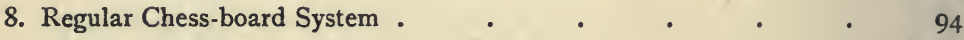

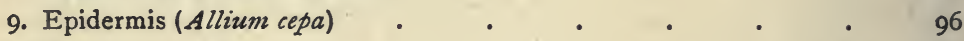

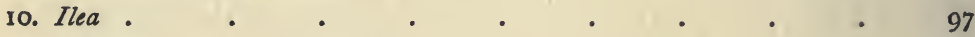

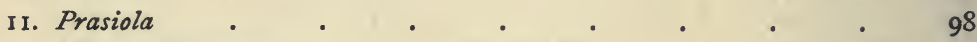

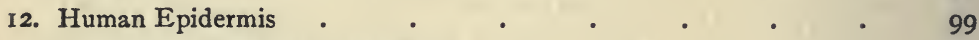

13. (I) Regular Chess-board System . . . . . . 100

13. (2) Effects of Gradation in a Chess-board System . . . IOI

I4. Allium porrum : Epidermis . . . . . . . 103

15. Chess-board System in Leaves of Mosses . . . . . 106

16. Mnium punctatum: Cells of the Leaf . . . . . 108

17. Bryum argenteum : Cells of the Leaf $\quad . \quad$. $\quad . \quad . \quad 109$

18. Curve of Errors $(a+b)^{10} \quad$ - $\quad$. $\quad$. $\quad$. $\quad$. $\quad$. 146

19. Curve of Committed Errors ; Curve of Observed Effects . . 152

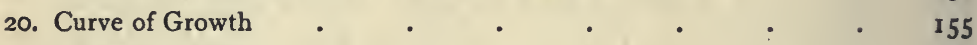

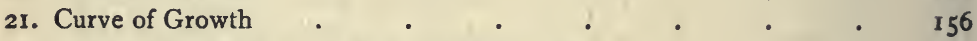

22. Curve of Development : Red, Hesitation, Blue . . . 157

23. Curves of Development of Three Primordia . . . . ${ }^{58}$

24. Symmetrical Variation Curve $\quad$. $\quad . \quad$. 161

25. Relation between Temperature and Growth . . . . 168

26. Gradation Curve $\quad$. $\quad$. . . . 201

27. Gradation Curves of Four Primordia . $\quad$ • . $\quad$. 203 


\section{THE QUANTITATIVE METHOD IN BIOLOGY}

\section{PART I}

\section{THE NOTION OF SPECIES IS A CHEMICAL NOTION}

$\S 1$.-Each animal and vegetable species 1 differs strictly from all others by the chemical composition of its living substance.

§ 2.-The so-called characteristics of each species are the product of reactions, in which there intervene on the one hand the external causes which affect the individuals during their development and on the other hand the living substance of the species under consideration.

§ 3.-Our knowledge of the chemical composition of living substance is too incomplete to found a RATIONAL classification of plants and animals based upon differences of chemical constitution. In the present state of science our classifications are founded merely on differences in observable characteristics (properties).

In our study of living beings we find ourselves in much the same position as a mineralogist would be if he were ignorant of the chemical constitution of the minerals, and were thus limited to the study of their properties, such as crystalline form, optical properties, density, hardness, colour, etc., and were to try to found on those data a classification of the mineral species. ${ }^{2}$ Fortunately, we dispose of a larger number of facts than our

1 The term species is used here in its most general significance (specific form) - that is to say, in the sense of a form of life (species properly so called, elementary species, race, etc.) characterized by hereditary properties.

${ }^{2}$ See Sir HENRY ALEXANDER MIERS, F.R.S., The Old and the New Mineralogy, in Trans. Chemical Society, 1918, vol. cxviii., pp. 364-386. In this interesting paper the author has recorded that, in former times, the characters of minerals which were used for the purpose of discriminating between species and of classifying them were the external or natural history properties (specific gravity, colour, crystalline form, etc.). Later on (DANA, I850) a new classification of the minerals, based upon their chemical composition, was adopted. 
supposed mineralogist: we may investigate the transmission of the properties (characteristics) by inheritance, the order in which they appear during individual development and, in many cases at least, the order in which species and groups of species have appeared during the geological ages. We may also modify the properties of a given species and bring about the appearance or disappearance of some of them by modifying the conditions of existence (external causes). In spite of all this, however, our classifications are of an empirical nature.

§ 4.-At first sight it seems impossible to accept the suggestion that a sufficient diversity exists in the chemical composition of the living substance to explain the existence of millions of animal and vegetable species. This difficulty disappears when we look upon the living substance of each species as consisting of a mixture of a rather small number of chemical entities-the components being very probably proteins (or substances related to the proteins) and each specific mixture differing from all others by at least one component.

If we suppose that the components of all the existing species are thirty in number and that twenty of them occur in each species, we realize the possibility of an enormous number of specific mixtures differing from each other by one, two or more components. ${ }^{1}$ If we suppose, moreover, that in certain species twenty, in others nineteen, eighteen, etc., components occur, the number of possible mixtures becomes practically unlimited, just as is the case with the number of living and fossil species.

§ 5.-In the present state of science it is impossible to verify the above suggestion. It is, however, made admissible by the following facts :-

(I) A large number of the combinations of carbon may be brought into natural groups, each group consisting of one or several series, each series including several terms.

EXAMPLE : one of the most important groups consists of the glycerides of the fatty acids (fixed oils and fats). In this group we find numerous series; for instance, the glycerides of the acids of the

acetic series $\left(\mathrm{C}_{\mathrm{n}} \mathrm{H}_{2 \mathrm{n}} \mathrm{O}_{2}\right)$,

acrylic (oleic) series $\left(\mathrm{C}_{\mathrm{n}} \mathrm{H}_{2 n-2} \mathrm{O}_{2}\right)$,

linolic series $\left(\mathrm{C}_{\mathrm{n}} \mathrm{H}_{2 \mathrm{n} \cdot 4} \mathrm{O}_{2}\right)$,

linolenic series $\left(\mathrm{C}_{n} \mathrm{H}_{2 n \cdot 6} \mathrm{O}_{2}\right)$, etc. ${ }^{2}$

\footnotetext{
1 The number of such specific mixtures differing by one component at least is 30,045 , or 5 .

${ }^{2}$ In EDWARD THORPE, $A$ Dictionary of Applied Chemistry, vol. iii. (I9I2), p. 744 , nine series are mentioned.
} 
Each series includes a certain number of terms (entities) which differ from each other by the value of $n$; for instance, to the acetic series belong the glycerides of

$$
\begin{aligned}
& \text { acetic acid }\left(\mathrm{C}_{2} \mathrm{H}_{4} \mathrm{O}_{2}\right) \text {, } \\
& \text { butyric acid }\left(\mathrm{C}_{4} \mathrm{H}_{8} \mathrm{O}_{2}\right), \\
& \text { caproic acid }\left(\mathrm{C}_{6} \mathrm{H}_{12} \mathrm{O}_{2}\right), \\
& \text { lignoceric acid }\left(\mathrm{C}_{24} \mathrm{H}_{48} \mathrm{O}_{2}\right) \text {, etc. ; }
\end{aligned}
$$

to the acrylic series belong the glycerides of

$$
\begin{aligned}
& \text { tiglic acid }\left(\mathrm{C}_{5} \mathrm{H}_{8} \mathrm{O}_{2}\right) \text {, } \\
& \text { oleic acid }\left(\mathrm{C}_{18} \mathrm{H}_{34} \mathrm{O}_{2}\right) \text {, } \\
& \text { erucic acid }\left(\mathrm{C}_{22} \mathrm{H}_{42} \mathrm{O}_{2}\right) \text {, etc., etc. }{ }^{1}
\end{aligned}
$$

Between the terms of each series and also between the series of a given group evident analogies exist, not only with regard to the chemical constitution, but also in the facies and physical properties.

(2) The PROTEINS 2 seem to be polypeptides which are formed by the conjugation of a large number of amino acids. Altogether more than fifty proteins are known to occur naturally in animals and plants, which differ from one another in physical and chemical properties. They may be brought into classes and groups in the following way ${ }^{3}$ :-

Class A : Simple Proteins.

Group I: Protamines.

" 2: Histones.

"3: Albumins.

" 4: Globulins.

" 5: Prolamins (Gliadins).

"6: Glutelins.

Class B": 7 : Conjugated Proteins.

Group 8: Nucleoproteins.

" 9: Glycoproteins.

", Io: Hæmoglobins.

" II : Phosphoproteins.

I2: Lipoproteins.

Class C": Derived Proteins.

Group I3: Proteans (Metaproteins).

", I4: Coagulated Proteins.

" I5 : Proteoses.

" I6: Peptones.

" I7: Peptides.

1 THORPE, loc. cit., vol. iii., p. 744 .

Ibid., vol. iv. (1913), p. 407.

The classification here given is adopted by American physiologists and chemists. See Thorpe, loc. cit., vol. iv. 


\section{THE QUANTITATIVE METHOD IN BIOLOGY}

In each group we find a certain number of substances; for instance :

In Group 3 (Albumins) : Legumelin, Leucosine, Ricin.

In Group 4 (Globulins): Amandin, Avenalin, Castanin, Conglutin, Corylin, Edestin, Excelsin, Globulin, Myosin, Ovoglobin, Fibrinogen, etc.

Since the way in which the highly complicated molecules of the proteins are built up is very incompletely known, their classification is more or less of an empirical nature. There exist, however, between those substances physical and chemical analogies enough to justify the conclusion that they are related to each other, at least to a certain degree, in a similar way as the glycerides.

(3) We find in the body of living beings, independently of the living substance, numerous so-called substances the composition of which is more or less completely known. Many of those substances are mixtures of several distinct chemical entities. It is, from a biological standpoint, a very important fact that such natural mixtures consist in the main almost always of components which belong to the same chemical family.

The natural oils and fats which are distributed throughout the vegetable and animal kingdoms afford us numerous instances of mixtures.

EXAMPLES: (a) Arachis Oil (seed of Arachis hypogea) contains glycerides of stearic, arachidic, lignoceric, oleic, hypogæic, linolic acids, etc. ${ }^{1}$

(b) In Linseed Oil (seed of Linum usitatissimum), the composition of which is not yet fully known, glycerides of palmitic, arachidic, linolenic, oleic acids have already been discovered. ${ }^{2}$

(c) In Cow Butter glycerides of the following acids occur:butyric, caproic, caprylic, capric, lauric, myristic, palmitic, stearic, oleic. ${ }^{3}$

Microscopical observation does not give us the slightest idea of the complicate composition of the natural mixtures which we call arachis oil, linseed oil and cow butter.

It may be remarked that the same glyceride very often occurs among the components of several oils and fats (for instance, oleic acid is found in the three above examples and many others; arachis oil and linseed oil have two components in common, although they are found in plants which belong to different families).

ANOTHER EXAMPLE: There are in opium (latex of Papaver somniferum) neutral compounds, acids and some twenty alkaloids, the most important of which is Morphine. ${ }^{4}$

${ }^{3}$ Ibid., vol.i. (I912), p. 577.

Ibid., vol. iv. (I913), p. I9. 
§ 6.-The facts stated in the preceding paragraph may be summarized in the following way:-a large number of natural substances are mixtures, consisting in the main of chemical entities which belong to one chemical family ; the components are associated in a different way in each species and each component may occur in a certain number of specific mixtures. On the other hand, the proteins may be looked upon as belonging to a single chemical family.

We may therefore accept the suggestion that living substance (the living contents of the cell) follows the ordinary rule and is a mixture, and since many well-known facts point to a chemical relation between living substance and proteins, we may admit that the components of the former are proteins-or substances which are related to the already known proteins and which might be called Bioproteins.

The properties ${ }^{1}$ of living substance are, indeed, so characteristic that we are, as it were, compelled to think that its components are not merely proteins properly so called. It may be suggested that these components are proteins of a peculiar kind, which deserve to be distinguished under the name bioproteins.

It may be further surmised that the molecules of the bioproteins are more complex than those of the proteins, and are formed by the conjugation of a larger number of amino acids, ${ }^{2}$ the proteins properly so called being hydrolitic degradation products of the bioproteins. According to this, a special class, under the name of bioproteins, ought perhaps to be added to the three classes mentioned in the classification adopted in $\S 5$.

$\S$ \%. - The living mixture which is found in a cell or a plasmodium does not consist entirely of a homogeneous association of components. Certain components are permanently or temporarily separated from the others, being localized among the living mass ${ }^{3}$ and differentiated in the form of nucleus, chromosomes, centrosomes, protoplasmic granulations and, in general, plastids. The differentiated parts may be themselves mixtures of several bioproteins. It is quite possible that a chromosome, for instance, is a complicated mixture of a number of bioproteic entities. A minute globule of cow butter,

${ }^{1}$ Contractility; semipermeability; division of nucleus and plastids: irritability, etc.

2 Or by the conjugation of two or several already discovered proteins.

3 Example: Nucleoproteins (see p. 3, Group 8), which are compounds of the strongly basic protamines (p. 3, Group I) with nucleic acid, seem to be localized in the cell nucleus (Thorpe, loc. cit., vol. iv., p. 4II). I do not look upon nucleoproteins as being bioproteins. Certain bioproteins, however, may be localized in certain parts of the cell in the same way as nucleoproteins. 
observed in a drop of milk by means of the most powerful microscope, seems to be a homogeneous mass, although it consists of nine different kinds of glycerides. It is therefore quite conceivable that a chromosome, a centrosome, the living stroma of a chloroplast, etc., contain a number of bioproteic components.

By the investigation of the differentiated parts of the living substance we may acquire very valuable knowledge of numerous observable properties and functions of the cells, yet we are not enabled to probe to the actual bottom of the subject. A biologist is sometimes induced to believe that it is possible, by proceeding along this path of study, to attain the limits of our science with regard to the explanation of the facts of heredity, variation and origin of species. Feeling themselves deceived, after many years of work, certain biologists seek for an explanation in a so-called vital force, which is a matter of belief and not susceptible of scientific analysis.

We must always bear in mind that all the differentiations and functions of the living substance, and also its physical constitution, after all is said and done, depend on the way in which the molecules of its components are built up. As soon as we want to look further, we leave the field of exact science.

\section{§ 8.-BIOTIC AND ABIOTIC CHEMICAL PROPERTIES.} -A living mixture may include and probably always includes substances which do not belong to its intrinsical components. Such substances might be called abiotic ; they may be absorbed from without (examples: food, oxygen and eventually any substance for which the living mixture is permeable), or produced within the living mixture and used for various physiological purposes (glucose and more respiratory combustibles), or excreted (carbonic acid) or stored (starch, proteins in the form of aleuron, etc.), etc.

The abiotic substances which are included in the living mixture (and also, of course, in the vacuolar liquid and the cellwalls) are exceedingly numerous, and many of them are characteristic of certain species or groups of species.

EXAMPLES: Morphine in Papaver, nicotine in Nicotiana, dipsacine and dipsacotine in many Dipsacece; colouring and odorous substances in numerous plants and animals; for instance, in Phallus impudicus, Chara, Cicindela, Coccinella, bugs, etc.

The so-called chemical characteristics of a species, which depend on the presence of abiotic substances, are to be strictly distinguished from the biotic chemical properties of the specific living mixture. This mixture is the laboratory in which the alysarine of Rubia tinctorum, the coumarine of Asperula 
odorata, the roseal substance of Cicindela, the $\mathrm{S}\left(\mathrm{NH}_{4}\right)_{2}$ of Phallus and other chemical characteristics are produced.

§ 8A.-HEREDITY. INDIVIDUAL VARIATION. MUTATION.-Let us venture to proceed one step further along the way of suggestion.

Almost all the properties of living beings are variable within the limits of each species. The abiotic chemical properties follow the ordinary rule. We know, for instance, that the composition of opium and many other animal and vegetable chemical products is variable according to external causes (conditions of existence; for instance, climate). It is therefore possible and even probable that the living mixture of each species is also subjected to variation. It may be suggested that two kinds of variation occur:

(I) Individual variation (variation properly so called) produced by the diversity of the conditions of existence (external causes). In this form of variation it may be supposed that the individuals differ quantitatively -i.e. in the proportions in which the biotic components of the living substance are mixed, the qualitative composition (that is to say, the nature of the components) of the specific mixture being invariable in the species.

The qualitative composition of each specific mixture is transmitted by inheritance, and therefore the possibility of producing the reactions which result in specific properties (characters) is also hereditary. (This does not exclude segregation among the components of the living mixture of a hybrid, in which the components of both parents are brought together into one mixture.) It is also admissible that the quantitative composition of each individual is hereditary to a certain degree, and, moreover, that quantitative individual peculiarities may be accumulated (increased) under the influence of selection ${ }^{1}$ so often as the same conditions of existence prevail for two or several generations, the increase alluded to being confined within certain limits which are characteristic of each species (see $\S 9$ ). A complete discussion of this question lies outside the scope of the present book. (See $\S$ r29.)

(2) Certain causes, which are probably diverse (§ I05), may produce, in the qualitative composition of the living mixture of certain individuals of a species, a modification which is hereditary and called sport, saltation or mutation. If one of the components disappears, or is transformed into a new chemical entity (for instance, into an isomer), or if one new component is added to those previously existing, a slight mutation takes place, the new living form being, for instance, a pure line ( $§$ I 9 ) or a subspecies (elementary species) little different from the

${ }^{1}$ I am alluding here especially to experimental (artificial) selection. 
original form. We may, for instance, look upon the transformation of blue flax into white flax (or vice versa), of Solanum nigrum with black fruits into Sol. nigr. with green fruits, etc., as being the result of a qualitative transformation of the living mixture with regard to one of its components.

We may also imagine two, three or more components to be simultaneously transformed, the consequence of which would be the appearance by saltation (mutation) of a new species quite different from the original one, and even of a new genus, a new family. (See bud-variation, $\S 20)^{1}$

§ 9.-MUTATION. LAMARCKISM.-Among the possible causes of mutation alluded to in $\S 8 \mathrm{~A}$, the influence of external factors deserves a special mention. (See $\S \S 35$ and ro5.)

A change in the conditions of life of certain specimens of a species may result directly in a mutation.

It is also conceivable that a quantitative modification of a living mixture produced by external causes may become important enough to bring about indirectly a qualitative modification-i.e. a mutation. We know that the reactions which take place in a mixture of chemical entities depend, in certain cases and to a certain degree, on the proportions in which the entities are mixed. Therefore it is conceivable that a change in the proportions of a living mixture (quantitative modification) might produce a new reaction resulting in a mutation.

If we adopt the suggestion that mutations may be brought about, directly or indirectly, by external causes, there is no longer any incompatibility between

The principle of mutation (saltation), according to which a new species may appear at once, and

The Lamarckian principle, according to which new species are produced by new conditions of existence. ${ }^{2}$

Both principles being combined, ${ }^{3}$ the transformation of a species into a new one, without transitory or transitional forms between both, becomes quite intelligible.

1 According to the above a fundamental distinction ought to be made between two kinds of heredity :

(a) The hereditary transmission of quantitative modifications of the living mixture of a species; by this, no new species can be produced.

(b) The hereditary transmission of qualitative modifications of the living mixture of a species; this gives birth to a new species.

${ }^{2}$ Without selection.

3 That is to say, the production of mutations by external causes being admitted. 


\section{PART II}

\section{THE OBSERVABLE PROPERTIES OF EACH SPECIES ARE PRODUCED BY REACTIONS OF ITS LIVING SUBSTANCE}

§ 10.-POSSIBLE AND OBSERVABLE PROPERTIES.The living mixture of each species is able to produce numerous reactions which bring about the observable properties (socalled characteristics). In each reaction internal (specific) causes, which depend on the composition of the living mixture, and external causes, which depend on the environment (conditions of existence), play a part. The possible properties of each species are very numerous; each individual exhibits only a part of them, according to the conditions of existence under which it has been developed, the other properties being latent. What we usually call the characteristics of a species are those properties which become observable under ordinary circumstances of life. It is in this sense that the descriptions in the floras and the faunas and also in anatomical and morphological literature are to be understood. If the conditions are modified, some of the described characteristics become latent and other properties appear.

Therefore, if we wish to discover all the possibilities (potentialities, possible properties) of a species, we must collect and examine specimens developed under all the different external conditions under which the life of the species is possible.

$\S$ 11.-RANGE OF POSSIBILITIES. PLASTICITY.The range of possibilities is very different in one species from what it is in another. I take as first example three species which are characteristic of the alpine flora: Soldanella alpina, Rhododendron ferrugineum and Leontopodium alpinum. When these plants are cultivated in the plains (for instance, in the Botanic Garden at Ghent), where the conditions are different from those which prevail in high altitudes, they behave in quite a different way. Soldanella is not at all or hardly modified, but it dies down after a certain time : the limits of external conditions under which its existence is possible are rather narrow. ${ }^{1}$ Rhododendron may be kept in the plains for an

1 This seems to be the case with many vegetable species (for instance, several very rare terrestrial orchids) which are only found on certain spots where peculiar conditions prevail. 
unlimited number of years without any important change in its observable properties. Leontopodium is suitable for cultivation in the plains, yet its properties (facies) are so deeply modified that it becomes hardly recognizable; in other words, this species is very PLASTIC (modifiable, facilis). (See $\S$ I4.)

§ 12.-EXAMPLES OF PLASTICITY.-Polygonum amphibium is a good example of a species with a living substance capable of numerous reactions according to the conditions of existence, which bring about an astonishing diversity in its observable properties. This species occurs (for instance, in Flanders) in three distinct forms (VARIANTS). The terrestrial form or variant is (in Flanders) a common and rather noxious weed in cultivated fields. Its stem is erect and rather robust, $50 \mathrm{~cm}$. to $\mathrm{I} \mathrm{m}$. high, with numerous spreading leaves. The aquatic form or variant is common in ponds and watery ditches. The stems are longer ( $2 \mathrm{~m}$. and more), flexible, floating ; the leaves are few, rather thick, spreading on the surface of the water and differing considerably from the leaves of the terrestial form by their facies and anatomical structure. The xerophytic variant is not uncommon on rather arid, sandy soil. Here the stems are more or less creeping, the leaves being more like those of the terrestrial form but smaller. Transitions between the three mentioned types frequently occur; for instance, in shallow or dried-up ponds, muddy ditches, etc. The types are so very different from one another by their facies and internal structure that one can hardly realize that there is no hereditary difference between them (in other words, that the living mixture is the same in each and all). This is, however, beyond any doubt, for it is possible to obtain the three types (variants) by bringing parts (with buds) of one specimen under the various conditions of existence mentioned above.

Another remarkable example of plasticity is Ranunculus scelevatus. In the terrestrial variant, which is common on rather wet soil, the stem is erect, the leaves are comparatively small, spread out and divided into segments. In the aquatic variant the leaves are thicker, larger, less divided and spread on the surface of the water. Their facies is so characteristic that they may be discerned at first sight from any other sort of floating leaves of our flora. Limiting ourselves to the study of the terrestrial variant, ${ }^{1}$ we would neither suspect the possibility nor guess at the properties of the floating leaves. These are produced by reactions which take place only in water.

The two preceding species are examples of what we call ordinarily variable or polymorphic species. Here polymorphism

${ }^{1}$ In a number of floras the floating leaves are passed over in silence. 
is a consequence of plasticity and depends entirely on the conditions of life. In both examples plasticity is prominent, yet every living species is plastic to a certain degree.

Other well-known examples of remarkable plasticity are the so-called light and shade leaves of many plants (for instance, Fagus sylvatica); the variation in the leaves of several thistles according as they are developed in a dry or in a moist atmosphere ; remarkable variations in the colours of a number of butterflies ${ }^{1}$ produced by external influences (temperature, food) affecting the caterpillar or the chrysalis, etc.

It seems as if many biologists did not pay much attention to the above facts. They continue to give us descriptions of species and anatomical contrivances, as if plasticity did not exist. Plasticity, however, is in itself a very important phenomenon, which deserves to be investigated quite independently of the question whether the observed variations may become hereditary or not.

§ 13.-COMPLEXITY.-In certain species, which are also called variable or polymorphic, the observed variation is independent of external causes and depends on the fact that the species under consideration consists of two or several distinct hereditary forms or subspecies (elementary species) which are brought together under one name. EXAMPLE: Solanum nigrum is variable with regard to the colour of the ripe fruit. In many localities (on the Continent) specimens with black, berries and others with green berries are found side by side under the same conditions of existence. We know, on the other hand, that each of the colours mentioned is transmitted by inheritance (DE VRIES). ${ }^{2}$ We may conclude, therefore, that $S$. nigrum is a COMPLEX species, including two subspecies (melanocarpum and chlorocarpum). Very probably $S$. nigrum includes more than two sub-species. We see, indeed, in BENTHAM'S Handbook of the British Flora (I866) that

"in Britain, the stem ... is usually glabrous or nearly so, but on the Continent often hairy or rough at the angles,"

that the

"berries . . . are . . . usually black, but sometimes, especially on the Continent, green, yellow or dingy red," and further, that the species is

"varying so much in warmer regions as to have been described under more than forty names" (loc. cit., p. 332).

It is only by means of experiments that we can hope to

${ }^{1}$ Certain of the variations alluded to have been observed fortuitously in the state of nature and described as very rare varieties.

${ }^{2}$ HUGO DE VRIES, die Mutationstheorie (Leipzig, Veit und Co.), vol. ii. (1903), pp. 156 and I $70-17$ I. 
discover whether the mentioned polymorphism, with regard to certain properties, depends on the existence of several subspecies differing from each other by their living substance, or is a consequence of plasticity with regard to other properties. As far as I know, we have exact information only with reference to the colours black and green. In the meantime it is advisable to collect facts and material without encumbering the botanical nomenclature with more names.

\section{§ 14.-PLASTICITY (continued). SENECIO AND CHRYS-} ANTHEMUM.- It may happen that certain species are very plastic with regard to a certain property, whereas in other species, which belong to the same systematic group, this same property seems to be independent of the conditions of existence.

EXAMPLE: In certain species of Senecio the number of marginal florets varies very little. In $S$. jacobcea, for instance, this number is $13 .^{1}$ On the other hand, in other Compositæ, this property is very variable. In Chrysanthemum carinatum, for instance, the extremes are about 3 and 30 or still more. In this plant the number of marginal florets may be augmented or diminished by modifying the conditions of existence: the highest figures are obtained (according to my experiments) when the plants are grown under favourable conditions (in good soil, at sufficient distances from each other), whereas lower figures are observed when the conditions are rather poor ; for instance, when the plants grow close together or when the soil is poor ( $(128)$.

The difference between the living mixture of $S$. jacobcea and that of $C$. carinatum is disclosed not only by the reactions which produce the so-called characteristics of each species, but also by the fact that $C$. carinatum is very plastic with reference to the above-mentioned property, whereas $S$. jacobaa is very slightly plastic.

The degree of plasticity is a specific property in itself. (See § II.)

§ 15. - PLASTICITY (continued). PHILODENDRON PERTUSUM.-In certain cases a property described as being in a high degree characteristic of a given species disappears (becomes latent) under the influence of certain external causes.

EXAMPLE: Philodendron pertusum bears large leaves pierced with round holes, which give to this plant the name of pertusum (perforated). In the Botanical Garden in Ghent several specimens of this species were cultivated for many years in a greenhouse which was rather cool and dry. The holes were

${ }^{1}$ In Flanders, I have counted the marginal florets of thousands of flowerheads in many localities, under very different conditions of existence. I always found 13 , except in three or four flower-heads in which the figure was 12 or 14 . 
rare : it happened sometimes that it was impossible to find one single perforation in all the leaves of a specimen. The plants were, in every other respect, quite healthy. In I903 they were brought into a new greenhouse which was warmer and moister. After a few months the new leaves were abundantly perforated, and from that time on the plant was again deserving of its name (J. V. BURVENICH).

§ 16. - PLASTICITY (continued). PRIMULA, CAMPANULA, CRIMSON RAMBLER.-In the preceding examples external causes brought about differences between specimens of the same species. Inversely, specific differences may disappear under the influence of unusual conditions of life.

EXAMPLES: In some subspecies of Primula sinensis the corolla is white, in others it is pink. Under ordinary circumstances, the temperature being $10^{\circ}$ to $20^{\circ} \mathrm{C}$., the colour is quite characteristic of each form. But if a certain pink subspecies is cultivated at a temperature of $30^{\circ} \mathrm{C}$., the pink colour disappears: the corolla becomes white and can no longer be distinguished from that of a white subspecies.

Similar facts have been observed in Campanula. Some species of this genus include blue and white subspecies. A certain subspecies with a blue corolla, when grown at a high temperature, is transformed into a white form (variant) which resembles a white subspecies.

The crimson rambler rose is cultivated at Ghent ${ }^{1}$ in many gardens. The flowers are comparatively small, very numerous on each flowering branch and crimson in colour. When an inflorescence (corymb) is crooked before the buds have reached their full size, the flowers of this branch, when expanded, are quite healthy, but white. The crimson rambler is, as it were, transformed into a white rambler. ${ }^{2}$

§ 17. - PLASTICITY (continued). CALLITRICHE. - In two examples mentioned in $\S \mathrm{I} 6$ a difference between two (sub)species disappears under conditions which are unusual or even abnormal. Inversely it is probable that, in numerous cases, two specific forms which are hardly different under ordinary conditions of life become distinctly different under unusual circumstances.

EXAMPLE: In IgII (in Flanders) the summer was hot and very dry. In dried-up ditches I observed repeatedly the terrestrial form (variant) of Callitriche. The stems were

1 Probably introduced from England.

2 This fact was observed by Mr COLLUMBIEN, SENIOR, horticultural teacher at Ghent. I repeated the experiment several times with success. I tried to obtain in the same way a similar transformation with two other sorts of roses with pink flowers, but without any effect. 


\section{4}

THE QUANTITATIVE METHOD IN BIOLOGY

ordinarily rooting at their base, the ascending part being about $5 \mathrm{~cm}$. high, with numerous leaves. In one ditch (between Beernem and Ruyselede, in West Flanders) I found a form with a creeping stem, distant, comparatively narrow leaves, the extremity of the stem not being erect. The difference between the two forms was striking and much more apparent than between the numerous specimens of the aquatic form which I have observed in many localities in Flanders. Therefore I surmise that the two terrestrial forms belong to two subspecies which can hardly be distinguished in their ordinary aquatic form.

REMARK : When we want to ascertain whether two plants belong to the same species (or subspecies) or not, we often cultivate specimens of both side by side under ordinary conditions. If a distinct difference is observed, we conclude that there exists a specific difference between them. If the specimens show the same properties, we are tempted to believe that they belong to the same species. The latter conclusion, however, may at times be erroneous. It is possible that certain reactions of the living mixture and the corresponding visible differences are only observed under unusual conditions. A better method would be to have comparative cultures under conditions as various as possible (soil of diverse composition; dry or wet; shady or sunny position, etc.). In this way we may hope that latent differential characteristics will become visible, which have not yet been observed. The principle of this method is, mutatis mutandis, adopted for the investigation of lower fungi, bacteria, etc. It might render good services to the study of critical species of phanerogams, mosses, etc.

\section{§ 18.-MONOTYPIC AND COMPLEX SPECIES.} SPECIES AND SUBSPECIES.-To sum up, the so-called variability (variation, polymorphism) of a species may depend on two quite distinct causes (compare $\S 8 \mathrm{~A}$ ) :

(I) The living mixture of a species is capable of reacting in various ways according to differences in the external conditions. I call this plasticity.

(2) A species may be (and many species are) a complex consisting of two or several subspecies differing from one another by the qualitative composition of their living mixture ${ }^{1}$ (each subspecies being, of course, plastic). I call this complexity.

The distinction between plasticity and complexity is well known. It may, however, be useful to recall it, because we often apply the terms variability, variation and polymorphism to both. This confusion occurs again and again in zoological

1 The chemical difference between two subspecies is smaller than between two species. (See § 8A.) 
and botanical systematic literature. Although it is often rather difficult to discriminate between plasticity and complexity without having recourse to experiment (see $\S$ I7, Remark), we must always bear in mind the fundamental difference between these two kinds of variation.

REMARK I.: The term variety is used with different meanings and has therefore no longer any exact significance. Certain authors have given a definition of it which they seem soon to have forgotten, since they use the term with various meanings, quite different from their own definition. In the floras and the faunas the term variety is often used as a synonym of subspecies, but unfortunately certain forms (variants) which depend on plasticity are also called varieties.

REMARK II. : I use the term subspecies in the sense of elementary species or petite espèce, because it is shorter and clearer than the latter expressions. I call variant any form of a species or subspecies which is brought about by plasticity. Variants are not to be designated by Latin names. (Examples of variants are given in $\S \S \mathrm{I} 2, \mathrm{I} 5, \mathrm{I} 6, \mathrm{I} 7$.)

REMARK III. : A species which includes only one subspecies may be called a monotypic species, whereas a complex species includes two or several subspecies.

§ 19.-PURE LINES.-It is very probable that many subspecies (and monotypic species) consist of two or more pure lines (JOHANSEN), separated from one another by qualitative chemical differences of their living mixture which are slighter than those which exist between subspecies $(\S 8 \mathrm{~A})$, each pure line being plastic. In the present state of science the discovery of pure lines is only possible by means of delicate experiments. As well-established facts are up to now not numerous, our knowledge of this very interesting subject is still slight. Therefore I limit myself to this brief mention of pure lines.

$\S 20$.-BUD-VARIATION.-It has often been observed that in a bud of a given plant a certain change takes place the nature of which is hitherto unknown, but the consequences of which are visible : the new parts (branches, leaves, flowers, etc.) produced by the modified bud react in a new way and exhibit properties (characters) by which they differ from the original plant. This peculiar form of variation is called bud-variation.

Numerous examples of bud-variation have been mentioned by several authors, among whom DARWIN must be cited in the first place. ${ }^{1}$

In many cases the new parts produced by a bud-variation

${ }^{1}$ CHARLES DARWIN, The Variation of Animals and Plants under Domestication (second edition, 1875 ), vol. i. 
have been propagated by means of cuttings, layers, tubers and other methods of vegetative propagation. It is possible to obtain in this way an unlimited number of specimens which are all characterized by the new properties and seem to belong to a peculiar species or subspecies. Many so-called horticultural species have their origin in a bud-variation.

EXAMPLES: Mr KNIGHT states that a tree of the yellow magnum bonum plum, forty years old, which had always borne ordinary fruit, produced a branch which yielded red magnum bonums (Darwin, loc. cit., p. 399). The black or purple Frontignan (grape) in one case produced during two successive years (and no doubt permanently) spurs which bore white Frontignan grapes (DARWIN, loc. cit., p. 399). Kemp's potato is properly white, but a plant in Lancashire produced two tubers which were red and two which were white. The red kind was propagated in the usual manner by eyes, and kept true to its new colour, and, being found a more productive variety, soon became widely known under the name of Taylor's fortyfold (DARWIN, loc. cit., p. 4IO).

The pseudo-species produced by bud-variation (we may call them bud-species or bud-subspecies) differ from the true species (seed-species) because their characteristic properties are not true to seed, which means that they are not transmissible by sexual reproduction: as a rule, the seeds of the bud-species produce specimens in which the new properties have disappeared. The bud-species are plastic just as the seed-species.

It may be suggested that a bud-species is produced by a qualitative change of the living mixture $(\S 8 \mathrm{~A})$ localized in a bud and transmissible only by vegetative multiplication. In other words, a bud-variation might be looked upon as being a non seed-fixed ${ }^{1}$ mutation.

In a hybrid specimen we observe, in general, a combination of a number of properties (characters) borrowed from the parents. This combination is ordinarily transmitted only to a part of the children (seedlings): the seminal offspring of a given hybrid is very variable, the properties under consideration being combined in various ways among the children (as a consequence of the principle of segregation). The hereditary transmission of the characteristic combination of a given hybrid by sexual reproduction is therefore impossible in horticultural practice, especially in those cases in which the combined properties are numerous-for instance, when the hybrid is a complex one, produced by successive crossings between several species. ${ }^{2}$

It is, however, possible to obtain from a hybrid an unlimited number of specimens similar to the parent by means of vegetative multiplication, the characteristic combination being transmitted in this way. Many so-called horticultural species consist in reality of the vegetative offspring of one hybrid specimen.

Between bud-species and hybrids a certain analogy exists in respect to heredity: in both cases the characters vanish by seminal reproduction and are transmitted by vegetative multiplication.

Concerning constant hybrids, see $\$ 105$.

REMARK: It is possible that bud-species (or subspecies) exist in the state of nature. A bud-variation might easily be

1 This is the translation of the Dutch word zaadvast (zaad=seed and vast $=$ fixed).

2 See, for instance, the complex hybrids in the genus Gladiolus mentioned by DE VRIES (Mutationstheorie). 
multiplied in the very numerous species (Ficaria ranunculoides, Ajuga reptans, Potentilla anserina, etc., etc.) which ordinarily multiply by vegetative means. ${ }^{1}$ If natural bud-species really occur, it would be impossible to distinguish them from seedspecies without experiment. One would expect to find eventually numerous specimens of them in narrowly limited localities.

$\S$ 21.-CONTINUOUS AND DISCONTINUOUS VARIATION.-Confusion exists in the use of the terms continuous and discontinuous variation.

The variation of a property is called continuous when all possible transitions exist between the extremes. When we measure, for instance, the length of the spike of a number of specimens of one subspecies (so-called race) of the rye, and set them in order into a series according to their length, we see that the measured property increases gradually from the shortest to the longest one: there are neither gaps nor jumps in the series (Dr C. DE BRUYKER).

If, on the contrary, a gap is observed in the series, by which the measured specimens can be divided into two groups, the variation is called discontinuous.

In a similar way we say that discontinuity exists when two groups of specimens differ from one another in a pair of properties which are distinctly different. EXAMPLE: In Lychnis diurna (Melandryum roseum) the petals are pink. In Lychnis vespertina (Melandryum album) the petals are white.

Those two kinds of discontinuity must be distinguished from one another. This subject is expounded more completely in § I30. (See also $\S$ II2.) In the present paragraph I content myself with calling attention to the very important fact that discontinuity (in the values of one property) sometimes occurs in a group of specimens between which no specific difference whatever exists, and that, on the other hand, continuity is often observed although the specimens under consideration belong to two (or even more) distinctly different specific forms.

§ 22.-ADAPTATION. ACCOMMODATION.-There is a relation between variation and so-called adaptation. A strict distinction ought to be made between individual adaptation (accommodation), which is the consequence of plasticity, and the HYPOTHETICAL adaptation of the species, which is supposed to be produced by natural selection (Darwinism) or by the hereditary transmission and fixation of individual adaptation (Neo-Lamarckism). (See on this subject §§ 44-45.)

§ 23.-VARIATION UNDER CULTIVATION OR DOMESTICATION AND IN THE STATE OF NATURE.-The

${ }^{3}$ A rather large number of indigenous species rarely bear seed. 
idea that plants and animals are more variable under cultivation and domestication than in the state of nature is adopted by almost every biologist.

It may be asked, however, whether there is not a certain exaggeration in that belief.

When a plant species, taken from the state of nature, is cultivated in a garden, we ordinarily grow a large number of specimens side by side. We pay much attention to our plants, looking at them again and again, and comparing them with one another. In this way we discover numerous and often unexpected individual differences. In the state of nature, on the contrary, the specimens of a given species are ordinarily more isolated from each other and therefore we have less opportunity to make comparisons. It happens very rarely that we observe carefully more than half-a-dozen specimens: this brings about the impression that there is less variation than among the cultivated plants.

If we compare a large number of specimens growing wild we are often compelled to collect them from a rather large area. A botanist who has collected two hundred specimens of a given species from an area of a hundred square miles, who has studied attentively the variation of the collected material and compared this with the variability of an equal number of cultivated specimens of the same species, belongs to a rarissima species.

If we only take the necessary trouble we shall see that variation (it may be complexity or plasticity) in the state of nature is greater than we fancied. In July and August, I9I6, I compared several hundreds of specimens of Dactylis glomerata collected between Withington and Alderley Edge (near Manchester), along the roads, on meadows, on waste ground and on the heath. Although shady and distinctly wet places were purposely excluded, the plants were very variable with regard to the length of the internodes, the dimensions of the leaves, the number and the length of the branches of the panicle and the density of the clusters of spikelets. When the extreme forms were placed side by side it seemed at first sight as if they belonged to different species. Phleum pratense was observed in the same way in the same district : in this species the variation was on the whole less marked, although notable in the length of the spike-like panicle (from 8 to $166 \mathrm{~mm}$.). ${ }^{1}$ I have made similar observations in Flanders, observing the variation of several properties of Centaurea nigra, Calluna vulgaris, Stellaria holostea, Stellaria media, Stellaria uliginosa, Primula elatior,

${ }^{1}$ Holcus mollis is exceedingly variable (plastic) in the Manchester district.

The herbarium of the University of Manchester contains an unlabelled specimen of $P h$. pratense the inflorescence of which has a length of $194 \mathrm{~mm}$. 
Hypericum perforatum, etc. I was again and again brought to the conclusion that the species under natural conditions are on the whole more variable than we are tempted to believe.

Among wild animals examples of astonishing variation are found as soon as attention is paid to a large number of specimens. EXAMPLES (observed in Flanders): Rana temporaria is very variable with regard to its colour. This is also the case with A phrophora, ${ }^{1}$ Eristalis tenax, ${ }^{2}$ Neritina fluviatilis, etc. On the dunes near the Flemish coast (Ostend, Blankenberghe, etc.), on certain hot summer days, Coccinella novemdecimpunctata is found in millions of specimens. If one collects several hundreds of them, places them side by side and observes them with a glass, one is astonished by their diversity. It is, however, very difficult to accept the suggestion that complexity is here in play.

The above examples of variation among animals are rather exceptional. It is incontestable, however, that even in ordinary cases we overlook variation in the state of nature because we almost never compare a sufficient number of specimens.

The conclusion is that the influence of cultivation and domestication on variation is on the whole less important than we have been told. Many years ago, at a time when our knowledge of variation was incomplete, attention was called to the variation of cultivated and domesticated species (DARWIN). Ever since, numerous new observations have been made, but the fundamental distinction between complexity and plasticity has been continually overlooked. Preconceived theories (Darwinism, Neo-Lamarckism), combined with the obsession of adaptation, have prevailed too much in the minds of many observers.

§ 24.-VARIATION UNDER CULTIVATION (continued). PLASTICITY OF MONOTYPIC SPECIES.-When we bring a plant species under cultivation the conditions of existence are more or less modified. They may be less favourable ${ }^{3}$ than in the state of nature, or they may be on the whole better, the plants being grown in a manured soil, at sufficient distances from one another, and watered, and protected against the prejudicial influence of weeds. The gardener often succeeds, after several fruitless attempts, in finding the best possible conditions.

${ }^{1}$ Here variation depends probably to a considerable extent on the fact that the larvæ of $A p h r$. spumaria live on various species of plants.

${ }^{2}$ This species was formerly exceedingly common in Flanders, the larvae being injurious to flax in the rettories (retting-ponds). It has been, like many other flower-visiting insects, almost completely destroyed by the cool, rainy summers of $1909-1910$. In 1911 it was rather a rarity.

${ }^{3}$ That is to say, less appropriate to the needs of the species. 
This is the ordinary rule in nurseries. ${ }^{1}$ What is the influence of the new state of things on plasticity, the material being monotypic (a monotypic species or a subspecies) ?

Under the new conditions certain reactions of the living substance of the species are modified; certain properties and even the facies are altered. In the successive experiments various alterations occur. We say that the species varies or is beginning to vary under cultivation. This is a misuse of terms. The faculty of varying, which depends on the specific living mixture, is not modified; only the visible properties are deviating from their previous state.

EXAMPLE: In the state of nature the length of the inflorescence (spike-like panicle) of Phleum pratense, for instance, varies ordinarily between 2 and Io $\mathrm{cm}$. (proportion, I:5; mean length, $6 \mathrm{~cm}$.), the extremes being uncommon. In a given garden the limits are, for instance, 3 and $15 \mathrm{~cm}$. (proportion, I: 5 ; mean length, $9 \mathrm{~cm}$.), the extreme values being easily found, since numerous specimens are growing on a small area. The absolute value of the difference between the limits is increased, and therefore we may have-the impression that the species is more inclined to vary, although the degree of plasticity, considered as a specific property, is not modified. ${ }^{2}$ (It is moreover possible to find under natural conditions specimens the inflorescence of which has a length equal or even superior to that of the longest inflorescence observed under cultivation.)

§ 25.-VARIATION UNDER CULTIVATION. MONOTYPIC SPECIES (continued). NEW PROPERTIES.-Under given conditions certain possible reactions of a species do not take place, the corresponding properties being latent (§ I0). I take as example the fasciation of the stem. Suppose that a species in which fasciation has never been observed under natural conditions is cultivated in a garden. It may happen that a number of stems become more or less fasciated. In this case it seems to be unquestionable that variability has been augmented by cultivation, ${ }^{3}$ for a new property has appeared,

1 If it seems impossible to obtain healthy, vigorous (commercial) plants, the experiment is abandoned. Failures are very rarely published or even mentioned, and we are told nothing about variation under unfavourable conditions.

${ }^{2}$ The possibility that altered conditions of existence may really modify temporarily the degree of plasticity (by altering the quantitative composition of the living mixture; see $\S 8 \mathrm{~A}$ ) is not excluded a priori, but we have no exact information about this. It is only by delicate experiments and by the use of the quantitative method that an answer to this question can be found.

${ }^{3}$ Using a well-known expression, we might say that the species has gone mad (l'espèce est affolée). 
and this property is variable. ${ }^{1}$ Nothing, however, is changed in the specific plasticity. The property fasciation becomes visible, in the same way in which the floating leaves of Ranunculus sceleratus (see $\S \mathrm{I} 2$ ) become visible when this species is developed in water.

\section{§ 26.-VARIATION UNDER CULTIVATION (continued).} COMPLEX SPECIES.--Suppose now that the species which is brought under cultivation is a complex one, consisting, for instance, of two subspecies. If these coexist in the same locality (which is very often the case), hybrids may occur. Many hybrid specimens resemble one of the parents, although one (or several) properties of the other parent are latent in them. If one of the seeds collected in the state of nature is a hybrid, we may obtain in the garden, in the first or in the second cultivated generation, specimens of two kinds (regression, MENDEL), and according to the principle of segregation (MENDEL. See $\S 33$ ), it may happen that even more than two kinds of plants appear, and this may be repeated in several successive cultivated generations. $^{2}$

Numerous species which are looked upon as being monotypic are actually complex. Some of their subspecies, being rather rare, are overlooked or looked upon as being occasional deviations, monstrosities, anomalies and, in general, curiosities. $^{3}$ On the other hand, many of them have been described as varieties or species properly so called. ${ }^{4}$ It may therefore be surmised that many species which have afforded examples of new properties when brought under cultivation were actually complex species. If we don't know that a cultivated species is complex, we may be tempted to believe that variation has

${ }^{1}$ In the given example (observed in my private garden with Enothera biennis; seeds collected at Deurel, near Ghent) the differences between the cultivated specimens with regard to fasciation depend on differences in the conditions of existence. These conditions are always different from one specimen to another, even when all possible precautions to avoid them are taken by the gardener. If the plants, for instance, are sown in a seed-pan and afterwards transplanted one by one, a slight difference in the manipulation of two specimens (roots more or less disturbed, young stems more or less pressed between the fingers, etc.) may have an important influence upon their further development.

${ }^{2}$ In this way new forms (new combinations of properties), which have never been observed before, may be obtained.

${ }^{3}$ EXAMPLE: In Flanders, Centaurea cyanus includes, as far as I know, three subspecies: (I) blue flowers, very common; (2) white flowers, uncommon ; (3) purplish flowers, rare. Many seed-fixed subspecies of Centaurea cyanus are found in seedsmen's catalogues (see, for instance, the price list of HAAGE and SCHMIDT, Erfurt). See also Solanum nigrum, \& 13.

4 Innumerable species of Mentha, Salicornia, Erythraa and many other polymorphic genera have been described. Although the great majority of these so-called species are simply based upon variants (variations produced by conditions of existence), there are certainly a number of subspecies among them. 
been increased by cultivation, although the observed facts are simply a consequence of the laws of hybridization.

\section{§ 2\%.-VARIATION UNDER CULTIVATION (continued). COMPLEX SPECIES. \\ LATENT PROPERTIES.-It may} happen that a species which is in fact complex has been hitherto considered monotypic, because the characteristic properties of one or several of its subspecies are practically always latent under natural conditions. ${ }^{1}$ HUGO DE VRIES has demonstrated, by means of numerous admirable experiments, that a number of so-called monstrosities (anomalies) are peculiar subspecies (DE VRIES calls them races). Certain of them are exceedingly rare in the state of nature, but in a garden they are obtained in numerous specimens when cultivated under very favourable conditions. In the same garden their characteristics become again latent whenever the conditions (manure, etc.) become less favourable.

I take as an example Dipsacus silvestris. Although this species is common in Europe, very few botanists have seen a specimen of subspecies torsus DE VRIES, characterised by a twisted stem; it has probably never been mentioned in any flora. ${ }^{2}$ HUGO DE VRIES, starting from the seed of one specimen, cultivated this plant for years and succeeded in obtaining an unlimited number of specimens as often as the conditions of existence were very favourable. In the most favourable cases about 30 per cent. of the cultivated specimens were twisted. ${ }^{3}$

Suppose now that a sample of seed taken at random from ordinary specimens (which do not exhibit any visible trace of the properties of subspecies torsus) was used to start a culture, and that we were quite ignorant of the experiments of DE VRIES and even of the existence of twisted stems. If one of the parental plants happened to be a torsus with latent properties, or if one seed was fertilized by a pollen grain from a latent torsus, it might happen that in the garden, in the first or in a subsequent generation, one or several specimens would exhibit

1 Compare $\$ 25$ (latent properties of a monotypic species).

2 I have observed thousands of specimens of $D$. silvestris in Flanders (Nieuport, Ostend, Blankenberghe, Ter Neuzen, etc., on clayey soil without limestone) and in the valley of the Meuse (between Huy and Namur, on rather clayey soil, limestone district). I did not succeed in finding a single specimen of the handsome subspecies torsus, although its characteristics are very apparent.

${ }^{3}$ Some years ago Prof. H. DE VRIES kindly sent me some seeds of his $D$. silv. torsus. Thirty-one plants were obtained and carefully cultivated on a bed in the Botanic Garden at Ghent by the head gardener, J. V. BURVENICH. Unfortunately the spaces between the plants were too small. This is very probably the reason why only one twisted specimen appeared. It grew at a corner of the bed, under better conditions than the others, because it there found plenty of space for its development. Seed was collected by Mr J. V. BURVENICH, who unfortunately fell ill and died soon afterwards. After his death the seed was not found. 
the characteristics of torsus. One might think that a very remarkable variation has been brought about by cultivation, the more so because the twisted stems would be hereditary by further cultivation under favourable conditions. Many horticultural species which have been found in a seed-plot have probably a similar origin. In reality, in such cases, no nere form is produced, the property of plasticity is not modified, but unusual external causes have brought about unusual reactions of the living mixture, which are no longer observed as soon as the unusual causes have ceased to prevail.

Among the subspecies (races) which have been investigated by $H$. DE VRIES in the same way as $D$. silv. torsus, with similar results, several subspecies with fasciated stems, ascidiform leaves, three cotyledons, etc., may be mentioned.

\$28.-VARIATION UNDER CULTIVATION (continued). REMARKS.-I think that the great majority of the examples of variation under cultivation, which are mentioned in biological literature may be brought into the four following groups :-

(I) Greater variation under cultivation is simply a delusive appearance, a consequence of incomplete information about plasticity in the state of nature ( $\$ \$ 23,24)$.

(2) Certain properties which are always or almost always latent under natural conditions become observable under the unusual conditions which prevail in a garden ( $\$ 25)$.

(3) When the cultivated material is regarded as being monotypic, although it is complex, the properties of certain of its monotypic components may become visible under cultivation because certain specimens are hybrids $(\$ 26)$.

(4) When the cultivated material is looked upon as being monotypic, although it is complex, the properties of certain of its monotypic components which are latent or very rarely observable in the state of nature may become visible under the new conditions which prevail under cultivation (\$27).

It is easily realized that several of the possibilities alluded to may coexist and bring about various and intricate combinations in one group of cultivated plants.

In short, it seems as if our ignorance about complexity and plasticity among plants and animals under natural conditions were the origin of the belief that variability is increased by cultivation or domestication. (A restriction is made in note 2 on p. 20 ; see further the present paragraph.)

Botanists and zoologists who are collectors may make much progress by observing and collecting specimens which exhibit unusual properties, inscribing on the labels exact information about the conditions of existence and about certain properties 


\section{THE QUANTITATIVE METHOD IN BIOLOGY}

(colours, etc.) which often disappear in the collections after a certain time. This method has been followed by $\mathrm{Mr} \mathrm{PH}$. DAUTZENBERG (Paris), in whose princely collection of shells the variation of numerous species is represented by unrivalled series of specimens.

It is, however, possible that the unusual conditions of life which prevail under cultivation may result in a quantitative modification of the living substance of certain specimens (note 2, p. 20), or may produce, directly or indirectly, a qualitative change-that is to say, a mutation. (See $\S \S 8 \mathrm{~A}$ and 9.)

It would be safer to have recourse to those hypotheses and to use the terms sport, saltation or mutation only after we have tried in vain to find another explanation. 


\section{PART III}

\section{QUANTITATIVE METHOD AND PRIMORDIA}

§ 29.-SUMMARY OF PARTS I. AND II. (§§ I-28).-The living substance of each monotypic species (or subspecies) is a mixture of a certain number of chemical entities (bioproteins?), each specific mixture differing from all others at least by one component. When the qualitative composition of a specific mixture is altered, a new specific form (sport, saltation or mutation) is produced.

Each observable property of a species is produced by a reaction in which its living mixture as well as external causes (conditions of existence) play a part. In each species the number of possible reactions and therefore of possible properties is very large. In a given specimen a part only of the possible properties is observable, the others being latent. External causes (temperature, light, food, etc.), which are, of course, very variable, determine which properties are observable and which are latent in each specimen. This produces variation (plasticity; variants) within the limits of each species without any qualitative alteration of its living mixture.

External causes may produce a quantitative alteration of a specific mixture. This alteration (and the corresponding alterations of the observable properties) may be transmitted by inheritance and augmented by (artificial) selection (but never beyond the specific limits as long as the external causes do not bring about a saltation).

Another form of variation depends on complexity. A species is complex when it consists of two or more subspecies which differ from each other by qualitative differences in the constitution of their living mixture slighter than the specific differences. Each subspecies is plastic just as is the species.

In both plasticity and complexity the variation of a given observable property may be continuous or discontinuous (§ 2I).

In Part II. I have mentioned a number of facts which prove that plasticity is greater than is actually realized by most biologists.

When we say that the (observable) properties of a species are hereditary, we must add the proviso that they are transmitted only when the external causes remain the same in the 
successive generations. It is more accurate to say that THE POSSIBILITIES ARE HEREDITARY. ${ }^{1}$

To discover all the possibilities of a species, we ought to observe it under all possible conditions of existence.

A classification of the living species based upon their observable properties is of an empirical nature. A rational classification based upon differences of chemical constitution is impossible in the present state of science. Our classifications are founded on the postulate that specimens in which the same possibilities are hereditary are identical (or similar) with regard to the constitution of their living substance and belong therefore to the same specific form or systematic group (pure line? ; subspecies, species, etc.).

We are still ignorant of the mechanical relations which exist between a given property of a species and its chemical constitution. In spite of this, certain hypotheses about the chemical constitution of the living substance (hereditary factors, etc.) may have a heuristic value and render good services.

§ 30.-QUANTITATIVE DESCRIPTION OF THE PROPERTIES.-The properties (characteristics) of animals and plants are ordinarily described by means of terms. This method is unsatisfactory; terms are vague, and the descriptions in faunas and floras. leave us often in doubt as to the identification of a given specimen. Is it possible to give a quantitative description of the living individuals and species, expressing the individual and specific properties by measurement?

The quantitative method has been already used along five different lines-viz.

(I) In the description and classification of species. (LINN EUS, LATREILLE, etc. See § $3 \mathrm{I}$.)

(2) In biometry properly so called. (QUETELET, GALTON, PEARSON, WELDON, etc. See $\$ 32$.)

(3) In the study of hybridization. (MENDEL. See $\S 33$.

(4) In phyllotaxis, including floral diagrams. (See $\S 40$.)

(5) In the measurement of certain physiological functions and corresponding properties. (See $\S 4 \mathrm{I}$.)

${ }^{1}$ In a similar way the state of equilibrium of a chemical entity (species) which is called its crystalline form depends on a specific possibility which takes the form of an observable property under certain conditions. In chemistry and mineralogy a confusion between the terms possibility and property is of no consequence, any ambiguity being precluded by our knowledge of the chemical structure of the entities. In a living species properties appear and disappear and are altered without any alteration of the possibilities, but the chemical constitution on which the latter depend is up to the present time unknown. Therefore, if we want to avoid ambiguity, we must always bear in mind that the state of equilibrium (see $\$ 43$ ) which we call a property is the temporary realization of a possibility (potentiality) of the species. 
§ 31.-THE USE OF THE QUANTITATIVE METHOD IN THE DESCRIPTION AND CLASSIFICATION OF SPECIES.-LINNEUS adopted a classification of the vegetable kingdom founded to a large extent on the number of stamens and pistils. For instance, the classes $\mathrm{I}$. to $\mathrm{X}$. of the Linnæan system included plants with one, two... ten stamens. Each class was divided in its turn into orders according to the number of pistils, etc. This system has been severely criticized and even violently attacked. It is certainly unnatural, but botanists have overlooked the creative power of the principle upon which it is based.

In the description of the mammalia we use the dental formula which indicates the number of incisors, canines, etc., in each species.

The ichthyologists find important specific characteristics in the number of dorsal and anal fins, in the number of their rays and also in the number of scales.

In the description of articulate animals much importance is attached to the number of segments (somites, articles) of the body, the legs, etc., the number of eyes, and even the number of certain kinds of hairs. LATREILLE is the author of a classification of the coleoptera based upon the number of segments of the tarses (Pentamera, Heteromera, Tetramera, etc.) which has rendered and is still rendering good services.

The mosses have been classified according to the number of teeth of the peristome.

One of the first applications of the quantitative method has been the measurement of the facial angle. An interesting application is the so-called bertillonage. This is the description of a person by means of a combination of figures, obtained by measuring certain properties.

We see from the above examples that the quantitative method has already been used to a large extent.

Most biologists, however, look upon the use of quantitative data as being something artificial. They overlook their PRACTICAL importance for the identification and the exact description of living beings-in general, for the exact description and comparison of biological facts-whatever may be their value as a base of classification and independently of any theory.

\section{§ 32.-THE MEASUREMENT OF VARIABLE PRO-} PERTIES. BIOMETRY. - The use of the quantitative method has been hitherto almost entirely confined to the measurement (including counting) of properties which are invariable or almost invariable. Its application is more difficult when we want to investigate variable properties. Every 
species is variable in respect of almost all its properties: we realize this better when we have recourse to measurement than when we content ourselves with mere observation. ${ }^{1}$

EXAMPLES OF QUANTITATIVE VARIATION IN PLANTS: In Mnium serratum (an acrocarpic moss) I have measured the length of the leaves of a number of fertile stems. In one stem this length varied between $\mathrm{I} \cdot 02$ and $4.7 \mathrm{I} \mathrm{mm}$. In the same species the number of cells of the leaves of the fertile stem (counted in the transversal direction, at the place of the greatest breadth of the leaf, excluding the differentiated border and the nerve) varied between 20 and 57.

In an allied species ( $M n$. subglobosum) the limits were: length of the leaves, I.02 to $7.34 \mathrm{~mm}$.; number of cells, 23 to Io6.

EXAMPLES OF QUANTITATIVE VARIATION IN ANIMALS : In twenty-eight specimens of Sciurus carolinensis four properties were measured by J. A. ALLEN. ${ }^{2}$ The extreme values were : length of the body, 8.25 to I0.20 inches; length of the tail, 6.75 to 8.75 inches. In the fore-foot the range of variation was less and in the head smaller still.

In Pseudoclytia pentata (a hydromedusa) the radial canals were counted by A. G. MAYER ${ }^{3}$ : the extreme values were 2 and 8. (See also Fig. I.)

Whatever may be the measured property, the figures seem at first sight to be capricious and independent of any rule whatever. The majority of biologists have been discouraged by the disconcerting variation which is almost always observed, and look therefore upon dimensions and numbers as being of accessory importance.

More than seventy years ago QUETELET 4 initiated a new method for the quantitative study of variable properties. According to this method a given property is measured in a large number of specimens of the same species (one of the examples studied by QUETELET was the height of soldiers). The distance between the limits (extreme values) is divided into a certain number of equal intervals; the specimens are distributed among the intervals according to their value (individual figure). In this way a variation curve of the

1 Properties which are really invariable are exceedingly rare. For instance, the number of fingers in man seems to be invariable. Examples of (hereditary) polydactyly are, however, not so rare as one is tempted to believe. Even examples of cyclopism (one eye on the median line) have been observed.

${ }^{2}$ Bull. Mus. Comp. Zoölogy, Harvard, I871. Quoted according to H. M. VERNON, Variation in Animals and Plants (Internat. Scient. Series, London, 1903), p. 4.

${ }^{3}$ Science Bull. Brooklyn Museum, vol. i. Quoted according to VERNON, loc. cit., p. 90 .

'QUETELET, Lettres sur la Théorie des Probabilités, Brussels, 1846. Anthropométrie, I870. QUETELET was born at Ghent in 1805 . 
measured property is obtained, which may be represented by a table of figures, or plotted out in the form of a diagram, in which the intervals are represented by equal segments of a horizontal line and the number of specimens in each interval by the length of a corresponding vertical ordinate erected in the middle of the interval.

EXAMPLE: D. C. M'INTOSH has measured the discbreadth of rooo specimens of Ophiocoma nigra. ${ }^{1}$ The following curve was obtained (in millimetres) :-

Disc-breadth Specimens

Disc-breadth Specimens

$$
\begin{aligned}
& \begin{array}{rrrrrrr}
4 & 5 & 6 & 7 & 8 & 9 & \text { I0 } \mathrm{mm} . \\
6 & \text { I7 } & 34 & 59 & \text { Io9 } & \text { I37 } & \text { I95 }
\end{array} \\
& \text { II I2 I3 I4 I5 I6 I7 } \mathrm{mm} \text {. }
\end{aligned}
$$

The arithmetical mean of all the measurements (I0,I06 mm. :

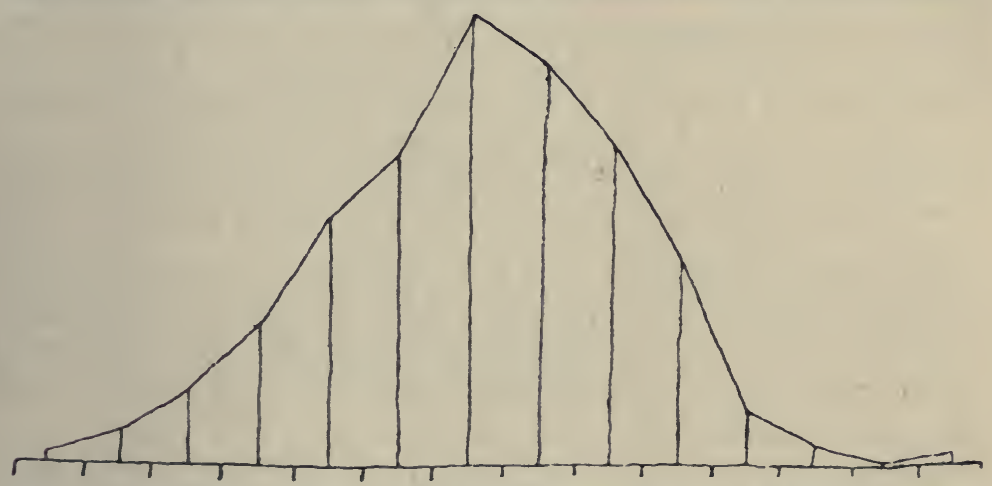

Fig. I.-Variation Curve of the Disc-Breadth of Ophiocoma Nigra. I4 Intervals

IO0O) is IO.II $\mathrm{mm}$. The most frequently occurring measurement is one of ro $\mathrm{mm}$.

We remark (I) that there is a heaping up of the measurements (specimens) in the region of the mean value; (2) that measurements deviating from the mean (hump of the curve) occur less and less frequently in a rough proportion to their degree of deviation; (3) that the measured property varies between certain limits ( 4 and $\mathrm{I} 7 \mathrm{~mm}$.); (4) that the distribution of the measurements follows approximately the law of frequency of error and is therefore ruled by chance (see $\S$ I08) ; (5) that two factors are taken into account: the absolute value and the frequency of each measurement. (Example: the frequency of the specimens the disc-breadth of which is $7 \mathrm{~mm}$. is $59:$ Iooo.) Using the method of which the above example gives some

${ }^{2}$ D. C. M'INTOSH, "Variation in Ophiocoma Nigra," Biometrika, vol. ii. (1902-1903), pp. 463-473. 
idea, the variation of a large number of properties of numerous species has already been investigated. According to QUETELET, the mean value may be taken as a measure of the property under consideration.

By means of a variation curve we may calculate not only the mean value, but also the probable error.

This may be represented in the following way (according to GALTON) :-Suppose that a given property has been measured in $n$ specimens ${ }^{1}$ (for instance, the height of $n$ soldiers taken at random in a certain district, or the length of the spike of the main stem of $n$ specimens of rye taken at random from a field). ${ }^{2}$ When all the specimens are placed side by side, in the order of their individual lengths, the smallest one being $\mathrm{N}^{0} \mathrm{I}$ and the largest one being $\mathrm{N}^{0} n$, the specimen $M$, which is in the middle (at the place $\frac{n}{2}$ ), represents very approximately the mean value. $^{3}$ The difference $D$ between the figure of $M$ and that of the specimen $Q_{1}$ which is at the place $\frac{n}{4}$ is the negative mean deviation. In the same way the difference $D^{1}$ between $M$ and the figure of the specimen $Q_{2}$ which is at the place $\frac{3 n}{4}$ is the positive mean deviation. In a perfectly normal (symmetrical) curve $D$ and $D^{1}$ are equal in value, but as no experimental result is perfect, they usually differ slightly in amount. A mean between the two is therefore taken: this mean is the probable error $=\frac{D+D^{1}}{2}$.

EXAMPLE : I put down $n=1000$. The mean between the specimens 500 and 501 (these specimens differ very little or not at all in amount) is the measure of $M$. In the same way the mean between the specimens 250 and $25 \mathrm{I}$ (place $\frac{n}{4}$ ) is $Q_{1}$ and the mean between the specimens 750 and 75 I (place $\frac{3 n}{4}$ ) is $Q_{2}$.

The probable error is a measure of the degree of spread of the curve; it is an index of the variability of the property under consideration. ${ }^{4}$

$1 n$ being a large number; for instance, rooo.

2 The latter example (rye) was studied in the Botanic Garden at Ghent by Dr C. DE BRUYKER.

${ }^{3}$ That is to say that 50 per cent. of all the measurements fall below it in magnitude and 50 per cent. above it.

4 The quotient probable error: mean value is the relative probable error. By means of the latter value the degree of variability of two or several series of observations (differing by their mean values) may be compared.

Another method of expressing the variability of a property is to calculate the arithmetical mean error. 
The importance of the ingenious statistical method initiated by QUETELET was not realized for many years. His work has been scorned and ridiculed by certain biologists.

WALLACE has done perhaps more than any other scholar to call attention to the method of QUETELET, by giving in his widely distributed book on Darwinism ${ }^{1}$ a series of diagrams illustrating the variation of certain properties in several animal species.

QUETELET'S results have been confirmed and extended by FRANCIS GALTON, ${ }^{2}$ who ultimately introduced the statistical method into biological science.

Among the numerous statistical researches which have already been published, the experiments of JOHANSEN on the pure lines (see $\S$ I9) deserve a special mention, not only because the notion of pure lines is important in itself, but because this author has called attention to the importance of the extreme values and also to the fact that two or several distinct curves may produce by their association one regular variation curve, in which it is impossible to discover (without experiment) or even to suspect the heterogeneity of the material.

In Igor a special review, Biometrika, ${ }^{3}$ devoted to biostatistical researches, was founded by WELDON, PEARSON and DAVENPORT, and this part of biological science has been called Biometry. A large amount of valuable material has already been collected. The biometrical researches, however, have been 'hitherto rather fragmentary.

The biometricians have constructed numerous variation curves and skilful calculations have been made, but the investigated properties have been taken a good deal at random, from species which belong to very different groups of the zoological and botanical kingdoms. Although numerous examples of correlation have been studied, there exist on the whole neither morphological nor physiological relations between the properties which have been the object of measurement, and there is no systematic relation between the species of which properties have been measured. Therefore descriptive natural science has only in exceptional cases found any help from the results of biometrical work, however important this work may be in itself.

There seem to be, moreover, two weak points in biometry: FIRSTLY, the exaggerated importance ascribed to the mean value. A mean value is not always the quantitative expression of a fact, of a reality; it is often a rather artificial result of

1 ALFRED RUSSEL WALLACE, Darwinism. London, Macmillan, 1890.

2 F. GALTON, Natural Inheritance. London, Macmillan, 1889 .

aiometrika, a Journal for the Statistical Study of Biological Problems, edited in consultation with FRANCIS GALTON by W. F. R. WELDON, KARL PEARSON, C. B. DAVENPORT, Cambridge University Press. 
calculation. There is often a complicated relation between a given mean value and the thing which it is regarded to express. ${ }^{1}$ This relation is very diverse, according to the case under consideration, and it is sometimes very difficult or even impossible to make it clear. When the significance of a mean value is vague, any figure deduced from it is still more vague (this question is expounded in Part VI., especially in $\S \S$ IO9, IIO, II6).

In biometrical literature some examples of a SECOND weak point are found. When we have collected a series of figures by measuring a property in a number of specimens, we are tempted to believe that the observed differences depend on chance (according to the principle laid down by QUETELET) and our calculations are based upon this belief. This is, however, not always the case. There are sometimes between the collected figures certain relations which are not governed by the laws of chance (probability), but by the laws of gradation. If chance and gradation are not distinguished, confusion is inevitable. This difficulty has not always been avoided. (See Part VIII. See also variation steps, § I27.)

§ 33. - APPLICATION OF THE QUANTITATIVE METHOD ON THE STUDY OF HYBRIDIZATION. MENDELISM.-The use of the quantitative method in biological science has been initiated along a third line by GREGORIUS MENDEL in I865-I866. ${ }^{2}$ This author chose Pisum sativum for his subject. Varieties (subspecies) in cultivation are distinguished by striking characters recognizable without trouble. The plants are habitually self-fertilized. Following his idea that the heredity of each character (property) must be separately investigated, he chose a number of pairs of properties, and made crosses between subspecies differing markedly in respect of one pair of properties. MENDEL took, for instance, two subspecies of which one was tall, being 6-7 feet high, and the other was dwarf, $\frac{3}{4}$ to $I \frac{1}{2}$ feet (the pair of properties is here tallness-dwarfness).

These two were crossed together. The cross-bred seeds thus produced grew into plants which were always tall, having a height not sensibly different from that of the pure tall subspecies. I call these plants $F_{1}$ (first filial generation). The

1 In other words, a mean value is often an indirect expression, not the direct expression of a reality.

${ }^{2}$ See W. BATESON, Mendel's Principles of Heredity (Cambridge University Press, 1909); xiv. + 396 pp., with three portraits of MENDEL, 6 coloured plates and 33 figures. This book contains a very instructive and complete account of the subject, a biography of MENDEL and a translation of his memoir, which was published in Verhandl. Naturf. Ver. in Brünn (Abhandlungen, vi. 1865 ) and appeared in 1866.

The short and simplified account given in the present paragraph is borrowed from BATESON (pp. 8-II) and MENDEL (BATESON, loc. cit., pp. 332-335). 
property tallness, which appears in $F_{1}$ to the exclusion of the opposite property, was called by MENDEL a dominant character; dwarfness, which disappears in $\mathrm{F}_{1}$, he called recessive.

The tall cross-bred $F_{1}$ in its turn bore seeds by self-fertilization. These are the next generation $\mathrm{F}_{2}$ (second filial generation). When grown up they proved to be mixed, many being tall, some being short, like the tall and the short grandparents respectively: Here the quantitative method was applied. Upon counting the members of this $\mathrm{F}_{2}$ generation it was discovered that the proportion of talls to shorts exhibited a certain constancy, averaging about three talls to one short, or, in other words, 75 per cent. dominants to 25 per cent. recessives.

These $\mathrm{F}_{2}$ plants were again allowed to fertilize themselves and the offspring $\mathrm{F}_{3}$ of each specimen was separately sown. It was then found that the offspring $\mathrm{F}_{3}$ of the recessives $\left(\mathrm{F}_{2}\right.$ dwarfs) consisted entirely of recessives. Further generations bred from the recessives again produced recessives only, and therefore the recessives which appeared in $\mathrm{F}_{2}$ are seen to be pure to the recessive property (dwarfness). But the tall $\mathrm{F}_{\mathbf{2}}$ plants (dominants) when tested by the study of their offspring $\mathrm{F}_{3}$, instead of being all alike, proved to be of two kinds-viz.

(a) Plants a which gave a mixed $\mathrm{F}_{3}$ consisting of both talls and dwarfs, the proportion showing (just as in $\mathrm{F}_{2}$ ) an average of three talls to one dwarf $(75: 25)$.

(b) Plants $b$ which gave talls only and are thus pure to tallness.

The ratio of the impure plants $a$ to the pure plants $b$ was as $2: \mathrm{I}$. The whole $\mathrm{F}_{2}$ generation therefore consists of three kinds of plants, although, by external appearance (visible properties), it seems to consist only of two kinds. There are, in fact, in $\mathrm{F}_{2}$ two kinds of dominants $(a$ and $b)$ - viz.
$25 \% b$
$50 \% a$
pure dominants impure dominants
3 dominants
$25 \%$ recessives
I recessive

The result is exactly what would be expected if both male and female germ-cells of the cross-bred $F_{1}$ were in equal number bearers of either the dominant $(D)$ or the recessive $(R)$ property, but not both. If this were so, and if the union of the male and female germ-cells occurred at random, the result would be an $\mathrm{F}_{\mathbf{2}}$ family made up of (supposing Ioo seeds to be taken) ${ }^{1}$

$$
25 D D+25 D R+25 R D+25 R R
$$

${ }^{1}$ In each pair of letters the first letter represents a $\delta$ and the second a germ cell.

If the union occurred at random, the four possible combinations $\mathrm{D} \& \times D$ \& $D \delta \times R \&, R \delta \times D \&$ and $R \delta \times R \&$ would occur in equal numbers, because there exists no reason why one sort of combination would be more favoured than any other. 


\section{THE QUANTITATIVE METHOD IN BIOLOGY}

But, as the first cross (between two subspecies) showed, when $D$ meets $R$ in fertilization the resulting individual $\left(\mathrm{F}_{1}\right)$ is in appearance $D$ (the property $R$ being latent); therefore $\mathrm{F}_{2}$ appears as $3 D: I R$ (the property $R$ being concealed in $D R$ and $R D)$. The results observed in the $\mathrm{F}_{3}$ generation are in exact agreement with this suggestion, for the $R R$ plants (in $\mathrm{F}_{2}$ ) give an offspring with the property $R$ only, and of the plants in which $\mathrm{D}$ is visible one-third $(D D)$ give $\mathrm{D}$ only, while two-thirds $(D R+R D)$ give the same mixture $(3 D+\mathrm{I} R)$ which was produced by $\mathrm{F}_{1}$.

Now since the fertilized $F_{1}$ ovum, formed by the original cross, was made by the union $(D \hat{\delta} \times R+$ or $R \hat{\circ} \times D$ 市) of two germ-cells bearing respectively tallness and dwarfness, both these elements (possibilities) entered into the composition of the generation $\mathrm{F}_{1}$; but if the germ-cells which that generation eventually forms are bearers of either tallness or dwarfness, there must at some stage in the process of germ formation be a separation of the two properties (possibilities). This phenomenon, the dissociation of properties (possibilities) from each other in the course of the formation of the male and female germs, we speak of as segregation.

In the above-described experiment plants were used which differed only in one essential property. MENDEL crossed also subspecies of 'Pisum sativum which differed in two properties-for instance, a subspecies $a$ with round seeds (property $D$ ) and yellow "albumen" (property d) crossed with a subspecies $b$ the seeds of which were wrinkled (property $R$ ) and the "albumen" green (property $r$ ). The produced seeds $F_{1}$ appeared $D d$ like those of the parent $a$. In each pair of properties $(D, R$ and $d, r)$ there was thus a dominant $(D, d)$ and a recessive $(R, v)$. The cross-bred $\mathrm{F}_{1}$ bore seeds $\mathrm{F}_{2}$ by selffertilization. The $F_{2}$ generation proved to consist (with regard to the visible properties) of four kinds ${ }^{1}$ of seeds-viz.
(a) $D d$ (round, yellow)
( $\beta$ ) $R d$ (wrinkled, yellow)
( $\gamma$ ) $\mathrm{Dr}$ (round, green)

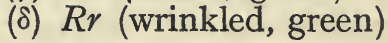

${ }^{1}$ In fact, nine combinations occur among the $F_{2}$ plants. This may be calculated by working out

The obtained terms are :

$$
(D+R)^{2} \times(d+r)^{2}
$$
(a) $D^{2} d^{2}+2 D R d^{2}+2 D^{2} d r+4 D R d r^{2}+$
(B) $d^{2} R^{2}+2 d r R^{2}+$
(r) $D^{2} \gamma^{2}+2 D R r^{2}+$
(o) $R^{2} \gamma^{2}$

In each combination in which $R$ meets $D$ the property $R$ is latent (concealed); in the same way $r$ is latent when meeting $d$. Therefore, as is easily seen, the nine combinations are reduced to four groups, $\alpha, \beta, \gamma$ and $\delta$, with reference to the visible properties. (See, on the use of formulas, §§ I04-I06.) 
The segregation of each pair of properties has taken place as if the other pair did not exist. In respect to the pair $D, R$ the plants are divided into two groups $D$ and $R$; in each of these the plants are divided in their turn into two groups $d$ and $r$-viz.

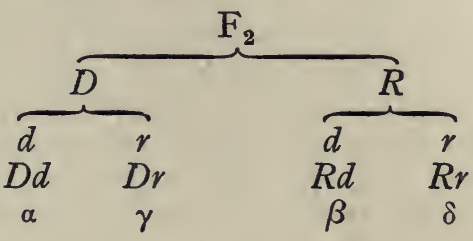

$\begin{array}{lllcccc}\text { Visible properties } & \cdot & \cdot & D d & D r & R d & R r \\ \text { Groups } & \cdot & \alpha & \gamma & \beta & \delta\end{array}$

In another experiment MENDEL crossed two subspecies which differed in three properties of the ripe seeds-viz.

Subspecies $a$ : seeds round $(D)$, albumen yellow $(d)$, seedcoat grey-brown $(\delta)$.

Subspecies $b$ : seeds wrinkled $(R)$, albumen green $(r)$, seedcoat white $(\rho)$.

In the $\mathrm{F}_{2}$ generation eight sorts of seeds were obtained: $D d \delta, D d \rho, D r \delta, D r \rho, R d \delta, R d \rho, R r \delta$, $R r \rho$. All the results were governed by the same rules as the two first experiments. (Complete explanation is given in $\S$ ro6.)

In a similar way as QUETELET'S work, the discovery of MENDEL passed unnoticed for a long time. Even the famous NÄGELI failed altogether to realize the importance of it. ${ }^{1}$ About Igoo MENDEL'S paper was discovered almost simultaneously by three botanists, CORRENS, TSCHERMAK and DE VRIES. These three repeated independently from each other MENDEL'S experiments and confirmed his results.

Since then numerous researches along the lines initiated by MENDEL have been carried out. A number of experiments have given results similar to those arrived at by MENDEL. In other cases the results of hybridization are more complicated. Several of these, however, have already been elucidated.

MENDEL has added to biological science a new branch (Mendelism) which is remarkable by the rigour of its reasoning and the exactitude of its conclusions. Both qualities are the result of the use of the quantitative method, based here upon counting in each generation the specimens in which the properties of the crossed subspecies are visible, latent or vanished, and comparing the figures. ${ }^{2}$

MENDEL not only devised a magnificent method for the

${ }^{1}$ See BATESON, loc. cit., p. 314. QUETELET and MENDEL met the same fate as MARIOTTE, KOELREUTER, CHR. K. SPRENGEL and several other botanists whose fundamental discoveries were overlooked for many years.

${ }^{2}$ This method of investigation is quite independent of MENDEL'S skilful suggestions about dominant or recessive properties and segregation. 
investigation of heredity; Mendelism teaches us more than this.

\section{§ 34.-MENDELISM (continued). THE NOTION OF} SPECIES.-From MENDEL'S experiments and the numerous experiments carried out by his successors we are allowed to draw the conclusion that the groups of specimens which we call species (or subspecies) are distinctly different from one another. The belief that intermediates (transitions) between the species exist is an unavoidable consequence of the proposition that subspecies, species, etc., arise through the transformation of masses of individuals by the selective accumulation of minute differences (impalpable changes). ${ }^{1}$ As often as intermediates (transitions) are proved not to exist, the above proposition about the origin of species ${ }^{2}$ cannot be accepted.

In fact, there is ambiguity in the use of the term intermediate. A distinction ought to be made between intermediate with regard to the properties and intermediate with regard to the possibilities. (See $\S 2 \mathrm{I}$.)

Intermediate forms (individuals) in respect to one or several observable properties are very common and this has brought about a misconception. Those intermediate forms are, in the state of nature (hybridization being excluded), a result of plasticity $(\$ 8 \mathrm{~A})$. They appear and disappear again and again as often as the conditions of existence are altered. (See, on the fugitiveness of observable properties, the examples mentioned in $\S \mathrm{I2}$.)

In other words, two species, observed under certain conditions of existence, may be seemingly connected by specimens with intermediate properties. Between both, however, a GAP exists with regard to their possibilities (which depend on qualitative differences in the composition of their living mixture). Although the gap may be narrow, it is permanent: there is no continuity.

This view, drawn from the study of innumerable examples of plasticity, and from the study of systematic natural science, is supported by numerous facts discovered by MENDEL and his successors. The distinction between properties and possibilities becomes evident by the observation of hybrids.

EXAMPLE: When two species (subspecies) are crossed which differ in one pair of properties $D$ (dominant) and $R$ (recessive) a new living mixture is produced and two possibilities exist in the offspring. In the first hybrid generation

1 " Once for all, that burden so gratuitously undertaken in ignorance of genetic physiology by the evolutionists of the last century may be cast into oblivion." BATESON, loc. cit., p. 289.

2 Just as any other theory explaining the origin of species by the accumulation of impalpable changes. 
( $\mathrm{F}_{1}$ plants) the possibility $D$ produces a reaction by which the property $D$ becomes observable. The property $R$ is latent, although the possibility $R$ exists. In the offspring $\mathrm{F}_{2}$ of any specimen whatever of $\mathrm{F}_{1}$ the possibility $R$ awakens and the property $R$ becomes visible in 25 per cent. of the children. In a similar way the transmission of the possibilities $D$ and $R$ may be traced through the $\mathrm{F}_{3}, \mathrm{~F}_{4} \ldots$ generations (although the property $R$ may be concealed in an unlimited lineage of successive seed-bearers) because the possibility $R$ is permanent in the impure plants (true hybrids ; heterozygots) $D R$.

REMARKS: (I) There is no difference in the observable properties between the $D D$ and the $D R$ plants, although a difference in the possibilities exists.

(2) The appearance of the property $R$ (which is only possible in the $R R$ plants) indicates the disappearance of the possibility D.

(3) The possibilities $D$ and $R$ may exist simultaneously (they are not incompatible) although the properties $D$ and $R$ are exclusive of each other.

The facts alluded to in the present paragraph are inconsistent with the notion that transitory or transitional forms (continuity) exist between the crossed species.

§ 35.-MENDELISM. THE NOTION OF SPECIES (continued). EXCEPTIONS WITH REGARD TO THE PROPERTIES.-In certain cases an intermediate property between the properties $D$ and $R$ is observed in the offspring $\mathrm{F}_{1}$ of a cross.

EXAMPLE: In Hyoscyamus niger subsp. annuus (this is the ordinary form) the corolla is brown. In $H$. niger subsp. pallidus it is pale (the brown colour does not exist). The cross gives $F_{1}$ plants with flowers of an intermediate tint, almost exactly as if one part of the brown colour of annuus had been diluted by addition of one part of the pale colour of pallidus. ${ }^{1}$

BATESON has given a very interesting discussion of this subject (intermediates and exceptions, loc. cit., pp. 235-244 and 245-265). He divides the examples of intermediate properties and other exceptions on the rules laid down by MENDEL into several classes. On the whole, we may conclude from the facts mentioned by BATESON that in many examples it is possible to prove that a so-called intermediate form exists only with regard to a pair of observable properties, while the possibilities are distinct and transmitted according to the principle of segregation.

'CORRENS, "Ueber die dominierenden Merkmale der Bastarde." Ber.deut. bot. Gesellsch. (1903), xxi., p. 133. Quoted according to BATESON, loc. cit. 
In some examples the existence of intermediate properties depends obviously on environmental influences. (BATESON, loc. cit., p. 243.) For instance, the cotyledons of many subspecies of peas are in all ripe seeds a full yellow, while those of many others are a full green. The contrast between the properties yellow and green in $\mathrm{F}_{\mathbf{2}}$ (after segregation) may be perfectly sharp and clear. Some subspecies, however, have many seeds which are in various degrees partly yellow and partly green. I have observed that it is sometimes possible to bring a number of seeds into a series from about $f u l l$ yellow to about full green in such a way that the difference between two successive seeds is very slight. In such a case, if we overlook the fundamental distinction between possibility and property, ${ }^{1}$ the existence of a gradual passage between the extremes seems to be incontestable. BATESON, after experimenting with such kinds, found that the parti-coloured appearance was caused by exposure to sun and weather. Plasticity is here in play, but no intermediates exist with regard to the possibilities, although the latter may coexist in the hybrids.

In other cases an intermediate property is observed in the hybrids $\mathrm{F}_{1}$ and transmitted to the generations $\mathrm{F}_{2}, \mathrm{~F}_{3} \ldots$ without segregation.

EXAMPLE: The subsequent generations raised from the hybrids Enothera muricata $\times E$. biennis showed no definite departure from the $\mathrm{F}_{1}$ type. $^{2}$

If this and other similar examples are not susceptible of any other explanation, the suggestion may be accepted that here a new, quite distinct living mixture $H$ has been brought into existence and that therefore a new property $H$ has appeared, the new mixture differing from the ordinary hybrid mixture because it finds itself in a state of stable equilibrium which is permanent and transmissible by heredity. ${ }^{3}$ (Constant hybrid.)

In other words, according to this view, a new subspecies $H$

${ }^{1}$ In other words, between chemical constitution and observable reaction.

${ }^{2}$ HUGO DE VRIES, die Mutationstheorie (Leipzig, Veit \& Co., I90I), vol. i., p. 67. In several successive generations the hybrid alluded to was constant, on the whole differing little from $E$. biennis. The middle radical leaves of the hybrid were similar to those of $\mathscr{E}$. biennis and distinctly different from those of $C$. muricata by their length, breadth, form, border and nerves. (See also BATESON, loc. cit., pp. 249-250.)

${ }^{3}$ This may be rendered more intelligible by the following comparison :when a fixed oil is mixed with water the mixture is in a state of unstable equilibrium : after a certain time segregation takes place and both components are separated. This corresponc's to an ordinary hybrid mixture. When a fixed oil is mixed with ether the mixture becomes a solution, which is in a state of stable equilibrium and therefore permanent, without segregation. This is comparable to the supposed mixture $H$ and also to any ordinary specific (not hybrid) mixture. It is conceivable that a similar principle finds application in the living mixtures, although these mixtures are very complicated. 
has been produced. ${ }^{1}$ This subspecies is strictly distinct from its parents by the seed-fixed possibility $H$ even if the corresponding property $H$ were variable, inclining (goneoclinous) sometimes toward one of the parents or towards the other, according to the principle of plasticity. (Compare the variable colour of the peas, p. 38.)

We might be tempted to call the new subspecies $H$ an intermediate between the parents. The term intermediate implies, at least in biological language, the idea of transition, gradual passage, continuity. Since the subspecies $H$ is strictly distinct from both parental species (in spite of the possible variability of the property $H$ ), it is not a transitory form. Therefore I think it is preferable to call it an interposed subspecies. (See § I05.)

The difference between transitory and interposed may be easily realized by means of a comparison. The two parental species may be compared to two terms $a$ and $c$ of a chemical series, for instance-the acrylic series (\$ 5), in which the atoms of carbon are $n$ and $n+2$ in number. Between the chemical species $a$ and $c$ certain differences exist in the observable properties-for instance, in the temperature of fusion. The subspecies $H$ is comparable to the term $b$ in which the number of atoms of carbon is $n+\mathrm{r}$. The term $b$ is separated from $a$ and $c$ by two distinct gaps with regard to the constitution of its molecule and also by its melting-point. ${ }^{2}$ There is no continuity between $a, b$ and $c$. The term $b$ is not transitory, but interposed between $a$ and $b$.

The number of facts which are ruled by the principle of segregation is very large, and the examples which at first sight seemed to be exceptions, but were later on proved to follow the Mendelian rule, are already numerous. Even if exceptions really exist, it is impossible not to accept the principle of segregation in point of fact as a biological rule.

Perhaps we may again have recourse to a comparison. Every biologist accepts as a rule the proposition that the development of a female germ is impossible without fertilization, although numerous examples of parthenogenesis are known.

It is also accepted as a rule that flower-visiting insects (bees, etc.) play an important part in the fertilization of flowers. The number of species which are partially or completely sterile when deprived of the aid of insects is so large that any doubt about the reality of the mentioned rule is excluded, although many examples of self-fertile plants are known, and although in a number of flowers which are visited by crowds of insects attracted by honey and perfumes seeds are produced by apogamy.

${ }^{1}$ This conclusion was adopted by JANCZEWSKI with reference to the hybrid Anemone silvestris $\times$ magellanica. (Bateson, loc. cit., pp. 250-251.)

If this suggestion were proved to be exact we would find in hybridization one of the possible causes of mutation. (In $\$ 9$ another possible cause is mentioned. See also $\$$ x 05.)

${ }^{2}$ Although this temperature is variable according to external influences, such as pressure, for instance. 
In a similar way the principle of segregation ought to be looked upon as being a biological rule, ${ }^{1}$ in spite of possible exceptions. Therefore the conclusion expressed in the first phrase of $\S 34$ is justified.

§ 36.-MENDELISM (continued). SIMPLE AND COMPOUND PROPERTIES. - A very important result of the Mendelian experiments is the conception that each property is in itself something definite, in a certain sense a unit which has a proper existence. By hybridization it is possible to transplant a given property from one species to another, as if the living individuals were the soil, the substratum on which the property grows.

We may express this conception in a different way by saying that a reaction which results in a certain property may become possible in a species $a$ in which it never occurred before when the composition of the living substance of $a$ is altered by hybridization.

From a number of Mendelian experiments it may be concluded that the observable properties ought to be brought into two classes :

(I) Simple properties (so-called elementary characters ${ }^{2}$ ), which it is impossible to decompose into more properties. A simple property might be called a PRIMORDIUM. ${ }^{3}$

(2) Compound properties, which at first sight seem to be simple, but depend on the coexistence of two or more simple properties. In other words, a compound property is a combination of primordia.

This distinction is of the highest importance for the study of many biological problems, especially in descriptive natural science, in which simple and compound properties are continually confounded.

A simple property is seen to be an entity. A compound property may be decomposed into its components in several ways, especially by Mendelian segregation. (See $\S 38$.)

EXAMPLES : In numerous cases a given colour of a species is a primordium, depending on the presence of one colouring substance. When the coloured species is crossed with a colourless one, segregation produces in the second hybrid generation $\left(\mathrm{F}_{2}\right)$ two sorts of specimens : coloured and colour-

1 I a void purposely the term law. See, on the distinction between law and rule, my lecture on "The Place of Science in History." Mem. and Proceed. Manchester Liter. and Philos. Soc., vol. lix., Part III. (I9I4-I9I5), p. 35.

2 I a void the term elementary. This term has various significances (see the dictionaries) and is therefore one of the rather numerous linguistic nuisances which embroil our notions and bring confusion to the mind of the biologist.

${ }^{3}$ This term is used by Lucretius in the sense of chemical element, thus in the sense of a simple something. 
less (yellow and white endosperm in maize. See BATESON, loc. cit., p. 4I).

In other cases a colour $Z$, which seems to be a primordium of a species $s$, depends on the coexistence of two colouring substances $a$ and $b$. When the coloured species $s$ is crossed with a colourless one, since each colouring substance is submitted to segregation independently from the other (see $\S 33$, p. 35), the two components $a$ and $b$ (both dominant when they meet white) are separated among the $F_{2}$ plants according to the following scheme :-

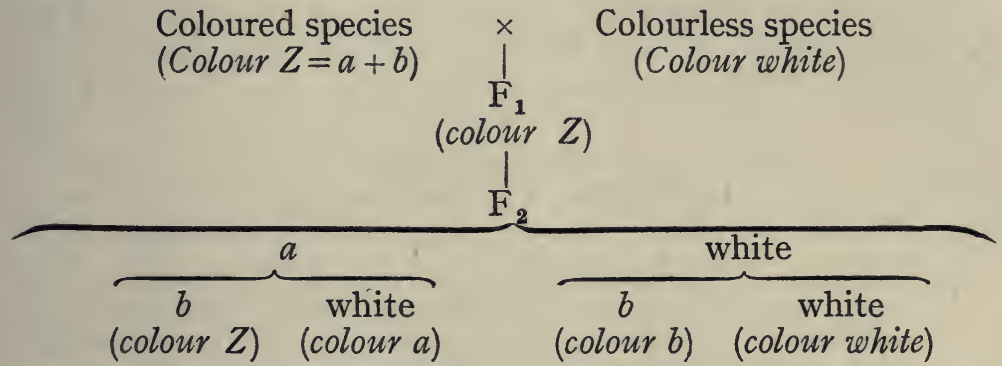

In this way two primordia $a$ and $b$ which existed but were not discernible ${ }^{1}$ in one of the parental species become visible in two groups of the $F_{2}$ generation. It seems as if two new properties had been produced by hybridization.

§ 3\%.-MENDELISM (continued). OBSERVABLE PROPERTIES AND HEREDITARY FACTORS.-In this book a property is looked upon as being a something which exists in itself. I content myself with the general notion that a property is the product of a reaction of the living mixture, the observable symptom of a certain possibility, without more. The scholars of the Mendelian School go further: they try to analyse the possibilities.

They start from the hypothesis that in each species certain hereditary factors (determiners) exist which bring about certain reactions by which the properties are produced. In the successive generations $F_{1}, F_{2} \ldots$ produced by a hybridization, the factors of the parental species are brought together or separated from one another according to the rule of segregation. In other words, the principle of segregation is no longer applied to the observable properties, but to hypothetical hereditary factors.

The Mendelians accept further the view that certain properties depend on the presence of one factor, while others are

${ }^{1}$ Certain persons who are endowed with a highly developed colour-sense may be able to discern the colours $a$ and $b$ in the mixture $Z$ of the coloured species $s$ (for instance, in certain subspecies of Matthiola). 
produced by the coexistence of two or more factors-that, for instance, a certain factor $C$ is able to produce a property $a$ as often as a certain factor $A$ is also present, and another property $b$ when it meets a certain factor $B$, but that neither $C$ nor $A$ nor $B$ are able to produce any observable property when they are isolated. ${ }^{1}$

A factor is a hypothetical something which is to be found in the living mixture. It may be surmised that a factor corresponds to a certain bioprotein, or to a certain abiotic substance (enzym, chromogen, etc.) ${ }^{2}$ produced by the living mixture. Although it is impossible to reach the actual bottom of the problem because of our ignorance of the chemical composition of the living mixture, I think that the theory of the hereditary factors may be further developed by a more complete investigation of the primordia in a series of species ${ }^{3}$ according to the method expounded in the present work. (See Part IX.)

Whatever it may be, by means of the ingenious but rather complicated theory of the hereditary factors 4 it has already been possible to classify and to explain numerous facts which seemed to be capricious and inscrutable.

It may be remarked once more that this very important part of natural science is based upon the use of the quantitative method initiated by MENDEL, counting the specimens which exhibit a given property and applying the method of calculation alluded to in the note on p. 34 and completely expounded in § I04-I06.

Unfortunately the theory of hereditary factors is hitherto only applicable in those cases in which hybridization and cultivation of the hybrids are possible. When we deal, for instance, with mosses, ferns and many other living organisms with which hybridization cannot be carried out with certainty, or with fossil species, we shall need another method.

Therefore, in order to answer the needs of descriptive science, I leave the hereditary factors out of account in the present work, limiting myself to the study of the primordia. I try to discern and to express the latter by measurement and to collect in this way exact notions, by means of which it may be possible to bring the inventory of living nature into a more useful form, and to throw more light upon the problems of heredity and the origin of species. I avail myself as often as possible of the information collected by the Mendelian School.

${ }^{1}$ In other words, the property $a$ is produced by the coexistence of both factors $A$ and $C$, the property $b$ by the coexistence of $B$ and $C$.

${ }^{2}$ See BATESON, loc. cit., p. 98.

${ }^{3}$ For instance, in all the species of a genus, a family, etc.

4 This subject is expounded in BATESON, loc. cit., passim. 
§ 38.-MENDELISM (continued). SEGREGATION OF COMPOUND PROPERTIES INTO THEIR COMPONENTS. COMPARISON BETWEEN MENDELIAN DISSOCIATION AND SEGREGATION PRODUCED BY PLASTICITY AND GRADATION AND IN THE COURSE OF INDIVIDUAL DEVELOPMENT. Causa dissimiles, similes effectus.-When two parental species differing in one pair of primordia $D$ and $R$ are crossed, both possibilities exist simultaneously in the first hybrid generation $\mathrm{F}_{1}$ and the property $R$ is latent. In the next generation $\mathrm{F}_{2}$ (in the typical cases) the property $D$ is visible in certain specimens and the property $R$ in others, according to the Mendelian rule of segregation (dissociation). For instance, the cross blue flax $\times$ white flax gives in $\mathrm{F}_{1}$ blue, in $\mathrm{F}_{2}$ white and blue.

Segregation produced by plasticity.-On the other hand, when we take the offspring of a certain blue Campanula and cultivate some specimens $D$ at ordinary temperature $\left(15^{\circ}\right.$ to $20^{\circ} \mathrm{C}$.) and other specimens $R$ about a temperature of $30^{\circ} \mathrm{C}$., the $D$ specimens are blue, the $R$ specimens white. In the offspring under consideration plasticity has brought about segregation. The result is the same, with regard to the visible properties, as if a blue Campanula had been crossed with a white one (§ I6).

When we divide one specimen of Philodendron pertusum (characterized by perforated leaves) into two parts $P$ and $p$, and bring $P$ into a warm, damp greenhouse and $p$ into a greenhouse which is cool and dry, the new leaves of $P$ are perforated, but in the new leaves of $p$ the characteristic perforations are not (or hardly) observed. Here, again, segregation is a consequence of plasticity. The plants $P$ and $p$ differ in an observable property, just as two specimens of the $F_{2}$ generation produced by a (supposed) cross between Philodendron pertusum and a Philodendron with non-perforated leaves.

The species Fagus silvatica includes two subspecies: the ordinary green beech (leaves green) and the copper beech, the leaves of which are reddish. When a copper beech is grown in deep shade its leaves are green; the reaction which produces the red colour is only possible under the influence of light. ${ }^{1}$ Between two specimens taken from a shady and a sunny place the same difference exists with regard to the colour as between two specimens of the $\mathrm{F}_{2}$ generation produced by a (supposed) cross green beech $\times$ copper beech. In this example of segregation produced by plasticity all possible transitory colours are observed between the extremes green and reddish, according to the variations in degree of light and shade, in the same way as in certain examples of hybridization continuous

1 I call shade and light the whole of the conditions of life which prevail in a shady or a sunny place. 
variation in the conditions of existence results in a series of transitions between the parental species (with regard to the observable properties) (§ 35, p. 38).

In the preceding examples ${ }^{1}$ segregation (produced by plasticity) brings about differences between specimens. It may also happen that segregation results in a difference between two parts of one specimen. This occurs in a certain sense in the case of Philodendron, in which the specimens $P$ and $p$ are, in fact, parts of one plant. In a similar way, when the crown of a copper beech becomes large enough, the leaves which are developed in the shady central part of the crown are green, while the peripheral leaves of the same crown, being exposed to sunshine, are red.

Some sorts of apples are green or greenish when ripe; other sorts are red. It often happens that in a fruit of a red sort the side which is exposed to light becomes red, while the opposite side is green. Both parts of the apple differ in the properties red and green, in the same way as two plants of the $\mathrm{F}_{2}$ generation after a (supposed) cross between a seed-fixed red sort and a seed-fixed green sort. Similar differences between two parts of one specimen are observed in certain hybrids: among the hybrids produced by a cross between the ordinary Antirrhinum majus with personate flowers and the subspecies with peloric flowers certain specimens bear simultaneously personate and peloric flowers.

Sometimes plasticity causes segregation in more than two groups of specimens. In Polygonum amphibium we observe: (I) a terrestrial form (stem erect, etc.); (2) an aquatic form (stem flexible, etc.); (3) a xerophytic form (stem creeping, etc.) (See $\S$ I2.)

Decomposition of a Compound Property into Primordia by Plasticity.-We have seen in $\S 36$ that a compound property may be dissociated into simple properties by hybridization. Plasticity may produce a similar effect. The colour of the leaves of the copper beech is a compound property; we call it red or reddish, but in reality it is produced by the coexistence of red and green. In the shade the primordium red becomes latent and the green colour is isolated.

Another interesting example is afforded by Deschampsia (Aira) caspitosa. According to the floras, this species grows in moist, shady places and its spikelets are silvery-grey or purplish. I have observed (Gatley, Wilmslow, Hazel Grove; near Manchester, August, I9I6) two forms which differ by their facies. In moist, sunny places the spikelets are shiny, purplish (or rather purplish-brown), the grey colour of the glumes being concealed by a purplish-brown pigment. In

1 These examples are taken from among a large number of similar cases. 
shady places (in woods) the pigment does not exist and the grey colour is visible. The spikelets are therefore shiny grey; in other words, silvery-grey.

Numerous similar examples will be undoubtedly observed as soon as the attention of the describing naturalists is called to this subject, and the descriptions will become more accurate.

Dissociation by Gradation. - I call gradation the variation of a given property along a given axis. This subject is expounded in Part VIII. In this paragraph I content myself with one example.

In Holcus lanatus (fam. Graminea) the sheaths of all the leaves of a fertile stem are clothed with down. Holcus mollis is described as being not generally so downy. In the latter species, according to my observations (numerous specimens in the neighbourhood of Manchester, August-October, IgI6), the primordium downy is variable along the fertile stem, which is here the axis of gradation. Comparing the successive leaves from below upwards to the (terminal) panicle, we observe that the sheath of the lowest leaf is downy ${ }^{2}$; proceeding upwards we see that the down gradually diminishes on the successive sheaths. The sheath of the upper leaf is always deprived of down (or hardly downy at its base). In this way in Holcus mollis the property downy is distinctly segregated from the property glabrous (absence of down) when the upper leaf and the lower leaf are compared.

If the sheaths of the successive leaves of one fertile stem of $H$. mollis are placed in order into a series according to their position along the axis, the variation of the primordium downy is the same as it would be among the hybrids produced by a cross between $H$. lanatus and a glabrous species of Holcus, supposing that among these hybrids the extremes (parental properties) downy and glabrous were connected by a series of transition forms. ${ }^{3}$ (See $\S 35$.)

According to the above, the difference between both species may be described in the following way ${ }^{4}$ :-

$H$. lanatus: sheath of the upper leaf of the fertile stem downy.

$H$. mollis: sheath of the upper leaf of the fertile stem glabrous (rarely downy at its base).

${ }^{1}$ Compare: "Segregation of the Parental Characters in Seminal Hybrids by Bud-Variation." DARWIN, The Variation of Animals and Plants under Domestication (second edition, 1875 ), vol. i., p. 425 .

2 The down is still visible during the flowering period, although the sheath is already fading.

${ }^{3}$ It would be interesting to know whether a Holcus with glabrous sheaths exists, and to cross it with $H$. lanatus.

- The description here given is applicable to the specimens observed in the Manchester district. It would be interesting to repeat my observations in other districts or countries. 
Innumerable similar examples are found in plants and also in animals.

Segregation in the Course of Individual Development.-According to one of the laws of heredity laid down by DARWIN, variations are inherited at a corresponding age. ${ }^{1}$

Several important consequences follow from this law. A direct consequence is that all the primordia of a species are not observed simultaneously, but successively. This is a cause of segregation. The study of individual evolution is therefore a method of discovering the primordia and of decomposing the compound properties into their components, just as the investigation of the Mendelian segregation.

The last period of the individual development (which has been hitherto rather neglected by embryologists) is especially interesting for the analysis of those properties by which subspecies, species and even genera are characterised. In this paragraph I limit myself to one example. (See Myosotis, §46, and Centaurea, § 47.)

A subspecies of Viola tricolor which resembles $V$. lutea is very common on the dunes along the Flemish coast. When the floral bud expands the five petals are on the whole pale yellow. After a certain time a blue pigment appears in the two upper petals, in which the yellow colour is no longer visible. The difference between young and older flowers is very striking. Suppose now that a Viola with blue upper petals has been crossed with a Viola with yellow upper petals, and that the properties are transmitted in the typical Mendelian way. In the second filial generation $F_{2}$ one would observe two sorts of specimens: blue and yellow. The difference would be exactly the same as between a young and an older flower in the above example. (On the relation between development and gradation, see $\S$ I33.)

Conclusion.-From the examples mentioned in the present paragraph it is seen that segregation (with regard to the observable properties) may be produced by four different causes: hybridization, plasticity, gradation and succession in the course of development. From this it may be concluded that segregation of the observable properties is in general independent of hybridization. In other words, segregation of the properties ought to be looked upon as being a something which has its proper existence, dependent in each peculiar case on a specific energy of the primordia under consideration, and which is not necessarily a result of the presence or absence of certain hereditary determiners (factors).

The analysis of the properties by the study of segregation is

${ }^{1}$ DARWIN, The Variation of Animals and Plants under Domestication (second edition, 1875 ), vol. ii., pp. 5I-6r. 
possible along four different lines. Mendelian segregation corresponds to one of these lines: it is a particular example of a phenomenon the importance of which extends far beyond the limits of Mendelism. It may be anticipated that the study of gradation, plasticity and ontogeny with regard to segregation may throw new light upon the facts observed in hybridization, and bring more accuracy to descriptive natural history.

§ 39.-MENDELISM (continued). THE MENDELIAN METHOD OF DESCRIBING HYBRIDS IS APPLICABLE TO THE DESCRIPTION OF SPECIES.-MENDEL has initiated a new method for the description of hybrids. According to this method each hybrid is characterized by the coexistence of two or several properties (primordia).

EXAMPLES: When two species which differ in two pairs of properties $D, R$ and $d, r$ are crossed the $\mathrm{F}_{2}$ generation consists of four sorts of specimens characterized by the combinations $D d, D r, R d, R r$. In a similar way, when the crossed species differ in three pairs of properties $D, R ; d, r$ and $\delta, \rho$, eight sorts of specimens are observed in the $\mathrm{F}_{2}$ generation-viz.

$\begin{array}{llll}D d \delta & D d \rho & R d \delta & R r \rho \\ & D r \delta & R d \rho & \\ & D r \rho & R r \delta & \end{array}$

This method is applicable to the description of all living beings. It may be adopted for the description of subspecies, species, genera, etc., as often as it is possible to discern a sufficient number of primordia susceptible of a strict definition. (A general application of the method is possible when the primordia are expressed by measurement. Each description becomes then a combination of figures. See Part IX.)

It happens very rarely that one property (eigenschap, Eigenschaft) is a character - that is to say, a distinctive mark (kenmerk, Kennzeichen) - by which a species may be distinguished from others. A species (just as a hybrid) is almost always characterized by the coexistence of several properties: their combination is a character.

Let us consider the six following properties of a flower:5 sepals; 5 petals; 5 stamens; I ovary; 5 styles; petals blue. Each of these properties exists in numerous species and is not a characteristic as long as it is taken separately. But flowers in which the six properties exist at the same time are found only in a very small number of species of the genus Linum. If each property was represented by a letter, the six letters being associated into a combination, this would enable us to recognise the two or three species of Linum under con- 
sideration among all the indigenous and cultivated plants of Central Europe. ${ }^{1}$

In a similar way, limiting ourselves to the British flora, the combination leaves angulinerve, perianth of 5 segments, 6-8 stamens, I ovary, 3 styles is found only in the genus Polygonum.

Holcus lanatus is characterized among all the British grasses by the following combination:-

Property $a$ : each spikelet two-flowered.

, $b:$ glume of the upper flower of each spikelet awned.

, $\quad c$ : glume of the lowest flower of each spikelet awnless.

,$\quad d$ : axis of the spikelet glabrous.

" $e$ : sheath of the upper leaf of the fertile stem downy.

Holcus mollis is characterized by the following combination:$a, b, c, d$ and

Property $f$ : sheath of the upper leaf of the fertile stem glabrous.

The combinations abcde and abcdf represent respectively $H$. lanatus and $H$. mollis as exactly as the combinations KNOOO and NaNOOO represent respectively potash-salpetre and sodasalpetre.

It is ordinarily impossible to find the characteristic combination of a species without investigating a sufficient number of primordia in all the species of the genus, the family, etc., to which it belongs, plasticity, gradation and even (in certain cases) the succession in the course of the individual development being taken into account.

In the floras and the faunas a mere enumeration of properties of each species is given. The reader, in other words, the unfortunate biologist, who wants to identify a plant or an animal is requested to discover by himself the characteristic combinations.

$\S 40$.-PHYLLOTAXIS. (See $\S 30(4))$.- This part of botany, which is the study of the relative position of the cauloms and the phylloms, is entirely based upon quantitative data. It might be called geometrical botany. It includes, among other things, the knowledge of the floral diagrams, which is of high importance for descriptive botany. The fundamental principles of phyllotaxis are expounded in the classic text-books; therefore I content myself with this short reference to it.

§ 41.-THE QUANTITATIVE METHOD APPLIED TO PHYSIOLOGICAL FUNCTIONS AND PROPERTIES. (See $\S 30(5))$.- - In the physiology of animals and also, to a certain degree, in the physiology of plants much progress has been made by the use of the quantitative method. By the measure-

1 A combination of properties is comparable to a word, which represents an exact notion, although each isolated letter is deprived of any significance. 
ment of certain vital functions several parts of physiology have reached a degree of accuracy hardly inferior to the exactitude prevalent in physical and chemical sciences. I content myself with a few examples.

The measurement of the so-called personal equation and of the duration of a sensation produced by a luminous impression upon our eye (JOSEF PLATEAU) have been the origin of the modern physiology of the nervous system and the sense organs, which includes experimental psychology. In this part of biological science a new world of facts and phenomena has been disclosed by means of measurement. The relations between stimuli and the physiological reactions which they produce, the physiology and the optical contrivances of the human eye, belong to the most admirable conquests of modern science. Here INVESTIGATION IS MEASUREMENT and almost every conclusion is drawn from a comparison of figures. Similarly the quantitative method has been introduced in physiology by the application of physics and chemistry to the study of physiological functions. Our knowledge of aerobic and anaerobic respiration, the conception of respiration in general, our knowledge of the osmotic properties of cell-sap (DE VRIES) and other liquids contained in the body of living beings (HAMBURGER) have been built up by means of methods borrowed from physics and chemistry, which are themselves governed by the quantitative method.

DARWIN'S remarkable experimental investigation of selfand cross-fertilization is based upon the measurement of the dimensions and the fertility of self- and cross-fertilized specimens. This line of experimental research is in close relation with the study of heredity. It is full of promise, although it is for the time being somewhat overlooked.

In the present state of biological science there is a rather disconcerting discordance between physiology, which is the investigation of the functions of the living beings, and descriptive biology, which is the study of the living objects themselves. In physiology quantitative investigation is already preponderant. In anatomy, morphology, embryology and in the description of species we still follow almost entirely the qualitative method. Physiology would say, for instance, that a certain thing $a$ is $I \cdot I 3$ times as long as $b$; descriptive biology would say that $a$ is rather longer than $b$. On the one hand an exact description is used; on the other hand, vague terms.

$\S 41_{\mathrm{A}}$.-Among the students of descriptive biology a prejudicial misconception seems to prevail. Many of them seem to believe that the use of the quantitative method is very easy and simple when applied to physics, chemistry and physiology. 
On the other hand, they look upon this method as being an impossibility in descriptive science, or a fearful something because of the long labour required for the measurement of the properties of animals and plants. It seems as if they did not realize that, for instance, the determination of the duration ${ }^{1}$ of the three periods of the contraction of a muscle and the measurement of the relations between fatigue, temperature, intensity of the stimulus, etc., and these periods require very long and exceedingly delicate work, and that numerous experiments are needed to establish one figure.

The aim of the quantitative method in descriptive science is not only to describe exactly the properties of the species and to make an inventory of the forms of life. This is important enough in itself, but there is more. It is difficult to obtain exact data about the development and the anatomy of animals and plants as long as the observed facts are described by means of mere terms. It is still more difficult to discover the origin of species and their phyletic relations without an exact knowledge of the investigated species. This can only be obtained by comparing their characteristic figures with the figures of other species. The object of the quantitative method is, in general, the exact description of the living objects.

The HAECKELIAN method has been, for more than forty years, an important instrument of progress. It is, however, open to certain criticism. (See $\$ 50$.) Among other things, it has diverted attention from the quantitative investigation initiated by QUETELET, MENDEL and also by DARWIN. Therefore the HAECKELIAN method, in spite of its high merits, does not enable us to get to the bottom of the biological problems. It cannot advance our knowledge beyond a certain limit.

${ }^{1}$ Expressed, for instance, in hundredths of a second. 


\section{PART IV}

\section{THE PRIMORDIA}

\$ 42.-THE ADULT STATE IS A STATE OF EQUILIBRIUM.-Every living being is at the beginning of its development ${ }^{1}$ in a state of unstable equilibrium. It passes through a series of transformations, brought about by reactions, till there is no longer any force (cause) by which a new reaction might be produced. In this way the individual is brought into a state of stable equilibrium which we call the adult state.

ई 43.-EACH PRIMORDIUM REPRESENTS A STATE OF EQUILIBRIUM.-As long as we are using the ordinary biological language we may content ourselves with the notion that a given individual is adult. This is, however, a complex notion. When we want to apply the quantitative method we are compelled to decompose the notion adult individual into simple concepts representing measurable things. This is possible by considering each primordium (simple property) separately.

In the course of the individual development the primordia appear in a certain order. (DARWIN. See $\S 38$, p. 46.) Each primordium is the product of a reaction ${ }^{2}$ which begins at a certain moment and continues till there is no longer any force (cause) by which further continuation might be produced. At that moment the material parts which participated in the reaction have reached a state of stable equilibrium: the primordium is adult.

This brings us to a mechanical definition of the term primordium: a primordium is the expression of a state of equilibrium, or, in short, a primordium is a state of equilibrium.

The expression adult individual may be used in its ordinary, vague sense. In reality an individual is never adult, because the development of certain of its primordia continues till it has ceased to live.

§ 44.-INDIVIDUAL ADAPTATION (ACCOMMODATION) IS EQUILIBRIUM. (See $\S 22$ ). - In any reaction (or

1 The beginning of the individual development is very often preceded by a period of rest.

2Or a series of reactions. 
series of reactions) which results in the production of an adult primordium, two sets of causes may be discerned ( $\$ \S$ Io and 18 ): on the one hand, internal or specific causes, which depend on the chemical composition of the living mixture; on the other hand, external causes, which depend on the environment. The internal causes may be looked upon as being the same in all the specimens of a given species, but the external causes are variable from one individual to another. According to this, each adult primordium is a priori variable in a given species, because it is, in each individual, in equilibrium with a particular combination of external forces. This equilibrium is called individual adaptation or accommodation. Since all the properties of a given individual are accommodated in this way, we may say that the individual, considered as a whole, is accommodated to (in equilibrium with) its conditions of life. An individual is accommodated to its environment, not in order to obtain certain physiological advantages, but because it cannot be otherwise.

§ 45.-EXAMPLES OF INDIVIDUAL ADAPTATION. -Several examples of individual adaptations (Polygonum amphibium, Primula sinensis, etc.) are mentioned in $\$ \S I 2$ and I4-I7. I call plasticity the variation produced by individual adaptation.

In the following example one single primordium is taken into account. Suppose that an adult petal $a$ of a given species has a length of $I 2 \mathrm{~mm}$. : in the course of its development the length has been successively I, $2 \ldots 9$, IO, II, I2 mm. When the length I2 $\mathrm{mm}$. was reached the primordium length was in equilibrium with the environment. Suppose now a second adult petal $b$ of the same species the length of which is Io $\mathrm{mm}$. The petal $b$ has been subjected to different influences ${ }^{1}$ during its development. It passed also through the series of values $I, 2 \ldots 9$, ro $\mathrm{mm}$., but it was in equilibrium with its environment when its length had reached Io $\mathrm{mm}$.

Both petals have been accommodated to their respective conditions of existence: the difference between them may be expressed by measurement.

REMARK: Although the shorter petal $b$ is adult, just as the longer one $a$, we may say that $b$ is in an infantile (juvenile, padogenetic) state with regard to the primordium length because its growth has been stopped in a younger state.

§ 46.-CLASSIFICATION OF THE PRIMORDIA WITH REGARD TO THEIR DEVELOPMENT.-In the course of the development of a living individual each of its primordia 1 Temperature, light, food, water, etc. (See § I19.) 
passes through a series of values till a maximum is reached, just as the length of a petal taken as example in $\S 45$. When we investigate the evolution of an individual ${ }^{1}$ we may follow the development of each primordium separately. We may compare the evolution of several primordia in order to obtain a view of the whole. We may also compare the development of a given simple property in several individuals or species.

In order to make such comparisons easier I give here an attempt to classify the primordia with respect to their development. Considering first the primordia at the beginning of their development, I bring them into three groups :

(I) The original primordia, which appear (or exist) at the beginning of the embryonic life of the individual (or of the part of the individual to which they belong). Examples: In a specimen of Spirogyra the total length and the number of cells are original properties: they are both already discernible and measurable at the beginning, when the specimen consists of one cell (zygospore). ${ }^{2}$ In a pluricellular simple hair of a plant the total length and the number of cells are both original with regard to the hair considered as a unit. The length and the breadth of a petal are original primordia with reference to the petal.

(2) The metamorphic primordia, which are produced by a transformation of a previously existing property. Examples: A colouring substance, which appears at a certain moment in a petal by a transformation of a chromogen. The presence of hairs on a leaf (primordium hairy or downy) is a metamorphic property, because each hair has its origin in a transformation of an epidermal cell. In higher animals and plants the metamorphic properties are exceedingly numerous.

(3) The awakening primordia, which are latent for a certain time, and appear at a certain moment, independently of any previously existing primordium. Awakening properties seem to be rare. Example: The initial cell (zygospore) of a Spirogyra is more or less oblong. After the second cell division two of the four cells are cylindrical. The primordium cylindrical appears at once: it is an awakening primordium. (See $\$ \S 54$ and 58.) It is sometimes difficult to determine whether a given primordium is metamorphic or awakening.

Considering the primordia at the end of their development (independently of their origin), I divide them into two groups :

' Or of a part of an individual; for instance, a petal, a leaf, an antenna of an insect, a scale of a lizard, etc.

'Here the value of the property total length is obtained by measuring the length of the zygospore; the value of the property number of cells is one. The value of each property increases till the definitive (adult) value is reached. 


\section{THE QUANTITATIVE METHOD IN BIOLOGY}

$A$. The arrested primordia, the growth (development) of which is arrested when they have reached a certain value, without any further increase or modification. Examples: The total length of a Spirogyra or of a petal. The number of scales of a hibernaculum, etc.

$B$. The transitory primordia, which are transformed at a certain moment into a new (metamorphic) primordium. Examples: In the limb of the corolla of Myosotis palustris three colours appear successively: white, rose, blue. The primordium white is original (with regard to the corolla) and transitory. The primordium rose, being very probably produced by a transformation of a chromogen which is already existing during the white period, is metamorphic; it is also transitory, because it is transformed into the primordium blue. The primordium blue is therefore metamorphic and also arrested, because the blue colour, when it has reached a certain intensity, is not subjected to any further modification. Such is the succession of the colours in the ordinary blue subspecies of Myosotis palustris. In the rose subspecies the blue colour does not appear; the property rose is therefore arrested. In the white subspecies the property white is arrested. ${ }^{1}$

The arrested properties in their turn may be divided into two groups :

Aa. The persistent properties, which are preserved till the end of the life of the individual (or part) in which they are observed. Example: The blue colour in Myosotis palustris.

$A b$. The caducous properties, which disappear at a certain moment. Their disappearance is often a direct consequence of the fact that the parts (segments, organs) to which they belong are caducous. Example: The leaves of many plants are clothed with hairs which fall off at a certain moment : all the primordia of the hairs and the primordium hairy itself disappear with the hairs. In a similar way all the primordia of the scales of a hibernaculum disappear when the scales fall off in the spring. In the course of the development of almost all (perhaps all) higher animals a number of primordia are caducous, ${ }^{2}$ owing to the resorption (degeneration, phagocytosis, etc.) of certain organs.

A primordium which disappears gradually may be called deciduous.

1 With regaird to the colour (all other properties being excluded), the white subspecies is infantile compared with the rose, and the rose is infantile compared with the blue. (See § 45.)

The succession of the colours in the blue subspecies is an example of segregation of three primordia. (See $\$ 38$.) About the transformation of red into blue, see $\S$ I33.

2 A caducous property is, of course, something quite different from a transitory property. 
All the mentioned groups of primordia are set out in order in the following table:-

$$
\begin{gathered}
\text { Classification of the Primordia (Simple Properties) according } \\
\text { to their Development } \\
\text { Primordia }\left\{\begin{array}{lll}
\text { original } & \begin{cases}\text { arrested } & \text { \{persistent } \\
\text { transitory } & \text { caducous (or deciduous) }\end{cases} \\
\text { metamorphic } & \begin{cases}\text { arrested } & \text { \{persistent } \\
\text { transitory } & \text { caducous (or deciduous) }\end{cases} \\
\text { ? awakening } & \left\{\begin{array}{l}
\text { arrested } \\
\text { transitory }
\end{array}\right. & \begin{array}{l}
\text { persistent } \\
\text { caducous (or deciduous) }
\end{array}
\end{array}\right.
\end{gathered}
$$

§ 47.-CLASSIFICATION OF THE PRIMORDIA WITH REFERENCE TO THEIR DEVELOPMENT (coniinued). EXAMPLES.-FIRST EXAMPLE: In $\S$ I6 I have mentioned a subspecies of Primula sinensis the corolla of which is red at ordinary temperature and white if the plant is cultivated at a temperature of about $30^{\circ}$. In this corolla (limiting ourselves to the limb) we observe the primordia length and breadth, which are both original, arrested and persistent. During the first period of its development the corolla is white ${ }^{2}$ : it contains very probably a chromogen, which is transformed at ordinary temperature into a red substance. The intensity of the red colour increases gradually till a maximum is reached. The property white is original and transitory; the property red is metamorphic, arrested and persistent.

If we look upon the primordia white and red as being two terms of one series, we see that three properties white-red, length and breadth follow in their development three separate lines (the velocity of increase of length and breadth is not the same). Along each of these lines the value of the corresponding property is continually varying, the variation of each property being governed by a peculiar law. At a given moment, for instance, after $n$ hours, a certain combination of values is found to exist; after $2 n$ hours a new combination is observed, etc. The so-called adult state corresponds to a certain combination. In other words, there exists a certain harmony ${ }^{3}$ between the three properties with regard to the progress of their development. The above facts may be brought into the form of

1 On accrescent properties, see $\$ 47$, second example.

2 It may be that the young corolla contains chlorophyl at a certain moment. This is of no importance for the subject under consideration.

The term harmony is used here in the meaning in which it was used by LEIBNITZ, the author of Monadologia and Harmonia prastabilita. LEIBNITZ was a mathematician. 
exact knowledge by means of the quantitative method, ${ }^{1}$ the properties being measured after $n, 2 n, 3 n$... hours, the figures being plotted down in the form of curves. (See, on the use of a leading property, § 49.)

Let us now consider the corolla of the same species when grown at a temperature of $30^{\circ} \mathrm{C}$. The properties length and breadth behave on the whole in the same way as in the preceding case. The primordium white is original. Since the reaction which produces the primordium red does not take place, white is arrested (its value is invariable and may be represented by $\mathrm{O}=$ no colouring substance) and persistent (instead of transitory).

In the preceding example only three primordia (colour, length, breadth) have been considered. It is, of course, possible to devote attention to a larger number of primordia at the same time; for instance, the number of epidermal cells and their dimensions, the number of stomata and the dimensions of their cells, etc.

SECOND EXAMPLE (ACCRESCENT PRIMORDIUM) : In a leaf of a tree we may distinguish, among other primordia (limiting ourselves to the limb) : (I) the length (measured along the mid-nerve); (2) the breadth (at the place of the greatest breadth); (3) the number of palissade cells (counted in the transverse direction at the place of the greatest breadth); (4) the breadth of the palissade cells (calculated by dividing the breadth by the number of cells).

The primordium number of cells increases from the beginning till the maximum is reached : it is original, arrested, persistent. During this first period of the development of the leaf (period of cell-division) the breadth of the cells may be looked upon as being constant. At (or about) the end of this period the cells begin to grow, and this process goes on till they have reached their full size. The primordium breadth of the cells is original, arrested and persistent. Since the increase of this primordium is continued after the primordium number has been arrested, it might be called ACCRESCENT in comparison to the primordium number. The primordia length and breadth of the limb are both original, arrested and persistent.

SECOND EXAMPLE (continued). SENSITIVE PERIOD, CORRELATION. The period of development of the leaves of any of our indigenous trees (for instance, Fagus silvatica) is divided by the winter rest into two parts: (I) the bud period (intragemmal period), which corresponds to the summer (JulySeptember) of the first year; (2) the spring period (vernal period), which begins when the bud expands, and extends (in

' Length and breadth may be easily measured. The measurement of colours is possible in several ways (scale of colours, chemical analysis, spectroscope). 
Fagus silvatica) in ordinary years (in Flanders) from about the end of April to about the middle of May. The period of celldivision is included within the bud period; therefore the plasticity of the primordium number of cells depends on external causes (temperature, etc.) which are acting in July, August, September, but this primordium is, of course, not affected by the external influences which prevail in the spring. The bud period is therefore the sensitive period (mobilis atas) of the primordium under consideration. ${ }^{1}$

On the other hand, the plasticity of the primordium breadth of the palissade cells depends almost entirely on the external conditions which prevail in the spring. Its sensitive period corresponds, therefore, to the vernal period.

The properties length and breadth of the leaf-blade may be looked upon as being primordia. They are, however, in reality compound properties, which depend on the number of cells and on their dimensions. As a consequence of this the sensitive period of the mentioned properties extends over both parts of the period of development of the leaf. ${ }^{2}$

The knowledge of the sensitive period of the primordia is important for embryology in general, and especially for the investigation of plasticity, adaptation and correlation between plastic properties.

A curious example of modified correlation in relation with the sensitive period has been described by DE VRIES. In Papaver somniferum, subsp. polycephalum, the central (normal) pistil is surrounded by a number of smaller supplementary pistils. In ordinary specimens an evident correlation exists between the dimension of the central pistil and the degree of development of the supplementary pistils, a large central pistil coinciding with well-developed supplementary ones, and vice versa. The sensitive period of the property supplementary pistils coincides with the early period of the life of the individual, whereas the sensitive period of the property dimension of the central pistil coincides with a later part of the individual life. If a specimen is brought under unfavourable conditions of existence (poor food) during the first weeks, the supplementary pistils are hampered in their development. If the same specimen is brought (at the age of about six weeks) under better conditions, a large central pistil may still be obtained. In this way a large central pistil coincides with incompletely developed supplementary pistils, the ordinary correlation being entirely

\footnotetext{
1 The sensitive period idea has been introduced in botanical science by DE VRIES.

${ }^{2}$ The sensitive period of several properties of the leaves of Fagus silvatica with reference to the influence of light and shadow has been investigated by Dr DE BOIS (Botanic Garden at Ghent).
} 
disturbed. The ordinary correlation is, of course, a consequence of the fact that the conditions of existence are ordinarily favourable or unfavourable through the whole life (a few months) of each specimen.

I have observed in Chrysanthemum carinatum remarkable modifications, the explanation of which is found in the sensitive period. Dr C. DE BRUYKER (Ghent) has observed similar facts.

This calls for reflection, especially with regard to the methods of studying correlation. Little attention has hitherto been paid to this interesting question.

THIRD EXAMPLE: In the ordinary blue subspecies of Centaurea cyanus (observed in Flanders) I consider two primordia of the marginal florets: length and colour. In a young bud the colour is white: this primordium is original and transitory. The second period of the development (within the bud) begins with the appearance of a very pale rose-purplish colour, which is very probably produced by a transformation of a previously existing colourless chromogen. The intensity of the new colour increases up to a certain limit which I call pale rose-purplish. This primordium is metamorphic and transitory. The third period is initiated (still within the bud) by a transformation of the pale rose-purplish into blue. The intensity of the blue colour increases till the flower-head is expanded. The primordium blue is metamorphic, arrested and caducous (strictly speaking, it is deciduous, since it vanishes by degrees during the post-floration). While the three terms of the property colour follow each other, the primordium length increases continuously till the maximum is reached (this happens a short time after the expansion of the bud). The primordium length is original, arrested and persistent. ${ }^{1}$

THIRD EXAMPLE (continued). PLASTICITY.-I have cultivated the blue Centaurea cyanus under very poor conditions of existence (about seventy specimens in a seed-pan, the diameter of which was about $30 \mathrm{~cm}$. and which contained only sand). The plants were dwarf; most of them produced only one terminal flower-head. The corolla of the marginal florets was distinctly shorter, the blue colour hardly paler than under ordinary conditions. We observe here a new example of the independence of the primordia: a modification of the conditions of life has here an important influence on the value of the primordium length and an almost negligible influence on the primordium colour. ${ }^{2}$ (In Primula sinensis the reverse was

${ }^{1}$ In the development of the colours mentioned an interesting example of gradation is observed. (See $\$ 133$.) The succession of the colours is an example of segregation. (Compare Viola, $\S 38$, p. 46 , and Myosotis, $\S 46$, p. 54.)

${ }^{2}$ In the experiment mentioned, under unfavourable conditions, the adult marginal florets were distinctly infantile with regard to the length, hardly infantile with regard to the colour. 
observed, the colour being affected, the length hardly or not at all. See this paragraph, first example, p. 55.)

FOURTH EXAMPLE: A rose-purplish subspecies of Centaurea cyanus (one specimen in a rye field, June, IgII); marginal florets. - The property length behaves exactly as in the above-mentioned blue subspecies; it is original, arrested and persistent. The development of the colour follows the same line as in the blue subspecies during the two first periods, the succession being white and rose-purplish. But when the latter colour has reached the value pale (which coincides with the end of the second period in the blue subspecies) the transformation into blue does not take place and a third period is not initiated. The second period is protracted, the intensity of the rose-purplish colour increasing gradually till the value intense rose-purplish is reached. This happens when the flower-head is expanded. The primordium rose-purplish is here metamorphic and arrested. ${ }^{1}$

REMARK I. : The above example is interesting with regard to the significance of the term infantile (juvenile, padogenetic). We might be tempted to say that the rose-purplish subspecies is infantile in comparison with the blue. Used in that way, the term infantile does not express an exact notion. The rosepurplish subspecies is deprived of the blue colour and therefore infantile with regard to the property blue. But in the blue subspecies the property rose-purplish is arrested in its development when it has reached the value pale; therefore the blue subspecies is infantile with regard to the colour rose-purplish.

In other words, each subspecies being considered as a whole, neither of them is infantile. In both the development of the colour follows the same line till the value pale rose-purplish is reached. After that the development continues along two diverging lines. We see, from this very simple example, that the term infantile (juvenile, padogenetic) ought to be used with regard to each property separately, but is not strictly applicable to a species, a subspecies (or even an individual) considered as a whole.

REMARK II. : In a similar way the terms progressive and retrogressive are ambiguous when applied to the phylogenic relations of specific forms. It might be said, for instance, that the rose-purplish subspecies has been produced by a progressive mutation of the blue subspecies with regard to the property rose-purplish; but one might say also that the rose-purplish subspecies is the result of a retrogression with regard to the property blue. The above remarks are not merely linguistic subtleties. In complicated cases, when a number of properties

1 I don't remember whether it is persistent or deciduous. See about gradation in Centaurea, $\$ 133$. 
are in play, the indiscriminate use of the above-mentioned terms may result (and has resulted) in inexact conceptions. For instance, in the comparative study of male and female individuals of the same species, clearer views would certainly be obtained if the terms infantile (juvenile), progression and retrogression were used for each property separately. The investigation of this important subject, which is in close relation with the secondary sexual characters, has been initiated by DARWIN. It has been considerably spoiled by the obsession of adaptation and other preconceived ideas, and it is rather overlooked by many biologists.

§ 48.-THE MEASUREMENT OF A STATE OF EQUILIBRIUM.-In $\S 43$ a primordium (simple property) is defined as a state of equilibrium. This is further explained in $\S 44$, and in $\S 45$ the property length of a petal is given as example. Just as the latter property, the primordia mentioned in $\$ \S 46-$ 47, during their period of development are passing through a series of values till a certain state of equilibrium is reached.

This view is based upon a mechanical conception. It may be asked how it is possible to express a state of equilibrium by measurement.

A state of equilibrium coincides with the simultaneous action of a certain number of forces. Strictly speaking, it ought to be expressed by an equation in terms of the forces. In the present state of biological science it is impossible to enumerate and to measure the forces which are at play. Therefore we must have recourse to an indirect method, measuring the material parts which are maintained in equilibrium by the acting forces. We may count the similar parts (organs, segments, etc.) which are in equilibrium, measure their dimensions, their form (any form may be expressed in terms of dimensions), their relative position (angles of divergence, etc. See, on phyllotaxis, § 40), their physical properties (elasticity, etc.), etc. The chemical properties properly so called, which depend on the presence of certain abiotic substances or mixtures $(\$ 8)$, are quantitatively known as soon as we know the chemical constitution and the quantity of the substances under consideration. ${ }^{1}$ In many cases the abiotic chemical properties may be measured indirectly (scale of colours, transparence, etc.). But whatever may be the object of the measurement, it must always be borne in mind that we are measuring something which coincides with a state of equilibrium.

The principles upon which the measurement of the primordia of the living beings is based are expounded in Part VI. (probability), Part VII. (variation steps) and Part VIII. (gradation).

1 This may be discovered by chemical research. 
§ 49.-THE QUANTITATIVE METHOD APPLIED ON EMBRYOLOGY. CURVES OF DEVELOPMENT. LEADING PROPERTIES.-In $\S 47$ I have given a short account of the development of certain properties of plants. The examples given are very simple and the facts mentioned may be observed without complicated technique, but the principles of the method are applicable to the study of any embryological subject. These principles may be summarized in the following way:-

(I) In the study of the development of a living individual (or part, segment, organ, etc.) we want to discover a certain number of simple properties (primordia).

(2) Since the primordia are on the whole independent of each other, the development of each primordium ought to be studied separately, by measuring its value at successive moments of the period of development.

(3) The primordia of a species are very numerous, in higher animals and plants practically unlimited in number. Therefore it is advisable to concentrate our attention upon the development of a small number of well-chosen properties.

(4) The successive values of each property ought to be set out in order in a chronological series. They may be represented by ordinates, by means of which a curve of development may be drawn.

(5) The moment at which a transitory property is transformed into a metamorphic one ought to be determined and indicated in the curve of development. In a similar way the moment at which a (caducous) property disappears or a (awakening) property appears ought to be determined and indicated in the curve.

(6) The curves (or series of figures) of all the investigated properties ought to be brought together into one table or one diagram ( $\$ 47$, first example). By means of an embryological table, or diagram constructed in that way, we may compare exactly the lines of development of several properties; we may find which is, at any given moment, the existing combination of values ${ }^{1}$; we may obtain a clear notion of the way in which a given state proceeds from the preceding state and gives birth to the next one; we may obtain valuable information about the segregation of the properties, for instance, with reference to the developmental continuity or discontinuity between two properties, and we may compare several individuals, species, etc., by comparing their tables or curves of development.

(The gradation curves mentioned in Part VIII. are constructed on the whole according to the above principles. See Fig. 27.)

In the third and fourth examples described in $\S 47$ I have

1 In other words (using the ordinary language), we may find which are the characteristics of a given embryo at any moment of its development. 
contented myself with a mere estimation of the successive values of the primordia. This method was applicable because it was possible to bring side by side into a series and to compare a number of specimens (florets of Centaurea cyanus) in various states of development. But in order to obtain exact results measurement is, of course, indispensable.

An important question is to determine at which moment the measurements ought to be made. Two general methods (followed in embryology) may be adopted:

(I) We may divide the time (hours, days, etc.) between the beginning and the end of the development into a certain number of intervals, measuring the properties at the end of each interval. This method is applicable in certain cases ; for instance, for the development of a bird or a fish within the egg, all the eggs developing under the same conditions. But this is rather exceptional. The rapidity of development often varies considerably according to external influences (temperature, etc.). Therefore two embryos of the same age may be in a very different state of development. It is, moreover, often impossible to know the exact age of an embryo.

(2) According to the second method, one property is taken as a standard or leading property, the development of the others being investigated in comparison with the standard. The choice of a leading property is, of course, arbitrary, and depends in each peculiar case on the investigated subject. In the development of a fish, a leaf, a petal, etc., the total length of the object is ordinarily a convenient leading property.

I have adopted the method of the leading property in the investigation of gradation along the stem of grasses and acrocarpic mosses (Part VIII.). (Compare § II4, Fig. 23.) See § I33.

§ 50.-VARIATION IN EMBRYOLOGY.-Many embryologists believe that variation does not exist or hardly exists in the early period of development of higher animals and plants. Conclusions drawn from the study of one or two specimens are regarded as being applicable to the species and also (according to the Haeckelian principles) to a whole genus and even to a family or a class. For instance, a paper in which two embryos of a tortoise are described is called a Memoir on the Embryology of the Chelonida., etc.

We know, on the other hand, that adult specimens are variable in their internal anatomy just as in their external properties. I have investigated by measurement thirty-eight properties in about ninety species and twenty-five so-called varieties of the genera Carabus and Calosoma. ${ }^{1}$ I have found a

${ }^{1}$ I have carried out about 250,000 measurements (September 1907 to July I914). 
large amount of variation within the limits of each species and even of each "variety," and, moreover, numerous specific differences which have never been mentioned and probably never surmised. The differences between the genera Carabus and Calosoma are described in the classical books in a few words ; they are, in reality, very numerous.

According to the Haeckelian School, embryos in an early state of development are to be compared to lower animals and plants. We know that the latter are variable just as the higher forms of life. For instance, a number of alge and fungi are exceedingly plastic, even in properties upon which classification has been based.

We may ask the question, Why should embryos be less variable than adult specimens or lower animals and plants? It is difficult to find any serious reason why embryos should be, as it were, sheltered from the influence of plasticity.

In certain groups, such as Mammalia and Birds, the conditions of existence of the embryos ${ }^{1}$ seem to be little variable, and therefore it may be expected that plasticity is rather small. Even here, however, the influence of complexity exists. It may be remarked that an important part of our knowledge of the embryology of mammalia and birds has been collected by the investigation of such animals as the dog, the rabbit and the chicken, three species which include numerous subspecies (socalled races), innumerable specimens being hybrids of very complex origin. In the books and memoirs in which the embryology of these species has been described again and again one finds hardly ever any information about the subspecies to which the described specimens belong. Variation produced by hybridization has been simply ignored.

It often happens that two scholars, endowed with an equal talent for observation and an equal mastery of technique, do not agree with one another, and that a third embryologist, investigating the same subject, causes still more confusion by publishing new discoveries. It may be supposed that complexity is here at play and that different subspecies (and hybrids) have been confounded under the name dog, or rabbit, or chicken.

The application of the quantitative method to embryology would enable us to reduce the complicated notion of DEVELOPMENT to terms of the simple notion of GROWTH of the primordia. It would enable us to investigate the influence of external conditions upon the development (growth) of one or several given primordia. Since the simple properties are, on the whole, independent of each other, it may be anticipated that the line (curve) of growth of each primordium may be modified separately

${ }^{1}$ For instance, temperature, light, food, etc. 


\section{THE QUANTITATIVE METHOD IN BIOLOGY}

by external causes; that the characteristics (combination of primordia) of an embryo in a given state may be therefore modified, bringing about a new starting-point, and that the further development may be modified in its turn.

We have seen, for instance ( $\$ 47$, p. 56 ) that in Primula sinensis an original transitory primordium (white) is transformed by unusual temperature into an original arrested persistent primordium, a second primordium (red) being suppressed altogether, while a third primordium (length) is hardly or not altered. There is, a priori, no reason why similar changes should not occur in the course of the individual development in any species whatever. It is only by means of the quantitative method (curves of development) that it is possible to investigate accurately such phenomena. (Compare Part VIII., gradation curves.)

§51.-REMARK: The quantitative method in embryology ought to be established by degrees by the investigation of not too complicated examples. This method is still very incomplete; its period of trial is not yet over. It is only by CARRYING OUT NUMEROUS MEASUREMENTS that serious progress is to be expected.

It is possible to investigate the development of many objects, in which only a few properties have to be taken into consideration and from which it is possible to collect numerous figures without serious practical difficulties.

EXAMPLES: The development of a phyllom, a trichom; a Spirogyra and other similar plants. In the animal kingdom, the development of the legs, antennæ, wings, etc., of articulate animals (Ärachnids, Crustacea, Hemiptera, Orthoptera, etc.), the shell of Bivalve Mollusca, etc.

The development of such comparatively simple objects is governed by the same mechanical lawes as that of a rabbit, a chicken or a frog, because the individual evolution consists, in each and all, of the passage of one state of equilibrium to another.

When we want to discover laws of nature the best method is, of course, to proceed from simplicity to complexity. This logical line has been followed and is still followed in those sciences which investigate inorganic nature. The founders of modern chemistry (LAVOISIER, PRIESTLEY) began with the study of very simple substances, such as water, carbon dioxide, sulphur dioxide, mercuric oxide, etc. If they had tried, at the end of the eighteenth century, to discover the constitution of complicated silicates, indigo or alkaloids, their efforts would have been fruitless. HÄUY has drawn up the fundamental laws of crystallography from the study of beautiful, regular crystals; later on he attacked complicated and 
irregular objects. MENDEL discovered very important principles of heredity by the investigation of a few comparatively simple facts. The rules which he laid down are to-day a guiding principle among the diversity of the phenomena of hybridization.

There seems to exist, in the mind of many biologists, a propensity to study problems which are INSOLUBLE in the present state of science. Our methods are not adequate for these difficulties.

In the present state of our knowledge the application of the quantitative method to complicated embryological subjects would be premature and result very probably in waste of labour and disappointment. 


\section{PART V}

\section{ATTEMPT AT A CLASSIFICATION OF THE PRIMORDIA}

§ 52.- PRELIMINARY REMARK : NUMEROUS PRI-
MORDIA ARE MENTIONED IN THE EXISTING DESCRIPTIVE LITERATURE.-When we intend to apply the quantitative method to the study of any species, we must first of all discover a certain number of its primordia. Very often we find the wanted information, at least to a considerable extent, by consulting a flora or a fauna in which the species is described. The amount of material accumulated in descriptive literature is inexhaustible and opens up, when adequately used, a wide field for quantitative investigation, not only with regard to the quantitative description of subspecies, species, genera, etc., but also for the study of the individual development. (See $\$ \S 46$ and 49-50.)

Many specific characters are in reality measurable primordia. Other characters may be brought into the form of measurable primordia. Certain characters are compound properties which may be decomposed into their primordial components. (See § 38, segregation, p. 43.)

A property, mentioned as a character, may, by analogy, lead to the discovery of other similar properties which have never been mentioned nor investigated before.

It very often happens that a character, which exists in a large number of species of a genus, a family, etc., is described in one of them and not mentioned in all the others. In such cases it is possible to investigate quantitatively the property under consideration through a long series of species. By the application of this method unexpected analogies and differences are discovered and many interesting comparisons are rendered possible. ${ }^{1}$ This affords an unlimited field for investigation.

The principle of the primordia and the quantitative method

1 A renowned embryologist of the modern school told me one day that it was a waste of time to identify the animal species of which I was studying the development; he said also, expressing his contempt by a jest, that entomology is the art of counting hairs on the coccyx of beetles. By counting the joints of the tarsus of innumerable species of Coleoptera, however, LATREILLE found the base of classification of these insects. By counting the teeth and the vertebræ, through the whole series of mammalia, most important results have been attained (CUVIER, R. OWEN). Etc. 
throw new light upon the innumerable details recorded in descriptive literature.

FIRST EXAMPLE: In the description of Anagallis tenella we find, among other things: segments of the calyx pointed but short; corolla deeply 5-cleft. ${ }^{1}$ We recognize here four measurable primordia: (I) length of the calyx; (2) id. of its segments; (3) length of the corolla ; (4) id. of its segments. The curve of development of each of these properties may be established by the study of flower buds. ${ }^{2}$ The same primordia may be investigated in the same way through the whole family of the Primulaceæ.

SECOND EXAMPLE: British species of genus Genista ${ }^{3}$ :

Genista: seeds several.

G. tinctoria: leaves sessile, from narrow lanceolate to broadly elliptical or nearly ovate. Pod nearly an inch long.

G. pilosa: leaves shortly obovate or lanceolate, obtuse. Pod rather shorter and broader than in G. tinctoria.

$G$. anglica: leaves small, lanceolate or ovate. Pods about six lines long, broad.

The characters mentioned have been observed accurately, but the descriptions are rather vague. Seven measurable properties may be taken into account in each species: (I) length of the petiole ${ }^{4}$; (2) $i d$. of the blade ; (3) breadth of the blade; (4) distance between the greatest breadth of the blade and its summit; (5) length of the ripe pod; (6) breadth $i d$.; (7) number of seeds. ${ }^{5}$

As long as we confine ourselves to the British flora it seems to be superfluous to examine thoroughly the above-mentioned primordia, because the three British species are easily distinguished by their thorns and hairs. But the quantitative investigation of the leaves, the pods and the seeds would render good service for the description of the numerous species (about seventy) of Genista which are found in other countries and eventually of their subspecies. And, moreover, a description ought to be something more than a short diagnosis.

THIRD EXAMPLE : In certain genera of the family of the Carabida the labrum bears two hairs; in other genera the hairs are four in number. In the description of the species of the genus Carabus these hairs are not mentioned, probably because they are numerous and their number variable in each species of this genus. I have counted the hairs under consideration in numerous species of Carabus, taking at least six $\hat{\delta}$ and six $q$ of

1 HOO KER, British Flora, I866, p. 306.

${ }^{2}$ The turgor being suppressed in one or another way.

3 HOOKER, British Flora, 1866, pp. 108-109.

- When the leaves are sessile, the length of the petiole $=0$.

${ }^{5} \mathrm{See}$, on the measurement of variable properties, Part VI. 
each species. This work has not been a waste of time. Although the figures of one species, taken separately, are of little importance, from the whole set of specific figures interesting conclusions may be drawn. At first is appears that the number of hairs is not very variable in certain species, whereas it is very variable in the majority of them. Secondly, all the species (ninety in number) being arranged in a series according to the value of the property under consideration, a gradual transition is observed from the lowest figure to the highest. In this series certain species which are (with regard to other properties) very different from each other are placed side by side, and certain species which are looked upon as being allied with one another are separated by a considerable distance. Thirdly, the species which are at both extremities of the series are distinctly different by their figures, in spite of variation. Therefore the extremes are easily distinguished by the primordium number of hairs of the labrum, without regard to any other property. ${ }^{1}$

FOURTH EXAMPLE (INTER-SPECIFIC CORRELATION) : We find in a classic book, which contains the description of about thirty-five species of the genus Carabus, that in one of these species the ultimate joint of the maxillary palp is shorter than the penultimate. For all the other species no information is given about the relative length of the joints mentioned. We are also told that the ultimate joint of the maxillary and labial palps is broad in certain species and narrow in others, ${ }^{2}$ but for the majority of the species this characteristic is passed over in silence. In order to replace this fragmentary information, which is rather irritating by its vagueness and incompleteness, by more usef $u l$ notions, I have measured in ninety species five properties - viz. (I) length of the ultimate joint of the maxillary palp; (2) breadth id.; (3) length of the penultimate joint id. ; (4) length of the ultimate joint of the labial palp; (5) breadth $i d$. All the figures being arranged in order in the same way as in the third example, the conclusions are similar with regard to each of the five properties. Such material is exceedingly interesting with reference to the correlation between several properties in a series of species. This form of correlation might be called inter-specific. It is something quite different from the correlation between properties of one species.

FIFTH EXAMPLE: In the classical descriptions of the leaves of the mosses, the length and the breadth of the leaves

1 I intend to give a complete account of these and many other similar facts in a work on Carabus and Calosoma which I hope to publish later on.

${ }^{2}$ The significance of the terms broad and narrow is, of course, an enigma which ought to be guessed by the unfortunate reader. 
are given for certain species but not for others. We are informed that the leaves are very narrow at their base in certain species and narrow or broad in others, but for many species the property breadth at the base is not mentioned. Here three properties may be measured: (I) length ; (2) greatest breadth; (3) breadth at the base. I have carried out this work for ten British species of the genus Mnium, ${ }^{1}$ replacing the terms long, short, large, small, broad, narrow, very narrow, etc., by three figures for each species. This subject is rather complicated because gradation comes into play here. (See Part VIII.)

§ 53.-CLASSIFICATION OF THE PRIMORDIA.-In the present work a number of primordia have already been mentioned-for instance, the length, the breadth and the number of cells of certain organs; the dimensions of the cells; the presence or absence of hairs; the number of hairs on the labrum of an insect; certain colours; the number of seeds in a pod, etc. Between those properties no relations exist; they have been taken at random, as examples. When we consult a flora or a fauna in order to find primordia $(\S 52)$ we are proceeding at a venture. We behave as if an indefinite number of properties (so-called characters) existed in each species; in each peculiar case we pick out and investigate some of them, but the choice we make is arbitrary. Similar remarks are applicable on the mass of different properties which have been investigated by the Mendelian School and by the biometricians.

We need a method enabling us to compile an inventory of the primordia of each species: such a method ought to be based upon a classification of the primordia. In $\S 46$ I have attempted to classify the simple properties (primordia) into nine groups according to their development. This classification may render service in embryology but is inadequate when we want to make up a list of the properties of a species.

W. BATESON ${ }^{2}$ has divided the phenomena of variation into two groups: variations in the processes of division and variations in the nature of the substances divided (loc cit. chapter ii., p. 3I). This classification of the variations is in reality equivalent to what I call a classification of the primordia. BATESON calls meristic variations the variations in the processes of division and substantive variations the changes in actual composition of material. $\mathrm{He}$ also uses the terms

${ }^{1}$ See my paper: "Quantitative Description of Ten British Species of the genus Mnium." Linncan Society's Journal-Botany, vol. xliv., November, I917. (Communicated by Prof. F. E. WEISS, D.Sc., F.L.S. Read ist June 1916.) 58 pages, 9 text-figures.

W. BATESON, Problems of Genetics (New Haven, Yale University Press. London, Humphrey Milford. Oxford, University Press). 1913. 
mechanical and chemical. ${ }^{1}$ With regard to cell-division (which is the simplest case of division), BATESON divides the mechanical variations in their turn into two groups: (I) the division properly so called and (2) the differentiation which brings about differences between the parts produced by a division.

It is possible to go further along the line indicated by BATESON. I want to expound this subject by means of examples. In the present work I limit myself almost entirely to the vegetable kingdom because at the time being the notes about the properties of animals, which I have collected for years, are not within my reach.

The researches the results of which are partly expounded in this book have occupied about thirty-five years. I began with measuring various objects taken at random among animals and plants, following the ordinary statistical method initiated by QUETELET. I submitted my first results (asymmetrical and multi-humped curves) to several biologists and mathematicians, who told me that QUETELET'S attempts were foolish and I was wasting my time.

Later I limited myself almost entirely to the measurement of various properties of numerous species of shells, and I spent several years before $I$ could find in a satisfactory way a sufficient number of primordia. I abandoned this exceedingly interesting work because of the difficulty of obtaining the material (numerous specimens of each species) I wanted for further methodical investigation. (See \& 89, third example.)

After that I began the study of insects, and after a preliminary work which lasted again several years I began in October, 1907 , the methodical investigation of the species of the genus Carabus (including Calosoma). This work was continued till July, I9I4, and interrupted by the war.

§ 54.-FIRST EXAMPLE: SPIROGYRA.-I take as example a specimen of Spirogyra (or Zygnema, or any other alga consisting of a series of cells without branches) the structure of which is very simple. This plant consists at the beginning of one cell (zygospore, egg). By its form this young individual resembles more or less an ellipsoid. Since we have no exact information about its form, we call it oblong or use another rather vague term. Two simple visible properties may be discerned here: length and breadth. ${ }^{2}$ Both ought to be measured according to two rectangular axes: longitudinal and transverse.

At a certain moment the egg is divided into two cells: the (imaginary) straight line which joins the centres of both new cells is the line or axis of division (segmentation); this axis coincides with the longitudinal axis of the egg.

The two cells (unicellular individuals) remain connected to

1 BATESON, using the terms actual composition of material (chemical variations), does not make any distinction between two notions which I look upon as being different: (I) the composition of the living mixture; (2) the chemical properties properly so called (abiotic chemical properties). (See \$ 8.)

2 These properties are variable, just as almost all the further mentioned properties. See, on the measurement of variable properties, Part VI. 
each other and are divided in their turn into $2,4 \ldots 2^{n}$ cells. ${ }^{1}$ All the successive divisions take place according to the already mentioned axis of segmentation and all the cells remain adherent. In this way an adult specimen of Spirogyra is produced. This is a uniaxial system of segments (Fig. 2).

I call this object a specimen. It may be called an individual. Unfortunately the latter term is used in different senses; it may be applied to the egg, to the adult pluricellular specimen and to each of its cells. ${ }^{2}$ The pluricellular specimen may be looked upon as being an individual of a certain order $x$. Taking this individual as starting-point, I call each of its unicellular segments (which are all equivalent) an individual of the order $x+\mathrm{I}$. In the present example we may put down $x=\mathrm{I}$; according to this, the pluricellular specimen is an individual of the first order and each cell an individual of the second order. ${ }^{3}$ I don't go further, looking (in the present work) upon each cell as being an individual (unit) of the last (simplest) order.

Generally speaking, I call individual of the order $x$ or individual $x$ any specimen, individual, segment, organ or part whatsoever 4 of which I want to investigate or to describe the constitution. An individual $x$ may be divided by segmentation into individuals $x+I$; these may consist in their turn of individuals $x+2$, etc.

REMARK: The above definitions are based upon the principle that the notion of individual is a relative one. The definition of the term individual involves a convention. In biology we use this term in the sense of unit; the definition of any unit is a matter of convention. Examples: the metre is the unit of length in the metric system. Since we know that an error has been committed in the original measurement of the metre, this unit is conventional. Moreover, we have been compelled to adopt a series of other units of length; for instance, the micron, the millimetre, the centimetre (C.G.S. system), the kilometre, etc., the standard being the metre. If the founders of the metric system had been pure logicians they might have taken the metric ton (Iooo kilogrammes) as the

${ }^{1}$ Certain particularities, which are of no importance for our subject, are passed over in silence in this description. See about the first cell-divisions in Zygnema: N. WILLE, in ENGLER and PRANTL, Natüvl. Pflanzenfam., Theil I, Abt. 2, Fig. II. See about Spirogyra: G. S. WEST, British Fresh. water Alge (Cambridge, 1904), Fig. 49.

${ }^{2}$ It happens under certain conditions that the cells separate from each other and become really independent individuals.

${ }^{3}$ It might be more logical to call each cell an individual of the first order, and the pluricellular specimen an individual of the second order, but in complicated cases it is very difficult or even impossible to adopt this notation. See note 1, p. 72 .

- A tree, a moss, a leaf, a hair, a Spirogyra, an insect, an antenna, etc., and by further extension a shell of a mollusc, the shell of an egg of a bird, etc. 
fundamental unit of weight, but they have wisely adapted the new system to the needs of practical application and therefore they have chosen the gramme. Nowadays we use the series milligramme, centigramme, gramme (C.G.S. system), kilogramme, metric ton, the gramme being the standard.

In physics and chemistry the molecules and atoms are in a certain sense individuals or units of a certain order. For many years the atom has been the ultimate term, in fact the standard. In the new chemistry the atom is divided in its turn into smaller units; the classic system of units has been completed, but neither altered nor disturbed by this innovation.

In a similar way we may express in biology the notion of unit or individual by means of one (or several) series of terms, the cell being the standard and (provisionally) the simplest term. The first series of units (see a second series in $\$ 70$ ) is based upon the principle of segmentation and includes the terms $x, x+\mathrm{I}$, $x+2 \ldots x+n$. If necessary we may ascribe to $x$ a definite value according to the case under consideration. If we want, for one reason or another, to proceed from the unicellular units to the more complex individuals, we may call the cell an individual $(x+n)$, the next (pluricellular) term being $(x+n)-\mathrm{I}$, etc. ${ }^{1}$

I do not attach much importance to the adopted notation of the successive units. More important is the principle of the adaptation of a series of biological units of successive order, a unit of a given order being a component of a unit of the preceding order and including several units of the next order.

I hope that the proposed system is elastic enough to render possible various applications. If we were compelled to divide the cell itself into smaller units, the system would be completed but not altered, $x+n$ remaining $x+n$.

§ 55.-FIRST EXAMPLE: SPIROGYRA (continued).An individual $x$ (adult specimen) of Spirogyra consists of a number of individuals $x+I$ (cells). This number is a primordium of the individual $x$. We may look upon all the cells as being cylindric, except both terminal cells, which are cylindric and rounded at their distal (external) extremity. ${ }^{2}$ We find here a very simple example of differentiation: the individuals $x+I$ (cells) are indeed of two kinds, terminal and intermediate.

1 In Spirogyra $n=1$. In a leaf of an elm, in the salivary gland of a horse, the value of $n$ is practically unknown. In these and similar complicated cases a given cell is called $(x+n)$. This means that it is the last term of a series, the number of terms $n+I$ and the value of the most complicated term $x$ being unknown. The value $(x+n)$ is therefore undetermined, but the value of $(x+n)-I$ is determined with regard to the cell.

${ }^{2}$ We must content ourselves with the term rounded because of our ignorance of the exact form of the extremity. 
In this example it is useless to complicate the question by numbering the cells; this becomes necessary in certain more complicated cases.

Since the two kinds of cells (units $x+\mathrm{I}$ ) have the same origin (the egg), they are identical with regard to their hereditary possibilities (\$29). The observed differences ought therefore to be ascribed to plasticitythat is to say, to causes external with regard to each cell. We may look upon the individual $x$ as being a society of individuals $x+\mathrm{I}$ (cells). Each member of the society undergoes the influence of two sorts of external causes: (I) EXTERNAL causes properly so called, such as temperature, light, etc. ; (2) SOCIAL causes which emanate from other members of the society or from the society taken as a whole. In other words, each member (cell) lives in a social environment: the differences brought about by the influence of this environment are SOCIAL differences (see below, Remark).

According to this, it is obvious that the difference between the intermediate and the terminal cells of Spirogyra is a social difference. It may be remarked that the longitudinal line (axis) of segmentation is also a line of differentiation. Indeed, following this line from one end to another, we observe the variation produced by differentiation. The line of segmentation and differentiation is already found in the egg: it is the longitudinal axis.

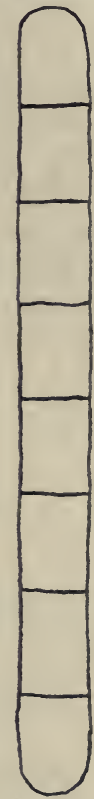

The principles, the application of which one finds in Spirogyra in a very simple form, govern the distribution of the properties in all organisms, from the simplest to the most complicated.

REMARK : The terms social cause, social environment and social difference may render good service in biology.

A very simple example of social differentiation is found in the pseudo-bulb of Phajus grandiflorus. The members (cells) of this society (individual $x$ ) which are near the surface are green because their so-called amyloplasts are impregnated with chlorophyll. At a certain distance from the surface the amyloplasts are colourless and the cells are white, because they are deprived of the influence of light by the presence of the external cells. Here the combined (simultaneous) action of an external cause (light) and a social cause is obvious : the observed difference is a social difference. 


\section{4}

THE QUANTITATIVE METHOD IN BIOLOGY

In the body of a vertebrate animal we find cells of various kinds ; for instance, nervous, glandular, epidermal, muscular, cartilaginous, ciliate cells, etc. The differences between these cells are strongly marked : if they were Protozoa, they would be classified into different genera, families, etc. Between them there are, however, no hereditary differences (the possibilities are the same in each and all), since they all belong to the offspring of one egg; in each of them certain peculiar reactions have resulted in peculiar properties according to the social influences. This example illustrates, perhaps better than any other, the fundamental distinction between hereditary possibilities and observable properties. Every biologist knows these facts, but only few realise the importance of the consequences which may be drawn from them.

§56.-FIRST EXAMPLE: SPIROGYRA (continued).--In each cell of a Spirogyra two primordia may be recognized: length and breadth. They are easily measurable, the measurements being carried out in the direction of two axes (longitudinal and transverse). ${ }^{1}$

§5\%.-FIRST EXAMPLE: SPIROGYRA (contimued).The primordia which we have already discerned in a Spirogyra (or a similar plant) may be brought into five groups :

(I) Number of axes (of segmentation and differentiation): one.

(2) Number of segments (cells = individuals $x+\mathrm{I}$ ).

(3) Number of sorts of segments: two (terminal and intermediate).

(4) Form of the two sorts of segments (cylindrical and cylindrical with one rounded extremity).

(5) Dimensions of the segments (length and breadth).

All these primordia are measurable (the term cylindrical represents a strictly geometrical notion) except the rounded extremity. (This is not a difficulty from a theoretical standpoint; it merely depends on our ignorance.)

We may add to the above list the length and the breadth of the egg (fifth group : dimensions).

It is possible to go further and to distinguish a number of primordia within the cells ; for instance, the number of chromophores, the dimensions of the nucleus, the number of chromosomes, the physical properties (optical axes, etc. STEINBRINK) of the cell-walls, certain chemical properties (presence of tanin in the vacuoles), etc. From a theoretical point of view

1 It would be interesting to ascertain whether any difference exists between the terminal and the intermediate cells with regard to their length and eventually whether the difference is the same in all the species. 
all these properties may be expressed by measurement. In the present work the internal properties of the cells are passed over in silence; therefore I content myself with a simple mention. (See $\$ \S 60,72,73$.

§58.-FIRST EXAMPLE: SPIROGYRA (continued).The mentioned primordia of an adult Spirogyra (or a similar plant) may be classified with reference to their development in the following way (see §46):-

(I) The properties (I), (2) and (5) are original, arrested and persistent.

(2) The property (3) (differentiation) is arrested and persistent. It may be looked upon as being an awakening property; it does not exist as long as the cells are only two in number (both being terminal) and it is not produced by a transformation of a previously existing property.

(3) The property (4) (form) is arrested and persistent for all the cells. It may be looked upon as being awakening. (I don't take into account certain peculiarities of Spirogyra.)

§ 59.-FIRST EXAMPLE: SPIROGYRA (continued). SENSITIVE PERIOD.-With regard to their sensitive period (see $\S 47$, second example), the mentioned properties of a Spirogyra (including the egg) may be classified in the following way:-

(I) The properties length and breadth of the egg (first state of each specimen) reach their final equilibrium (see $\S 45$ ) within a cell of the mother plant. Their development and, of course, their sensitive period, are arrested when the egg is ripe. Later on they are independent from any external cause (temperature, light, etc.) whatsoever.

(2) A certain time (period of rest) after the sensitive period of the above properties the sensitive period of the property number of cells is initiated by the first cell-division. The value of this property depends on the number of cell-divisions. If we suppose that the divisions follow each other regularly, taking place simultaneously in all the cells of a specimen, the property number would pass through the series of values $I, 2,4,8$, I6, $32 \ldots 2^{n}$. The state of equilibrium (definitive number) may be reached sooner or later (in a given species) according to the external agencies which may augment or diminish the number of divisions. Although we have little information about this subject, it may be considered certain that temperature, food and light have an influence. If the cell-divisions are arrested (for instance, by falling off of temperature) in a given specimen when the number $2^{4}=16$ is reached and in a second specimen of the same species when the cells are $2^{5}=32$ in number, a 
difference $I: 2$ will exist between both; but if we take the number of divisions into account, the difference is only $4: 5$ or I: I.25. There seems, at first sight, to exist a complete disproportion between cause and effect. ${ }^{1}$ When the last celldivision has taken place the sensitive period of the property number of cells is over. (Compare $\S 66$.

(3) When the specimen has reached its equilibrium in respect of the number of cells, the latter have not yet attained their full size. This is certainly the case with their length, the further increase of which may be considerable ${ }^{2}$ and is certainly influenced by external causes. The sensitive period of the property length of the cells begins really after the last celldivision and is therefore limited to the last part of the period of development (growth) of the specimen.

(4) The property number of axes is (as far as we know) independent from the conditions of existence.

(5) The properties number of sorts and form of the cells seem to be also independent from external influences, except if the number of cells did not exceed two, which is thinkable (if so, cylindric intermediate cells would not exist).

We see from the above that the sensitive periods of three groups of properties of Spirogyra (length and breadth of the egg, number of cells, length of the cells) do not coincide. Therefore the three groups are independent from each other with regard to plasticity. It is, for instance, a priori, possible that a small egg produces a specimen with numerous short cells, that a big egg produces a specimen with few long cells, etc., etc. This must be taken into account whenever we wish to investigate any form of correlation between the mentioned properties.

These principles are, of course, applicable on any animal or vegetable species. (See $\$ 47$, p. 56.)

§ 60.-FIRST EXAMPLE: SPIROGYRA (continued).-In Spirogyra a longitudinal axis really exists. I have also supposed the existence of a transverse axis in the egg and in each cell, but this axis remains in reality latent till sexual reproduction takes place. When the moment of reproduction approaches, two specimens of Spirogyra place themselves side by side, the cells facing each other by pairs. Each cell produces a tubular outgrowth which meets the corresponding outgrowth of the opposite cell. The axis of each outgrowth clearly indicates the position of the transverse axis of the cell. Since all the outgrowths of each specimen seem to be in the same plane, we may

1 Compare the law of Weber.

2 I have no information about the further increasu of the breadth. 
conclude that the transverse axes of all the cells are probably in one plane. ${ }^{1}$

The conjugating processes have (apart from their position) certain simple measurable properties (length, diameter) which belong to the fifth group (dimensions) in $\S 57$. The existence of the sexual outgrowths is a result of a differentiation within the limits of one cell and ought therefore to be brought into a sixth group of properties. (Compare the five groups in $\$ 57$. The properties of the outgrowths are awakening, arrested and rather caducous or deciduous. Their sensitive period very probably begins after that of all the other properties.

§ 61.-THE UNIAXIAL SYSTEM IS A PRIMARY SYSTEM. - Since the segments (cells) of a Spirogyra follow each other according to one axis, I call an adult specimen of this plant a uniaxial system. This is the simplest system of segmentation; it is observed again and again in the animal and in the vegetable kingdom. ${ }^{2}$ It is a primary system from which several other systems are derived.

Since the properties of the living beings are ordered with reference to their axes, the determination of the axes is of high importance for the exact definition and the measurement of each property.

The study of the uniaxial system and its derivatives is continued in $\S 69$. In $\S \S 62-68$ I mention four special systems of segmentation which have merely indirect relations (if any relation at all) to the uniaxial system and about which I have incomplete information.

§ 62.-SPECIAL SYSTEMS OF SEGMENTATION. I. RADIAL SYSTEM.-Under this name several different systems are confounded. A radial system is observed in Polyps. The radial system of the Echinoderms has a different origin.

The radial system of the spiral and pseudo-cyclic flowers proceeds indirectly from the uniaxial system, and is, on the other hand, in relation with the sectorial symmetry which prevails in the true cyclic flowers.

See also Pediastrum tetras, $\S 64$, Fig. 3.

1 The egg $e$ has probably, within its mother-cell, a definite position with regard to the transverse axis $b$ of the latter. On the other hand, the position of the transverse axes $b^{1}$ of the cells of the specimen produced by $\theta$ is probably already determined in the $\operatorname{egg} e$. It would be interesting to know the relative position of $b$ and $b^{1}$.

2 Examples: The hairs of innumerable plants (here the segments are unicellular), the antenna of an insect (here the segments are so-called joints), etc. In the simplest case a uniaxial system includes only two segments ; for instance, the teleutospores of Puccinia, the first pair of cells produced by the segmentation of the egg in animals and plants, etc. 


\section{8}

\section{THE QUANTITATIVE METHOD IN BIOLOGY}

§ 63.-SPECIAL SYSTEMS OF SEGMENTATION (continued). II. THE TETRAHEDRAL SYSTEM.-This wellknown system of segmentation is observed in the pollen of a number of Phanerogams (Erica, Rhododendron, etc.), in the spores of many Cryptogams (Selaginella, Saccharomyces, etc.), etc. This system is a primary system from which more complicated systems are derived. Interesting examples of such complications are observed in the pollen of Mimosa and certain Orchids.

§ 64.-SPECIAL SYSTEMS OF SEGMENTATION (continued). III. PEDIASTRUM, EUASTROPSIS.-Among the algæ we find several peculiar dispositions of the segments, some of which are remarkable by their singularity and elegance. ${ }^{1}$

A specimen (conobium, individual $x$ ) of Pediastrum ${ }^{2}$ consists of a certain number of cells (individuals $x+I$ ) which are united into a regular discus. The constituent cells of a given discus are produced by successive divisions of one cell, just as the cells of a Spirogyra; but in Pediastrum the cells do not remain attached to each other after each division; they separate and become for a certain time independent, swimming within a vesicle which proceeds from the mother-cell. At a given moment the hitherto isolated cells are united by juxtaposition; they become adherent and constitute a disciform society called conobium (specimen, individual $x$ ).

This discus is, in the full sense of the word, a society of cells which find themselves in a state of equilibrium. We discern here (as in Spirogyra) a differentiation into two sorts of cells ; the marginal cells are of different form from those in the centre and they are furnished with a pair of diverging processes. ${ }^{3}$ This differentiation is brought about by social causes ( $\$ 55)$, for all the cells are alike (without processes) as long as they are independent. The number of cells is $4,8,16,32 \ldots$ as in a typical Spirogyra.

In the genus Euastropsis (allied to Pediastrum) the development proceeds on the whole as in Pediastrum, but the individual $x$ (canobium) consists of two cells.

Our information about the relative disposition of the cells in Pediastrum and Euastropsis is somewhat incomplete. A

1 See the classic illustrated works on fresh-water algæ; for instance, G. S. WEST, $A$ Treatise on the British Fresh-water Alga (Cambridge University Press, 1904).

2 Ibid., p. 209.

3 These processes are an example of differentiation within the limits of one cell. (Compare the sexual outgrowths in Spirogyra, § 6o.) Certain cells in certain mosses (marginal cells of the leaves of Tortula ruralis) are furnished with processes which recall those of the marginal cells of Pediastrum. Compare also several Desmids. 
bicellular specimen of Euastropsis is more or less comparable with a uniaxial system with two segments. In Pediastrum tetras the cells are ordinarily four in number, united into a rectangular cross (radial system? rectangular biaxial system?). In other species of Pediastrum certain specimens consist of eight cells, one of which is central and the seven others marginal. This disposition in (more or less distinct) concentric
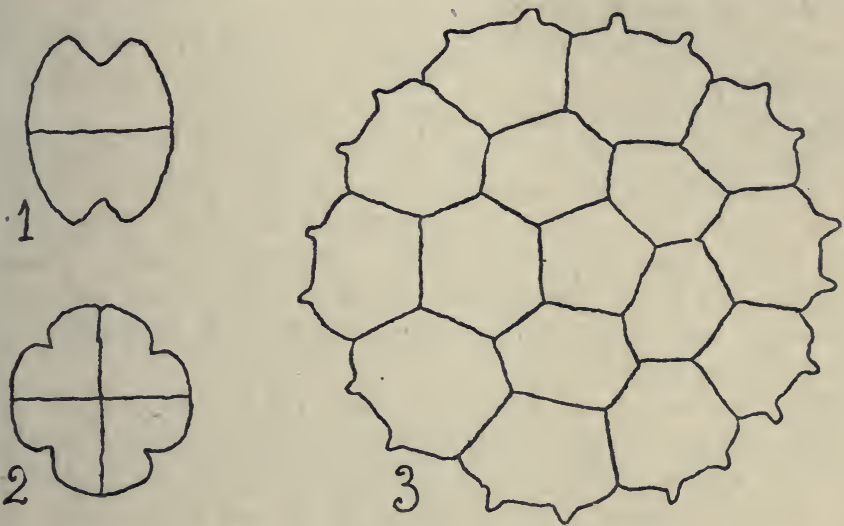

FIG. 3.-I. Euastropsis. 2. Pediastrum tetras. 3. Pediastrum consisting of sixteen cells. (Schematic, after WEST)

rings is also observed when the cells are more numerous. According to NAEGELI, ${ }^{1}$ the following dispositions are the commonest :-

Specimen of 8 cells $\mathrm{I}+7$

$$
\begin{array}{llll}
\text { " } \quad \text {, I6 } & \text {, } & \text { I }+5+\text { IO (Fig. } 3,3) \\
\text {, } & \text {, } 32 & \text {, } & \text { I }+5+\text { IO + I6 }
\end{array}
$$

Although these regular arrangements are not always observed, it is incontestable that a remarkable plan of structure exists in these algæ. This calls for reflection.

§ 65.-SPECIAL SYSTEMS OF SEGMENTATION. III. PEDIASTRUM AND EUASTROPSIS (continued). FRUIT OF MYXOMYCETES AND GASTEROMYCETES. POLYPIFORM ANIMALS AND OTHER EXAMPLES. MORPHOLOGICAL HOMOLOGY AND MECHANICAL CONCORDANCE.-The classical morphology is based upon embryological investigation. We try to explain the structure of a given adult organism by the knowledge of its development. Starting from the initial cell and proceeding step by step, we look upon each state of development as being produced by a transformation of

${ }^{1}$ Quoted after G. S. WEST, loc. cit., p. 209. 
a previous state. This ontogenetic method had an enormous influence upon the progress of morphological science, apart from any theory about the origin and phylogenetic relations of species. ${ }^{1}$ The results obtained by the comparative method which was formerly used alone (Comparative Anatomy of CUVIER), and which is based upon the comparison of adult specimens, have been explained, verified and often corrected by embryological investigation.

It may be asked, however, whether the universal use of the embryological method does not divert our attention from certain aspects of the morphological problems.

In the example of Pediastrum the curious structure of the adult specimen is quite independent of any previous state. It appears suddenly, by the juxtaposition of parts (cells) between which there was previously no relation at all. Since our morphological (embryological) method does not afford any explanation of the structure produced in this way, Pediastrum is put apart as a curiosity.

Pediastrum is not an isolated case. It is impossible to find any embryological explanation of the regular disposition of the cells in an adult specimen of Volvox, Hydrodictyon, etc. (See $\S 68$.) Other interesting examples are found among the Myxomycetes. In the numerous species of this group a certain number of isolated cells (amæbo-spores, etc.) are produced by successive divisions of one initial cell (spore). These cells wander about within the substratum; after a certain time two cells meet each other and are united into a plasmodium, which becomes a centre of attraction: more cells join this centre. In the plasmodium no definite morphological structure exists because the relative position of the cells (represented by their nuclei) is continually modified by amæboid movements. At a certain moment the movements are stopped and the society of cells is brought into a state of stable equilibrium; it becomes transformed into a so-called fruit.

In numerous Myxomycetes the fruit has a regular form which is characteristic of each species. Since it is impossible to find any relation between this form and the preceding state, morphology based on embryology gives us little help when we want to investigate the structure of the fruits of the Myxomycetes. Here a morphology of a peculiar kind ought to be created. The primordia of the objects under consideration ought to be determined and measured in order to find a base for comparison. Each primordium represents a state of equilibrium or, in other words, a part of a system which is in equilibrium. An exact

1 A similar method is applied in historical science; for instance, in palæography, philology, numismatics (see the works of LELEWELL, SERRURE and others), economic history, etc. 
quantitative knowledge of the parts may enable us to analyse the whole system. In this way a Morphology of the states of equilibrium may be built up: this is, of course, only possible by comparing numerous species.

The resemblances which exist between the fruits of several Myxomycetes may be brought under the principle of mechanical concordance, in order to distinguish them from the morphological homologies.

It may be expected that a morphology of the states of equilibrium, based upon the quantitative investigation of the primordia, may throw new light not only upon the structure of the above-mentioned plants, but also upon numerous resemblances to which the morphologists have hitherto paid little attention.

EXAMPLES : A remarkable resemblance exists between the fruits of certain Myxomycetes and that of certain Gasteromycetes (Lycoperdon, Tulostoma, etc.). Both groups of objects are widely different in their phylogenetic origin, their individual development and their morphological significance. For the Gasteromycetes we may follow the embryological method, starting from an initial cell and proceeding step by step till the adult state is reached. This method, however, does not afford a complete elucidation of the final state of equilibrium. The resemblance with the Myxomycetes remains unexplained, because the embryological method is not applicable on the latter plants. As long as we are influenced by the idea that morphological facts are merely an expression of genealogical relations and may be completely elucidated by embryology, the resemblances alluded to are a remarkable something, without further significance. But when we look upon the objects mentioned as being states of equilibrium, a new basis of comparison may possibly be obtained.

Let us recall the striking similarity between certain Polyps (Campanularia, Sertularia, etc.) and certain plants with regard to the relative position of the branches; the resemblance between the epidermic scales of many reptiles, the dermic scales of many fishes and even the cuticular scales of butterflies with regard to their relative position; the astonishing resemblance between the seeds of Drosera and those of many orchids; the well-known so-called analogy between the fore-legs of Gryllotalpa and Talpa, between the eye-shaped spots which adorn the feathers of certain birds, the wings of certain butterflies and the skin of certain fishes, etc., etc.

In all similar cases, we try to explain the observed facts by means of the principle of converging adaptation (which is based, at least in part, upon physiological analogy). This principle involves a number of hypotheses. Adopting the theory of natural selection, we are compelled to accept that:

(I) The observed similarities have been brought about gradually, by the accumulation of a long series of impalpable variations in each of the compared species.

(2) These variations have been hereditary.

(3) Each successive step has been the cause of certain advantages in the struggle for existence, important enough to bring about the selection (survival) of the varying specimens.

(4) The successive changes have been accumulated along the same line in forms of life which differ from each other as decply as a Myxomycet from a Gasteromycet, a butterfly from a fish, etc.

If we adopt the neo-Lamarckian theory, we must suppose that :

(I) Each of the observed resemblances is the result of individual adaptations (accommodations) to similar physiological functions or conditions of existence.

(2) The variations produced by accommodation (in widely different species) have been fixed by heredity.

All the above hypotheses require verification. As long as this has not been 
carried out in a satisfactory way, the term convergent adaptation is a delusive screen behind which we conceal the problems which ought to be solved. And moreover, even if convergent adaptation were proved to be a reality, it would give us merely a physiological explanation, the morphological aspect of each example being simply overlooked.

I think it is preferable to adopt the method of the mineralogists. We know many examples of substances, completely different by their chemical constitution, which occu in the same crystalline form. The mineralogists, looking upon each crys $\lambda$ as being a system of molecules which are in equilibrium, have built up a morphology of the crystals which is an exact science quite independent of any theory about the origin and the transformations of the crystallized substances. This has been rendered possible by discerning and measuring the simple properties of the crystals.

Two different substances, both of which crystallize in the form of a regular octahedral or a pentagonal dodecahedral are in the same state of equilibrium. In a similar way, a ripe fruit of a given Myoxmycet and a ripe fruit of a $L y c o$ perdon are in a comparable state of equilibrium: they are, as it were, crystallized in the same system. ${ }^{1}$ I express this by saying that mechanical concordance exists between them. Similarly, an adult Pediastrum, an adult Spirogyra, the fore-legs of Gryllotalpa and Talpa, etc., are systems of material parts which are in equilibrium, for a very simple reason; if they were not in equilibrium they would be modified (further developed) till a state of equilibrium is reached. (See $\S 45$.

We are tempted to consider that the above-mentioned objects are known when they have been described in a few lines by means of vague terms (long, short, broad, narrow, convex, oboval, etc.). In reality, such descriptions, piled up in thousands of volumes, are incomplete. In a similar way, the term octahedral gives incomplete information about a crystal, because a number of different octahedrals exist which can only be distinguished by the measurement of their angles and internal properties. The quantitative investigation of the primordia of animals and plants would not only enable us to describe and to identify them more exactly than by the ordinary method: we may expect to find in the collected data (figures!) material for a morphology of the states of equilibrium - which might be, in a certain sense, a crystallography of the organisms, quite independent of any theory about their origin and genealogy.

Between the suggested line of investigation and classic morphology there is neither discordance nor contradiction. Following the method based upon the measurement of the primordia, we want to avail ourselves of the information alveady collected by systematic natural history, embryology, classic morphology and also physiology 2 -trying to complete and to perfect this information by investigating the facts from a different standpoint.

See on PARALLEL VARIATION, § I35.

§ 66.-SPECIAL SYSTEMS OF SEGMENTATION. III. PEDIASTRUM AND EUASTROPSIS (continued). SENSITIVE PERIOD.-Two specimens of Pediastrum which differ by the number of cells may be looked upon as being of different age with reference to the primordium number. In the course of the development of each specimen this number passes through the values (compare $\S 59$ ) : I, $2,4,8 \ldots 2^{n}$, which coincide with $0, I, 2,3 \ldots n$ cell-divisions.

In a specimen $b$ consisting, for instance, of $2^{5}=32$ cells, each cell considered separately has been after the fifth division in a

1 At least with reference to a part of their properties.

2 I am using here the term physiology in its broadest sense, including biology properly so-called (pollination of flowers, dissemination of seeds, symbiosis, etc.), heredity (Mendelism, etc.), etc. 
state of equilibrium of such a kind as to suppress any cause which might bring about a new division. ${ }^{1}$ In a specimen $a$ consisting of $2^{4}=16$ cells, the same state has been reached after the fourth division. Therefore it may be said that $a$ is younger than $b$ in respect of the property under consideration. (This remark is also applicable on Spirogyra, § 59.)

As soon as the cells are connected with one another the sensitive period of the property number is over. Since the cells have not yet reached their definitive dimensions, the sensitive period of the primordium dimensions (size) begins about that moment. The sensitive periods of number and size being independent, both properties are also independent with regard to their plasticity. (Compare Spirogyra, § 59.) An adult specimen with small cells is younger than a specimen with large cells in respect of the property size, whatever may be the number of cells. A given difference between two adult specimens which belong to the same species depends on plasticity; the same difference between two specimens which belong to distinct species depends on a difference in their living mixture if the conditions of existence have been the same through the whole duration of their development.

§ 67--VARIATION STEPS IN PEDIASTRUM.--See on VARIATION STEPS, Part VII.

§ 68.-SPECIAL SYSTEMS OF SEGMENTATION (continued). IV. VOLVOX, HYDRODICTYON.-In these Alge the cells are united into a very characteristic system of equilibrium (society), ${ }^{2}$ which is, as far as I know, distinctly different from any other system in the animal and vegetable kingdoms.

As in Pediastrum, the initial cell undergoes a certain number of successive divisions, the produced cells separating after each division. When the definitive number is reached, all the hitherto independent cells unite at once into a cœnobium, which is an elegant hollow sphere or utricle. There is thus no morphological relation between the relative position of the segments (cells) in an adult specimen and the preceding states of development. (Compare Pediastrum, §64, and the Myxomycetes, § 65.)

$\S 69$ (continued from $\S 6 \mathrm{r}$, p. 77).-SYSTEMS OF SEGMENTATION DERIVED FROM THE UNIAXIAL SYSTEM. RAMIFICATION AND CLEAVAGE.-We have seen, in § 6r, that the uniaxial system is a primary system, from which several other systems are derired.

1 The equilibrium alluded to is, of course, distinct from the equilibrium which exists between the cells when they have met one another.

${ }^{2}$ See G. S. WEST, loc. cit., pp. 195, 207. 
The uniaxial system may produce more complicated systems along two different lines: (I) by ramification; (2) by cleavage -i.e. a secondary segmentation in the direction of a new axis. (See $\$ 77$. )

§ \%0.-RAMIFICATION OF THE UNIAXIAL SYSTEM. FIRST EXAMPLE: PSEUDOCHÆTE.-Among the Alga we find a number of simple examples of ramification of the

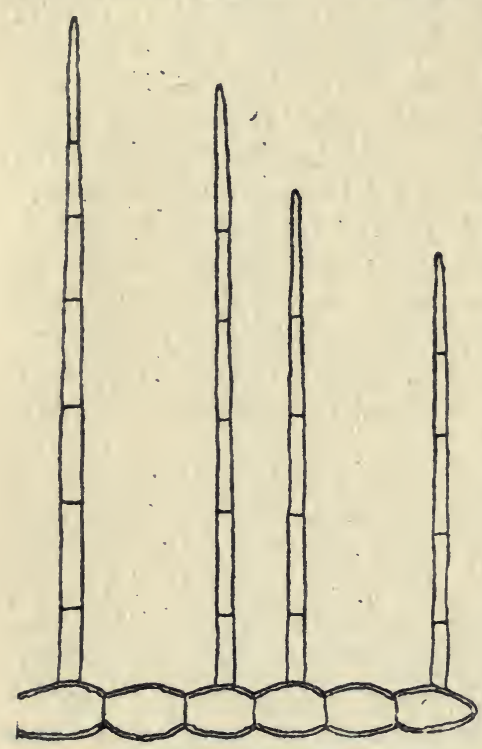

FIG. 4.-Pseudochate gracilis. (Schematic, after WEST, loc. cit., Fig. 30) uniaxial system. I take as example Pseudochate gracilis (allied to Herposteiron), which occurs as an epiphyte on aquatic plants. ${ }^{1}$ A specimen $x$ consists, at first, of one row of cells united into a uniaxial system similar to Spirogyra. I represent this primary filament (pluricellular individual) and its axis by $x A$ or $A$. The individual (stem) $A$ creeping on the surface of an aquatic plant, its axis may be called horizontal.

Certain cells of $A$ produce a lateral erect branch $B$ (or $x B$ ), the axis of which is vertical. ${ }^{2}$ In each branch $B$ a certain number of segments (cells) are produced by segmentation (celldivision): $B$ becomes in this way in its turn a uniaxial system.

According to the notation adopted in $\S 54$, each constituent segment (cell) of an individual (stem) $A$ is called $A+\mathrm{I}$ (or $x A+\mathrm{I}$ ) ; each cell of an individual $B$ is called $B+\mathrm{I}$ (or $x B+\mathrm{I}$ ).

One might be tempted to believe that I am bringing useless complications into the subject. I am, in fact, facing complications which really exist, and which must not be overlooked if we want to apply the quantitative method.

In Pseudochate gracilis a fully developed specimen or individual $x$ is, indeed, a society constituted by one individual $x A$ (or $A$ ), and several individuals $x B$ (or $B$ ), which consist themselves of simple individuals (cells) $A+\mathrm{I}$ and $B+\mathrm{I}$. All the cells have been produced by successive divisions of one initial

${ }^{1}$ G. S. WEST, loc. cit., p. 88.

2 Between a branch $B$ and one of the reproductive branches (outgrowths) of Spirogyra ( $\$ 60)$ mechanical concordance very probably exists. It may be recalled that mechanical concordance may be independent of any physiological analogy and of any morphological homology. 
cell: therefore the possible reactions (hereditary possibilities, latent properties) are the same in each and all. The observable properties of a specimen $x$ (mentioned in our books) depend on the possibilities of its cells, but all these properties are not observable in each cell: they are distributed among the cells according to certain laws. In a given cell, certain reactions have produced certain primordia (or a certain value of a given primordium); in another cell other primordia (or another value) have become observable because different reactions have taken place. (Compare §55. Remark, p. 74.)

The differences between the unicellular individuals (cells) and between the pluricellular individuals $A$ and $B$ depend on social causes ( $\$ 55$. Remark, p. 73 ) and are governed by social laws. Therefore, when we want to compare several specimens $x$ (societies of individuals, Fig. 4) by measuring a primordium $p$ in each and all, we must give an exact definition of the segments (branches, cells and, in general, individuals) in which $p$ is measured.

In $\S 54$ (Remark, p. 7I) I have adopted a series of biological units (individuals) $x, x+\mathrm{I}, x+2 \ldots$ subordinated to each other according to the principle of segmentation, $x+2$ being produced by segmentation of $x+\mathrm{I}$, and $x+\mathrm{I}$ by segmentation of $x$. Here I adopt a second series of units, $A, B, C$, . . based upon the principle of ramification, $C$ being produced by ramification of $B$, and $B$ by ramification of $A$, etc. (In Pseudocheete $A$ and $B$ exist.)

In Pseudochate gracilis both series of units ought to be distinguished: $B$ (or $x B$ ) is any individual (branch) produced by a ramification of an individual $A$ (or $x A$ ). Any primordium of an $x B$ (for instance, its length, measured along its axis) is comparable with the same primordium in any other $x B$ whatever. $B+\mathrm{I}$ (or $x B+\mathrm{I}$ ) is a unit (in our example a cell of an erect branch) produced by segmentation of a unit $B$, which is itself a branch of a unit $A$. A primordium of a unit $B+I$ is comparable with the same property in any other unit $B+\mathrm{I}$. (See $\$ 72$, p. 87.)

It may be expected that a further development of the quantitative method will render the adoption of a notation indispensable. I have used, in $\S 54$ and in this paragraph, a notation in order to express the notion of series of subordinated units in a GENERAL FORM, which renders application possible in any case whatever. In the present state of things, however, it is possible to use terms. Example: I call a certain individual the first $B+\mathrm{I}$ (numbering the cells or individuals $B+\mathrm{I}$ along the axis $B$ from its proximal to its distal extremity). The same individual may be called the basal cell of an erect branch. 


\section{§ 71.-RAMIFICATION OF THE UNIAXIAL SYSTEM.} FIRST EXAMPLE: PSEUDOCHATE GRACILIS (continued). GRADATION. HAIRS. IMPORTANCE OF THE AXES.-The five groups of primordia which I have distinguished in an adult Spirogyra ( $\$ \S 57$ and 60) are found in Psendochate gracilis. Here they are, of course, to be measured separately in the creeping stems (units $A$ ) and in the erect branches $B$. In this way, it is possible to bring the description of a given specimen $x$ into the form of about a dozen of notions (primordia) expressed by measurement.

In the erect branches $B$ we observe a very simple example of gradation. Each of these branches has the form of a cone which is very narrow in proportion to its height (length). The constituent cells are (as in Spirogyra) of two sorts (differentiation) : the terminal cell is conical ; each of the other cells has the form of a truncated cone. The diameter of the cells (expressed, for instance, by the diameter $y$ of their proximal base $c$ ) decreases regularly from the base (proximal extremity) to the summit (distal extremity) of the conic branch.

I call GRADATION the variation of a given primordium along a given axis. (See $\$ 38$ and Part VIII.) Here the varying property is the diameter $y$. In a given cell, the value $y^{1}$ of the diameter measured at its base $c$ depends on the distance $x^{1}$ between $c$ and the origin (base) of the axis (branch). In other words, in general, $y$ is a function of $x$. In the given example the relation between $y$ and $x$ is very simple (the gradation curve being a straight line, oblique in respect of the axis).

The axis of an erect branch of Pseudochate gracilis is: (I) an axis of segmentation $(\S 54) ;(2)$ an axis of differentiation $(\S 55) ;(3)$ an axis of gradation. This is applicable in general on any axis whatever. ${ }^{1}$

The great importance of the axes is brought into prominence by the fact that an axis is always a line of segmentation, differentiation and gradation. All the segments (individuals, units) of a living being are arranged according to the direction of its axes and all its properties are arranged with reference to these axes. Each property ought to be measured in the direction of an axis, or in a direction which is definite with regard to an axis.

In an erect branch of Ps. gracilis we may measure the degree of gradation; this may be roughly expressed by the ratio between the diameter of the base of the basal cell and the length of the branch. This ratio, being a quotient obtained by dividing a primordium with a second one, is a compound property.

1 In an egg of Spirogyra, for instance ( $\$ 54)$, the longitudinal axis is the axis of segmentation and differentiation of the adult specimen. Since the transverse diameter of the egg is variable along the mentioned axis, the latter is also an axis of gradation. 
In many plants we find hairs consisting of one row of cells, which are similar to an erect branch of Ps. gracilis, the terminal cell being different from the others in one or another way. In such a hair the same primordia as in an individual $B$ of $P_{s}$. gracilis are found. The mechanical concordance between both objects is obvious. (Compare Fig. 5 with the erect branches in Fig. 4.)

§ 72.-RAMIFICATION OF THE UNIAXIAL SYSTEM. FIRST EXAMPLE: PSEUDOCHÆTE GRACILIS (continued). CLASSIFICATION OF THE PRIMORDIA.The primordia of Psendochate gracilis ${ }^{1}$ may be classified according to the following scheme (compare $\S \S 57,60$ ) :-

(I) Stem and branches (axes): two sorts ( $A$ and $B$ ).

(2) Number of each sort.

(3) Relative position of the axes $A$ and $B$. This is a phyllotaxic property.

(4) Number of axes of segmentation in stem and branches (one axis in $A$ and in $B$ ).

(5) Number of segments (cells) in $A$ and $B$.

(6) Form of the segments (cells) in $A$ and $B$ (cone, truncated cone, etc.).

(7) Dimensions of the segments (cells) in $A$ and $B$.

(8) Total length of the stem $A$ and the branches $B$.

(9) Gradation (branches $B$ ) : a, with reference to the breadth (conical form); $\beta$, with reference to the variation of the length of the successive cells. (In the creeping stems $A$ gradation is, I think, imperceptible.)

(I0) Degree of gradation in the branches $B$ (compound property).

Since several branches $B$ occur, we may content ourselves with measuring the properties $5,6,7,8,9$ and ro only in the longest branch. With regard to 7 (dimensions of the cells in the branches $B$ ) we may limit ourselves to the basal and the terminal cell of the longest erect branch.

The above scheme is applicable to any object

similar to Ps. gracilis in its structural plan. Most of the

1 The contents of the cells bcing excluded.

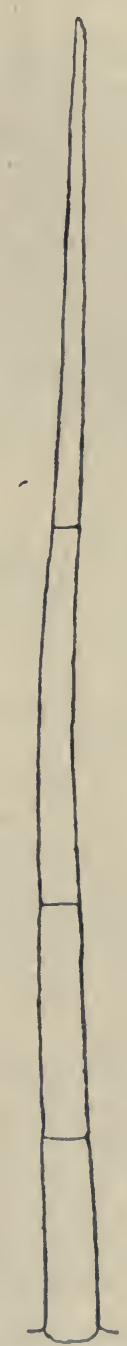

FIG. 5.-A hair consisting of four cells. (Petiole of Erodium moschatum) 
mentioned properties are variable within the limits of a given species: the method of measuring variable properties is expounded in Part VI.

§ 73.-RAMIFICATION OF THE UNIAXIAL SYSTEM. COMPLICATED CASES.-In Pseudochate gracilis the ramification of the uniaxial system is very simple: the whole plant $x$ consists of one uniaxial individual (creeping stem) $A$ of the first order or generation and several individuals (erect branches) $B$ of the second order or generation.

The system of ramification of innumerable plants, belonging to various systematic groups, is based upon the same principles as that of Ps. gracilis.

EXAMPLE: A young tree (for instance, Fagus or Quercus) $x$ consists the first year of a simple stem $A$ (uniaxial individual of the first order or generation) divided into several segments or internodes ${ }^{1}$ which are segments or individuals $A+\mathrm{I}$. The stem $A$ produces by ramification uniaxial individuals (branches) $B$ of the second generation, divided in their turn into internodes $B+I$. When this state is reached the young tree $x$ is comparable to a Ps. gracilis (each internode taken as a whole being comparable to a cell).

The branches $B$ may produce in their turn individuals (branches) $C$, and so on. Along each branch (axis) the branches of the next generation and the internodes may be numbered from the base to the summit. Whatever may be the number of generations, branches and internodes, each individual (stem, branch, internode) has a definite place in the society of subordinate individuals which is called a tree.

The differences between the individuals (stems, branches, internodes) which are associated in a given tree ${ }^{2}$ depend on their position - that is to say, on social causes. I leave out of account the differences brought about by external causes-for instance, temperature, rainfall, light, shade, etc., which influence the primordia of each segment during their sensitive period.

(See, on this subject, $\$ \$ 59$ and 66.)

In any ramified plant we find a large number of simple properties, which may be distinguished and classified according to the scheme in $\$ 72$.

The ramification of a uniaxial system does not only produce branches properly so called, but cauloms and phylloms of various kinds (leaves, phyllodes, cladodes, scales, glumes, sepals, petals,

1 An exact definition of the limit between two internodes is a rather subtle morphological question. With regard to the application of the quantitative method, the usual empiric and somewhat conventional definition of this limit may be adopted.

${ }^{2}$ In other words, the individual variation within the limits of one specimen 
etc.). All these individuals, ${ }^{1}$ whatever may be their nature, have a definite position. Each of them may be regarded as a uniaxial system in which several primordia may be discerned. Moreover, the leaves, petals, stamens, etc., may be ramified in their turn (leaves of Trifolium, petals of Reseda, stamens of Fumaria, etc.). In all the segments produced in this way primordia may be discerned according to the scheme in $\S 72$. Similar principles are applicable on the trichomes (hairs, glands, etc.). (See $\S \S 57,60$.)

Certain primordia are not mentioned in $\S 72$. Some of them are important, for instance:

(I) Certain segments (individuals) may be united. In a gamopetalous corolla (or gamosepalous calyx) the parts are united into a cup, tube or ring. The stipules are detached from the leaf or adhering to the leafstalk or united into a ring or sheath round the stem, etc.

All such properties ${ }^{2}$ are mentioned or described in the floras : they are almost always easily measurable. Examples: In a gamophyllous corolla or calyx we may measure the length of the tube, the length and the breadth of the free portions (segments, lobes. teeth). In a leaf of a rose, we may measure the total length of the stipules and the length of their free portion.

(2) The colours: each colour is measurable by means of a scale of colours or by a chemical or spectroscopical analysis.

§ \%4.-RAMIFICATION OF THE UNIAXIAL SYSTEM. COMPLICATED CASES (continued).-The different sorts of units (cauloms, phylloms and trichoms) which constitute a ramified system, their relative position and the forms of ramification are described in the classic literature on morphology and phyllotaxis (including the floral diagrams).

Let us now compare two specimens, $a$ and $b$, with regard to a given property; for instance, the length of the leaves. This property is almost always very variable within the limits of each specimen; the differences depend for a part on social causes (place of the leaves). ${ }^{3}$ For a comparison between $a$ and $b$ the social differences ought to be eliminated. When a leaf $a$ has been measured in $a$ we want to find and to measure in $b$ a leaf $\beta$

1 The differences between the individuals alluded to are comparable to the differences between different sorts of specialized individuals observed in certain polypoid animals.

2 Whatever may be their morphological significance.

${ }^{3}$ All the leaves of a specimen (for instance, a tree) are individuals of a certain sort which belong to one society (just as certain specialized individuals in certain polypoid animals). The variation of each of their primordia (for instance, their length) is in part a consequence of plasticity (external causes); for another very important part a consequence of social causes (gradation, Part VIII.). 
which has been developed under the same social conditions as $a^{1}$ This problem is solved by determining the position of $a$ with regard to the system of axes of $a$ and by finding in $b$ a leaf $\beta$ which has the same position with regard to the axial system of $b$.

The method is applicable as often as the system of axes is not too complicate.

EXAMPLE: We want to compare two or several specimens of Quercus robur pedunculata with regard to the primordia length of the leaf and number of leaves. The question is comparatively simple if we take young specimens; for instance, in their third year. The main stem $A$ may be practically looked upon as consisting of three segments (successive annual shoots) $A+\mathrm{I}$ coinciding with the three years. Each segment $A+\mathrm{I}$ is divided into internodes $A+2$. The leaves may be counted, for instance, in the third $A+$ I (terminal shoot of the main stem). The lowest (first) leaf of this segment (=the first leaf of the third yearly shoot) may be taken for the measurement of the primordium lenglh. ${ }^{2}$ The mentioned leaf being measured and the leaves being counted in all the specimens, social variation is eliminated and the figures are comparable, just as if we had measured, for instance, the breadth of the third cervical vertebra in a number of specimens of one species of mammalia.

The above method, applied on a series of species of one genus (or on the indigenous trees and shrubs) would give very interesting results; many characteristic features, many unsuspected similarities and differences would be discovered. For such a comparison of different species it would be, of course, necessary to take a number of specimens ${ }^{3}$ of each species, because individual variation ought to be taken into account (Part VI.).

§ 75.-RAMIFICATION OF THE UNIAXIAL SYSTEM. COMPLICATED CASES (continued). INDIVIDUAL DEVELOPMENT. PRIMORDIA OF THE SUCCESSIVE UNITS OF ONE SPECIMEN. PRIMORDIA OF CUTTINGS AND GRAFTS.-Suppose we want to study the embryology of the leaf of Quercus pedunculata. If we take at random a certain number of leaves in successive stages of development and compare them, the observed differences certainly depend for a part on the social differences between the investigated leaves (which are individuals). If we want to obtain exact results, the

1 In other words, the leaf $\beta$ ought to be a social equivalent of $\alpha$.

${ }^{2}$ In reality it would be preferable to measure the longest leaf of the terminal shoot. (See Gradation, Part VIII.)

${ }^{3}$ Material (seedlings) of many species may be obtained at a rather low price from any well-equipped free nursery. 
method expounded in $\$ 74$ ought to be followed. Leaves between which social equivalence exists ought to be taken in successive states; and, moreover, the method of the curves of development ought to be applied. (See § 49.) We may investigate in a similar way the embryology of the internodes, the scales, the trichoms, etc.

We might be tempted to say, for instance, that the terminal shoot of the main stem produced in the course of the fourth year represents a further state of development of a tree than the terminal shoot produced in the course of the third year. This would be, in reality, inexact. The successive yearly segments do not coincide with successive stages of development. These segments (shoots) are individuals of a certain order $(A+\mathrm{I}$; see $\S 74)$, which are produced successively by means of buds; we may call them bud-generations. The successive budgenerations are superposed, as if they were grafted on each other; this results in social relations. Therefore the differences between the successive yearly (terminal) shoots of a main stem $^{1}$ are not embryological but social differences. (See gradation, Part VIII.)

Cuttings: We may take, for instance, the terminal shoot of a main stem as a cutting and cultivate it separately; the social relations with the main stem being suppressed, the next bud-generation produced by the cutting is more or less different from the bud-generation which would have been produced if the previous relations had been preserved. ${ }^{2}$ In certain cases the produced modification is very distinct.

Grafts: In a similar way a terminal (or any other) shoot $A+I$ of a specimen $x$ may be grafted upon another specimen $x^{1}$; new social relations are brought about and in the next budgeneration produced by $A+I$ the properties may be modified. If the material is strictly monotypic-in other words, if there is no specific difference between the specimens $x$ and $x^{1}$-the observed modifications are a consequence of the social changes. But if $x$ and $x^{1}$ belong to different species ${ }^{3}$ the observed changes depend not only on social causes, but also on a specific influ-

1 Such differences always exist. In many species they are very apparent; for instance, with reference to the properties of the leaves (Cecropia, Morus nigra, Symphoricarpus racemosa, many Leguminosa with compound leaves, etc.).

2 Suppose the cutting is the terminal shoot of a main stem developed in the course of the tenth year. It may happen that the next shoot (produced by the cutting) has leaves similar to those produced by the tree in its first, second or third year. Starting from the erroneous idea that the tenth year represents a further state of development than the first, second or third years, and from the principle that the successive yearly shoots coincide with successive states of the phylogenetic evolution, we are tempted to say that the cutting shows a reversion to an ancestral state. We are deceived, I think, by an illusory appearance.

Example : Pyrus cydonia grafted upon Cratagus monogyna. 
ence of $x^{1}$ upon $A+I$, certain properties of $x^{1}$ being eventually transmitted to $A+\mathrm{I} .^{1}$

The quantitative investigation of the primordia of the species $x$ and $x^{1}$ and of allied species, and a similar investigation of the individuals (cauloms, phylloms and trichoms) produced by the graft might bring us nearer the elucidation of the complicated problems alluded to.

§ 76.-RAMIFICATION OF THE UNIAXIAL SYSTEM. COMPLICATED CASES (continued). ANNUALS, PERENNIALS, BULBOUS PLANTS, SHRUBS, TREES.-The quantitative investigation of annuals, perennials and bulbous plants (Orchis, many Liliacea, Amaryllidacea, etc.), the ramification of which is comparatively simple, may be carried out according to the principles expounded in $\S \S 73-75$. But as often as a large number of bud-generations are united into one specimen a complete analysis of the whole is very difficult, although the theoretical possibility always exists. In such cases we may make a choice among the numerous parts (individuals) which are united into one society (specimen) according to certain CONVENTIONS.

All the herbaceous perennials and suffrutescent plants produce every year (in our climate) new fertile stems which die after flowering (Solidago, Iris, many Graminea, etc.). For a quantitative description of the species we may limit ourselves to these stems. If two or several stems are produced by one specimen (stock or woody base), it is advisable to take the first stem which is ordinarily (not always) more vigorous than the others and flowers earlier than these.

In the shrubs and the trees it is somewhat difficult to find comparable material for the specific description of the primordia of the vegetative parts. More or less satisfactory results may be obtained by taking (if possible) terminal segments (shoots) $t$ at the extremity of main stems, ten or more years old, or terminal segments $t^{1}$ of lateral branches consisting of successive terminal shoots produced for a period of ten or more years. It may be admitted that such segments $t$ (respectively $\left.t^{1}\right)$ have developed under social conditions which are approximately the same for each and all. In several species a distinction ought to be made between short shoots (spurs, Kurztriebe) and long shoots (Langtriebe). ${ }^{2}$ Segments developed at the

1 The specific influence and the possible transmission alluded to are quite independent of the question whether the transmitted properties are fixed in the seeds produced by the graft $A+\mathrm{r}$.

${ }^{2}$ An exact definition of short and long shoots and exact information about the social conditions under which they are produced may be expected from quantitative investigation.

Certain branches having produced typical short shoots for a number of 
periphery of the crown (sunshine) ought to be distinguished from segments developed in the central parts of the crown (shade). Adventitious branches proceeding from the main trunk or from its base ought to be excluded (or to be investigated separately).

This subject is exceedingly complicated. Since the quantitative method is still incompletely established, it is advisable to limit ourselves, for the quantitative specific description of the properties of the vegetative parts, to the study of young trees and shrubs raised from seed (p. 90).

We may have recourse, however, to the quantitative investigation of the fertile parts; for instance, inflorescences, bracts, flowers, fruits, seeds. These parts, indeed, are brought into existence under certain definite social conditions in each species and are therefore comparable, at least approximately. In these parts we find a number of primordia large enough to render possible, in a satisfactory way, a quantitative description of all the species.

§ 7\%.-RECTANGULAR BIAXIAL SYSTEM, PRODUCED BY SECONDARY SEGMENTATION OR CLEAVAGE OF THE UNIAXIAL SYSTEM (continued from $\$ 69$, p. 84). - An adult specimen (individual $x$ ) of Spirogyra is divided by segmentation into a number of segments or individuals (cells) $x+\mathrm{I}$, which follow each other in the direction of one axis. I call this axis the principal

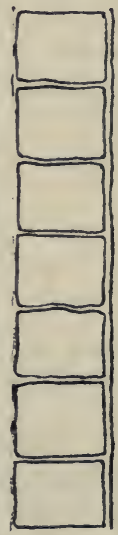

1

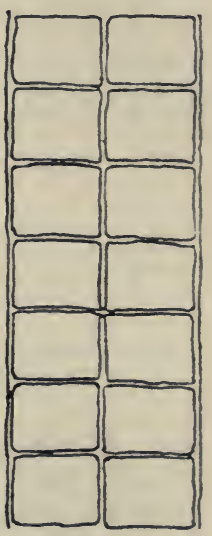

2

Frg. 6.- Prasiola parietina. (Schematic; after WEST, Fig. 36.) (I) young specimen (uniaxial system). (2) Older specimen (rectangular biaxial system) or primary axis, or axis North-Soulh $(N S)$. If each segment (cell) is divided in its turn into two segments in the direction of a secondary axis East-West $(E W)$ perpendicular on $N S$, a new system, represented in Fig. 6, 2, is obtained. This is a rectangular biaxial system. I call segmentation or principal segmentation (primary segmentation, segmentation $N S$ ) the division in the direction of the primary axis NS and secondary segmentation or cleavage (segmentation $E W$ ) the division according to the secondary axis $E W$.

If the segmentation NS has been limited to the production of two segments (cells), and if each of the latter has produced only two segments by cleavage $E W$, a system of four segments years begin to produce long shoots at a certain moment (for instance, in Sorbus aucuparia). 
is obtained. This is often (not always) observed in Pleurococcus vulgaris (Fig. 7). ${ }^{1}$ In the segments of a rectangular system (for instance, Fig. 7,5 ) a number of successive divisions may take place. If divisions $N S$ and $E W$ occur in all the

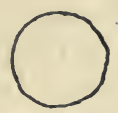

1
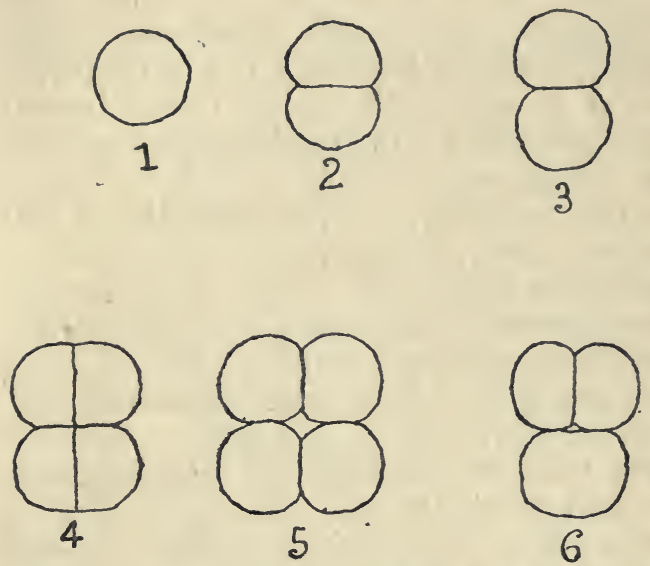

FIG. 7.-Pleurococcus vulgaris. (Schematic.) (I-5) Successive states. (6) Irregular specimen segments (cells), the segmentations NS and $E W$ alternating regularly, a rectangular system is obtained, in which all the segments are regularly placed in rows $N S$ and rows $E W$, as the squares of a chess-board. I call this a chess - board system.

Regular or almost regular examples of the chess - board system are found in certain Algæ (for instance, certain Ulvacea), in the leaves of certain mosses (disposition of the cells), in the disposition of the scales on the wings of numerous butterflies, in the elytræ of a number of Coleoptera, in many shells, etc.

Examples of the chess-board system, more or less altered, are innumerable. The knowledge of this system is important for the investigation of the primordia of plants. It is of the highest importance in the animal kingdom.

\section{§ 78.-PRIMORDIA IN A} RECTANGULAR BIAXIAL SYSTEM (CHESS-BOARD SYSTEM).--In a regular chessboard system four primordia may be distinguished: (I) the number of segments in the longitudinal direction NS; (2) the number of segments in the transversal direction $E W$; (3) the dimension of

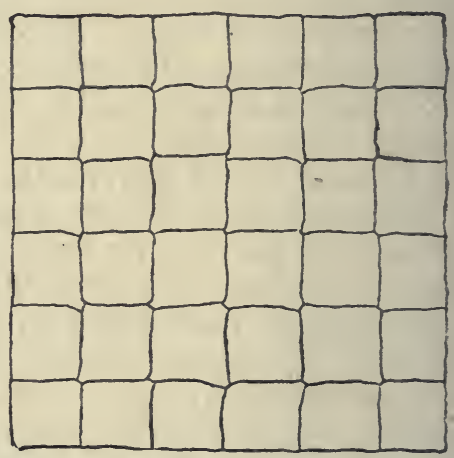

Fig. 8.- Part of a regular chessboard system. (Schematic) the segments in the direction NS (length); (4) the dimension of

1 The system represented in Fig. 7,5; is; of course, quite different by its origin from the quadricellular cœnobium represented in Fig. $3 ;$ p. 79. Between both mechanical concordance probably exists. 
the segments in the direction $E W$ (breadth). These very simple notions are applicable, for instance, on the quantitative investigation of the scales on the wings of the butterflies, taking socially equivalent segments in the wings of all the spieces of a genus or a family.

§79.-ALTERATIONS OF THE CHESS-BOARD SYSTEM. - The typical chess-board system (Fig. 8) may be modified along several lines. This results in numerous deviations and complications, many of which have been described as isolated facts, or regarded as adaptations or mere curiosities. ${ }^{1}$ All these modifications, however various and complicated they may be, ought to be looked upon as states of equilibrium. Adopting this view, we may regard them all from one standpoint-in a similar way, as the mineralogists have brought together into a whole the various deviations and complications of innumerable crystals.

In order that we might be able to analyse the primordia of a given chess-board system, we want, above all, to know the direction of the axes. This is almost always easily found: we may take as axis $N S$ the longitudinal axis of the object under consideration. Sometimes it is more convenient to take an anticlinal (radial) or a periclinal (tangential) direction as axis $N S$. In certain cases, the choice of the primary axis is arbitrary for instance, in Pleurococcus (Fig. 7, 5), in which it is impossible to discover any difference between the axes $N S$ and $E W$.

I want to recall that any axis whatever is a line of equilibrium, segmentation (or cleavage), differentiation and gradation: therefore the axes are the lines of orientation (ordonnance) of all the primordia of a biaxial system.

In general, the primordia of a chess-board system may be classified according to the scheme in $\S 72$ (supplement in $\S 73$, p. 89). (See also $\S \S 57,60$.)

Taking the above principles into account and starting from the regular chess-board system (Fig. 8, p. 94), the alterations of this system may be classified in the following way ${ }^{2}$ :-

I. A chess-board system (segment, unit or individual $x$ ) may be divided into groups of cells which are individuals or units $x+I$ intermediate between the whole system $x$ and its simple components or cells $x+2$. In a similar way the pluricellular units $x+$ I may be divided into pluricellular units $x+2$, the cells being $x+3$, etc. (See $\S 80$.)

1 Numerous examples are found in the specific descriptions of shells, insects; fishes, reptiles, etc.

${ }_{2}^{2}$ The following classification is probably incomplete : it ought to be regarded as being a first attempt to set in order a number of facts which have been hitherto overlooked or described in a fragmentary way. 
II. In a chess-board system $x$ gradation may be observed in one of the directions $N S$ or $E W$, or in both directions at the same time $(\$ 82$.

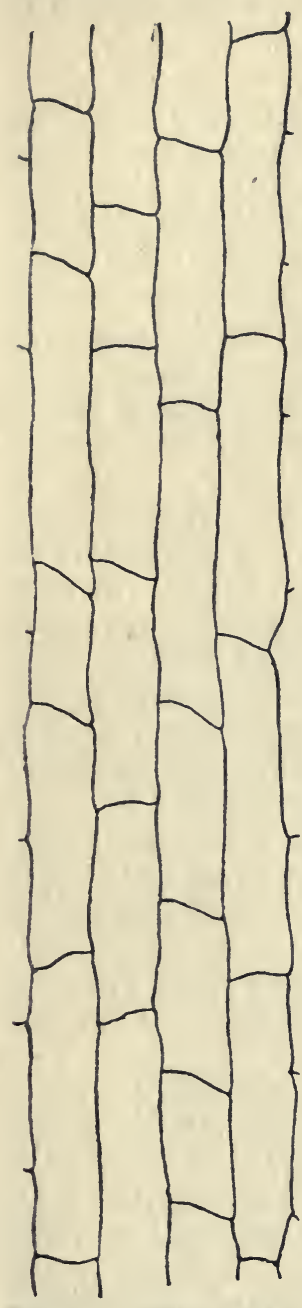

FIG.9. - Allium cepa. Epidermis $x$ of the interior surface of a scale of a bulb. Four longitudinal rows (segments $x+\mathrm{r}$ )

III. In a similar way gradation may be observed in the intermediate units (segments) $x+\mathrm{I}, x+2, \ldots$ alluded to. (Sub. I.)

IV. In a chess-board system differentiation may occur. $(\S 83$.

V. In a similar way differentiation may be observed within the limits of the intermediate units $x+\mathrm{I}, x+2$, etc.

VI. In a chess-board system one axis or both axes may be curved lines. (In reality, a curved axis consists of a succession of very short, straight axes.) (§ 84.)

VII. A chess-board system may become irregular, its constituent segments being in disorder. (\$ 85.)

VIII. A rectangular chess-board system may be altered by the existence of oblique axes (false axes?) in the plane NS-EW. (§ 86.)

§ 80.-ALTERATIONS OF THE CHESS - BOARD SYSTEM (continued). INTERMEDIATE UNITS.-The epidermis of the interior surface of a scale of an onion bulb (Allium cepa) consists of one layer of cells, which are united into a chess-board system $x$. We observe a segmentation into a number of segments $x+\mathrm{I}$ following each other in the direction $E W$ (transverse direction). Each segment $x+I$ (longitudinal row) is segmented in its turn into unicellular segments $x+2$ according to the direction $N S$. The longitudinal rows $x+\mathrm{I}$ are individuals intermediate between the epidermis considered as a whole and the cells. In each longitudinal row the limits between the cells are independent by their position of those in the adjacent rows-in other words, each row has its own independent segmentation. The cells are almost always longer than broad.

In this example the properties are distributed in a different way according to both axes. This difference is, moreover, expressed by the fact that the resist- 
ance to traction of the epidermis is greater in the direction $N S$ than in the direction $E W$.

It may happen that the division into intermediate segments occurs in the direction of both axes; this is observed in certain Algæ; for instance, Ilea. (See N. WILLE in ENGLER und PRANTL.) Here the segments $x+I$ consist of four cells each, and follow each other in both directions in the same way, being united into a regular checker-work. ${ }^{1}$

A more complicated segmentation isfound in the genus Prasiola. (See N. WILLE in ENGLER und PRANTL.) Here a specimen $x$ is segmented into units $x+\mathrm{I}$, which follow one another according to both axes, $N S$ and $E W$. Each unit $x+I$ consists of four units, $x+2$. Each unit $x+2$ consists of four units (cells), $x+3$ (Fig. II).

In the three above examples (onion, Ilea and Prasiola) the individuals intermediate between $x$ and the cells are very small and consist of a few cells. Very often the segments are larger, the laws of segmentation being the same.

The (epidermal) scales of the lizards and other (not all) reptiles are segments (individuals, units) of a certain order produced by a segmentation of the epidermis.

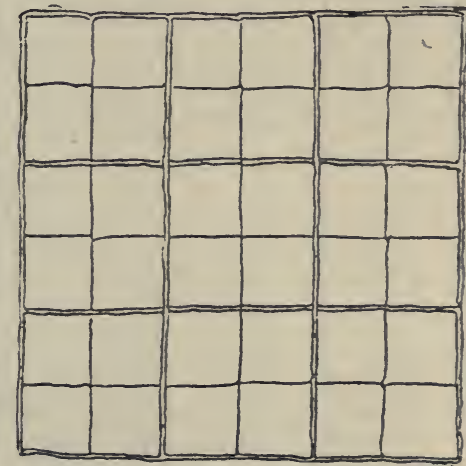

FIG. 10.-Ilea. (Schematic) In the tail of a lizard, for instance, the epidermis $x$ is divided into transversal (annular) segments $x+\mathrm{I}$, which follow each other in the (longitudinal) direction $N S .^{2}$ Each segment $x+\mathrm{I}$ is divided in its turn into multicellular units, $x+2$ (scales), which follow each other according to an axis $E W$. (This disposition is in a certain sense inverse of that observed in the onion, in which the segments $x+I$ are longitudinal.)

In the elytra of the Coleoptera we find innumerable examples of chess-board systems, altered in the most various ways, which all consist of multicellular units. One of the finest examples is observed in Calosoma sycophanta (and other species of the same

${ }^{1}$ A similar segmentation is observed in certain forms of Pleurococcus vulgaris, but here the society of cells has an ephemeral existence : the cells isolate themselves after a certain time.

${ }^{2}$ The segmentation of the epidermis of the tail of a lizard into annular segments $x+1$ is independent of the segmentation of the interior parts, which finds its expression in the vertebral column (vertebrx), the muscular system, etc. The conception that the body of a vertebrate animal is divided into segments is chiefly based upon the skeleton. In reality, two or even several (more or less concentric) independently segmented systems exist. In a similar way, two or more independent systems exist in the body of the Articulates, the Annelids, etc. (See Triaxial System, §88.) 
genus). An elytrum of this handsome beetle is divided into a number of units (longitudinal ribs), which follow each other in the direction $E W$. Each rib is segmented in its turn into multicellular quadrangular segments $x+2$, which follow each other according to an axis $N S^{1}$ On the whole, the disposition of the segments recalls that of the cells in the epidermis of an onion (Fig. 9). (Mechanical concordance.)

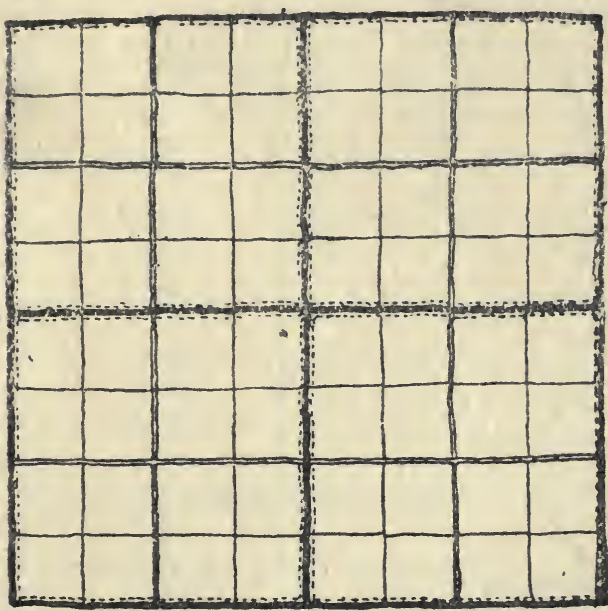

Fig. II.-Prasiola. (Schematic)

An unlimited number of various examples are observed in the shells of the molluscs.

These objects have been hitherto described in a rather empirical way. When they are looked upon as being chessboard systems, governed by the principles expounded in this book, they afford a very interesting and fascinating subject of investigation and measurement. ${ }^{2}$ In order to realize the importance of the shells, which have been rather neglected by the morphologists (and disdained by many biologists), one may consider their importance for the study of plasticity (influence of the conditions of existence), , zoological geography, oceanography, palæontology (here investigation is limited to the shells) and geology. (See § 89.)

§ 81.-LIMITS OF, THE SEGMENTS. VEXILLARY MARKS.- In the preceding examples the limits between the segments are distinct. These limits, however, may get more or less obliterated or disappear completely. Even in such cases it is often possible to discover the disposition of the segments and to count them by means of certain vexillary marks.

FIRST EXAMPLE: In certain parts of the human skin, for instance on the palm of the hand, we observe a number of parallel (somewhat curved and irregular) furrows, ${ }^{3}$ separated by intervals of about one half-millimetre. Each ribbon-like segment between two furrows is an individual $x+\mathrm{I}$ (the epidermis being $x$ ) comparable to the longitudinal segments $x+I$ in Fig. 9 and to the annular segments of the tail of a lizard. In

1 In this description, only the part of the elytrum comprised between its proximal border (sutura) and the so-called series umbilicata (raphe) is taken into account. A number of details are passed over in silence.

2 I have measured a number of primordia in many species. My notes are not within my reach. See further.

${ }^{3}$ These furrows are easily distinguishable from the very variable oblique wrinkles of the skin. 
certain places we observe (on the hands of certain persons) ribbon-like segments, which are divided themselves by slight transverse furrows ${ }^{1}$ into square segments or scales, $x+2$, which correspond (mechanical concordance) to the scales of a lizard or the unicellular segments $x+2$ in Fig. 9. When it happens that two or three adjacent ribbon-like segments are divided into square segments, the chess-board system becomes evident: one might say that the epidermis consists of scales. ${ }^{2}$ In the centre of each scale the opening of one gland is visible.

Ordinarily, however, the slight transversal furrows are obsolete, but the pores (openings of the glands) remain always distinct, as vexillary marks which indicate the latent segmentation: they may be counted (for instance, at the finger-ends) and from their number we know the number of amalgamated scales.

SECOND EXAMPLE: It may happen that the limits between the segments of a chess-board system are obsolete, but that the segments differ from each other by one or another property. In such cases the segments may be counted and their limits are more or less (although indirectly) discernible. The shell of many molluscs (for instance, Cassis tessellata) is adorned with a regular system of coloured spots in longitudinal and transverse rows. ${ }^{3}$ These spots are vexillary marks which point to the existence of a chess-board system in one of the layers of the shell.

THIRD EXAMPLE: The curious square

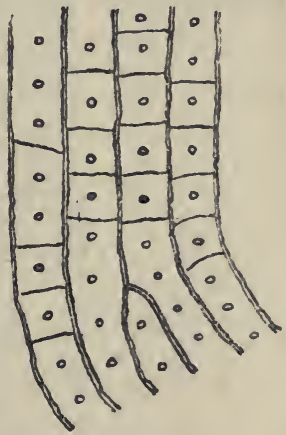

FIG. 12.-Portion of human epidermis divided into scales. In the middle of each scale a gland

spots which form a sort of checker-work in the epidermis of the perianth of certain flowers (Fritillaria meleagris, certain Colchicacea, Vanda corulea, etc.) have perhaps a similar significance.

REMARK : Between the examples mentioned or alluded to in $\S \S 80-8 \mathrm{r}$, neither morphological homology nor physiological analogy, nor phylogenetic relations exist. They are all governed by the general principle of mechanical concordance-just as deeply different chemical entities which crystallize in the same system.

1 To discern these slight furrows I have used a power of $\times 16$.

${ }^{2}$ After desquamation, by which the corneous layer of the epidermis is carried off; the longitudinal and the slight transversal furrows are reformed in the new corneous layer exactly as they were before. From this it may be concluded that the existence of the scales depends on a segmentation of the merislematic layer (rete mucosum) of the epidermis.

${ }^{3}$ Periclinal $(E W)$ and anticlinal $(N S)$ rows. These terms are used here with reference to the margin (border) of the aperture of the shell. With regard to the shell taken as a whole periclinal=longitudinal and anticlinal =transverse (spiral). See p. II 3 . 


\section{THE QUANTITATIVE METHOD IN BIOLOGY}

\$82.-ALTERATIONS OF THE CHESS-BOARD SYSTEM (continued from § 80). GRADATION IN A CHESS-BOARD SYSTEM $x$ OR IN THE SYSTEMS $x+\mathrm{I}, x+2$, ETC. - In the examples mentioned in $\S \S 80-8 \mathrm{I}$, gradation (Part VIII.) has been purposely overlooked. In reality, however, it is very difficult to find a chess-board system in which gradation does not exist. Here I content myself with a schematic example.

I start from the regular system $x$ represented in Fig. I3, I. I suppose (Fig. I3, 2): (I) that $x$ is divided in the direction $E W$ into two segments, $x+\mathrm{I}$, the limit sy-sy being a plan of symmetry; (2) that each segment $x+I$ is divided into three longitudinal segments $x+2(a, b, c ; c, b, a) ;$ (3) that each longitudinal segment $x+2$ is divided into a series of segments

\begin{tabular}{|c|c|c|c|c|c|}
\hline 0 & 0 & 0 & 0 & 0 & 0 \\
\hline 0 & 0 & 0 & 0 & 0 & 0 \\
\hline 0 & 0 & 0 & 0 & 0 & 0 \\
\hline 0 & 0 & 0 & 0 & 0 & 0 \\
\hline 0 & 0 & 0 & 0 & 0 & 0 \\
\hline 0 & 0 & 0 & 0 & 0 & 0 \\
\hline
\end{tabular}

FIG. 13, I. System $x$

$x+3$ following one another in the direction $N S$; (4) that each segment $x+3$ is adorned with a central spot.

Taking each primordium separately, I suppose (5) that the breadth of the segments $x+2(a, b, c ; c, b, a)$ decreases regularly in both directions (eastward and westward) from the plan of symmetry to the lateral borders; (6) that in each longitudinal segment $x+2$ the length of the segments $x+3$ decreases from the base to the summit, the decrease being less rapid in $c, c$ than in $b, b$, and in $b, b$ less rapid than in $a, a$; (7) that the gradation of the breadth of the spots is governed by the same law as the gradation of the segments in the direction $E W ;(8)$ that the gradation of the length of the spots (dimension NS) is governed by the same law as the gradation of the length of the segments (of each longitudinal row) in the direction $N S$ (the spots disappear at the extremity $N$ of the segments $a, a$, because their length becomes o).

In this way we obtain the system represented in Fig. I3, 2. This example gives us an idea of the endless variety of the derivatives of the biaxial system produced by gradation. (In the direction of each axis segregation may be observed. See $\S 38$, p. 45.) However complicated the derivatives may be, it is possible to analyse them by measuring each primordium 
separately in the direction of both axes. By the application of this method to the description of shells and insects, of the epidermis of plants, etc., an exact quantitative description of the species will be rendered possible. It may be anticipated, moreover, that interesting similarities and mechanical laws will be discovered.

§ 83. - ALTERATIONS OF THE CHESS-BOARD SYSTEM (continued). DIFFERENTIATION. - Differentiation may be brought about by various causes and occurs in all possible degrees.

When a segment of any system (uniaxial or biaxial) is different from the other segments by one or several properties, we call it differentiated. ${ }^{1}$

For instance, in the epidermis (chess-board system) of numerous plants and insects certain cells are different from the others because they are transformed into hairs or glands, or because they contain a colouring substance or

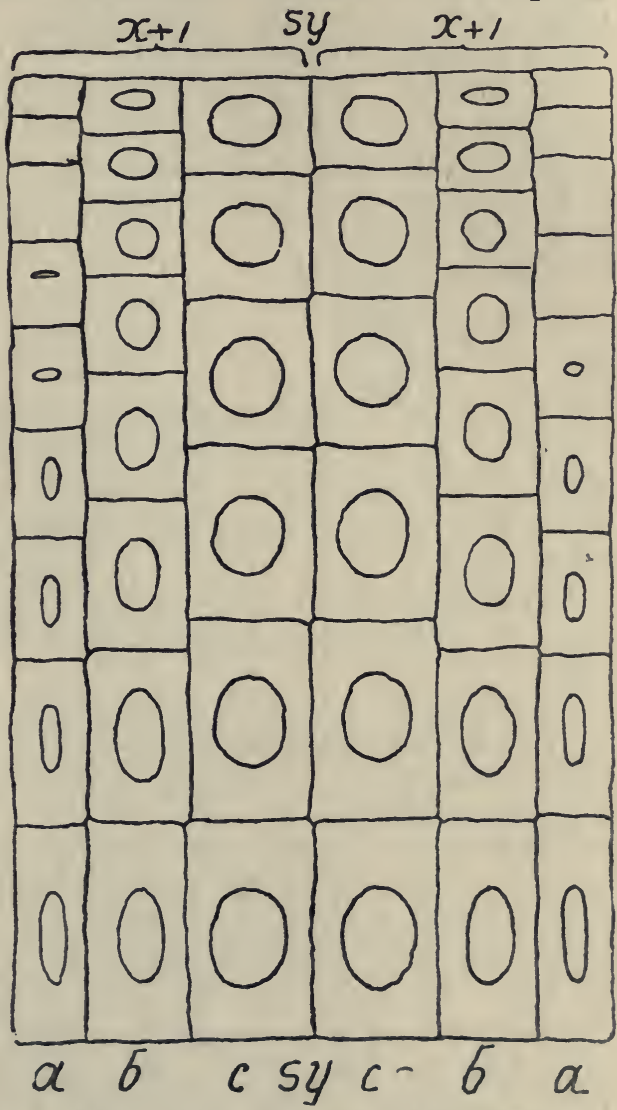

FIG. 13, 2.- sy-sy, plane of symmetry a cystolith. It seems often as if the position of such a differentiated unicellular segment (idioblast) was accidental.

In many cases, however, a differentiation may be regarded as a result of a gradation of a peculiar kind, and it may even be surmised that this is a general rule.

In a typical example of gradation the variation of a property $p$ along an axis is gradual, without any sudden jump. I call

${ }^{1}$ Segmentation and differentiation, which are quite distinct notions, aro sometimes confounded under the term differentiation.

Instead of saying, for instance, that an antenna of a certain insect is differentiated into twelve joints, we ought to say ... segmented .... or ... divided. . . . 


\section{THE QUANTITATIVE METHOD IN BIOLOGY}

this continuous gradation. In the conical hair represented in Fig. 5 (p. 87), for instance, the gradation of the primordium breadth of the cells is continuous along the axis.

When, on the contrary, a sudden change is observed in the value of $p$ at a certain level of the axis, gradation is discontimuous and produces differentiation.

EXAMPLE: An antenna of Carabus is (with regard to the exoskeleton (=cuticula)) a uniaxial system divided into eleven segments (articles). ${ }^{1}$ The gradation of the primordium length of the segments may be described (in the majority of the species) in the following way:-

Joint $I$ : long.

" 2 : short.

" 3 : long.

" 4: short.

"5-II : length decreasing gradually from 5 to II.

Here joint 2 is differentiated from $I$ and 3 . Between 3 and 4 the differentiation is very distinct in certain species, less distinct in others. From 5 to II the gradation is almost always continuous.

Between typical continuous gradation and typical discontimuous gradation (differentiation) all possible transitions exist.

In a chess-board system continuous gradation (Fig. I3, 2), typical differentiation and all possible transitions between both may be observed in the direction of one or both axes and in various primordia.

EXAMPLE: The epidermis of a young leaf of Allium porrum is divided in the direction $E W$ into a number of segments, each of which consists of one longitudinal row of cells, in the same way as the epidermis of an onion scale (Fig. 9, p. 96). In each cell we may distinguish an extremity $S$ (proximal) and an extremity $N$ (distal); a latent cause of gradation according to the axis $N S$ exists in each cell. At a given moment of the development each cell (unit $x+2$ ) is divided into a northern cell $b$ and a southern cell $a$, and now gradation finds its visible expression, the $N$-cell $b$ being much shorter than the $S$-cell $a$. Since the difference in length between $a$ and $b$ is very distinct, we may say that gradation results here in differentiation.

Later on a second difference between $a$ and $b$ becomes apparent (Fig. I4): a develops into an ordinary epidermal cell, whereas $b$ is divided (in the direction $E W$ ) into two cells which form a stomate. In this way the curious differentiation of the units (longitudinal rows) $x+I$ into alternative stomatic

\footnotetext{
${ }^{1}$ In reality, the segments are twelve in number, the first segment being very small and concealed.
} 
segments and epidermal segments properly so called may be regarded as a consequence of gradation.

In the $S$-cells a latent gradation exists ; it finds often its expression in a division into a $N$-cell $a^{\prime \prime}$ and a $S$-cell $a^{\prime}$, the cell $a^{\prime \prime}$ being shorter than $a^{\prime}$. (See Part VIII.)

§ 84. - ALTERATIONS OF THE CHESS-BOARD SYSTEM (continued). SIMPLE AND COMPOUND AXES. CURVED AXES.-An axis, in its simplest form, is the imaginary line which joins the centres of two cells produced by a division ${ }^{\mathbf{1}}$; it is therefore a straight line. Such an original axis may be called a simple axis. In the hitherto mentioned examples I have looked upon the axes of the objects under consideration as being straight lines. Those axes are indeed simple axes (teleuto-spores of Puccinia, §6r, p. 77 ; the axis $E W$ of a stomate, Fig. I4, etc.), or compound axes consisting of a number of successive simple axes following each other in the direction of one straight line (Spirogyra, § 54, Fig. 2).

It happens, however, very often that a compound axis is curved. The curvature of a compound axis ought to be regarded as a secondary modification, which may depend on various causes. In each peculiar case the cause ought to be discovered.

I place in a FIRST GROUP those numerous examples of curvature which are due to external causes, such as gravity, wind, accidental mechanical causes, etc. EXAMPLES: The

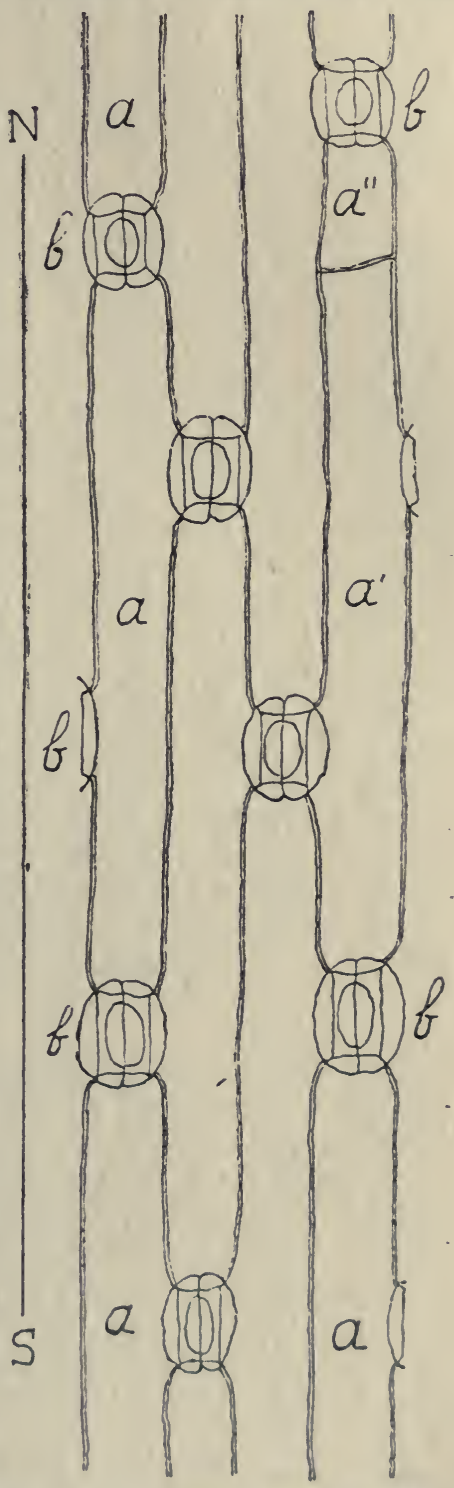

Fig. 14.-Allium porrum. Epidermis. NS, North-South. $a, a$, $a^{\prime}, a^{\prime \prime}$, epidermal cells. $-b, b$, stomates axis of the flower stalk of many plants is straight; later on it is 


\section{THE QUANTITATIVE METHOD IN BIOLOGY}

gradually curved in proportion as the weight of the fruit increases. The flowering stems of a number of Graminece (and many other plants) are more or less curved (drooping) under the influence of gravity, the degree (and the plan) of curvature being variable according to the intensity (and the direction) of the wind.

SECOND GROUP: More interesting are the cases in which the curvature, depending on internal causes, is fixed and constitutes a characteristic feature of the object.

FIRST EXAMPLE: An oblong or oval leaf of a moss (Mnium, Bryum, Tortula, Catharinea, etc.) is limited on both sides by a curved line (margin), the median nerve being straight. This object is a more or less modified chess-board system, consisting of numerous unicellular segments, the axes being NS (longitudinal) and $E W$ (transverse). How can it be explained that the axis $N S$ is straight in the middle and curved along both margins? Two factors are here at play.

The first factor depends on gradation. When the cells are counted in the transverse direction at successive levels from the base to the summit (from $S$ to $N$ ) it is seen that their number increases till the place of the greatest breadth of the leaf is reached. Here we find the maximum. Further towards the summit the number gradually decreases. The property number of cells is thus variable all along the axis NS. A consequence of this gradation is a displacement of the marginal cells, ${ }^{1}$ which do not any longer form a straight longitudinal row. Two successive marginal cells, taken at random, are joined by a straight simple axis; the successive simple axes follow one another in the form of a broken line, which is a compound axis.

The second factor depends on the flexibility and elasticity of the cell walls. Since all the successive marginal cells are united by their walls, they form a continuous whole, the margin, which is brought into a new state of equilibrium: the margin is curved over its whole length and assumes the form of a continuous curve (the angles between the simple axes being as it were, smoothed out). The form of the curved (marginal) axis depends thus (I) on the relative position and the direction of the simple axes, which direction and relative position depend themselves on gradation; (2) on the flexibility and elasticity of the cell-walls.

The cells which form one longitudinal row (or several parallel rows) in the middle of the leaf are not displaced: here all the successive simple axes form one straight compound axis. In a leaf considered as a whole the direction of the middle nerve

1 And, of course, of all the longitudinal rows of cells, in proportion as they are at a greater distance from the nerve. 
may be taken as the axis NS. If we want to study the parts near the margin (for instance, the cells of the differentiated border) it is in general more convenient to take the tangential (periclinal) direction as the axis $N S$ and the radial (anticlinal) direction as the axis $E W$. (At the place of the greatest breadth of the leaf the periclinal axis is, of course, parallel to the nerve.)

SECOND EXAMPLE: It may happen that in a chess-board system (Fig. I3, I) the primordium number of cells in the successive longitudinal rows (counted in each row in the direction NS) augments gradually in the transversal direction; for instance, from $W$ to $E$ (the dimensions of all the cells being supposed to be the same). As a consequence of this gradation the whole system will be bent in such a way that the margin $W$ will become concave and the margin $E$ convex. Just as in the first example, the curvature depends here on gradation, and each margin forms a continuous curve, the explanation being the same as for a leaf of a moss. A similar curvature may be produced by a gradation of the primordium length of the cells (from $W$ to $E$ ) according to the axis $E W$. If the primordium number of cells is at play, the sensitive period of the curvature coincides with the period of cell-division; if the curvature depends on the primordium length of the cells its sensitive period comes later, coinciding with the period of increase of the cells. Concave-convex curvatures are very common; for instance, in the mandibles of almost all the insects, in many fruits (Medicago, etc.), etc. For the investigation of such objects, we may limit ourselves to the epidermis, which is a biaxial system.

§ 85.-ALTERATIONS OF THE CHESS-BOARD SYSTEM (continued). DISORDER.-The segments of a chess-board system are often in disorder, forming an irregular mosaic-work in which it is sometimes difficult to discern the prmiitive disposition and the direction of the axes. In the leaves of the mosses we observe all possible transitions between a regular or almost regular checker-work in which the direction of the axes is distinct and complete disorder. In the epidermis of the leaves of the Monocotyledons the checker-work is ordinarily regular ; in the majority of the Dicotyledons the epidermic cells of the leaves are in disorder.

Several causes may produce disorder; in each peculiar case the cause ought to be investigated. I content myself with mentioning three causes of disorder:

(I) If the cells were disposed regularly into longitudinal and transverse rows as the divisions of a chess-board they would be quadrangular, and four cell-walls would meet each other at 


\section{THE QUANTITATIVE METHOD IN BIOLOGY}

each corner of each cell. This is a mechanical impossibility, because the cell-walls always meet each other three by three. Therefore a supplementary (more or less curved) facet is always
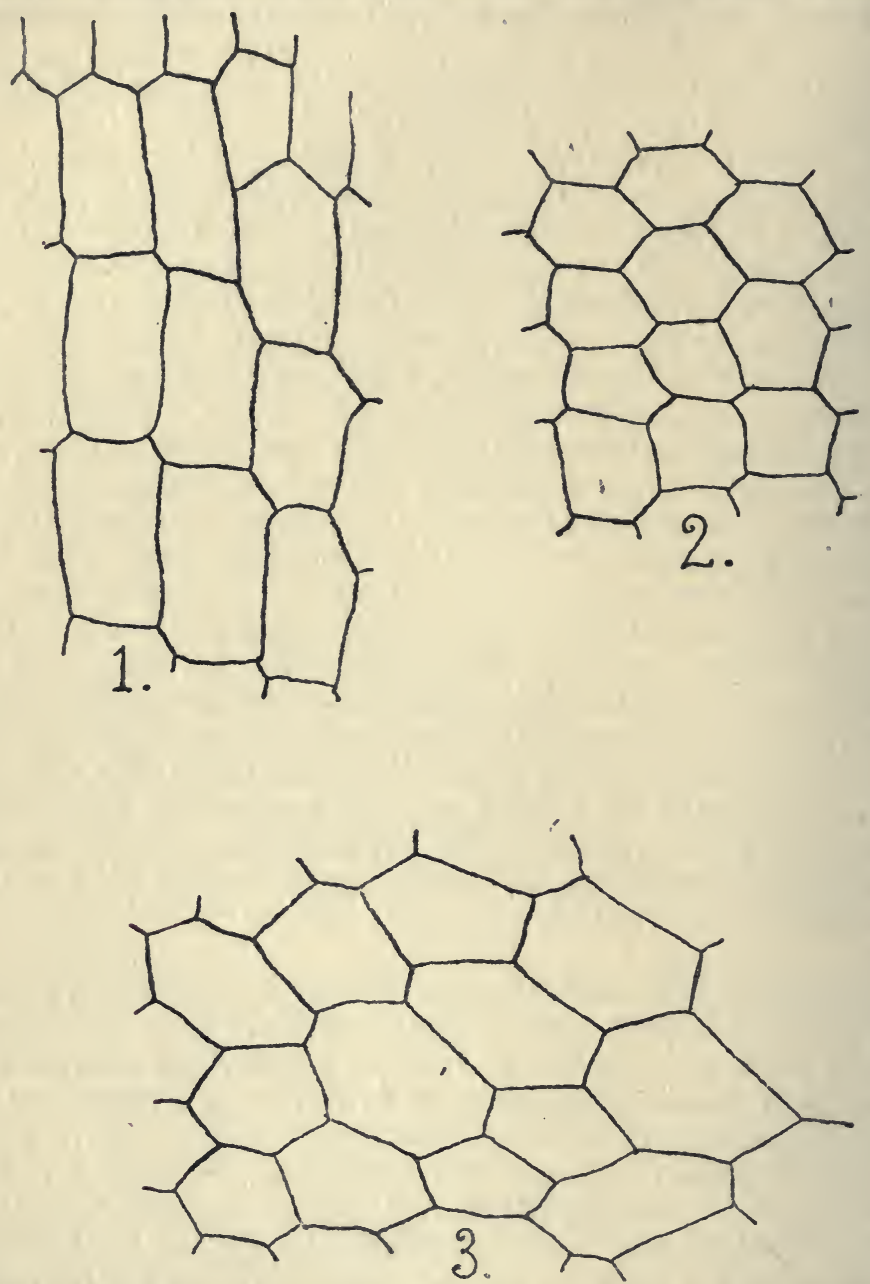

FIG. 15.-Chess-board system in leaves of mosses.-I. Cathavinea undulata, almost regular. 2. Id., id., slight disorder. 3. Mnium undulatum, disorder. Ad naturam

interposed at each corner: an alteration of the form of the cells and a certain degree of disorder are unavoidable consequences of this interposition. The cause of disorder is universal, but its effects are ordinarily rather unimportant. (Fig. 8.) 
(2) Disorder may be a consequence of gradation. We have seen, for instance ( $\$ 84$, first example), that in a leaf of a moss gradation produces a displacement of the cells and a curvature of certain axes: it is obvious that disorder may be brought about at the same time.

(3) In a chess-board system each segment (for instance, each cell) is an individual which is more or less independent of the adjacent individuals. ${ }^{1}$ All the individuals are plastic (as any living individual whatever). Therefore diversity in the conditions of development (see below) brings about variation, for instance, with regard to size and form, and this is a cause of displacement and disorder.

The development of the segments is influenced in various ways by external causes within the limits of one system. For instance, a small object may cover a part of the surface of a system (a leaf of a moss, the epidermis of an animal or a plant, etc.) and modify locally temperature and light ; certain segments may be affected by a shock or by temporary contact with any object, etc. Such causes, acting during the sensitive period, may favour or thwart cell-division in certain segments (Fig. I5), accelerate or slacken the growth of certain units, a consequence of such local modifications being disorder.

When comparable parts are investigated in several species in respect of disorder it is often seen that regularity prevails in certain species and disorder in others. Therefore disorder seems to be, in a certain degree, a property of certain species. (Compare, for instance, the dorsal surface of the pronotum, which is a chess-board system, in a series of species of Carabus.)

It may be surmised that regularity prevails in the majority of those cases in which the system or its segments are elongated according to one of the axes (NS or EW), whereas disorder is ordinarily observed when the system or its segments are rather isodiametric. EXAMPLE: The epidermal cells of

1 This physiological independence may be easily demonstrated. In the epidermis of an onion bulb, for instance, certain cells which are weakened by one or another cause (a shock, a short contact with a hot or a very cold object, etc.) may be killed by a certain poison, whereas the adjacent healthy cells are not visibly influenced. If the poison is a plasmolysing substance (for instance, $\mathrm{KNO}_{3}$ at ro per cent.), the healthy cells are plasmolysed; in the weakened cells only the wall of the vacuole (tonoplast) is plasmolysed and separated from the exterior part of the protoplasma (including the nucleus) which is killed. In cells which are still more weakened the whole of the living contents of the cell is killed at once by the mentioned poison without any trace of plasmolysis.

If a small quantity of eosine (purissima) is added to the plasmolysing solution the above differences between adjacent cells become still more evident, since the killed parts are stained, the living (plasmolysed) parts being colourless (E. VERSCHAFFELT). This question has been thoroughly investigated by A. J. J. VANDEVELDE. 


\section{THE QUANTITATIVE METHOD IN BIOLOGY}

plants have ordinarily a regular position when elongated and are rather in disorder when isodiametric.

It happens that the limits between the segments of a chessboard system are obsolete, each segment being represented by a vexillary mark $(\S 8 \mathrm{I})$. If disorder exists at the same time, the chess-board-like disposition may be at first sight indiscernible because of the irregular position of the marks. EXAMPLE: Disorder often prevails in the disposition of the hairs $w_{4}$ th

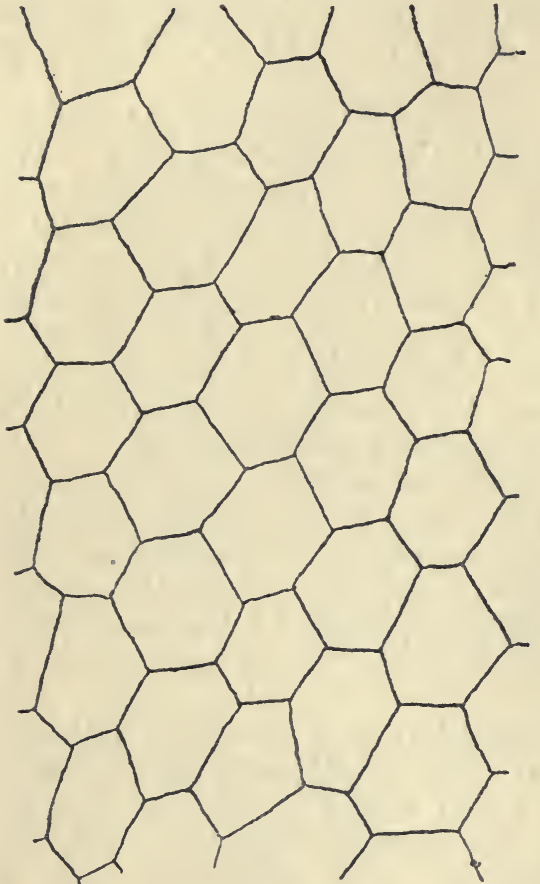

FIG. I6.-Mnium punctatum. Cells of the leaf. $N-N$; nerve. Ad naturam which the epidermis of many insects and plants is clothed, each hair representing one segment.

The plan of structure is, however, often recognizable by comparing several species (some of them being regular), or by investigating accurately the object in order to discover traces of the limits, and perhaps by studying its embryonal development.

Disorder is certainly the most important cause owing to which the universal distribution of the biaxial system in animals and plants has been hitherto overlooked. I regret that I have not been able to find any method to measure the degree of disorder.

\section{§ 86.-ALTERATIONS OF THE CHESS-BOARD SYSTEM} (continued). OBLIQUE AXES IN THE PLANE NS-EW (FALSE AXES ?).--In a number of biaxial systems the disposition of the segments points to the existence of oblique axes. This is observed, for instance, in the leaves of certain mosses. In Mnium punctatum the cells are often placed in longitudinal and oblique rows, the latter being directed from the nerve towards the margin and from the base towards the summit of the leaf (Fig. I6). This is described as a character of the species. 
It is rather difficult to find an explanation of obliquity. $A$ priori three possibilities exist :

(I) The observed obliquity is merely an illusion due to a quincunxial disposition of the segments.

(2) Obliquity is a consequence of an oblique position of the cell-walls in each longitudinal row. In certain leaves of Bryum argenteum I have observed that several longitudinal rows are sometimes regular and parallel, the transversal cellwalls being oblique (Fig. I7). Each row resembles a ladder with oblique rounds. This curious disposition being limited to a small part of the leaf, it may be supposed that obliquity is here secondary, the cell-walls being oblique, the simple axes being rectangular.

(3) It is conceivable that an obliquangular system really exists. This would be obtained if the divisions were succeeding each other alternately, for instance, in the directions NS and $S E-N W$. In this case the axes of both kinds would be in reality lines of segmentation, gradation and differentiation. I could not find any example of this supposed obliquangular biaxial system. The determination of the exact direction of the nuclear spindles might throw some light upon this question.

Curious examples of obliquity are observed in the shells of certain Mollusca and are mentioned as

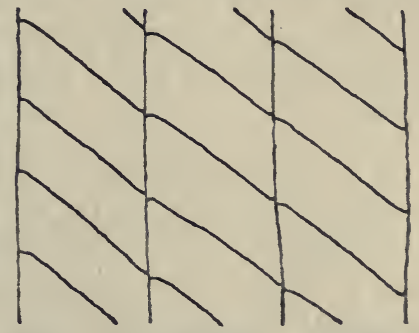

FIG. I7.-Bryum argentersm. Cells of the leaf. (Schematic) specific characteristics; for instance, in certain species of Tellina ( $T$. fabula), Pecten, etc. (In these shells a rectangular system is ordinarily predominant, the axes being anticlinal and periclinal.)

§ 8\%--REMARKS ON THE BIAXIAL SYSTEM (CHESSBOARD SYSTEM, §§ 77-86). SIMPLE PROPERTIES.When we want to discern and to measure the primordia of a given biaxial system we ought before all to establish the direction of the axes and the existing alterations ought to be determined. After this preliminary work the primordia (simple properties) are measured in the direction of each axis, as if each of both axes existed alone. In other words, the whole system ought to be regarded as a compound of two independent uniaxial systems. The primordia of each system may be enumerated and classified according to the scheme in $\S 57$ (see also $\$ \S 60$, $72,73,78)$, each primordium being measured separately.

It happens very often that two or more alterations exist simultaneously in a given system. Since the possible alterations may coexist in the most various ways, numerous combinations 
are possible and are really observed. In each system the primordia themselves are combined (coexist) in a certain way, which varies from one case to another, and the value of each primordium is variable according to the species investigated. Therefore the diversity of the chess-board system is practically unlimited, although the fundamental plan of structure is always the same.

By the application of the principles expounded in $\$ \S 77-86$ it is possible, I think, to disentangle even very complicated cases, to bring innumerable facts, which seem to be accidental and capricious, under general rules, and to establish comparable figures for long series of specific forms.

The investigation of a certain number of examples is indispensable for the further development of the quantitative method. It is advisable to begin this work with examples which are not too complicated and to have recourse again and again to the comparative method. Investigation of a certain number of primordia in a series of well-known species of the same genus (or allied genera) is, I think, the most profitable way.

\section{§ 88. - SECOND SECONDARY SEGMENTATION} (SECOND CLEAVAGE) IN THE BIAXIAL SYSTEM. RECTANGULAR TRIAXIAL SYSTEM. (See $\S 69$, p. 83 , and $\S 77$, p. 93).-A rectangular biaxial system is produced by primary segmentation $N S$ and first secondary segmentation or first cleavage $E W$. In such a system each segment may be divided in its turn into individuals (segments) by a second secondary segmentation or second cleavage according to an axis $Z N$. Since this axis is perpendicular to the plane of the axes $N S$ and $E W$, I call it the axis Zenith-Nadir $(Z N)$. It is the second secondary axis or axis of the second cleavage.

In this way a rectangular triaxial system is produced. In a biaxial system the segments are united into one layer. A triaxial system consists of two or several superposed layers of segments, each layer being a biaxial system. ${ }^{1}$

In the simplest case a triaxial system has the form of a rectangular, straight prism, consisting of several superposed chess-board systems. This form is observed, for instance, in Sarcina, in certain specimens of which it is remarkably regular.

In a triaxial system three planes may be distinguished (just as in a triaxial crystal) - viz.

(I) The plane NS-EW, the position of which is determined by the axes $N S$ and $E W$ (horizontal plane).

(2). The plane $N S-Z N$, determined by the axes $N S$ and $Z N$ (longitudinal plane).

${ }^{1}$ The choice of the axes $N S ; E W$ and $Z N$ is arbitrary. See $\S 79$, p. 95. 
(3) The plane $E W-Z N$ determined by the axes $E W$ and $Z N$ (transverse plane).

EXAMPLE: In a number of Phanerogams (Asclepiadacea, A pocynacea, etc.) the epidermis consists of two layers of cells and is therefore a very simple triaxial system. If we take, for instance, in a leaf the plane which is parallel to the surface of the epidermis as $N S-E W$, a longitudinal section (parallel to the middle nerve and perpendicular to the epidermis) represents the plane $N S-Z N$, and a transverse section (perpendicular to the middle nerve and therefore to the surface) represents the plane $E W-Z N$. When we take the plane $N S-E W$ (parallel to the surface) as base, in each of the superposed systems (two layers), which follow each other in the direction $Z N$, we may find all the alterations and properties which may exist in any biaxial system ( $\$ \S 77-87$ ). Since the superposed layers are more or less independent of each other, differences may be observed between them. The whole triaxial system may be investigated by starting from one of the three planes, for instance, $N S-E W$, and comparing the layers which are superposed according to the axis $Z N$, by studying and measuring their primordia on sections exactly parallel to the planes $N S-Z N$ and $E W-Z N$ (longitudinal and transverse sections).

In the triaxial systems the alterations and the primordia of each layer (biaxial system), combined with the differences between the layers, bring about an endless diversity and various complications, which reach the highest degree in the massive parts of the higher animals and plants. ${ }^{1}$

By the application of the above principles it is theoretically possible to analyse the most difficult objects and to express their properties by measurement. In many cases, however, the structure is so intricate that the difficulties seem to be practically insurmountable as long as the quantitative method is not better established. The impossibility of making sections of one object according to three different planes is a serious obstacle. Therefore, when we need to compare quantitatively several specimens, a choice between the three planes ought to be made, the properties being measured in the same plane in all the specimens.

A large amount of information has already been collected, especially by histologists and embryologists, about the internal structure of animals and plants. Unfortunately the observed facts have been rarely measured in a convenient way (if measured at all), and the fundamental distinction between simple and compound properties has been overlooked. Much attention has been paid to morphological homologies, but

${ }^{1}$ Complication is often increased by obliquity (see $\$ 86$ ) and also by the curvature of certain axes (see $\$ 84$ ) and by disorder $(\$ 85)$. 


\section{2}

mechanical concordance and social equivalence have been often lost out of sight, and even physiological analogy has been rather neglected, especially by the zoologists. In spite of all this, the knowledge already gathered affords a guide for the quantitative investigation of the primordia in the triaxial systems.

§ 89.-RECTANGULAR, TRIAXIAL SYSTEM (continued). EXAMPLES.-According to the general scientific method, which consists in proceeding from the simple to the intricate, we ought to begin the quantitative investigation of the triaxial system with the study of simple examples, limiting ourselves to some easily measurable primordia. I give here four examples :

FIRST EXAMPLE: The root of many Phanerogams before the secondary growth is initiated. This organ may be regarded as a triaxial system, the axes being longitudinal (NS), periclinal (tangential, $E W$ ) and anticlinal (radial, $Z N) .^{1}$ On a transverse section of the root (plane $E W-Z N$ ) the following ten primordia may be measured (the list is incomplete) :-

(I) The number of cells of the cortex in the radial (anticlinal, $Z N)$ direction. In each root these cells ought to be counted according to three or four or even more radii, the mean value being taken as the figure of the root.

$(2-4)$ The number of cells of the endodermis and their radial and tangential dimensions.

(5) The number of radial rays of the xylem.

(6) The mean number (or, in each root, the minimal and maximal number) of ligneous vessels in one ray.

(7-Io) In the phloem bundles the number and the dimensions of the cells in the radial and the tangential direction (investigating three or four bundles and taking the mean values ${ }^{2}$ as the figures of the root).

It would be very interesting to study in this way the root of a series of species of one genus (for instance, of Allium, Iris, Narcissus, Poa, etc.). Of course roots of several specimens of each species ought to be studied, terminal branches of the root system (social equivalence, see $\$ \S 74-75$ ) being taken and the sections being made at a given distance from the summit in each and all.

A monograph of a genus being obtained, it would be interesting to cultivate certain species under different conditions (in sand, clay, peat; moist and dry, etc.), and to study quantitatively the plasticity of the primordia above mentioned. By means of

${ }^{1}$ Considering any cell whatever, its simple axes are $N S, E W$ and $Z N$. Its simple axis $N S$ belongs to the longitudinal axis which passes through its centre. Similarly its simple axis $Z N$ is a part of a radial axis and its simple axis $E W$ is a part of a curved (circular) periclin axis. (See, on the curved axes, $\$ 84$.)

2 Or the minimal and the maximal values. 
a series of successive sections from the summit towards the base it would be possible to construct the developmental curve of each primordium.

A number of subjects of research may be found along this line of investigation.

SECOND EXAMPLE: The siphon of the Pelecypods.

THIRD EXAMPLE: The shell of the Molluscs. This shell consists of two or several superposed layers. Each layer may be looked upon as being a chess-board system, the axes of which are periclinal and anticlinal. In each layer (system) all possible alterations ( $\$ 79)$ may exist and are combined in various ways. The successive layers are superposed according to an axis $Z N$ (normal to the surface of the shell). They are more or less independent of each other. It happens, for instance, that in the external system (superficial layer) the segmentation in the direction of the anticlinal axis ${ }^{1}$ is predominant, whereas the segmentation according to the periclinal axis (division into spirally curved resp. radiair segments) prevails in the second layer. In other cases the same segmentation (anticlinal or periclinal) is equally predominant in both layers. In certain species the second layer is completely concealed by the exterior one, the properties of the latter being visible at the surface of the shell. In other species the exterior layer is moulded upon the second layer in such a way that the former bears the impression of certain properties of the latter, the external characteristics of the shell being a combination of the properties of both layers. In many shells the coloured lines, spots, etc., are vexillary marks (see § 8I). In certain species oblique axes are observed (see $\S 86$, p. I09). Very often segmentation is obsolete, except at or near the margin, where it is indicated by teeth (Donax anatina, etc.), coloured spots (species of Cassis, etc.), etc.

All the mentioned properties may be studied and measured according to the method indicated for the biaxial system, each layer being investigated separately.

More properties of the shells are easily measurable, for instance: (I) in the spiral shells, the height of the shell and its diameter at the place of the greatest breadth; (2) in the conic shells (Patella, etc.), the height, the length and the breadth; (3) in the Bivalves, the length and the breadth of the valves and the transverse diameter (the valves being closed and taken as a whole).

The properties mentioned above are, of course, compound properties. For

${ }^{1}$ In the majority of the Gasteropods and Cephalopods (Ammonites, Nautilus, etc.) the shell has a spiral form. Here the anticlinal axis $N S$, crossing the free margin of the aperture of the shell at right angles, is a spirally curved line as the shell itself. The periclinal axis $E W$ is tangent to the margin. In Patella, Ancylus and other similar Gasteropods and also in the Pelecypods, the periclinal axis is concentric (tangent) and the anticlinal axis is radial with regard to the shell considered as a whole. 


\section{THE QUANTITATIVE METHOD IN BIOLOGY}

the description of the species, they may be regarded without inconvenience as simple.

Several authors have tried to find in the dimensions of the shells (for instance, the ratio breadth: length, etc.) characters of the species. This method has met hitherto with little success, because the majority of the authors did not know in which way variable properties ought to be measured (see Part VI.).1

In $\S 80$, p. 98 , I have called attention to the importance of the study of the shells. Since the notes and the material which I have collected for years are not within my reach, I must content myself with the above very incomplete indications.

FOURTH EXAMPLE: The retina of the vertebrate animals is a triaxial system, the structure of which is complicated but comparatively regular. I think that it is practically possible to measure certain of its primordia. ${ }^{2}$ A comparative investigation of the retina of several allied species would be here, as for many other subjects, the best method.

1 See HENRY EDWARD CRAMPTON (Professor of Zoology, Barnard College, Columbia University), Studies on the Variation, Distribution and Evolution of the Genus Partula (the species inhabiting Tahiti). 3 I4 pages, $34+19$ (very beautiful) plates and numerous diagrams and tables. (Carnegie Institution of Washington. (Publication No.228. $4^{\circ}$. Issued 20th January I9I 7.)

In this interesting work (with which I became acquainted through the kindness of Prof. S. J. HICKSON, Manchester University) four properties (length and width of the shell, $i d$. $i d$. of the aperture) are measured in numerous specimens of a number of species and local races.

2 Dimensions of the cones, rods, pigmentary cells, etc. 


\section{PART VI}

THE MEASUREMENT OF VARIABLE PROPERTIES OF ANIMALS AND PLANTS. SIMPLE NOTIONS OF PROBABILITY (FREQUENCY).

§ 90. - The application of the quantitative method to the study of animals and plants is almost entirely based upon the theory of probability (theory of chance). This theory has been applied to biological problems along two different lines: by QUETELET (I846) and his followers (see § 32) to the measurement of variable properties and by MENDEL (I866) to the study of heredity (see $\S 33$ ).

The knowledge of the principles of this part of mathematical science is indispensable to any biologist who wants to investigate quantitatively the properties of living beings. In the works in which the theory of probability is expounded we find a large amount of mathematical knowledge, whereas facts and realities are mentioned in a few words only and looked upon as being of secondary importance. Such works do not answer the needs of the biologist; they are beyond his reach. This is a fact ... a reality by which the progress of biology is seriously hampered.

The path followed by the theory of probability is slippery ground. From a biological standpoint the theory of chance (frequency) ought to be built up by continual association of observation, measurement, comparison, experiment and mathematical deduction. A conclusion, drawn from exact figures by means of an irreproachable mathematical argument may be delusive! Therefore any conclusion ought to be VERIFIED by the quantitative observation of more facts.

Many biologists seem to believe that the quantitative method is in relation with certain theoretical views about heredity, variation, selection, origin of species, etc. ; that the object of the method is to DEMONSTRATE the reality of certain principles. This conception of the question is erroneous. ${ }^{1}$ I want to emphasize once more that the object of the quantitative method is not to demonstrate something, but to DISCOVER facts and realities which it is impossible to discover in

1 The same mathematical principles have been applied by MENDEL to the study of the hybrids and by QUETELET to the measurement of the stature of man. 


\section{THE QUANTITATIVE METHOD IN BIOLOGY}

any other way, and to find an exact expression for the discovered facts. This is independent of any biological theory.

In Part VI. I wish to expound some principles of the theory of chance (frequency) in a simple form by means of a series of examples. The following pages are written for biologists, who prefer concrete facts to abstract considerations.

\section{§ 91.-FIRST EXAMPLE: THE POSITION OF EQUI-} LIBRIUM OF A SPHERE ON A HORIZONTAL PLANE.Let us suppose that a ball (for instance, a billiard ball), exactly spherical and homogeneous, is thrown at random and falls upon a horizontal plane surface $p$. After a certain time all motion ceases; the ball is then at rest on the plane. Its state of equilibrium is characterized by two measurable values: (I) the direction of the straight line which joins the centre (of gravity) $G$ of the ball and the point of contact $P$ (this line is vertical) ; (2) the distance GP (radius of the ball).

Which are, in this experiment, the relations between cause and effect?

The cause is, in reality, a combination or resultant of an enormous number of forces or factors, such as the direction in which the ball has been thrown, its initial velocity, the initial rotatory motion, its successive positions while rolling over the plane before it came to rest, etc. Since it is practically impossible to determine or even to enumerate the factors which are in play, the cause is called chance: we may call it a combined cause. If the above experiment is repeated several times the cause is, of course, different from one throw to another, for a given combination of factors practically never occurs a second time. In each experiment the cause may be called accidental or fortuitous.

The effect, on the other hand, is always the same; it is the above described state of (indifferent) equilibrium of the ball. This effect is invariable, because it depends on certain properties of the object. If the ball were an animal or a plant, we should say that it always reacts in the same way, according to its specific energy, and that its primordia (direction of GP and length of $G P$ ) are invariable.

In this example chance, in spite of its unlimited variation, produces an invariable effect. (Compare § I04.)

§ 92.-SECOND EXAMPLE : THE POSITIONS OF EQUILIBRIUM OF A COIN. HEAD OR TAIL. In the above experiment ( $\S \mathrm{I}$ ) the spherical ball may be replaced by any other object, all the conditions being the same. Let us throw, for instance, a very thin disc (practically a thin coin), one of its sides being called head or $a$ and the other side tail or $b$. Here 
two states of equilibrium are possible-viz. $a$ and $b$; in other words, two events $a$ and $b$ may be observed. ${ }^{1}$ The cause is chance (combined cause), just as in the example of the ball. The variation of this cause is unlimited, but it has only two different effects : $a$ or $b$. This depends on certain properties of the coin; in other words, on its specific energy. (If the coin were a living being, we should say that there is alternative variation with regard to a pair of primordia $a$ and $b$. $)^{2}$

The two events $a$ and $b$ are equally possible, because one cannot discover any cause (factor) by which one of both would be more easily realized than the other. ${ }^{3}$

Let us now have recourse to experiment. If several series of experiments are made, each series consisting of a rather small number of tosses (for instance, twenty), the order of succession of the events $a$ and $b$ is quite irregular in each series and the ratio in which $a$ and $b$ are observed is very variable from one series to another. It seems as if there were no rule whatever. But if we persevere, repeating the experiment, for instance, 500, I000, I500 ... times, we observe that the number of events $a$ and the number of events $b$ approach more and more to equality, in proportion as the total number of experiments (tosses) is increased. If this number is, for instance, ro,000, each of the events $a$ and $b$ occurs about 5000 times. ${ }^{4}$

In general, if the number of tosses is $n$ (a large number), the event $a$ (head) occurs approximately $\frac{n}{2}$ times.

We call probability (frequency) of the event $a$ the ratio between the number of tosses in which $a$ is observed and the total number of observations (tosses); thus $\frac{n}{2}: n=\frac{1}{2}$. The same value is, of course, the approximate expression of the frequency of $b$.

The above expression of frequency is drawn from experience: the value $\frac{1}{2}$ means that in a second series of $n^{\prime}$ tosses $\left(n^{\prime}\right.$ being a large number) the event $a$ will be observed approximately $\frac{n}{2}$ times $\left(n^{\prime} \times\right.$ the frequency of $\left.a\right)$.

On the other hand, the probability (frequency) may be

1 In reality a third state of equilibrium (event) is possible, in which the coin would be in a vertical position, resting on the plane $p$ by one point of its border. This event practically never occurs and may therefore be left out of account.

2 When the coin has reached its final state of equilibrium (adult state !) three primordia may be discerned ( $G=$ centre of gravity; $P=$ centre of the side of the coin on which it is resting): $(x)$ the length $G P$ (invariable): (2) the direction of GP (always vertical); (3) the sign of $G P$ (head $=a=+$ and tail $=b=-1$. Alternative variation exists here in respect of the primordium sign.

${ }^{3}$ The two states of equilibrium $a$ and $b$ are equally stable.

- Contrary to the belief of many gamblers, the order of succession is always irregular, however great the number of tosses may be, because a given toss has no influence upon the next one. 


\section{THE QUANTITATIVE METHOD IN BIOLOGY}

calculated a priori in the following way:-in the example under consideration (one coin) the number of possible cases is two ; both cases are equally possible ${ }^{\mathbf{1}}$; one case is favourable for the event $a$ and one for the event $b$. The probability (frequency) of a given event is obtained by dividing the number of favourable cases by the number of possible cases ${ }^{2}$; thus for $a$ and for $b$ the probability is $\frac{1}{2}$.

The term probability is used here in a definite sense; it is a quotient. Since this term has, in the ordinary language, a rather vague significance, it is a serious cause of misunderstanding. Therefore it is preferable to replace it as often as possible by the term frequency.

It must be borne in mind, once for all, that the notion of frequency represents an approximation, and that it has very little practical significance, if any significance at all, when the number of observations is too small.

§ 93.-EXPERIMENTAL VERIFICATION: EXPERIMENTS WITH ONE COIN.-I have tossed a coin (a British penny) 3000 times. In 150 series of 20 successive tosses the events $a$ and $b$ were observed ${ }^{3}$ :

In I series : $a \quad 5$ times; $b$ I 5 times

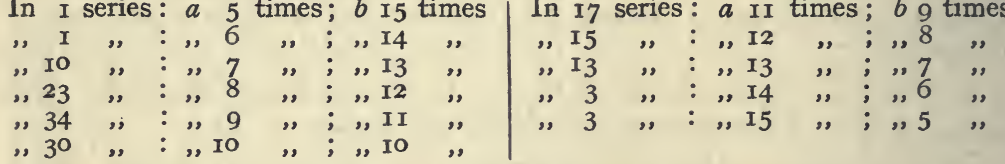

Taking the event $a$ (head), we see that its observed frequency is variable within very wide limits-viz. $\frac{5}{20}$ and $\frac{15}{20} 4$ and that in I20 out of the I5O series a deviation from the calculated frequency (which is $\frac{10}{20}$ ) exists. Therefore we are in danger of being seriously deluded if we draw any conclusion from one series of 20 tosses.

In 30 series of roo successive tosses the event $a$ (head) was observed :

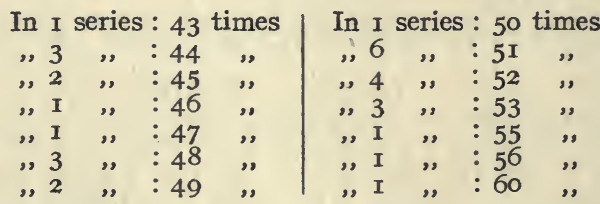

The calculated frequency is $\frac{50}{100}$. The observed frequency is variable between $\frac{43}{100}$ and $\frac{60}{100}$. The concordance between the

1 Both states of equilibrium are equally stable.

2 Possible states of equilibrium of equal stability.

${ }^{3}$ I have used a penny which was worn flat on both sides.

4 The possible limits are $\frac{0}{20}$ and $\frac{20}{20}$. 
series is thus more satisfactory than between the series of 20 tosses. One series of roo observations (tosses) with one coin gives, therefore, more or less reliable information.

In 6 series of 500 successive tosses the event $a$ was observed

$$
\text { 235, 239, 248, 248, 262, } 262
$$

times. The calculated frequency is $\frac{250}{500}$. Here the concordance is still more satisfactory than between the series of roo tosses.

The 3000 tosses being brought together into one series, the observed frequencies were : heads I494 times ; tails, I506 times.

The observed ratio is $0.996: \mathrm{I}$.

The calculated ratio is $I 500: I 500=I: I$.

The observed figures are as satisfactory as might be expected from similar experiments. (Compare $\S \S 95$ and ro3.)

§ 94.-THIRD EXAMPLE: THE POSITIONS OF EQUILIBRIUM OF A SYSTEM OF TWO COINS. Let us toss successively two coins I. and II. Under the influence of chance the first coin I. may give the events $a$ (head) or $b$ (tail), which we call from henceforth simple events. We ascribe to the letters $a$ and $b$, which represent the simple events, the numerical value of their respective frequencies; thus (according to $\S 92$ ) $a=\frac{1}{2}$ and $b=\frac{1}{2}$ (or 0.50 and 0.50 ).

In a similar way the second coin II. may give the simple events $a$ or $b$ (frequencies: $a=\frac{1}{2}=0.50$ and $b=\frac{1}{2}=0.50$ ). By the combination of the simple events two by two (the number of coins is two), four compound events may be brought about-viz.

$a$ (coin I.) followed by $a$ (coin II.) : compound event $a a$

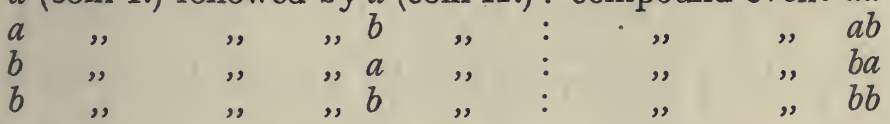

Since four possibilities (states of equilibrium, compound events) exist, and since they are equally possible (stable), the frequency of each compound event (calculated a priori) is $I$ : 4 . (See $\S 92$.) This is expressed by the numerical value of each of the monomials which represent the compound events-viz. $a a=\frac{1}{4} ; a b=\frac{1}{4}$, etc.

In general, the frequency of any compound event is the product of the frequencies of the simple events of which it consists.

We have hitherto taken the order of succession of the simple events into account. We may, however, neglect this order and consider only the final result, as if both coins were tossed at the same time. (By adopting this standpoint we do not alter the facts.) We see then that there is no longer any difference between $a b$ (head-tail) and $b a$ (tail-head); both are 


\section{0}

THE QUANTITATIVE METHOD IN BIOLOGY

confounded, and only three different compound events ought to be distinguished-viz.

$$
a a \quad a b+b a \quad b b
$$

or

$$
a^{2}+2 a b+b^{2}
$$

These three compound events have not the same frequency. Each of the events $a^{2}$ and $b^{2}$ is produced in one way; its frequency is $\frac{1}{4}$. The event $a b$ may be produced in two ways ( $a b$ or $b a$ ), each of which has the frequency $\frac{1}{4}$. The frequency of $a b$ is the sum of the frequencies of these two ways-viz. $\frac{1}{4}+\frac{1}{4}=\frac{1}{2}$.

The trinomial $a^{2}+2 a b+b^{2}$ affords us complete information about the events which may occur when two coins are tossed once-viz.

(I) Each letter represents a simple event (two simple events are in play).

(2) The numerical value of each letter represents the frequency of the corresponding simple event $\left(a=\frac{1}{2}\right.$ and $\left.b=\frac{1}{2}\right)$.

(3) From the number of terms we know how many sorts of compound events are possible (three).

(4) The numerical value of each term represents the frequency of the corresponding compound event (for instance, the frequency of $a b$ is $2 a b=\frac{2}{4}=\frac{1}{2}$ ).

(5) The sum of all the coefficients ${ }^{1}$ is the number of possible compound events, the order of succession being taken into account $(I+2+I=4)$.

(6) The letters of each term represent the constitution (simple events) of the corresponding compound event.

(7) The coefficient of each term indicates in how many ways the corresponding compound event may be brought about (for instance, $a b$ in two ways : $a b$ and $b a$ ).

All the above information may be obtained in the following way :-

The binomial $a+b$ or $(a+b)^{1}$ (in which $a=b=\frac{1}{2}$ ) represents the events which may be observed when one coin is tossed. When two coins are tossed we obtain a complete representation of all the events by multiplying the binomials of both coins into one another-viz.

$$
(a+b) \times(a+b)=(a+b)^{2}=a^{2}+2 a b+b^{2}
$$

All the above may be verified approximately by observation, under the condition that the number of experiments (tosses) is large enough. Example: If two coins are tossêd 3037 times, the event $a b$ may be expected approximately I5I8.5 times (I5I8 or I5I9 times), and each of the events $a^{2}$ or $b^{2}$ approximately $759^{\circ} 25$ (759) times.

1 Or the denominator of the numerical value of any term. 
REMARK: In the examples hitherto mentioned we have at our disposal two methods for discovering the effects of the variable combined cause which is called chance : (I) calculation a priori, based upon the properties (specific energy) of the objects under consideration (coins); (2) observation of facts in sufficient number.

§ 95.-FOURTH EXAMPLE: THE POSITIONS OF EQUILIBRIUM OF THREE COINS.-Three coins being tossed successively, the possible compound events are eight in number-viz. :

$\begin{array}{cccc}a a a & a a b & a b b & b b b \\ & a b a & b a b & \\ b a a & b b a & \end{array}$

The order of succession being neglected (the coins being tossed simultaneously), the eight compound events are reduced to four. Taking the binomial of each coin (in which $a=b=\frac{1}{2}$ ), complete information is obtained in the following way:-

$$
\begin{aligned}
(a+b) & \times(a+b) \times(a+b)=(a+b)^{3}= \\
& =a^{3}+3 a^{2} b+3 a b^{2}+b^{3}
\end{aligned}
$$

From this polynomial we obtain similar information to that found in the trinomial in the third example (p. I20, (I)-(7)).

Experimental verification: I have tossed three coins (British pennies) simultaneously rooo times. Result:

First Series : 500 Successive Tosses

\begin{tabular}{c|c|c}
\hline $\begin{array}{c}\text { Compound } \\
\text { Events }\end{array}$ & $\begin{array}{c}\text { Observed } \\
\text { Frequency }\end{array}$ & $\begin{array}{c}\text { Calculated } \\
\text { Frequency }\end{array}$ \\
\hline$a^{3}$ & 65 & $500 \times \frac{1}{8}=62.5$ \\
$a^{2} b$ & 200 & $500 \times \frac{3}{8}=187.5$ \\
$a b^{2}$ & $\mathrm{I} 8 \mathrm{I}$ & $500 \times \frac{3}{8}=187.5$ \\
$b^{3}$ & 54 & $500 \times \frac{1}{8}=62.5$ \\
\hline
\end{tabular}

Second Series : 500 Successive Tosses

\begin{tabular}{c|c|c}
\hline $\begin{array}{c}\text { Compound } \\
\text { Events }\end{array}$ & $\begin{array}{c}\text { Observed } \\
\text { Frequency }\end{array}$ & $\begin{array}{c}\text { Calculated } \\
\text { Frequency }\end{array}$ \\
\hline$a^{3}$ & 47 & $500 \times \frac{1}{8}=62.5$ \\
$a^{2} b$ & 175 & $500 \times \frac{3}{8}=187.5$ \\
$a b^{2}$ & 216 & $500 \times \frac{3}{8}=187.5$ \\
$b^{3}$ & 62 & $500 \times \frac{1}{8}=62.5$ \\
\hline
\end{tabular}


First and Second Series: Iooo Tosses

\begin{tabular}{c|c|c}
\hline $\begin{array}{c}\text { Compound } \\
\text { Events }\end{array}$ & $\begin{array}{c}\text { Observed } \\
\text { Frequency }\end{array}$ & $\begin{array}{l}\text { Calculated } \\
\text { Frequency }\end{array}$ \\
\hline$a^{3}$ & II2 & I000 $\times \frac{1}{8}=I 25$ \\
$a^{2} b$ & 375 & I000 $\times \frac{3}{8}=375$ \\
$a b^{2}$ & 397 & I000 $\times \frac{3}{8}=375$ \\
$b^{3}$ & II6 & IOOO $\times \frac{1}{8}=I 25$ \\
\hline
\end{tabular}

According to the above figures, the simple event
$a$ (head) has been observed 1483 times
$b$ (tail)

The observed ratio is heads: tails $=0.978: x^{\circ}$, the calculated ratio being $I: I$. In $\S 93$ (3000 tosses) the observed ratio was heads : tails $=0.996:$ I. (See $\S$ I03.)

§ 96.-FIFTH EXAMPLE: POSITIONS OF EQUILIBRIUM OF A SYSTEM OF $n$ COINS.-Whatever may be the number of coins, complete information about all the possible events is obtained by means of the expression $(a+b)^{n}$, in which

(I) $a$ and $b$ represent the simple events ( $a=$ head and $b=$ tail);

(2) $a=b=\frac{1}{2}$ (frequency of the simple events) ;

(3) $n=$ number of coins (number of simple events which are combined into compound events).

Let us suppose that six coins, I., II., III., IV., V. and VI., are tossed. The order of succession being taken into account, sixty-four compound events are equally possible (stable)-viz.

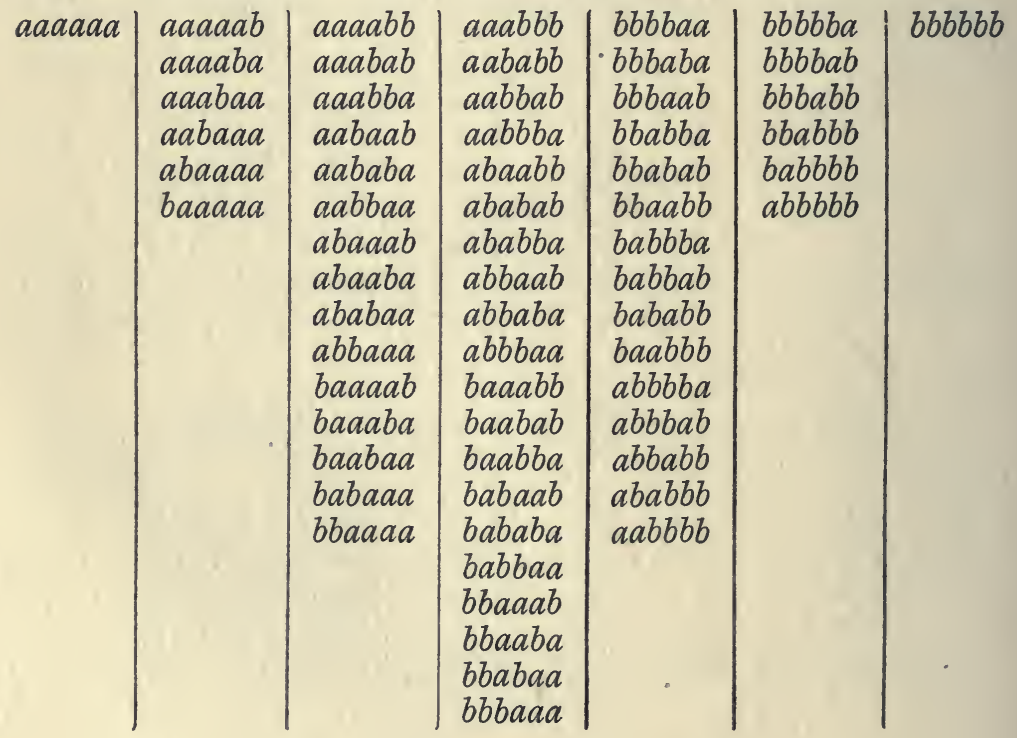


The order of succession being neglected, the sixty-four events are reduced to seven, which are represented by the terms obtained by expanding $(a+b)^{6}$, in which $a=b=\frac{1}{2}-$ viz.

$$
(a+b)^{6}=a^{6}+6 a^{5} b+15 a^{4} b^{2}+20 a^{3} b^{3}+15 a^{2} b^{4}+6 a b^{5}+b^{6}
$$

About the information given by these terms, see p. I20, (I)-(7), and compare with the above table.

QUESTION I. : Which is the frequency of the event $a^{4} b^{2}$ (four heads and two tails)?

Answer : ${ }^{15}: 64(=0.234)$.

QUESTION II. : In a series of $x$ tosses the event $a b^{5}$ has been observed 300 times. How many times did the event $a^{2} b^{4}$ occur ?

Answer : Approximately 750 times.

QUESTION III. : Which is in Question II. the value of $x$ ?

Answer : Approximately 3200 tosses.

QUESTION IV. : The number of tosses being 200, how many times will the event $a^{6}$ be observed ?

Answer : Approximately three times (this answer has hardly any practical value, because the number of tosses is too simall).

QUESTION V.: The number of tosses being 6000, in how many tosses will the number of events $a$ (heads) be an even number?

Answer : Approximately 2906 times.

§ 9\%.-REMARKS ABOUT THE PRECEDING EXAMPLES.-Chance is a vague something which is continually varying. At first sight the effects of chance seem to be capricious, as if they were independent of any rule whatever.

In the example of the spherical ball ( $(9 \mathrm{I})$, however, all the possible effects of chance are reduced to one simple event, the occurrence of which is certain.

Tossing one coin $(\$ 92)$, we have reduced all the possible effects of chance to two simple events $a$ and $b$. The frequency of each of them is $\frac{1}{2}$. The sum of their frequencies (probabilities) is $\mathbf{I}$. The figure $\mathrm{I}$ is the expression of certitude. If we consider one toss, we may foretell with certitude that $a$ or $b$ will be observed, but we do not know at all which of both will happen : the notion of frequency (probability) is in this case a pure fiction. But in proportion as the tosses become more numerous the existence of a rule becomes more apparent. We learn from EXPERIENCE that the frequencies of $a$ and $b$ approach more and more to equality, which is represented by their frequencies $\left(\frac{1}{2}\right.$ and $\left.\frac{1}{2}\right)$ calculated a priori.

The events $a$ and $b$ afford us a fixed starting-point for further investigation. We look upon them as being simple causes (or forces) the combinations of which produce combined causes (resultants). We have succeeded in discovering certain rules by which the combined causes and their effects are governedwhatever may be the number $n$ of simple causes (simple events) which are combined.

The rules discovered are rules (or laws) of chance. The 


\section{THE QUANTITATIVE METHOD IN BIOLOGY}

cause which we call chance is indeed a combined cause which consists of an unlimited (unknown) number of simple causes.

§ 98.-SIXTH EXAMPLE: AN URN CONTAINING Ioo WHITE AND Ioo BLACK BALLS.-When one ball is extracted at random from the urn, two simple events are possible : white $=a$ or black $=b$. Since the number of cases (possibilities) favourable for $a$ is Ioo and the total number of possible cases 200 , the frequency of $a$ is $100: 200=\frac{1}{2}$. The frequency of $b$ has, of course, the same value. The conditions are thus exactly the same as in the example of one coin $(\$ 92)$. If the balls are extracted by series of $2,3 \ldots n$, taking them one by one and putting each ball back into the urn after the colour has been ascertained, ${ }^{1}$ the same compound events (combinations) will occur as when $2,3 \ldots n$ coins are tossed.

If the balls are extracted (one by one), for instance, in series of eight, all the possible combinations and the frequency of each of them may be calculated $a$ priori by expanding $(a+b)^{8}$, in which $a=b=\frac{1}{2}-$ viz.

$(a+b)^{8}=a^{8}+8 a^{7} b+28 a^{6} b^{2}+56 a^{5} b^{3}+70 a^{4} b^{4}+56 a^{3} b^{5}+28 a^{2} b^{6}+$ $8 a b^{7}+b^{8}=$ I (certitude). ${ }^{2}$

QUESTION I.: What is the frequency of the compound event 6 white (a) and 2 black (b) balls ?

Answer: Approximately $28: 256$ (=0.109).

QUESTION II.: Which is the frequency of $a a b a b b a b$ ?

Answer : Approximately I : 256 =0.004.

§ 99.-SEVENTH EXAMPLE: AN URN CONTAINING 200 WHITE AND Ioo BLACK BALLS.-When one ball is extracted the frequency of $a$ (white) is $\frac{200}{300}$ (number of favourable cases divided by number of possible cases) or $\frac{2}{3}$, and the frequency of $b$ (black) is $\frac{1}{3}$. All possible information is obtained by expanding $(a+b)^{n}$, in which $n$ is the number of extracted balls (taken one by one; see the note, p. I24), $a=\frac{2}{3}$ and $b=\frac{1}{3}$. (See (I)-(7), p. I20.)

QUESTION I. : Six balls being extracted, which is the frequency of the compound event two white and four black balls? (See $(a+b)^{6}$, p. 123.)

Answer : Approximately 60: 729 (=0.082).

QUESTION II. : I5,000 series of eight balls being extracted, how many times has the combination seven white and one black ball been obtained ? (See $(a+b)^{8}$, p. 124.)

Answer: $15,000 \times 8 a^{7} b=15,000 \times \frac{1}{6} \frac{024}{56}=$ approximately $234 \mathrm{I}$ times.

1 If the ball were not put back into the urn after each extraction, the frequency of the simple events would be continually modified and the calculations would become more complicated.

Let us suppose that the first extracted ball is $a$. When a second ball is taken, the frequency of the event $a$ is no longer $\frac{100}{200}$, but $\frac{99}{199}$, and the frequency of the event $b$ is $\frac{1}{1} 8 \%$, etc.

2 Sum of the coefficients $=2^{8}=256$. 
$\S 100$ - -EIGHTH EXAMPLE: AN URN CONTAINING Ioo WHITE, IOo BLACK AND Ioo RED BALLS.-When one ball is extracted three simple events are equally possible: $a$ (white), $b$ (black) and $c$ (red). The frequency of each of them is $\frac{100}{300}=\frac{1}{3}$. This is represented by the trinomial $a+b+c$, or $\frac{1}{3}+\frac{1}{3}+\frac{1}{3}=$ I (certitude).

When two balls are extracted successively the possible events with regard to the second ball are similarly represented by $a+b+c$. Since the simple events are combined two by two, nine compound events are (equally) possible-viz.

$\begin{array}{llllll}a a & b b & c c & a b & a c & b c \\ & & & b a & c a & c b\end{array}$

The frequency of each compound event is $\frac{1}{3} \times \frac{1}{3}=\frac{1}{9}$.

The order of succession being neglected, the nine events are reduced to six. The expression of these six compound events is obtained by multiplying into one another the trinomials representing the simple events which are combined (see § 94, p. I20)-viz.

$$
\begin{gathered}
(a+b+c) \times(a+b+c)=(a+b+c)^{2}= \\
a^{2}+b^{2}+c^{2}+2 a b+2 a c+2 b c=\frac{9}{9}=\mathrm{I}
\end{gathered}
$$

The frequency of each compound event is expressed by the numerical value of its term.

Complete information about all the possible compound events when series of $3,4 \ldots n$ balls are extracted is obtained by expanding $(a+b+c)^{n}$, in which $n$ is the number of simple events (extracted balls of one series) and $a=b=c=\frac{1}{3}$. (Continued in § II5.)

§101.-NINTH EXAMPLE: ONE DIE, TWO DICE.-In the preceding examples the effects of chance are limited to a definite number of simple events. In each event a certain simple property (head, tail ; colour) of the objects is rendered visible. The simple events and properties are combined (coexist) in various ways, according to the rules of chance.

Between the above-mentioned simple properties (primordia, see $\S 92$, p. II 7 , note 2) no quantitative relations exist. Each primordium is distinctly different from the others; it is present or absent, visible or latent (concealed), without more.

It may happen, however, that the properties under consideration are measurable, each simple event coinciding with a certain value. In this case the rules of chance are unaltered, but chance has certain effects which we have not yet alluded to.

One ordinary die being cast, six states of equilibrium or simple events are equally possible: in each event one of the 
faces of the die becomes visible. The frequency of each event (face) is $\frac{1}{6}$. If we represent the faces by six letters, $a, b, c, d, e, f$, and ascribe to each letter the value of its frequency, which is $\frac{1}{6}$ for each, the possibilities are expressed by the polynomial

$$
a+b+c+d+e+f=\frac{6}{6}=\mathrm{I} \text { (certitude) }{ }^{1}
$$

Two dice being cast successively, the simple events are combined two by two, and thirty-six compound events are equally possible, according to the expression $(a+b+c+d+e+f)^{2}$. (See \$ I0o.) These thirty-six events are represented by $a a, a b \ldots$ $b a, b b \ldots$. . etc. The frequency is $\frac{1}{36}$ for each.

If the order of succession is neglected, the thirty-six events are reduced to twenty-one (see $\S$ IOO) - viz.

$$
\begin{gathered}
(a+b+c+d+e+f)^{2}= \\
\text { TABLE } a \\
a^{2}+2 a b+2 a c+2 a d+2 a e+2 a f+2 b f+2 c f+2 d f+2 e f+f^{2} \\
+b^{2}+2 b c+2 b d+2 b e+2 c e+2 e d+e^{2} \\
+c^{2}+2 c d+d^{2}
\end{gathered}
$$

It is possible to go further. Since each letter represents one of the faces of a die, we may ascribe to each letter two distinct values: (I) the value of the frequency of the corresponding simple event, which is $\frac{1}{6}$ for each letter ; (2) the value of the corresponding face of the die $(a=1, b=2, c=3, d=4, e=5, f=6)$. This jacial value is quite independent of the frequency.

In Table $\alpha$ each monomial is the expression of a compound event. The arithmetical sum of the letters of each monomial is the facial value of the corresponding compound event; for instance :

$$
\begin{aligned}
& a^{2}=a+a=\mathrm{I}+\mathrm{I}=2 \\
& a b=\mathrm{I}+2=3 \\
& a c=\mathrm{I}+3=4 \\
& b^{2}=b+b=2+2=4 \\
& \dot{f}^{2}=\dot{f}+f=6+\dot{6}=\mathrm{I} 2
\end{aligned}
$$

When only the facial values are taken into account, the twentyone events in Table $\alpha$ are reduced to eleven, characterized by the values

$$
2,3,4,5,6,7,8,9 \text {, Io, II, I2 }
$$

(In Table $\alpha$ the monomials are arranged in such a way that they have the same facial value in each vertical column.)

1 This polynomial is also the expression of the six possible events when one ball is taken from an urn containing six sorts of balls in equal number. (See § IOO.) 
TABLE $\beta$

\begin{tabular}{l|l|l|l|l|l|l|l}
$\mathrm{A}$ & $\mathrm{I} . \mathrm{I}$ & $\mathrm{I} .2$ & $\mathrm{I} .3$ & $\mathrm{I} .4$ & $\mathrm{I} .5$ & $\mathrm{I} .6$ & $\mathrm{C}$ \\
& $2 . \mathrm{I}$ & 2.2 & 2.3 & 2.4 & 2.5 & 2.6 & \\
& $3 . \mathrm{I}$ & 3.2 & 3.3 & 3.4 & 3.5 & 3.6 & \\
& $\mathrm{~B} . \mathrm{I}$ & 4.2 & 4.3 & 4.4 & 4.5 & 4.6 & \\
& $5 . \mathrm{I}$ & 5.2 & 5.3 & 5.4 & 5.5 & 5.6 & \\
& $6 . \mathrm{I}$ & 6.2 & 6.3 & 6.4 & 6.5 & 6.6 & $\mathrm{D}$
\end{tabular}

In Table $\beta$ the thirty-six compound events are represented by their facial values; in each pair of figures the first figure represents the first die. In each of the eleven oblique rows parallel to the diagonal $\mathrm{BC}$ the compound events have the same facial value.

The frequency of the eleven facial values is expressed by the sum of the arithmetical values of the monomials which belong to the same vertical column in Table $\alpha$. For instance, the frequency of 4 ( 4 dots with 2 dice) is $2 a c+b^{2}=\frac{2}{36}+\frac{1}{36}=\frac{3}{36} \cdot{ }^{1}$

In Table $\gamma$ the eleven facial values are given with their respective frequencies:

\section{TABLE $\gamma$}

$\begin{array}{llllllllllll}\text { Fac. value } & 2 & 3 & 4 & 5 & 6 & 7 & 8 & 9 & \text { IO } & \text { II } & \text { I2 }\end{array}$

$\begin{array}{llllllllllll}\text { Frequency } & \frac{1}{36} & \frac{2}{36} & \frac{3}{36} & \frac{4}{36} & \frac{5}{36} & \frac{6}{36} & \frac{5}{36} & \frac{4}{36} & \frac{3}{36} & \frac{2}{36} & \frac{1}{36}\end{array}$

The frequency increases regularly from 2 to 7 and decreases further till I2. (Compare Table $\beta$.) This regular result (which may be verified by experiment ; see $\S$ I03) is brought about by chance! The variation of the facial values is included between two limits : 2 and I2.

If $n$ dice are cast the frequency and the facial value of all the possible events may be obtained by expanding $(a+b+c+d+$ $e+1)^{n}$.

The same method is applicable, of course, whatever may be the number of faces of the dice (tetrahedral, octahedral, dodecahedral, icosahedral dice, etc.) and the number of dice in each cast. A coin may be looked upon as being a die with two faces. In the experiments with coins ( $\$ .94$; see also $\S 98)$ all the possibilities are latent in the expression $(a+b)^{n}$ : this is a peculiar case of the general method expounded in the present paragraph.

§ 102.-TENTH EXAMPLE: ONE CAST WITH TWO DICE: DIVERSITY OF THE EFFECTS.-In the preceding example we consider a first series of six events (first die) which coincide with the facial values $I$ to 6 , and a second similar series

${ }^{1}$ In other words, the facial value 4 is obtained in three different ways, each of which has a frequency $\frac{3}{36}$. (See Table $\beta$.) 


\section{THE QUANTITATIVE METHOD IN BIOLOGY}

of six events (second die). In each of the thirty-six possible combinations one event of the first series coexists with one event of the second series. The two figures (facial values) of each combination may be looked upon as being two causes or forces, which may work together in order to produce a certain effect. This is easily realized if we suppose that each cast with two dice indicates, by the sum of both figures (facial value of the compound event), for instance, a number of kilograms which ought to be raised, of kilometres which ought to be travelled over, of shillings which ought to be paid, etc.

In the simplest case the effect (resultant) of the two coexisting causes is expressed by the sum of their facial values and may be calculated by means of a simple addition: in this way the thirty-six possible compound events are reduced to eleven ( $($ IOI), the frequencies of which are given in Table $\gamma$ (p. I27). Two coexisting causes (forces), however, may be associated into one resultant in an unlimited number of ways; the effect may depend not only on their sum, but, for instance, on their difference, their product, their quotient; on the diagonal of a rectangle the length and the breadth of which are indicated by the two coexisting figures; on the volume of a cone determined by these figures, etc.

Whatever may be the way in which two simple causes (the coexistence of which depends on chance) work together, all the possible effects and the frequency of each of them may be calculated a priori.

Starting from one cast with two dice (Table $\beta$, p. I27), I take the following four examples:-

EXAMPLE (A): By means of the thirty-six pairs of figures in Table $\beta$ we may construct thirty-six rectangles, the surface of each being the product of the figures of the corresponding pair. With reference to the resulting products, the thirty-six possibilities are reduced to eighteen, because a number of those products are realized in more than one way-viz.

\section{Surface I realized in I way}

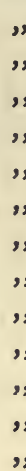

\section{2}

,

,

,

,

,

,

,

,

,

,

,

,

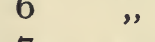

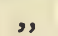

2 ways

Surface $I_{5}$ realized in 2 ways

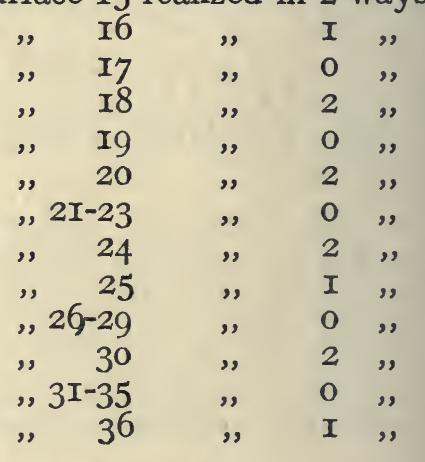


Between the limits I and 36 several irregular gaps exist; the distribution of the frequencies is also very irregular. It seems as if the above figures were accidental, independent of any rule whatever. They are, however, governed by definite rules, which are rules of chance. I have verified the above calculated figures by experiment. (See $\S$ I03.)

EXAMPLE (B): Let us suppose that the figures of each pair in Table $\beta$ (p. 127) express the length and the breadth of thirtysix leaves of a certain species, and let us calculate the ratio breadth: length of each of them (in each pair of figures in Table $\beta$ the first figure expresses the breadth). The following result is obtained :-

\section{TABle $\delta$ (Compare TABle $\beta$, p. I27)}

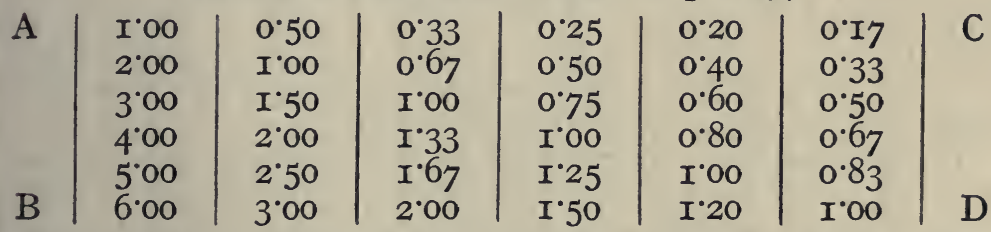

If the thirty-six figures in Table $\delta$ had been obtained from the measurement of thirty-six leaves, we might be tempted to bring them into the form of a variation curve (see p. 29 and $\S$ I08)-viz.

\begin{tabular}{|c|c|c|c|c|}
\hline$R$ & d & ength & $0-0 \cdot 99=I 5$ & $\mathrm{av}$ \\
\hline " & " & " & $I-I \cdot 99=I 2$ & ", \\
\hline ", & ", & " & $2-2 \cdot 99=4$ & $"$ \\
\hline " & $"$ & ", & $3-3 \cdot 99=2$ & \\
\hline " & " & $"$ & $4-4 \cdot 99=I$ & \\
\hline$"$ & " & ", & $5-5 \cdot 99=I$ & \\
\hline ", & ", & , & $6-$ & \\
\hline
\end{tabular}

A certain regularity is observed in this curve: it recalls certain unilateral curves which have been actually obtained and described. (See experimental verification in § I03.)

Remark about the preceding examples (dice): Starting from the thirty-six pairs of figures in Table $\beta$ (p. 127), and taking successively the sum (Table $\gamma, p .127$ ) the product (p. I28) and the quotient (Table $\delta, p$. 129) of the figures of each pair, we have obtained three different results : in two cases (sum and quotient) the distribution of the frequencies is regular or fairly regular ; in one case (product) it seems to be capricious. In the three cases, the cause of the observed facts is chance (combined cause). In each cast chance brings about certain reactions which are going on till a certain state of equilibrium exists and the corresponding values of the dice (dots) become visible. The two values (one of each die) which become visible at the same time are the expression of forces which may work together in various ways. In other words, forces which depend on the specific energy of the dice are brought as it were into action by chance. The system of two dice is a sort of machinery, through which chance is acting. In the three given examples the effects depend on the machinery, the cause CHANCE being exactly the same in each. 


\section{0} THE QUANTITATIVE METHOD IN BIOLOGY

EXAMPLE (C) : I suppose two dice the six faces of which are coloured with six pure spectral colours-viz.

$$
\begin{array}{lll}
\text { red }=r=I & \text { orange }=0=2 & \text { yellow }=y=3 \\
\text { green }=g=4 & \text { blue }=b=5 & \text { violet }=v=6
\end{array}
$$

The dice being cast, the thirty-six possible events (combinations of colours) may be found by means of the expression $(r+o+y+g+b+v)^{2}$ (compare Table $\beta$, p. I27)-viz. :

\section{TABLE $\epsilon$}

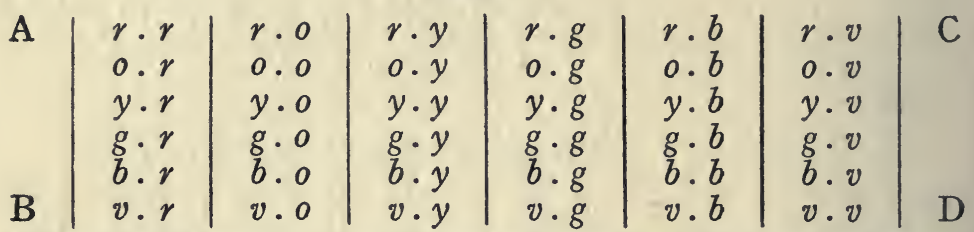

When both terms of each pair are added (in one or another way) the following colours are perceived:-

(I) The pairs in which both terms are alike give a pure spectral colour (see the diagonal row AD) ; this occurs six times.

(2) The pairs which consist of two complementary colours (red + green, yellow + blue, orange + violet) give white; this occurs six times $(r g, o v, y b, g r, v o, b y)$.

(3) The pairs which consist of different (not complementary) colours give a mixed colour; this occurs twenty-four times.

The respective frequencies are thus:

$$
\text { mixed : white : pure }=24: 6: 6=4: I: I
$$

(See experimental verification in $\S$ I03.)

EXAMPLE (D): I suppose that the figures on the faces of the first die represent a corresponding number of cubic centimetres of an acid liquid and that the figures of the second die represent in the same way an alkaline liquid, both liquids being prepared in such a way that I cubic centimetre of the first neutralizes exactly I cubic centimetre of the second. The two dice being cast, the thirty-six possible events are given in Table $\beta$ (p. I27). If thirty-six mixtures are made in the proportions (volumes) indicated by the figures of each pair, it is seen that:

(I) The pairs in which the first figure is predominant give an acid mixture ; this occurs fifteen times.

(2) The pairs in which the second figure is predominant give an alkaline mixture ; this happens also fifteen times.

(3) The pairs in which both figures are equal give a neutral mixture; this occurs six times.

The respective frequencies are thus:

$$
\text { acid : alkaline : neutral }=I_{5}: I_{5}: 6=5: 5: 2
$$

(See experimental verification in $\S$ I03.) 
MEASUREMENT OF VARIABLE PROPERTIES 131

§ 103.-ONE CAST WITH TWO DICE. EXPERIMENTAL VERIFICATION OF THE EXAMPLES IN §§ IOIro2. I have cast two dice 3600 times. Result :

TABle $\zeta$ (Compare TABle $\beta$, p. I27): 3600 CAStS with 2 Dice: OBSERVEd FREQUENCIES

\begin{tabular}{|c|c|c|c|c|c|c|c|}
\hline & Die II : I & Die II : 2 & Die II : 3 & Die II : 4 & Die II : 5 & Die II : 6 & Total \\
\hline 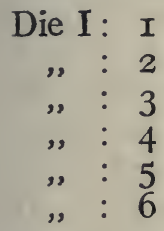 & $\begin{array}{r}97 \\
\text { I03 } \\
\text { II } 4 \\
96 \\
84 \\
\text { I07 }\end{array}$ & $\begin{array}{r}\text { I00 } \\
99 \\
90 \\
99 \\
87 \\
99\end{array}$ & $\begin{array}{r}\text { I20 } \\
90 \\
84 \\
96 \\
\text { I00 } \\
\text { I04 }\end{array}$ & $\begin{array}{r}\text { II } \\
98 \\
\text { II6 } \\
91 \\
\text { IO2 } \\
84\end{array}$ & $\begin{array}{r}\text { I02 } \\
98 \\
91 \\
\text { 102 } \\
\text { 108 } \\
\text { 103 }\end{array}$ & $\begin{array}{r}99 \\
96 \\
97 \\
\text { 102 } \\
\text { I05 } \\
\text { II8 }\end{array}$ & $\begin{array}{l}637 \\
584 \\
592 \\
586 \\
586 \\
615\end{array}$ \\
\hline Total & 601 & 574 & 594 & 610 & 604 & $6 \mathrm{I} 7$ & \\
\hline
\end{tabular}

According to calculation, the figure roo was expected in each of the thirty-six divisions. In twenty cases the difference between the observed and the calculated value does not exceed 0.04 of the latter. Although the number of casts is rather small (no less than thirty-six compound events are compared) the concordance is not unsatisfactory.

In the horizontal rows and in the vertical columns the deviations from the calculated figure (600) are small; in the most unfavourable case it reaches hardly 0.062 of the latter.

Looking upon the 3600 casts as being 7200 casts with one die, taking the figures of each die separately and calculating how many times even and uneven figures were obtained (equality is expected), we find :

$$
\begin{array}{rrr} 
& \text { Die I } & \text { Die II } \\
\text { even }(2,4,6 \text { dots) }: \text { I785 } & \text { I80I } \\
\text { uneven }(I, 3,5 \text { dots }): \text { I8I5 } & \text { I799 }
\end{array}
$$

Both dice together (expected $3600: 3600$ ) :

$$
\text { even : } 3586 \text { uneven: } 36 \mathrm{r}_{4}
$$

Deviation from the expected figures: 0.004. The observed ratio is even: uneven $=0.992: \mathrm{I}$.

Compare this very satisfactory result with the irregularity of the series of Ioo.

Compare the series of 100,500 and 3000 in $\S 93$ (p. II8) and the series of 3000 in $\S 95$ (p. I22).

When we take in each of the thirty-six compound events in Table $\beta$ the sum of the facial values of both dice, the thirty-six 


\section{THE QUANTITATIVE METHOD IN BIOLOGY}

events are reduced to eleven, the calculated relative frequencies of which are (according to Table $\gamma$, p. I27) :

$\begin{array}{lccccccc}\text { Facial values } & 2 & 3 & 4 & 5 & 6 & 7 & 8 \\ \text { Relative frequencies } & \mathrm{I} & 2 & 3 & 4 & 5 & 6 & 5 \\ \text { Facial values . } & 9 & 10 & 11 & 12 & & & \\ \text { Relative frequencies } & 4 & 3 & 2 & \text { I } & & & \end{array}$

From the figures in Table $\zeta$ (p. I3I) we may easily deduce the observed relative frequencies in our series of 3600 casts-viz.

\section{TABle $\eta: 3600$ Casts with 2 Dice}

$\begin{array}{lcccccc}\text { Facial values } & & \mathbf{2} & \mathbf{3} & \mathbf{4} & \mathbf{5} & \mathbf{6} \\ \text { Calculated frequencies } & : & \text { I00 } & 200 & 300 & 400 & 500 \\ \text { Observed " } & : & 97 & 203 & 333 & 395 & 467 \\ \text { Facial values " } & \mathbf{7} & \mathbf{8} & \mathbf{9} & 10 & 11 & 12 \\ \text { Calculated frequencies } & 600 & 500 & 400 & 300 & 200 & \text { 100 } \\ \text { Observed ", } & 603 & 477 & 405 & 294 & 208 & \text { II8 }\end{array}$

In Example (A) (§ I02, p. I28) the frequencies of the eighteen values of the rectangles constructed by means of the thirty-six

Table $\theta$ (Surface of Rectangles)

\begin{tabular}{|c|c|c|c|c|c|}
\hline \multirow[b]{2}{*}{ Surfaces } & \multicolumn{2}{|c|}{ Frequencies } & \multirow[b]{2}{*}{ Surfaces } & \multicolumn{2}{|c|}{ Frequencies } \\
\hline & Calculated & Observed & & Calculated & Observed \\
\hline$I$ & IOO & 97 & I9 & - & - \\
\hline 2 & 200 & 203 & 20 & 200 & I 85 \\
\hline 3 & 200 & 234 & $2 I$ & - & - \\
\hline 4 & 300 & $3 I 4$ & 22 & - & - \\
\hline 5 & 200 & I86 & 23 & 一 & - \\
\hline 6 & 400 & 386 & 24 & 200 & I86 \\
\hline 7 & - & - & 25 & IOO & I08 \\
\hline 8 & 200 & I97 & 26 & - & - \\
\hline 9 & IOO & 84 & 27 & - & - \\
\hline IO & 200 & I85 & 28 & - & - \\
\hline II & - & - & 29 & - & - \\
\hline I2 & 400 & 407 & 30 & 200 & 208 \\
\hline I3 & - & - & $3 I$ & - & - \\
\hline I4 & - & - & 32 & - & - \\
\hline I5 & 200 & IgI & 33 & - & - \\
\hline I6 & IOO & $9 I$ & 34 & - & 一 \\
\hline I7 & - & - & 35 & - & - \\
\hline I8 & 200 & $20 I$ & 36 & IOO & II 8 \\
\hline
\end{tabular}


pairs of facial values have been calculated a priori. From Table $\zeta$ (p. I3I) the observed frequencies may be deduced. In Table $\theta$ (p. I32) both series of relative frequencies are compared :

Although the above concordance is hardly satisfactory (because the casts are not numerous enough), it is sufficient to prove that the calculated figures, however capricious they seem to be, are the expression of really existing rules of chance.

In Example (B) (§ I02, p. I29) the first figure of each pair has been divided by the second. The thirty-six quotients have been brought into seven groups and the frequency of each group has been calculated. The calculated and the observed frequencies (deduced from Table $\zeta$ ) are compared in Table $\iota$ :

TABLE ‘ (Quotients)

\begin{tabular}{l|r|r}
\hline & \multicolumn{2}{|c}{ Frequencies } \\
\cline { 2 - 3 } Quotients & Calculated & Observed \\
\hline & & \\
\hline $0-099$ & I500 & I535 \\
I-I 99 & I200 & II72 \\
2-2 99 & 400 & 393 \\
$3-399$ & 200 & 2 I3 \\
4-4 99 & I00 & 96 \\
$5-599$ & I00 & 84 \\
6 & I00 & I07 \\
\hline
\end{tabular}

With regard to the colours mentioned in Example (C) (§ I02, p. I30) a comparison between the calculated and the observed values (deduced from Table $\zeta$ ) is given in Table $\kappa$ :

TABLE $\kappa$ (COLOURS)

\begin{tabular}{l|c|c}
\hline & \multicolumn{2}{|c}{ Frequencies } \\
\cline { 2 - 3 } & Calculated & Observed \\
\hline Mixed colour & & \\
Pure colour & 2400 & 2402 \\
White. & 600 & 597 \\
600 & 601 \\
\hline
\end{tabular}

Here the concordance is as satisfactory as possible.

In Example (D) ( $\$$ I02, p. I30) the frequencies of the three 


\section{THE QUANTITATIVE METHOD IN BIOLOGY}

reactions, acid, alkaline, neutral, have been calculated a priori. In Table $\lambda$ they are compared with the observed frequencies (deduced from Table $\zeta$ ) :

TABLE $\lambda$ (REACTIONS)

\begin{tabular}{l|r|r}
\hline & \multicolumn{2}{|c}{ Frequencies } \\
\cline { 2 - 3 } & Calculated & Observed \\
\hline Acid : & I500 & I468 \\
Alkaline & I500 & I535 \\
Neutral & 600 & 597 \\
\hline
\end{tabular}

§ 104.-ELEVENTH EXAMPLE: APPLICATION OF THE PRINCIPLES OF PROBABILITY (FREQUENCY) TO THE HEREDITARY TRANSMISSION OF PRIMORDIA IN MENDELIAN HYBRIDS.-In $\S 33$ (p. 32) I have given a short account of MENDEL'S experiments and principles. Let us now consider this subject from the standpoint of the rules of chance.

In one of his classic experiments with the edible pea MENDEL crossed a variety (subspecies) $\delta$ with round seeds (primordium $D$ ) with a variety $\rho$ with wrinkled seeds (primordium $R$ ). In this cross each egg or seed (hybrid of the $\mathrm{F}_{1}$ generation) is made by the union of a germ cell $D$ taken from the parent $\delta$ and containing a certain cause or factor corresponding to the primordium $D$, and a germ cell $R$ taken from $\rho$ and containing a factor corresponding to the property $R$. Both germ cells are, of course, taken at random ; their union is a compound event. One possibility exists (compare $\S 9 \mathrm{I})$ : the production of an egg or seed $D R$ in which the causes $D$ and $R$ meet each other. ${ }^{1}$ The coexistence of both factors brings about a reaction by which the dominant primordium (state of equilibrium) $D$ becomes visible, whereas $R$ is concealed or latent (compare Example (D), p. I30) : all the seeds are round.

From the seeds $D R\left(\mathrm{~F}_{1}\right.$ generation) plants $\mathrm{F}_{1}$ are raised which give birth to $\hat{\sigma}$ and $q$ germ cells. According to the principle of segregation, the germ cells are of two sorts, $D$ and $R$, both sorts being in equal number among the $\hat{\delta}$ just as among the $q$. The plants are fertilized with their own pollen, the $\hat{\delta}$ and the $q$ germ cells being united according to the rules of chance. If we suppose that, for instance, the $\hat{\delta}$ germ cells are $500 D+500 R$

1 It is supposed that the $\delta$ and the $\$$ germ cells are equivalent with regard to the hereditary transmission of the primordia. 
and the $q$ germ cells also $500 D+500 R$ in number, ${ }^{1}$ the $500 D$ $\hat{\sigma}$ being united at random with 500 \% , $250 \mathrm{D}$ of meet $250 \mathrm{D}$ ㅇ and $250 D$ o meet $250 R$, and in a similar way $250 R$ meet $250 D$ \& and $250 R \hat{\sigma}$ meet $250 R$ \% . Four sorts of compound events are equally possible, and therefore four sorts of seeds $\left(F_{2}\right.$ generation) are produced in equal numbers-viz.

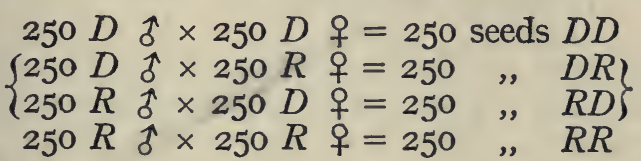

All the events under consideration are the same as if a very large number of white balls $D$ and an equal number of black balls $R$ were brought into an urn and taken one by one in I0oo series of two, the first ball of each series being $\hat{\delta}$ and the second ball $q$. All the possible events are expressed by the trinomial obtained by working out $(D+R)^{2}$, in which $D=R=\frac{1}{2}$ (see $\S 98$ ) - viz.

$$
(D+R)^{2}=D^{2}+2 D R+R^{2}
$$

This trinomial gives us complete information about the hereditary possibilities and visible properties of the Iooo seeds of the $\mathrm{F}_{2}$ generation and about the frequency of each sort of seeds (compare $\S 94,(I)-(7)$, p. I20) :

(I) Each letter represents a simple event; in other words, a germ cell ( $\hat{\sigma}$ or $q$ ) containing a factor $D$ or $R$.

(2) The numerical value of each letter is the expression of the frequency of the corresponding simple event ; in other words, of the relative number of existing germ cells of each sort ( $D=R=0.50$ of the total number).

(3) From the number of terms we know how many sorts of compound events are possible (the order of succession of the simple events being neglected) ${ }^{2}$; in other words, how many sorts of seeds are produced. Three sorts exist, but as often as a germ cell $D$ meets a germ cell $R$ the coexisting simple cvents (factors) produce a resultant by which the primordium $D$ becomes visible and $R$ latent. Therefore it is impossible to distinguish $D^{2}$ from $D R$ (or $R D$ ) and (with regard to the visible properties) only two sorts of seeds (round or wrinkled) exist. (Compare examples (C) and (D) in $\S$ I02, p. 130.)

(4) The numerical value of each term represents the frequency of the corresponding compound event; in other words, the relative number of seeds of the corresponding sort.

1 The figure 500 is taken arbitrarily instead of $x$.

2 This means the sexual difference being overlooked : the first simple event of each pair (first ball or germ cell) is supposed to be $\delta$, the second 8 . 


\section{THE QUANTITATIVE METHOD IN BIOLOGY}

With reference to the visible properties, two sorts of seeds exist (see (3)): round seeds represented by $D^{2}+2 D R\left(=\frac{1}{4}+\frac{2}{4}=\frac{3}{4}\right)$, and wrinkled seeds represented by $R^{2} \quad\left(=\frac{1}{4}\right)$. The ratio is round: wrinkled $=3: \mathrm{I}$.

In MENDEL'S experiment 7324 seeds were obtained; among them 5474 were round or roundish and I850 angular wrinkled. Therefrom the (observed) ratio 2.96 to I is deduced. ${ }^{1}$

With reference to the hereditary possibilities, two sorts of round seeds exist: a first sort represented by the term $D^{2}$ (numeric value $\frac{1}{4}$ ), which is able to produce round seeds only, and a second sort represented by the term $2 D R$ (value $\frac{2}{4}$ ), which contains the factors $D$ and $R$ and may therefore produce round and wrinkled seeds. Therefrom (among the plants raised from round seeds) the ratio plants yielding I sort of seeds: plants yielding 2 sorts of seeds $=\frac{1}{4}: \frac{2}{4}=\mathrm{I}: 2$.

In MENDEL'S experiment, among 565 plants which were raised from round seeds I93 yielded round seeds only; 372 , however, gave both round and wrinkled seeds. Therefrom the (observed) ratio $I: I .93$ is deduced. ${ }^{2}$

(5) The sum of the three coefficients $(I+2+I=4)$ expresses the number of sorts of possible compound events (sorts of seeds), the order of succession of the simple events (distinction between $\hat{\delta}$ and $q$ germ cells) being taken into account.

(6) The letters of each term indicate the constitution of the corresponding compound event ; in other words, the hereditary causes or factors contained in the corresponding sort of seeds. (See (4).)

(7) The coefficient of each term indicates in how many ways the corresponding compound event may be brought about; in other words, in how many ways the corresponding seeds may be produced. The seeds $D^{2}$ (coefficient I) and $R^{2}$ (coefficient I) are produced each in one way $(D \hat{\delta} \times D$ 우 $R \hat{\delta} \times R$ \%). The seeds $2 D R$ are produced in two ways $(D \hat{\delta} \times R+q$ or $D$ i $\times R$ ô).

Each coefficient indicates, moreover, how many sorts of seeds $\left(\mathrm{F}_{3}\right.$ generation) may be yielded by the corresponding plants. (See (4).) The plants raised from the seeds $D^{2}$ will produce one sort of germ cells $(D)$ and therefore one sort of seeds (just as the parent $\delta$ ). For the same reason the plants raised from the seeds $R^{2}$ will yield one sort of seeds (as the parent $\rho$ ). The plants raised from the seeds $2 D R$ will produce two sorts of germ cells and (with regard to the visible properties) two sorts of seeds, as the plants $(D R)$ of the $F_{1}$ generation-viz.

${ }^{1}$ See MENDEL, in BATESON, loc. cit., p. 326.

${ }^{2}$ Ibid., p. 329 . 


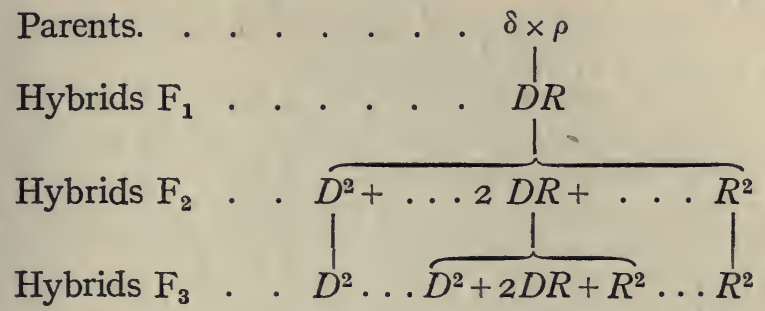

§ 105.-ELEVENTH EXAMPLE (continued).-In a second experiment MENDEL crossed a variety or subspecies (pea) a with round seeds $(D)$ and yellow albumen $(d)$ with a variety $b$ with wrinkled seeds $(R)$ and green albumen $(r)$. Here each egg (or seed) of the $\mathrm{F}_{1}$ generation is made by the union of a germ cell (taken from $a$ ) containing two factors $D$ and $d$ and a germ cell taken from $b$ and containing the factors $R$ and $r$. One possibility exists : the production of a seed $D d R r(D$ and $d$ dominant ; $R$ and $r$ recessive).

From the $\mathrm{F}_{1}$ seeds $D d R r$ plants are raised which give birth to four sorts of germ cells. With regard to the pair of primordia $D, R$, the germ cells are segregated into two groups $D$ and $R$, which are in equal numbers among the $\hat{\delta}$ and among the $q-$ let us suppose $250 D \hat{\delta}, 250 D$ o , 250 $R \hat{\delta}, 250 R$ o. With regard to the pair $d$ and $r$, a similar segregation occurs, independently of the first one, in such a way that each of the four above groups is segregated into two equally numerous groups. Eight groups of germ cells are obtained-viz.

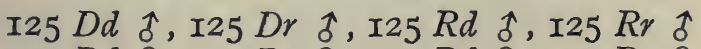

$$
\begin{aligned}
& \text { I25 } D d \text { \%, I25 } \mathrm{Dr} \text { \% , I25 Rd o , I25 Rr के }
\end{aligned}
$$

The germ cells of any given $\hat{\alpha}$ group being distributed at random among the four groups of $q$ germ cells, since the latter groups are equally numerous, the frequency of each of the four possible sorts of compound events is $\frac{1}{4}$. The $\hat{\sigma}$ groups being four in number and equally numerous, the frequency of each sort of $\frac{1}{\text { germ cells }}$ is $\frac{1}{4}$. Each of these 4 groups giving 4 compound events, the total number of possible compound events (seeds) is 16 , the frequency of each being $\frac{1}{4} \times \frac{1}{4}=\frac{1}{16}$-viz.

\begin{tabular}{|c|c|c|c|c|}
\hline & $D d \delta$ & $D r \delta$ & $R d \delta$ & $R r \delta$ \\
\hline$D d \uparrow$ & $D d . D d$ & $D r . D d$ & $R d . D d$ & $R r . D d$ \\
\hline Dr + & $D d . D r$ & $D r . D r$ & $R d . D r$ & $R r \cdot D r$ \\
\hline$R d$ i & $D d . R d$ & $D r \cdot R d$ & $R d \cdot R d$ & $R r \cdot R d$ \\
\hline$R r \stackrel{+}{q}$ & $D d \cdot R r$ & $D r \cdot R r$ & $R d . R r$ & $R r \cdot R r$ \\
\hline
\end{tabular}


Complete expression of the events under consideration (seeds) may be obtained in the following way:-

Each pair of primordia (factors) is taken separately. With regard to the first pair, the four possible events are obtained by expanding $(D+R)^{2}$. (See $\S$ I04.) With regard to the second pair, the four possible events are obtained by expanding $(d+r)^{2}$. Since the four compound events of both groups are combined two by two, the sixteen possible combinations are obtained by multiplying $(D+R)^{2}$ with $(d+r)^{2}$ (see $\left.\S \S 94,95\right)-v i z$.

$$
\begin{aligned}
& (D+R)^{2} \times(d+r)^{2}= \\
D^{2} d^{2}+2 D R d^{2}+4 D d R & = \\
D^{2} \gamma^{2}+2 D^{2} d \gamma+ & d^{2} R^{2}+2 D R r^{2}+ \\
R^{2} r^{2}+2 d r R^{2} &
\end{aligned}
$$

In this way, the difference between $\delta$ and $q$ being neglected, the $I 6$ sorts of seeds are reduced to 9 sorts. (Compare § 95.)

Remark: The 16 possible events (sorts of seeds) are comparable to the 16 events which may take place when two dice with four faces, for instance, two regular tetrahedra (triangular pyramids) I. and II., are cast successively, I. being $\delta$ and II. being $\&$, the faces of I. being marked $D d, D r, R d, R r$, the faces of II. bearing the same marks. According to $\S$ IOI, the possible events are calculated a priori by expanding $(D d+D r+R d+R r)^{2}{ }^{1}$ If both tetrahedra are cast simultaneously, the distinction between I. and II. (sex) disappears and the possible events are 9 in number. The result is the same as with the first method. ${ }^{2}$

From a biological standpoint the example of the tetrahedra contains perhaps (? ?) something more than a method of calculation. In that example I suppose that only two sorts of germ cells exist, one $\delta$ sort and one $q$ sort, each sort containing all the primordia of both parents and being thus completely hybrid. According to the classic hypothesis, eight sorts of germ cells (four of sorts and four $\$$ sorts) exist. On the other hand, we know (see $\S 38$ ) that a combination of properties may be segregated into primordia in several ways without dissociation among the germ cells. In the above example of the tetrahedra we may find perhaps a starting-point for a new explanation of the Mendelian facts. . ?

One feels that there is in the Mendelian hypothesis of segregation, however ingenious and useful it may be, something artificial which is rather inconsistent with the ways of nature.

From the nine terms of the above polynomial (p. 138) we obtain the same information as from the trinomial in the first experiment. It is useless to repeat here the explanations given on p. I20, (I)-(7). I limit myself to the following examples:-

(Compare (3), p. I20.) From the number of terms we know how many sorts of seeds are found in the $\mathrm{F}_{2}$ generation : nine

${ }^{1}$ Remark : The faces $D d, D r, R d, R r$ represent compound events, the simple events $D, R, d, r$ corresponding to causes or factors $(\S 97)$. The compound events are combined in their turn two by two when the tetrahedra are cast.

2 This may be easily demonstrated in the following way:-

$$
\begin{aligned}
(D+R)^{2} \times(d+r)^{2} & =[(D+R)(d+r)]^{2} \\
{[(D+R)(d+r)]^{2} } & =(D d+D r+R d+R r)^{2}
\end{aligned}
$$


sorts exist, but as often as a germ cell $D$ meets an $R$, the property $R$ is latent; and in a similar way $r$ is latent when $d$ meets $r$. Therefore the 9 sorts are reduced to 4 -viz.

The seeds $D^{2} d^{2}$ are $D d$ (round, yellow)

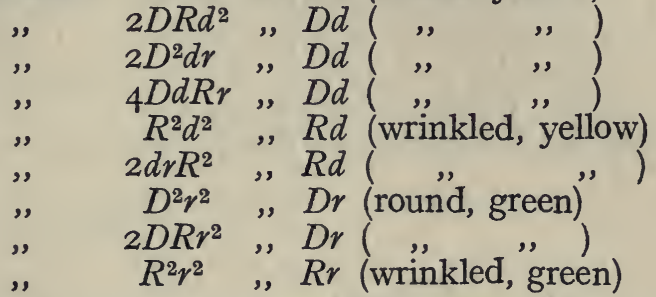

(Compare (4), p. I20.) The numerical value of each term is the frequency of the corresponding sort of seeds-viz.

Round, yellow $(D d): \frac{1+2+2+4}{16}=\frac{9}{16}$
Wrinkled, yellow $(R d): \frac{1+2}{16}=\frac{\frac{3}{16}}{16}$
Round, green $(D r): \frac{1+2}{16}=\frac{3}{16}$
Wrinkled, green $(R r): \frac{1}{16}=\frac{1}{16}$

or $9: 3: 3:$ I (relative frequencies).

In MENDEL'S experiment (556 seeds yielded by I5 $^{F_{1}}$ plants) the figures were ${ }^{1}$ :

$R r$ (wrinkled, green)

$\operatorname{Dr}$ (round, green)

$R d$ (wrinkled, yellow)

$D d$ (round, yellow)

\begin{tabular}{|c|c} 
Observed & Calculated $^{2}$ \\
\hline 32 seeds & $556 \times \frac{1}{16}=35$ seeds \\
IO8 ", & $556 \times \frac{3}{16}=$ IO4 ", \\
IOI ", & $556 \times \frac{3}{16}=$ IO 4, \\
3I5 ", & $556 \times \frac{9}{16}=3$ I3 ",
\end{tabular}

Considering the four above groups with reference to their hereditary possibilities, we discern:-

Among the plants raised from round, yellow seeds:

(a) Plants raised from seeds $D^{2} d^{2}$, which are expected to yield I sort of seeds (round, yellow); this is expressed by the coefficient of the term, which is $I$.

$(\beta)$ Plants raised from $2 D R d^{2}$; coefficient $2 ; 2$ sorts of seeds (round, yellow; wrinkled, yellow).

( $\gamma$ ) Plants raised from $2 D^{2} d r$; coefficient $2 ; 2$ sorts of seeds (round, yellow; round, green).

( $\delta)$ Plants raised from $4 D R d r$; coefficient $4 ; 4$ sorts of seeds (round, yellow; round, green; wrinkled, yellow; wrinkled, green).

1 MENDEL, in BATESON, loc. cit., p. 333. Compare the method of calculation adopted by Mendel and the method followed here.

2 These experimental results are very satisfactory. Compare the figures obtained by tossing 500 times one coin, p. I19. 


\section{THE QUANTITATIVE METHOD IN BIOLOGY}

Since $30 I$ fertile plants were raised from 315 seeds, the numerical values of the four terms under consideration no longer represent the frequencies of the four groups in respect of the total number of seeds (which is 556), but their relative frequencies in respect of the number of plants, which is 30r. The numerical values are $a=\frac{1}{16} ; \beta=\frac{2}{16} ; \gamma=\frac{2}{16}$, and $\delta=\frac{4}{16}$. The relative frequencies are $I, 2,2,4$; the expected figures are $301 \times \frac{1}{9} ; 301 \times \frac{2}{9} ; 301 \times \frac{2}{9}$, and $301 \times \frac{4}{9}$.

In MENDEL'S experiment the figures were ${ }^{\mathbf{1}}$ :

(a) Plants bearing $D d$ seeds

( $\beta)$
$D d$ and $R \dot{d}$ seeds $D d$ and $D r$ seeds $D d, D r, R d$ and $R r$ seeds

\begin{tabular}{|r|c} 
Observed & Calculated \\
\hline 38 & $301 \times \frac{1}{9}=33$ \\
60 & $301 \times \frac{2}{9}=67$ \\
65 & $301 \times \frac{2}{9}=67$ \\
I38 & $301 \times \frac{4}{9}=134$
\end{tabular}

Among the plants raised from wrinkled, yellow seeds we can distinguish :

( $\epsilon$ ) plants raised from seeds $R^{2} d^{2}$; coefficient I; I sort of seeds (wrinkled, yellow).

(ङ) Plants raised from $2 d r R^{2}$; coefficient $2 ; 2$ sorts of seeds (wrinkled, yellow; wrinkled, green).

From IoI wrinkled, yellow seeds 96 fertile plants were obtained. The numerical values of the terms are $\epsilon=\frac{1}{16}, \quad \xi=\frac{2}{16}$. The relative frequencies are therefore $\mathrm{I}, 2$; the expected figures are $96 \times \frac{1}{3}$ and $96 \times \frac{2}{3}$.

In MENDEL'S experiment the figures were:

(€) Plants bearing $R d$ seeds . . 28

(ङ) $\quad$ " $\quad R d$ and $R r$ seeds

\begin{tabular}{|c|c} 
Observed & Calculated \\
\hline 28 & $\begin{array}{c}96 \times \frac{1}{3}=32 \\
96 \times \frac{2}{3}=64\end{array}$
\end{tabular}

Among the plants raised from round, green seeds we can distinguish :

( $\eta$ ) Plants raised from $D^{2} \gamma^{2}$; coefficient I ; I sort of seeds (round, green).

$(\theta)$ Plants raised from $2 D R r^{2}$; coefficient $2 ; 2$ sorts of seeds (round, green ; wrinkled, green).

From 108 round, green seeds 102 fertile plants were obtained. The numerical values of the terms are $\eta=\frac{1}{18}, \theta=\frac{2}{16}$. The relative frequencies are therefore $I, 2$; the expected figures are $102 \times \frac{1}{3}$ and $102 \times \frac{2}{3}$.

${ }^{1}$ Compare MENDEL'S calculation in BATESON, loc. cit., p. 334 . 
In MENDEL'S experiment the figures were:

\begin{tabular}{cc|c|c}
$(\eta)$ & Plants bearing $D r$ seeds . & 35 & I02 $\times \frac{1}{3}=34$ \\
$(\theta)$ & ", $D r$ and $R r$ seeds & 67 & I02 $\times \frac{2}{3}=68$
\end{tabular}

The plants raised from rerinkled green seeds-that is to say, from (c) $R^{2} r^{2}$-were expected to bear one sort of seeds (wrinkled, green).

In MENDEL'S experiment 30 fertile plants raised from 32 seeds yielded seeds $R r^{1}{ }^{1}$

$\S$ 106.-ELEVENTH EXAMPLE (continued).-In a third experiment MENDEL crossed two varieties (subspecies) of the edible pea differing in three primordia-viz.

\section{Parent a}

Seed round $(A)$

Albumen yellow $(B)$

Seed-coat grey-brown $(C)$
Parent $\beta$

Seed wrinkled $(a)$

Albumen green $(b)$

Seed-coat white $(c)$

The seeds (first hybrid generation $\mathrm{F}_{1}$ ) are $A B C$ as the parent a, the primordia $A, B, C$ being dominant.

The plants raised from these seeds yielded (by self-fertilization) numerous sorts of seeds. In order to calculate all the possible compound events (sorts of seeds), the method indicated for the second experiment (p. I38) may be followed-viz.

For the three pairs of primordia all the possible combinations of the germ cells are obtained by working out-

$$
(A+a)^{2} \times(B+b)^{2} \times(C+c)^{2}
$$

1 The plants raised from seeds $R r$ yield in their turn seeds $R r$ and so on in all the subsequent generations. All these plants are similar to the parent $b$. In many crosses between two species $a$ and $b$ differing in two pairs of properties, the recessive property $R$ belongs to $a$ and $r$ belongs to $b$. In all such cases the plants $R r$ are characterized by a NEW combination of two properties which do not coexist in any of the parental species. Since the new combination $R \boldsymbol{r}$ is transmitted without any variation to all the successive generations it may be said that a new specific form (constant hybrid) has been produced. A similar remark is applicable to the combination $a b c$ in $\$ 106$ and to any combination of recessive properties.

It may be recalled that a new specific form may be produced in four different ways - viz.

(I) By a saltation (mutation) which is a direct result of a change in the conditions of life (\$\$ $8 \mathrm{~A}$ and 9$)$.

(2) By a saltation which is an indirect result of a change in the conditions of life $(\S 9)$.

(3) By a cross between two specific forms, the new form being interposed between the parental species $\$ 35$ ).

(4) By a cross between two specific forms, the new form being characterized by a new combination of properties. 


\section{THE QUANTITATIVE METHOD IN BIOLOGY}

the value (frequency) of each letter (simple event) being $\frac{1}{2}$. In this way 27 terms (sorts of seeds) are obtained (see below).

Remark (compare Remark, p. 138) : According to the principle of segregation, 8 sorts of germ cells of each sex are produced by the plants raised from the $\mathrm{F}_{1}$ seeds-viz. $A B C, a B C, A b C, A B c, A b c, a B c, a b C$, $a b c$.

The $\delta$ germ cells being united at random with the \& germ cells, the result is the same as if two dice I. and II. with eight faces each (for instance, two regular octahedra) were cast successively, the 8 sorts of germ cells being marked on the faces of each die (Die I. being $\delta$ and Die II. being \&). All the possible events are found by working out ${ }^{1}$

$$
(A B C+a B C+A b C+A B c+A b c+a B c+a b C+a b c)^{2}
$$

the value (frequency) of each term being $\left(\frac{1}{2}\right)^{3}=\frac{1}{8}$.

We obtain in this way 64 terms, which are reduced to 27. The latter are the same as those obtained by working out

$$
(A+a)^{2} \times(B+b)^{2} \times(C+c)^{2}
$$

\begin{tabular}{|c|c|c|c|}
\hline \multirow{5}{*}{$\begin{array}{l}A^{2} B^{2} C^{2} \\
A^{2} B^{2} c^{2} \\
A^{2} b^{2} C^{2} \\
a^{2} B^{2} C^{2} \\
A^{2} b^{2} c^{2} \\
a^{2} B^{2} c^{2} \\
a^{2} b^{2} C^{2} \\
a^{2} b^{2} c^{2}\end{array}$} & \multirow{6}{*}{$\begin{array}{l}2 A a B^{2} C^{2} \\
2 A^{2} B b C^{2} \\
2 A^{2} B^{2} C c \\
2 A a B^{2} c^{2} \\
2 A^{2} B b c^{2} \\
2 A a b^{2} C^{2} \\
2 A^{2} b^{2} C c \\
2 a^{2} B b C^{2} \\
2 a^{2} B^{2} C c \\
2 A a b^{2} c^{2} \\
2 a^{2} B b c^{2} \\
2 a^{2} b^{2} C c\end{array}$} & \multirow{4}{*}{$\begin{array}{l}4 A a B b C^{2} \\
4 A a B^{2} C c \\
4 A^{2} B b C c \\
4 A a B b c^{2} \\
4 A a b^{2} C c \\
4 a^{2} B b C c\end{array}$} & \multirow{5}{*}{$\frac{8 A a B b C c}{\text { value }: \frac{8}{64}}$} \\
\hline & & & \\
\hline & & & \\
\hline & & & \\
\hline & & \multirow{2}{*}{\multicolumn{2}{|c|}{ 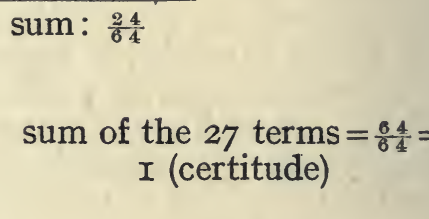 }} \\
\hline \multirow[t]{2}{*}{ sum: $\frac{8}{64}$} & & & \\
\hline & & & \\
\hline
\end{tabular}

The 27 terms are :

From these 27 terms $\left(\mathrm{F}_{2}\right.$ seeds) we may draw the same information as from the 3 terms in the first experiment ((I)- $(7)$, p. I20) and from the 9 terms in the second experiment (p. I38). By analysing the 27 terms successively the reader may easily find in each of them the information alluded to. Therefore I limit myself to the following remarks :-

FIRST REMARK: Since the factors $A, B$ and $C$ are dominant, in all the terms in which one of them coexists with the recessive of the same pair, the recessive property is latent.

1 Each octahedral die represents a germ cell ( $\delta$ or $\$$ ) in which the 8 combinations of all the factors of both parents $\alpha$ and $\beta$, and thus the factors themselves, coexist. In this way, instead of 16 sorts of germ cells ( 8 of each sex), only 2 sorts (I sort of each sex) are needed. Compare the tetrahedra, p. I38, Remark.

2 This may be easily demonstrated in the following way :-

$(A+a)^{2} \times(B+b)^{2} \times(C+c)^{2}=[(A+a)(B+b)(C+c)]^{2}$

$[(A+a)(B+b)(C+c)]^{2}=(A B C+a B C+A b C+A B c+A b c+a B c+a b C+a b c)^{2}$ 
Therefore the 27 sorts of seeds are reduced to 8 sorts with regard to their visible properties ${ }^{1}$ - viz.

I. The seeds $A^{2} B^{2} C^{2}, 2 A a B^{2} C^{2}, 2 A^{2} B b C^{2}, 2 A^{2} B^{2} C c, 4 A^{2} B b C c$, $4 A a B^{2} C c, 4 A a B b C^{2}, 8 A a B b C c$ are $A B C$ (round, albumen yellow, coat grey-brown). The sum of the frequencies (numerical values of the 9 terms, the value of each letter being $\frac{1}{2}$ ) is $27: 64$.

II. The seeds $a^{2} B^{2} C^{2}, 2 a^{2} B b C^{2}, 2 a^{2} B^{2} C c, 4 a^{2} B b C c$ are $a B C$ (wrinkled, albumen yellow, coat grey-brown); frequency $9: 64$.

III. The seeds $A^{2} b^{2} C^{2}, 2 A a b^{2} C^{2}, 2 A^{2} b^{2} C c, 4 A a b^{2} C c$ are $A b C$ (round, albumen green, coat grey-brown) ; frequency $9: 64$.

IV. The seeds $A^{2} B^{2} c^{2}, 2 A a B^{2} c^{2}, 2 A^{2} B b c^{2}, 4 A a B b c^{2}$ are $A B c$ (round, albumen yellow, coat white) ; frequency $9: 64$.

$\mathrm{V}$. The seeds $A^{2} b^{2} c^{2}, 2 A a b^{2} c^{2}$ are $A b c$ (round, albumen green, coat white) ; frequency $3: 64$.

VI. The seeds $a^{2} B^{2} c^{2}, 2 a^{2} B b c^{2}$ are $a B c$ (wrinkled, albumen yellow, coat white) ; frequency $3: 64$.

VII. The seeds $a^{2} b^{2} C^{2}, 2 a^{2} b^{2} C c$ are $a b C$ (wrinkled, albumen green, coat grey-brown); frequency $3: 64$.

VIII. The seeds $a^{2} b^{2} c^{2}$ are $a b c$ (wrinkled, albumen green, coat white) ; frequency $I: 64 .^{2}$

The relative frequencies of the 8 sorts of seeds are thus: 27, 9, 9, 9, 3, 3, 3, I. (Compare p.r39 . Compare also the proportions, p. I30.)

These curious relations are calculated a priori; they have been verified by MENDEL. In his third experiment, from $24 \mathrm{~F}_{1}$ plants 687 seeds were obtained in all. From these in the following year 639 fertile plants were raised, and there were among them (according to the seeds they yielded)-

\begin{tabular}{|c|c|c|c|c|}
\hline & & & Observed & Calculated \\
\hline lants raised from & seeds $A B C$ & & 269 & $639 \times \frac{27}{64}=270$ \\
\hline ", & $A B c$ & & 981 ล & $639 \times \frac{9}{84}=90$ \\
\hline , & $A b C$ & & $86\}$ & $639 \times \frac{9}{64}=90$ \\
\hline ", & $a B C$ & & $88)^{\pi}$ & $639 \times \frac{9}{64}=90$ \\
\hline , & $A b c$ & . & 27) 욤 & $639 \times \frac{3}{34}=30$ \\
\hline , & $a B c$ & & 34 듕 & $639 \times \frac{3}{64}=30$ \\
\hline , & $a b c$ & & $30 \int$ & $639 \times \frac{3}{84}=30$ \\
\hline " & $a b c$ & . & 7 & $639 \times \frac{1}{64}=10$ \\
\hline
\end{tabular}

${ }^{1}$ These 8 sorts are indicated by the 8 terms the coefficient of which is $\mathrm{r}$. In those terms $A$ and $a$ cannot exist together, nor $B$ and $b$, nor $C$ and $c:$ the number of sorts of seeds is equal to the number of terms which are free from products $(A a, B b, C c)$ and composed only of squares.

${ }_{2}$ The seeds in which 3 dominants exist (Group I.) have the frequency $27: 64$. Each of the groups II., III. and IV. in which 2 dominants exist has the frequency $9: 64$. Each of the groups V., VI. and VII. with I dominant has the frequency $3: 64$. Group VIII., without any dominant, has the frequency $I: 64$. The relative frequencies are:

$\begin{array}{lllll}\text { Dominants : : } & 0 & \text { I } & 2 & 3 \\ \text { Frequency } & \text { I } & 3^{1} & 3^{2} & 3^{3}\end{array}$




\section{THE QUANTITATIVE METHOD IN BIOLOGY}

SECOND REMARK: The number of sorts of seeds $\left(F_{3}\right.$ generation) which the plants raised from any of the 27 groups may bear is indicated by the coefficient of the corresponding term. According to this-

Each of the 8 terms with coefficient I will yield I sort of seeds; total frequency $8: 64$.

Each of the I2 terms with coefficient 2 will yield 2 sorts of seeds ; total frequency $24: 64$.

Each of the 6 terms with coefficient 4 will yield 4 sorts of seeds; total frequency $24: 64$.

The term with coefficient 8 will yield 8 sorts of seeds; frequency $8: 64$.

In MENDEL'S experiment $639 \mathrm{~F}_{2}$ plants fruited and there were among them-

Plants yielding I sort of seeds . 2 sorts of seeds.

",

"

$"$ 8

\begin{tabular}{|c|c|}
\hline Observed & Calculated \\
\hline 77 & $639 \times \frac{8}{64}=80$ \\
\hline 228 & $639 \times \frac{24}{64}=240$ \\
\hline 256 & $639 \times \frac{24}{64}=240$ \\
\hline 88 & $639 \times \frac{8}{64}=80$ \\
\hline
\end{tabular}

THIRD REMARK : The coefficient of each term indicates in how many ways the corresponding seeds have been produced. Examples: The seeds $A^{2} B^{2} C^{2}$ are produced in one way: $A B C \uparrow \times A B C$ o $\$$. The seeds $4 A a B b C^{2}$ are produced in four ways: $A B C \hat{\delta} \times a b C$ ㅇ, $a b C \hat{\jmath} \times A B C$ 으, $A b C \hat{\jmath} \times a B C$ 우, $a B C$ กิ $\times A b C$ ㅇ. Etc.

§ 10\%.-THE METHOD OF QUETELET FOR THE MEASUREMENT OF THE VARIABLE PROPERTIES OF LIVING BEINGS. MEAN VALUE.-In $\$ 32$ I have briefly expounded the method initiated by QUETELET for the measurement of the variable properties of animals and plants.

This method is based upon the principle that the variation of a given primordium within the limits of a given species depends on chance (variable combined cause) and is therefore governed by the rules of probability (frequency). QUETELET and his followers measure a given primordium in a large number of specimens of the same species ( $\$ 32)$; they construct the variation curve and calculate the mean value.

I think that the importance of the latter has been exaggerated. Before I expatiate on this subject I am going to expound briefly, by means of examples, the way in which the method of QUETELET is used for the measurement of the properties of inanimate objects - in general, for the determination of magnitudes (constants, etc.), in inorganic nature. 
MEASUREMENT OF VARIABLE PROPERTIES 145

§ 108.-TWELFTH EXAMPLE: THE MEASUREMENT OF THE DENSITY OF A SOLID BODY a.-In order to obtain the required value as exactly as possible, the density of a (for instance, a metal) is determined a number of times. We observe (this is a matter of fact) that the successively obtained values are more or less different from each other. We find, for instance, the following figures, each of them being obtained several times :-

$4^{\cdot 84}, 4^{\cdot 85}, 4^{\cdot 86}, 4^{\cdot 87}, 4^{\cdot 88}, 4^{\cdot 89}, 4^{\circ} 90,4^{\circ} 9$ I, $4^{\circ} 92,4^{\circ} 93,4^{\circ} 94,4^{\circ} 95$, $4^{\circ} 96,4^{\circ} 97,4^{\circ} 98,4^{\circ} 99,5^{\circ} 00,5^{\circ} 01,5^{\circ} 02,5^{\circ} 03,5^{\circ} 04,5^{\circ} 05,5^{\circ} 06,5^{\circ} 07$, $5^{\circ} 08,5^{\circ} \mathrm{O}, 5^{\circ} \mathrm{IO}, 5^{\circ} \mathrm{II}, 5^{\circ} \mathrm{I} 2,5^{\circ} \mathrm{I} 3,5^{\circ} \mathrm{I} 4,5^{\circ} \mathrm{I} 5,5^{\circ} \mathrm{I} 6$

Which is in reality the density of $a$ ? In order to answer this question we add up all the figures and divide the sum by the number of observations: the quotient is the arithmetic mean or mean value. I suppose that the mean value is $5^{\circ} 00$ : this figure is, among all the observed figures, the most probable value of the density of $a$.

Most of the observed figures deviate from the mean, because of errors committed in the determinations. These errors depend on numerous causes (forces, factors), certain of which tend to produce a positive error, whereas others result in a negative one. In each determination these causes (or certain of them) act simultaneously: their combination (resultant) brings about a more or less important positive or negative error. This is expressed by saying that each error depends on chance. ${ }^{1}$

We may construct in the following way the curve of errors, or, using biological language, the variation curve of the measurements. The distance between the extremes $\left(4^{\circ} 84\right.$ and $\left.5^{\circ} 16\right)$ is divided arbitrarily into a certain number of equal intervals, for instance, II-viz.

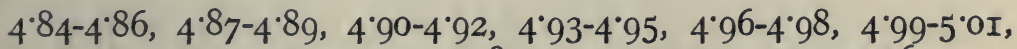
$5^{\circ} \mathrm{O} 2-5^{\circ} 04,5^{\circ} 05^{-5} 5^{\circ} 07,5^{\circ} 08-5^{\circ}$ IO, $5^{\circ}$ II $-5^{\circ} 13,5^{\circ} 14-5^{\cdot} 16$

The observed figures included in each interval are counted. A horizontal line is divided into II equal segments, each of which corresponds to an interval. From the middle of each segment a vertical ordinate is erected, proportionate to the number of figures (measurements) in the corresponding interval. The extremities of the ordinates are joined by straight lines (Fig. I8). The curve of errors obtained in this way is a diagrammatic representation of facts, without any calculation.

We SEE that the observations (measurements) which deviate the least from the mean (interval VI.) are the most numerous :

${ }^{1}$ Compare with the second example (one toss with one coin), $\$ 92$, p. 116. 


\section{THE QUANTITATIVE METHOD IN BIOLOGY}

the central ordinate $m^{1}$ is, indeed, the highest one : it corresponds to the so-called summit or hump of the curve. The successive ordinates become shorter in proportion as they are farther from the centre. In other words, the positive as well as the negative errors (deviations from the mean value) become less numerous in proportion as they are greater. The curve is symmetrical: the positive and negative errors are equally numerous.

Each error, considered in isolation, depends on chance, and may be looked upon as being accidental. When we consider,

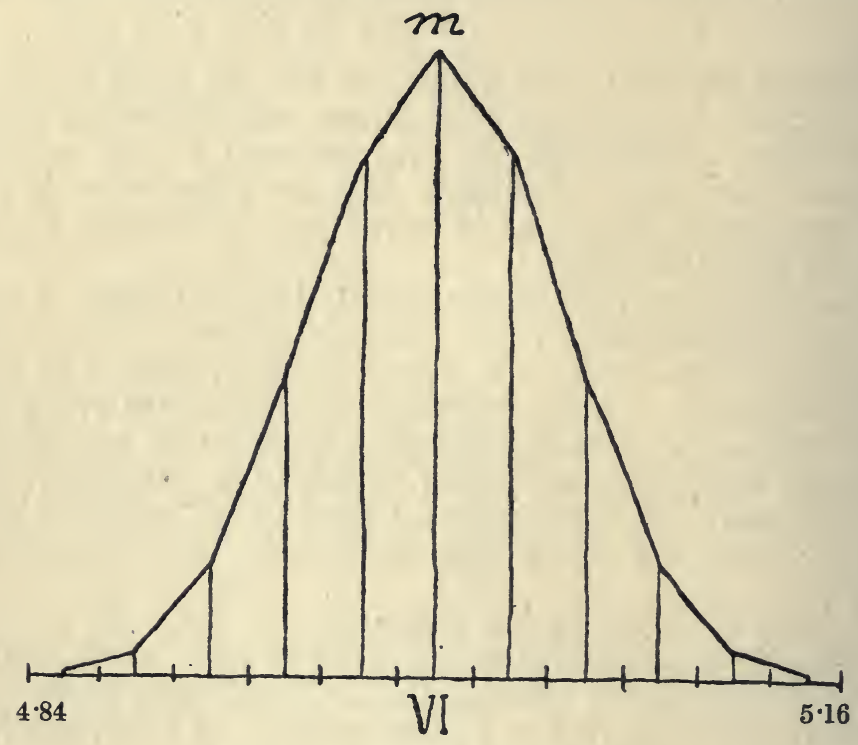

FIG. 18.-Curve of errors $(a+b)^{10}$

however, all the errors at the same time as a whole, we see that their distribution (among the eleven groups) is governed by a definite rule. According to experience, the length of the successive ordinates is approximately proportionate to the numerical values of the terms obtained by expanding $(a+b)^{n}$, in which $a=b=\frac{1}{2}$. If we suppose $n=$ Io, we obtain II terms-viz.

$$
\begin{gathered}
a^{10}+\text { IO } a^{9} b+45 a^{8} b^{2}+\mathrm{I} 20 a^{7} b^{3}+2 \mathrm{IO} a^{6} b^{4}+252 a^{5} b^{5}+ \\
\text { 2IO } a^{4} b^{6}+\mathrm{I} 20 a^{3} b^{7}+45 a^{2} b^{8}+10 a b^{9}+b^{10}
\end{gathered}
$$

The numerical value of each term is given by its coefficient divided by $2^{10}=$ I024, thus $\frac{1}{1024}, \frac{10}{1024}$, etc.

1 The length of the central ordinate represents the number of measurements from $4^{\circ} 99$ to $5^{\circ}$ O I. The mean is $5^{\circ} 00$. 
If we suppose that the number of observations has been 10,240 (or in general $x$ ), we would expect to find approximately -

$$
\begin{aligned}
& \text { In interval I.: Io figures }\left(=x \times \frac{1}{1024}\right) \\
& \text { "II. : I00 " }\left(=x \times \frac{10}{1024}\right) \\
& \text { " III. : } 450 \quad, \quad\left(=x \times \frac{45}{1024}\right)
\end{aligned}
$$

etc., the approximation being more and more close the greater the number of observations $(x) .^{1}$

REMARKS: (I) The above polynomial represents all the possible events and their frequencies when Io coins (dice with two faces) are tossed ( $a=$ head, $b=$ tail). (See $\S 96$.

(2) The II terms of the above polynomial represent the relative frequencies of the errors (deviations) in each of the II groups, but they are independent of the absolute values of the measurements.

(3) In this example two groups of causes (forces, factors) have an influence upon each determination of the density of $a$.

In the first group I put one cause or force, which is the density we want to discover. This density is a definite, invariable property of $a$. It is an invariable force, a constant. The mean value is the measure of this constant.

The second group includes a number of accidental causes (chance), the combination (resultant) of which varies continually and produces in each determination an error (or deviation). Each observed figure is the constant \pm an error.

(4) Here the importance of the mean value is preponderant : it represents a definite something the existence of which is independent of chance. The extreme errors are of very little importance because they are indefinite. When the operator is skilled and disposes of good instruments, the extreme errors come nearer the mean and nearer each other than when the operator is inexperienced and the instruments mediocre. And, moreover, the possibility always exists that, in a new determination, an error may be committed greater than the greatest one previously committed. In other words, in the given example, the range of deviation is unlimited. ${ }^{2}$ We will see below that this is not always the case.

1 In reality, the arithmetical method followed here is not quite accurate : a curve of errors is governed by a more complicated mathematical expression deduced by GAUSS. The series of values (terms) obtained by expanding $(a+b)^{n}$ approximates more and more closely to the probability curve of Gauss the greater the value of $n$. If $n=20$ the error is not very important, and for a greater value of $n$ the error (difference between the arithmetical curve and the curve of Gauss) becomes rapidly smaller and smaller. I take $n=$ Io (which is too small) in order to avoid an exaggerated number of terms. The arithmetical method is sufficient for the object of the present work.

This finds its expression in the curve of Gauss. 


\section{THE QUANTITATIVE METHOD IN BIOLOGY}

§109.-THIRTEENTH EXAMPLE: THE MEASUREMENT OF A GIVEN WEIGHT OF A CERTAIN SUBSTANCE. -I want a certain number of portions of sand, each weighing 200 gr. A first operator $A$, inexperienced and disposing of a mediocre balance, is trusted with the necessary work. A weight of $200 \mathrm{gr}$. being placed in one of the scales of his balance, he weighs successively a Ist, a 2nd . . . a $x$ th portion of sand, each portion being kept separately. A second skilled operator $B$, disposing of a good balance, is trusted with the verification of the work of $A$. Let us suppose that $B$ does not commit any error. He will find that almost all or all the portions of sand weigh more or less than $200 \mathrm{gr}$. The figures observed by $B$ are comparable to those observed in the preceding example (density, § 108). If we construct the curve of the errors (variation curve of the portions of sand) committed by $A$ and discovered by $B$, we see that they are distributed according to the rule expressed by $(a+b)^{n}$, just as in the preceding example, the mean value being (approximately) $200 \mathrm{gr}$. (and the extreme errors being indefinite).

Here again we discern :

(I) One simple cause, which is measured by the mean (200 gr.).

(2) Chance, which is variable and brings about errors (deviations).

From a mathematical standpoint both examples ( $\S$ ro8 and I09) are identical. For the naturalist, however, they are dissimilar because the mean value does not represent the same thing in both.

In the first example we have discovered a certain property (density) of $a$ measured by the mean value. In the second example the mean value represents something quite distinct from any property of the sand. It represents, indeed, a cause or force (the weight of $200 \mathrm{gr}$. in one scale of the balance) external with regard to the substance sand and acting continually and uniformly through the whole time during which the successive portions (individuals) of sand were taking birth.

Using biological language, we might say that the mean value ( $200 \mathrm{gr}$.) and the variation curve discovered by the verifier $B$ express the conditions of existence which prevailed while the individuals (portions) of the species sand were developing. ${ }^{1}$ These conditions are : (I) one simple cause ; (2) chance (variable combined cause).

§ 110.-FOURTEENTH EXAMPLE: A MIXTURE OF TWO VOLUMES OF WATER.-We dispose of two pipettes $A$ and $B$. The pipette $A$ is narrow, exactly graduated, each

1 More strictly, while the primordium weight of the individuals was reaching its state of final equilibrium (adult state). (See $\$ 45$. 
division being 0.0 I c.c. The pipette $B$ is wider, graduated in such a way that each division is O.I c.c. It is supposed that it is possible to measure exactly a certain volume of water by means of $A$, whereas errors are unavoidable when $B$ is used.

By means of $A$ we measure exactly a volume of water of Io c.c., and an equal volume is measured rather inexactly by means of $B$. Both volumes are united into one portion. The same operation is repeated a number of times, each portion being kept separately.

Thereafter all the portions are measured exactly. From the collected figures we may calculate the mean volume (approximately 20 c.c.). We may construct the curve of errors (variation curve of the individuals); the limits of error are indefinite.

On the whole, this example recalls the preceding one (sand, $\S$ I09). There is, however, a difference between both with regard to the significance of the mean value. In the case of the sand, the mean value represents one simple invariable cause (200 gr.); in the case of the water the mean (20 c.c.) represents the resultant ${ }^{1}$ of two simple causes, which have acted in each of the successive operations. One of these causes (pipette $A$ ) is invariable ; the other cause (pipette $B$ ) is also invariable, but its effects have been continually augmented or diminished by chance.

Looking upon the portions of water as being specimens of the species water of which we have measured one variable property (volume), we may say that the observed values represent the conditions of existence under which the specimens have been developed. The mean value and the variation curve are independent of any property whatever of the water.

In the previously discussed examples, in which there is question of a sphere, coins, balls in an urn, dice, and in the example of the typical Mendelian hybrids, chance produces a limited number of simple events (heads or tails, seeds round or wrinkled, etc.). Chance is acting through a machinery which may be brought into a limited number of states of equilibrium. The observed effects depend on certain properties (specific energy) of the objects under consideration. In the two last examples, in which the machinery consists of sand or water, the observed and measured facts are independent of the machinery through which chance is acting. Each figure is a direct effect of external causes. The variation is unlimited, because it depends merely on the variation of chance, which has no limits.

§ 111.-FIFTEENTH EXAMPLE: A MIXTURE OF AN ACID AND AN ALKALINE LIQUID.-We dispose of two

${ }^{1}$ In this example, the resultant is simply the arithmetical sum of both causes under consideration (ro +10$)$. 


\section{THE QUANTITATIVE METHOD IN BIOLOGY}

watery solutions, containing respectively an acid and an alkaline substance. The solutions are prepared in such a way that Io c.c. of the acid neutralize exactly ro c.c. of the alkali. By means of the (exact) pipette $A$ of the preceding example (§ IIO) Io c.c. of the acid are taken; by means of the (imperfect) pipette $B$ we take rather inexactly Io c.c. of the alkaline solution. Both volumes being mixed into one portion, we add one drop of turnsol, by which the reaction (acid red, alkaline blue) is indicated.

A number of portions being obtained, we see that the red and the blue portions are (about) equally numerous. How can this result be explained?

All the operations have been carried out exactly as in the preceding example ( $\S$ IIO). Since the acid has been measured by means of $A$, the volume acid is exactly Io c.c. in all the portions. The alkaline solution has been measured by means of $B$, which is imperfect, and therefore the alkaline volume is variable from one portion to another. In all the portions in which the alkal. vol.<Io c.c., the colour is red (acid predominant), whereas the portions in which alkal. vol.> Io c.c. are blue. ${ }^{1}$

We know from the example in $\S$ Io8 (density) that the errors depend on chance. A curve of errors (Fig. I8, p. I46) is symmetrical, positive and negative errors being equally numerous. Since each positive error (alkal. vol. $>$ Io) produces blue and each negative error (alkal. vol.<Io) red, both colours are observed an equal number of times.

In this example the variation produced by chance (the colours only being taken into account) is not expressed by means of figures. Chance may produce only two events (states of equilibrium) : red or blue. When chance is alone at play, red and blue are equally frequent. (If, however, a simple cause interfered, augmenting, for instance, slightly the acid volume in each portion, the frequency of the event red would increase, and vice versa.)

\section{§ 112.-REMARKS ON THE PRECEDING EXAMPLES:} CONTINUOUS AND DISCONTINUOUS VARIATION.-In the examples mentioned in §§ I08-IIo (density, sand, two volumes of water) the variation of the observed values is continuous : it is expressed by a series of figures in which no gaps occur, the transition from one value to the next one being gradual (see the figures, p. I45) ${ }^{2}$ and the frequency of the

1 It is thinkable that the reactions of certain portions were neutral, both constituent volumes being strictly equal. The probability (frequency) of this event is exceedingly small, and therefore it may be practically excluded. Compare the possible states of equilibrium of a coin, $\$ 92, \mathrm{p}$. I I 7 .

2 In the mentioned series of observed values (p. I45) the difference between two successive figures is not an existing gap: its value depends on the used 
successive figures varying gradually. In the last example (acid + alkali, $\S I I I)$, on the contrary, discontinuous variation exists in the effects of chance ; there is, indeed, a distinct gap between red and blue.

The above phenomena recall respectively the continuous and discontinuous variation observed in animals and plants. ${ }^{1}$ (See § 2I.)

A comparison between the fourteenth and the fifteenth examples is interesting for the biologist. In both cases (volume and colour) all the conditions are the same, the operations are the same, the causes are the same. The effects, however, are quite different : continuous in one case, discontinuous in the other. It might even be possible to observe both effects (volume and colour) at the same time in each portion (specimen), if it is supposed that the chemical reaction has no influence upon the total volume.

This being admitted, each portion acid + alkali may be looked upon as being an individual of a certain species of which we have investigated two primordia, volume and colour. With regard to the volume, continuous variation is observed, the variation curve being regular, as in Fig. I8; with regard to the colour, variation is discontinuous. We might be tempted to ascribe the difference to a difference in the causes. ${ }^{2}$ We know, however, that the very same causes have produced dissimilar effects because each property has its own specific energy which produces its characteristic states of equilibrium. ${ }^{3}$ (Compare Centaurea, § 47, p. 58.)

§ 113.-SIXTEENTH EXAMPLE: UNILATERAL VARIATION (UNILATERAL VARIATION CURVE).-We dispose of two watery solutions containing respectively two salts $a$ and $b$. The solutions are prepared in such a way that Io c.c. of $a$ precipitate exactly Io c.c. of $b$, the weight of the precipitate being I gr. = I000 mgr.

By means of pipette $A$ ( $\S$ IIo) we measure exactly Io c.c. of $a$; by means of pipette $B$ (which is imperfect) we measure Io c.c. of $b$. Both volumes are mixed. A number of mixtures being

unit. On p. I45 the unit is $0^{\circ}$ or of the density of water. If we take, for instance, $0^{\circ} \mathrm{OOI}$ as unit, the difference under consideration is ten times smaller than when $0^{\circ} \mathrm{I}$ is taken, etc. However small the adopted unit may be, perfect continuity is never obtained, owing to the necessity of using ciphers for the expression of the measurements.

The form of variation observed in the last example (red-blue) is often called alternative variation. It may be looked upon as being discontinuous variation with two terms.

${ }^{2}$ For instance, to the existence of different determiners, factors, pangenes, etc.

${ }^{3}$ The same cause has produced two kinds of variation, in one case continuous, in the other case discontinuous; but there is a connection between the two kinds-e.g. if $a$ is a blue specimen and $\beta$ a red, then vol. of $a>$ vol. of $\beta$ and this rule is invariable. 


\section{THE QUANTITATIVE METHOD IN BIOLOGY}

prepared in this way, we determine exactly the weight of the

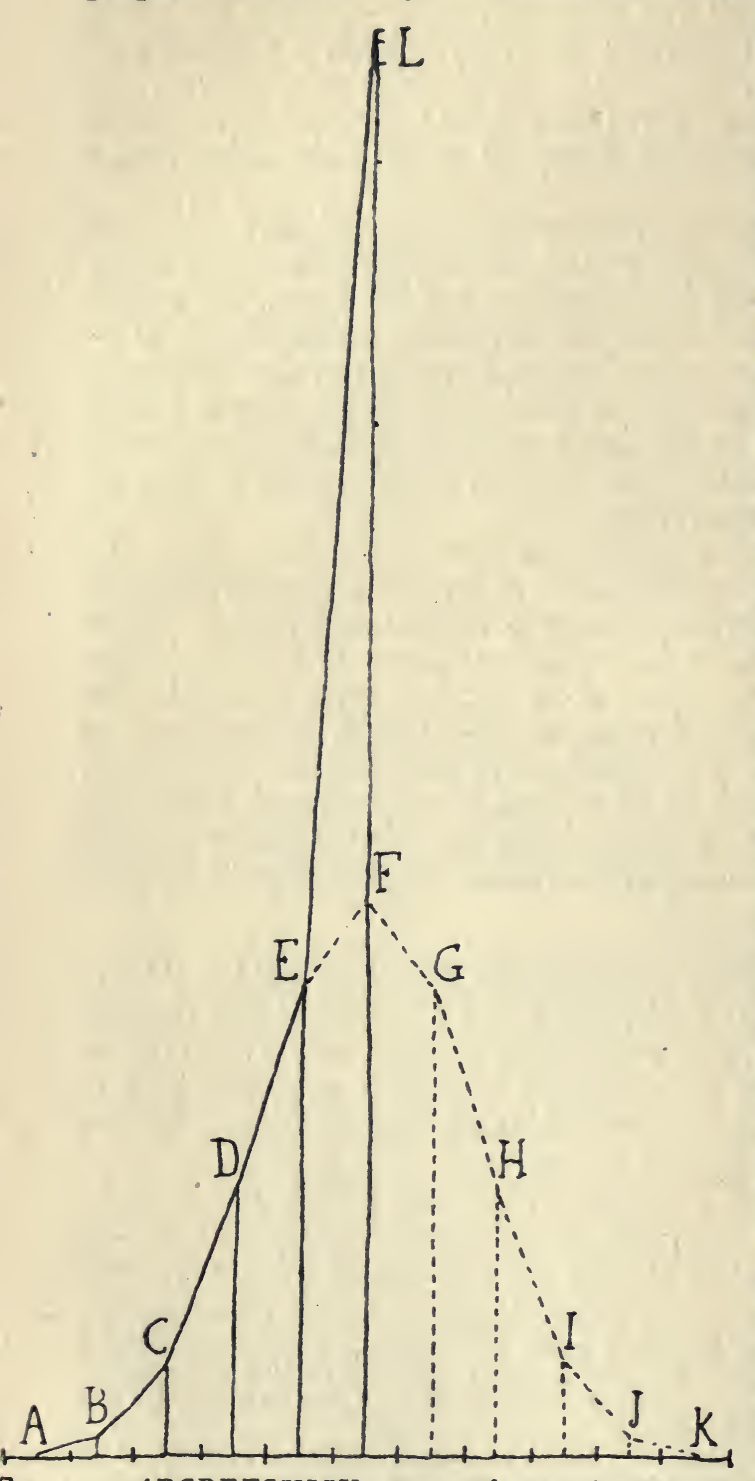
precipitate in each mixture. The value of this weight depends on two causes, one of which (pipette $A$ ) is invariable, the second one (pipette $B$ ) consisting of an invariable cause \pm a variable cause which is chance. The variation (errors) of the weight precip. is therefore governed by the rules of chance, but here the effects of chance are of a peculiar kind.

Suppose that the greatest errors (with regard to the volume) committed by using pipette $B$ have been +0.16 and -0.I6 c.c. Between these extremes all the errorsaredistributed according to a curve similar to Fig. I8, the negative errors being equal in number to the positive ones.

Since the volume of $a$ is exactly ro c.c. in all the mixtures, each negative error results in a diminution of the weight precip. For instance, the greatest negative error, which amounts to 0.016 of (symmetrical). ABCDEL, curve of observed effects (unilateral)

Io c.c., corresponds to $984 \mathrm{mgr}$. of precipitate instead of Iooo, etc. The positive errors, on the contrary, don't produce any 
increase of the weight precip., since this cannot exceed Iooo mgr.

Therefore the variation curve of the weight precip. does not coincide with the curve of the committed errors. The series of committed errors (from 9.84 to Io.I6 c.c.) being divided into eleven groups (intervals; compare p. I45), and the relative number of mixtures of each group being represented by a vertical ordinate, a symmetrical curve of errors (Fig. Ig) is obtained similar to Fig. I8, p. I46. In the six groups $A, B, C$, $D, E, F$ the weight precip. increases from $A$ to $F$. In $F$ it reaches the value of rooo mgr. In the groups $G, H, I, J, K$ the maximal value rooo mgr. is invariable. Therefore if the variation curve of the weight precip. (observed effects) is constructed, the frequencies $G, H, I, J, K$ are added to the frequency $F$, and the curve $A B C D E L$ (Fig. Ig) is obtained ( $F L=G+H+I+J+K)$.

The causes which have produced in the present example a unilateral variation curve I.EDCBA are exactly the same as those which resulted in a symmetrical curve $(A B C D E F G H I J K$, Fig. I9) in the fourteenth example (Io + Io c.c. water, § IIO). The difference between the two curves does not depend on a difference in the causes, but merely on a difference in the specific energy of the measured properties (volume ; precipitate) of the mixtures.

REMARK : Comparing the fourteenth, fifteenth and sixteenth examples, we see that the same causes may produce : (I) continuous variation, expressed by a symmetrical curve ; (2) discontinuous variation; (3) continuous variation expressed by a unilateral curve.

In the sixteenth example the maximal value (weight precip. I000 mgr.) has a preponderant importance; it is, as it were, a measure of the resultant of the two simple causes (ro c.c. solution $a+$ Io c.c. solution $b$ ) which have acted simultaneously. The minimal limit, on the contrary, is indefinite. From all the observed figures a mean value may be easily calculated, and it might be possible to find a mathematical expression of the (rather complicated) relation between this mean value and the maximum. The significance of the mean value is, however, rather a fictitious one, at least for the naturalist.

We see from this example that a unilateral variation curve may be simply a product of chance acting through a certain machinery, without the intervention of any peculiar cause. (Compare § I02, Example (B), p. I29.)

§ 114. -THE FOURTEENTH, FIFTEENTH AND SIXTEENTH EXAMPLES MODIFIED BY A UNIFORM INCREASE OF PIPETTE B.-In the mentioned examples ( $\S$ IIO, III and II3) there is question of a mixture of two liquids $a$ and $b$, Io c.c. of each being measured respectively by 


\section{THE QUANTITATIVE METHOD IN BIOLOGY}

means of an exact pipette $A$ and an imperfect pipette $B$. (See p. I48.) The three series of experiments may be repeated under the following conditions :-

(I) The successive mixtures are prepared at equal intervals of ten minutes each and marked with a number indicating their order of succession.

(2) Pipette $B$ is supposed to increase regularly (unknown to the operator) through the whole duration of each series of experiments, ${ }^{1}$ with such a velocity that the volume indicated by degree ro is increasing by 0.01 c.c. in the course of each interval of ten minutes. I ascribe here to pipette $B$ a property of the living beings-namely, growth.

(3) At the beginning of each of the three series degree ro of pipette $B$ coincides (unknown to the operator) with a volume of 9 c.c. instead of ro.

Suppose that in each series 200 portions (mixtures) are prepared. In all the portions the already mentioned properties are measured or observed-viz.

Ist Series (fourteenth example): water + water : property volume.

and Series (fifteenth example) : acid + alkali : property colour (red or blue).

3rd Series (sixteenth example): salt $a+$ salt $b$ : property weight of the precipitate.

Ist Series. - If no errors were committed, volume I (first portion) ${ }^{2}$ would be $10+9=$ Ig c.c. In a similar way-

\begin{tabular}{|c|c|c|c|c|}
\hline Volume & 2 & would k & e Ig.OI & c.c. \\
\hline ", & 3 & ", & I9.02 & ," \\
\hline - & - & - & • $\quad \cdot$ & .. \\
\hline " & 30 & ", & I9.29 & , \\
\hline " & $3 I$ & ", & I9:30 & ", \\
\hline - & - & - & - $\cdot$ & - \\
\hline ", & 90 & " & Ig.89 & ", \\
\hline ", & $9 I$ & ," & I9.90 & ", \\
\hline - & - & - & $\cdot \quad \cdot \quad \cdot$ & - $\quad$ • \\
\hline " & IOO & ", & I9.99 & ", \\
\hline ", & IOI & ," & $2 \cdot 000$ & ", \\
\hline • & - $\cdot$ & - & - $\cdot$. & :. \\
\hline ", & IIO & ", & 20.09 & $"$, \\
\hline , & III & ", & $20 \cdot 10$ & ," \\
\hline . & - $\cdot$ & . & - $\cdot$ & \\
\hline$"$ & 200 & " & $20 \cdot 99$ & ", \\
\hline
\end{tabular}

1 For instance, by an increase of its diameter unperceived by the operator.

2 Volume $I$ is prepared at the moment 0. 
MEASUREMENT OF VARIABLE PROPERTIES 155

But since errors are committed with pipette $B$, the effects of the cause (volume) $B$ are continually varying according to the law of errors ( $\S$ I08) and the increase of the volume given by $B$ is no longer regular, but varying continually. If the greatest

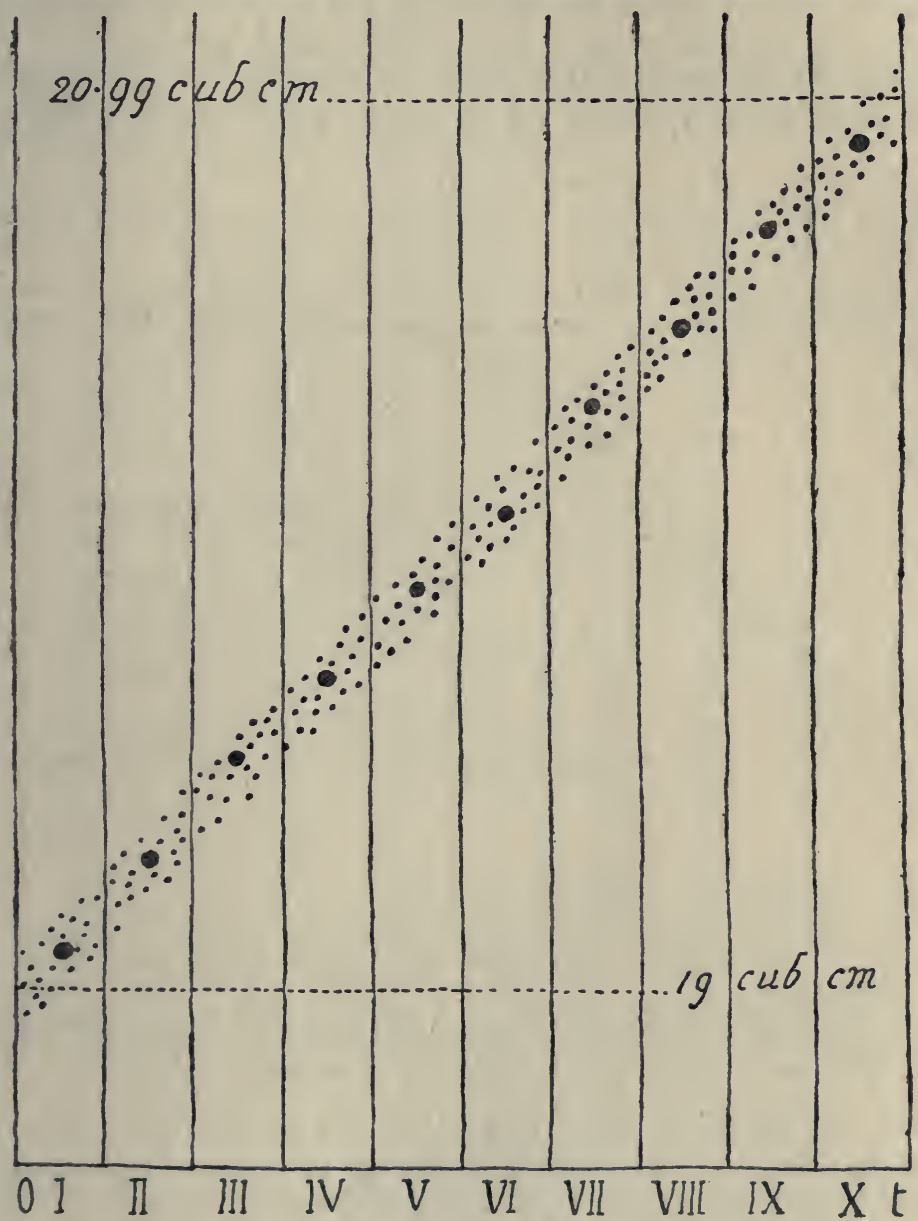

FIG. 20.-The distance between each small dot and ot is supposed to represent the volume of a portion. The thick dots represent the curve of growth (see text); ot, time; 0 , origin

errors are supposed to be $+0 \cdot$ IO and $-0 \cdot$ IO c.c., irregularities may occur in the following way:-the volume of portion 30 (for instance) is expected to be (without error) I9.29 c.c. ; if the error is, for instance, +0.06, the observed volume becomes I9.35. The volume of portion 31 is expected to be 19.30; if the error is $-0 \cdot 10$, the volume is reduced to 19.20. More or 


\section{THE QUANTITATIVE METHOD IN BIOLOGY}

less important errors being continually committed, the effects of the regular increase of pipette $B$ (the effects of growth) are disordered according to the rules of chance.

The 200 portions may be represented by 200 small dots (Fig. 20), the distance between each dot and a horizontal line ot representing the volume of the corresponding portion.

Fig. 20 represents the observed growth of the property volume (during a period of $I 99 \times$ IO $=$ I990 minutes) deduced

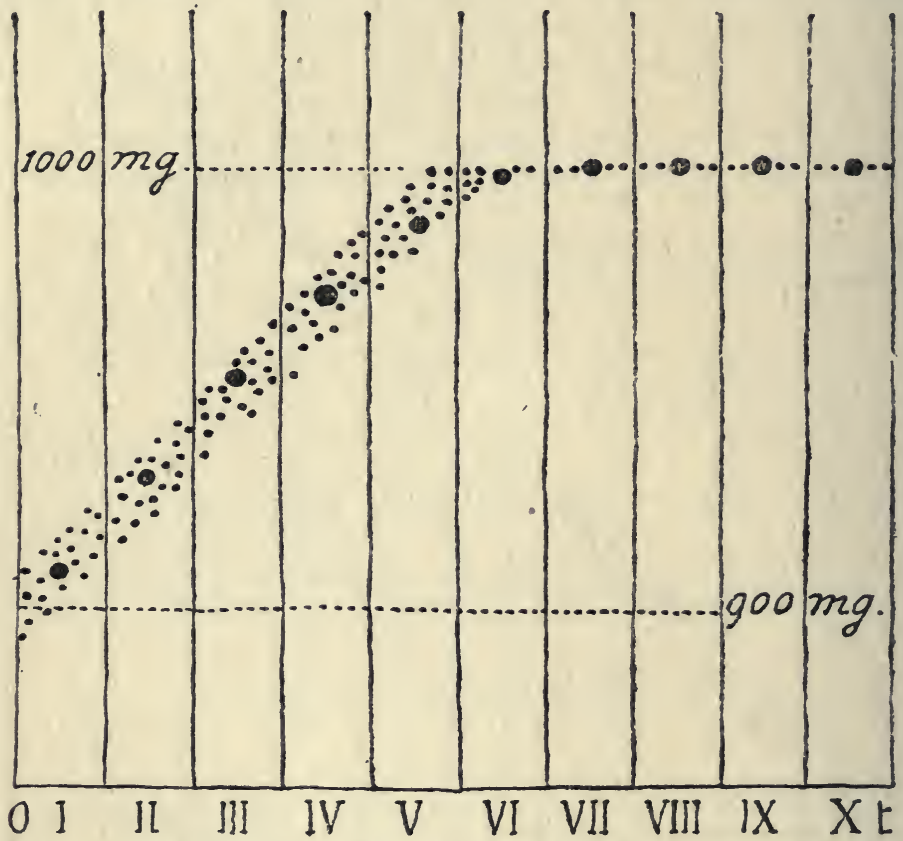

FIG. 21.-The distance between each small dot and ot is supposed to represent the weight of the precipitate in a portion. The thick dots represent the curve of growth (see text); ot, time; o, origin

from the measurement of 200 specimens of successive ages, the last specimen (last small dot) being I99 $\times$ IO $=$ I990 minutes older than the first one. This total duration may be divided, for instance, into Io equal intervals, I., II., ... X. For each interval the mean volume of the corresponding specimens (small dots) may be calculated. Since each interval includes twenty specimens, the positive and negative errors are counterbalancing one another in a certain degree. ${ }^{1}$ The ten mean values being plotted out in the form of thick dots, it is seen that the latter are situated approximately on a straight line which is the curve of

1 The result would be, of course, better if the portions were more numerous. (See, on the conclusion drawn from a series of twenty observations, §93, p. I I8.) 
growth ${ }^{1}$ and represents the mean growth. On both sides of this line the specimens (small dots) are distributed (according to the law of errors) within a zone, which is limited by the greatest errors $(+0 \cdot I$ and $-0 \cdot I)$. This zone is the variation zone of the curve of growth.

2nd Series.-See below, p I57.

$3^{r d}$ Series. - The weight of the precipitate is determined in the 200 portions and the curve of growth is constructed in the same way as for the first series (Fig. 2I).

In the intervals I.-IV. everything happens as in the first series, the curve of growth (thick dots) being, on the whole, an obliquely ascending straight line. As soon as portion $9 \mathrm{I}$ is reached (in the middle of interval V. ; see Table, p. I54) the weight of the precipitate cannot exceed Iooo mgr, even if the greatest possible positive error ( $+0 \cdot$ Io c.c., which coincides with + Io mgr. of precipitate) is committed. When portion IoI is reached the maximal value of the weight precip. (I000 mgr.) is reached if no error is committed. (See Table, p. 154.) This weight may be diminished by a negative error, but it cannot be augmented by any positive error whatever. From portion III to the last one the value Iooo mgr. is certainly invariable; it cannot be modified even by the greatest negative error. Therefore in the intervals VI.-X. all the small dots (with the possible exception of the portions IoI-IIo) are situated exactly on a horizontal straight line (second part of the curve of growth), and here a zone of variation does not longer exist.

Remark: The property weight precip. may be compared to an arrested persistent property. (See § 46.)

2nd Series.-Here we find an example of discontinuous variation (red, blue) which gives rise to a curve or line of growth of a peculiar kind. In the intervals I.-IV. the acid is predominant whatever may be the errors, and the colour is always red. When portion 92 is reached pipette $B$ is expected to give $9 \cdot 91$ c.c. of alkali, but if a maximal error $(+O \cdot I)$ is committed the volume $B$ may reach ro.01, and since the volume $A$ is ro.00, the colour of the mixture is blue. From portion 92 to III errors may produce an irregular alternation of red and blue.

\section{. . rrrrrrrrrrrbrrbrbrbrbrbrbrbrbrbbrbbbbbbbbbbbbbbbbbb ... \\ $1092 \quad 111 \quad 200$}

Frg. 22.-Development of the colours : $r$, red ; $b$, blue. (See text.)

In all the portions II2-200 the alkali is predominant in spite of any error whatever and the colour is always blue. In the development of the property colour we can therefore distinguish three periods (Fig. 22)-viz. red; hesitation between red and blue (alternative variation); blue.

1 This curve is an embryological curve. (See \$ 49.) 


\title{
158 THE QUANTITATIVE METHOD IN BIOLOGY
}

\author{
Remark I.: In Fig. 22 the letters represent specimens of successive \\ age.
}

Remark II.: The primordium red is original, arrested, transitory; the primordium blue is metamorphic, arrested, persistent. (See § 46.)

Remark III.: The primordia red and blue are two terms of an embryological series. (See § r33.)

Remark IV.: The possibility of investigating the three primordia (volume, weight precip., colour) in the same mixture is conceivable. This would be realized if we disposed of an acid solution $a$ and an alkaline solution $b$ producing a precipitate when mixed, in such a way that every excess of $a$ would be indicated by red and vice versa, supposing, moreover, that the total volume

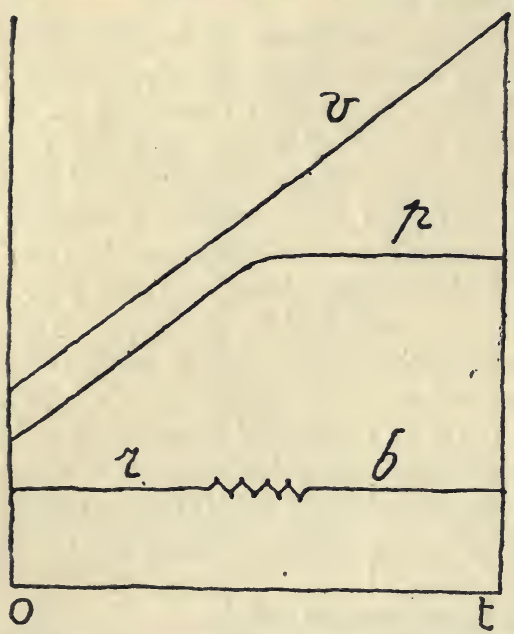

FIG. 23.- Curves of development of three primordia of a mixture of two liquids (see text)- $v$, curve of growth of the total volume; $p$, curve of growth of the weight of the precipitate; $r b$, curve of development of the colour: $r$, red period; $b$, blue period-between both a period of hesitation; ot, duration of the development ; 0 , origin on embryology. In Fig. 23 the volume is the most convenient leading property.)

of the mixture were not modified by the occurring chemical reactions. A chemist could perhaps indicate two substances which would satisfy the required conditions.

However it may be, the above possibility being admitted, we may look upon the 200 portions (mixtures) as being specimens of different age of the same species. The three primordia being observed and measured in all the specimens and their curves being constructed, a diagram similar to Fig. 23 would be obtained.

Since the causes (pipettes $A$ and $B$ ) are exactly the same for the three primordia, the curve of each primordium depends on its specific energy.

Remark V.: Each of the three curves in Fig. 23, considered separately, does not represent the development of a specimen considered as a whole. This development is a complex something, the exact investigation of which is possible by measuring the growth of each primordium separately. In the leaves of the mosses and other objects I have observed facts which recall the above example (gradation curves, Part VIII.). (Compare \$ 49: § 115.-SEVENTEENTH EXAMPLE: AN URN CONTAINING IOo PRISMS $a$ AND IOo PRISMS $b$ (continued from $\S$ IOO).-An urn contains :

(I) Ioo right prisms $a$, the base of each being a square of side I cm., the height $2 \mathrm{~cm}$.

(2) IOo prisms $b$ differing from the prisms $a$ only by their height, which is $3 \mathrm{~cm}$.

It is obvious that the conditions are the same as if the urn contained Ioo white and Ioo black balls (see this example in $\S 98)$. When the prisms are taken one by one in series of $n$ prisms (each prism being put again into the urn after its height 
has been observed; see $\S 98)^{1}$ all the possible compound events and their frequencies may be calculated $a$ priori by expanding $(a+b)^{n}$, in which $a=b=\frac{100}{200}=\frac{1}{2}$.

The prisms being extracted, for instance, in series of Io, and this operation being repeated, for instance, 102,400 times, ${ }^{2}$ all the events (combinations of Io prisms) are represented by-

$$
\begin{aligned}
(a+b)^{10}= & a^{10}+10 a^{9} b+45 a^{8} b^{2}+120 a^{7} b^{3}+210 a^{6} b^{4}+252 a^{5} b^{5}+ \\
& 210 a^{4} b^{6}+120 a^{3} b^{7}+45 a^{2} b^{8}+10 a b^{9}+b^{10}=\mathrm{I}
\end{aligned}
$$

The denominator of all the terms is $2^{10}=1024$. The frequency of each term is $\frac{1}{1024}$ multiplied by its coefficient.

Example: The frequency of the combination $a^{2} b^{8}(2$ prisms $a+8$ prisms $b)$ is $\frac{45}{1024}$; since we have extracted $1024 \times 100$ series, $\mathrm{a}^{2} b^{8}$ occurs approximately $45 \times$ Ioo times.

I ascribe to the letters $a$ and $b$ two values :

(I) The value $\frac{1}{2}$, which is the frequency of the corresponding simple events.

(2) A second value (facial value), which is quite independent of the frequency and represents the measure of the corresponding simple events ( $§$ IOI, p. I26)-i.e. $a=2 \mathrm{~cm}$. and $b=3 \mathrm{~cm}$. In this way the sum of the letters of each term is the total height of the Io prisms of the corresponding combination (resultant of the simple causes).

Example: The term Io $a b^{9}$ represents I prism $a+9$ prisms $b$, the total height of which is $(2 \times \mathrm{I})+(3 \times 9)=29 \mathrm{~cm}$.

By a very simple calculation one finds that the total heights increase regularly from the first to the last term, the values being :

$$
\text { 20, 2I . . 29, } 30 \mathrm{~cm} \text {. }
$$

We construct now a large number of new prisms of eleven sorts, the respective heights of which are given by the above values $(20$ to $30 \mathrm{~cm}$.), the number of each sort being proportional to the frequency (numerical value) of the corresponding term.

(The base of all the prisms is $\mathrm{I} \mathrm{cm}^{2}$.)

Examples: The term $a^{10}=\frac{1}{1024}$ represents the frequency of the combination the total height of which is $20 \mathrm{~cm}$. We construct, for instance, I000 prisms of $20 \mathrm{~cm}$. The term $10 a^{9} b=\frac{10}{1024}$ represents the frequency of the prisms of $2 I \mathrm{~cm}$. According to this, we construct 10,000 prisms of this sort, etc. The total number of prisms is $1,024,000$.

All the prisms (each within a case) are mingled and put

${ }^{1}$ Each prism is supposed to be enclosed within a case, in such a way that it is impossible to distinguish an $a$ from a $b$ without opening the case.

${ }^{2} 102,400=2^{10} \times 100$. I take this figure in order to simplify the calculations below. 


\section{THE QUANTITATIVE METHOD IN BIOLOGY}

into an urn. One case being extracted, the probability (frequency) of each sort of prisms is given by $(a+b)^{10}-$ viz.

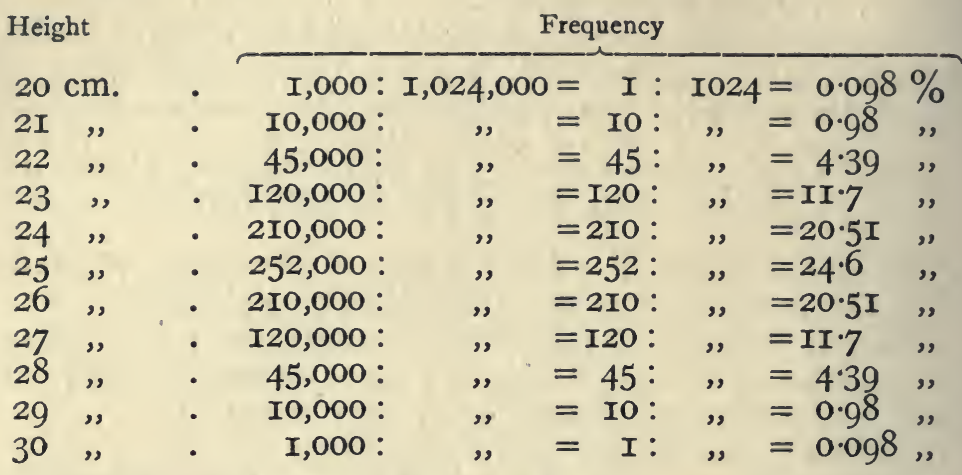

When a large number of prisms, for instance, I02,400, are extracted one by one, we may expect approximately the following result :-

Height of the prisms
Number of prisms Height of the prisms Number of prisms . $2 I, 000 \quad I 2,000 \quad 4500 \quad I 000 \quad I 00$

The eleven sorts of prisms are, as it were, specimens of a certain species, a variable property of which (height) has been measured. The above figures represent the variation curve, which is governed by chance (Fig. 24.)

§ 116.-SEVENTEENTH EXAMPLE (continued).-Let us now suppose that we find in the state of nature an unlimited number of specimens of a given species varying with regard to the property stature (height), the extremes being 20 and $30 \mathrm{~cm}$. A large number of specimens taken at random being measured, a variation curve is obtained. It happens often (not always), especially in the animal kingdom, that the successive values are distributed approximately according to the rules of chance (expressed by $\left(\frac{1}{2}+\frac{1}{2}\right)^{n}$; see note, p. I47), just as in the above variation curve of the species prism. The latter (in which $n=10$ ) being taken as example and plotted out in the form of a diagram, the obtained figure (Fig. 24) is the same as the curve of errors mentioned in $\S$ ro8. (See Fig. I8, p. I46, density of a solid 
MEASUREMENT OF VARIABLE PROPERTIES 161 body.) From this similitude QUETELET has deduced that variation in the living beings is governed by chance (law of errors). (See $\S \S 32$ and $\mathrm{Ir} 8$.)

From a mathematical standpoint, a curve of errors obtained by measuring a density ( $\S$ I 8 ) and a typical variation curve (height of the prisms, §II5) are similar. From the standpoint of the naturalist, however, two fundamental differences exist between them.

A first difference exists with regard to the significance of the mean value. When the density of a solid $a$ is determined by means of a series of measurements, two groups of causes

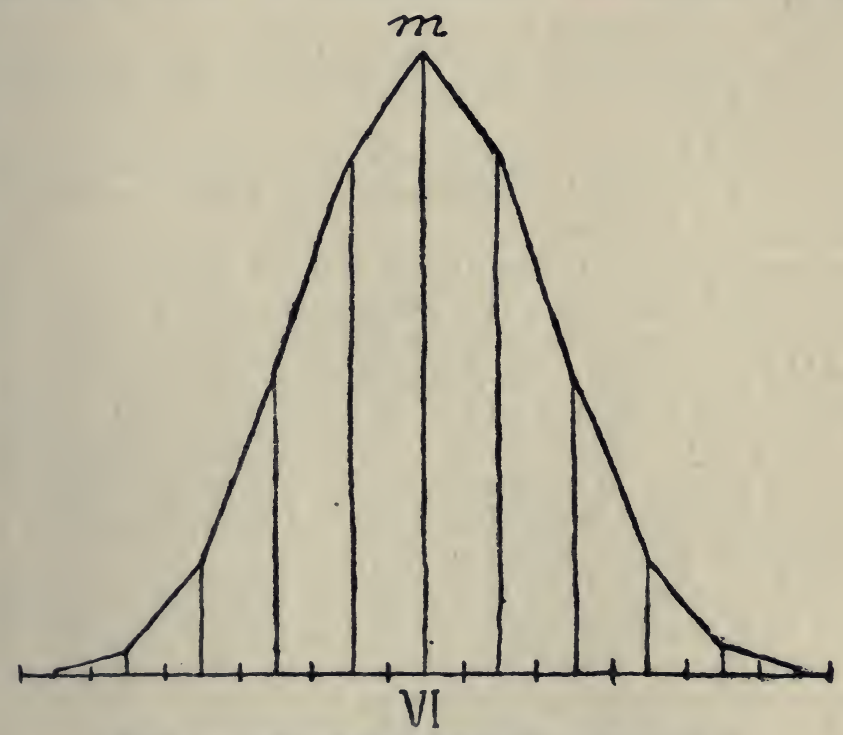

FIG. 24.-Symmetrical variation curve $(a+b)^{20}$

(forces) are at play: (I) a definite simple cause, the density of $a$; (2) a variable combined cause (chance). The mean value represents a definite something : it is the measure of a property of $a$-i.e. a physical constant ( $(108)$; the errors (deviations from the mean) are produced by chance. ${ }^{1}$ In the example of the prisms it is possible to calculate a mean (its value is $25 \mathrm{~cm}$.), but this does not represent a definite constant, a property of the objects (compound prisms) under consideration. Here the mean is produced by the variable combined cause (chance). Its value depends (I) on the simple causes which have been combined $(a=2 \mathrm{~cm}$.; $b=3 \mathrm{~cm}$.; see $\S$ III) ; (2) on the frequency of those causes $\left(a=\frac{1}{2} ; b=\frac{1}{2}\right) ;(3)$ on the number of causes (simple events) which have been combined $(n ;$ in the

${ }^{2}$ In other words, each observed value consists of the constant \pm an error. 


\section{THE QUANTITATIVE METHOD IN BIOLOGY}

given example $n=\mathrm{I0}$ ). The mean represents therefore a very complex something. In order to realize its significance in general we are compelled to have recourse to a rather complicated argument (expounded in $\S$ II5), starting from $(a+b)^{n} .^{1}$ In each peculiar case, we must know the numerical value of the data $a, b$ and $n$.

It is, however, possible to give a definition of the mean value by saying that -

The mean value is the arithmetical mean of all the observed figures (this definition is, for the naturalist, a fictitious something),

\section{Or-}

The mean value is the most frequent resultant of the combined causes; in other words, the most frequently observed (the most probable) value.

Although the latter definition is more satisfactory than the former, we don't find in it the notion of a directly measurable simple thing (a constant).

Moreover, the arithmetical mean and the most frequent value do not always coincide. This coincidence exists in the typical symmetrical variation curves ; for instance, in the example of the prisms ( $\S I I 5, \mathrm{p} . \mathrm{I} 60)$. In this case we start from an urn containing simple prisms $a$ and $b$ in equal numbers. Since the frequencies of the simple events are equal, the variation of the compound prisms is expressed by a symmetrical curve, and the mean $(25 \mathrm{~cm}$ :) coincides with the central ordinate (the most frequent value; hump of the curve).

If it is supposed that the first urn contains roo prisms $a$ $(2 \mathrm{~cm}$.) and 200 prisms $b(3 \mathrm{~cm}$.), the variation curve of the compound prisms would be obtained by expanding $(a+b)^{10}$, the frequencies being $a=\frac{100}{300}=\frac{1}{3}$ and $b=\frac{200}{300}=\frac{2}{3}$ (compare the balls in \$ 99)-viz. (59,049 compound prisms being extracted) :

Height of the

$\begin{array}{lrrrrrr}\begin{array}{c}\text { prisms } \\ \text { Number of } \\ \text { prisms }\end{array} & 20 & 21 & 22 & 23 & 24 & 25 \\ \begin{array}{c}\text { Height of the } \\ \text { prisms }\end{array} & \text { I } & 20 & \text { I80 } & 960 & 3360 & 8064 \\ \begin{array}{c}\text { Number of } \\ \text { prisms }\end{array} & 26 & 27 & 28 & 29 & 30 & \\ & \text { I3,440 } & \text { I5,360 } & \text { II,520 } & 5 \text { I20 } & \text { I024 } & \end{array}$

This curve is asymmetrical. The most frequent value

1 It is impossible to distinguish in each of the eleven observed values a constant \pm an error.

${ }^{2}$ See the eleven terms, p. I59. The numerical values are : $a^{10}=\left(\frac{1}{3}\right)^{10}=\frac{51}{59049}$; ro $a^{9} b=\operatorname{Io}\left(\frac{1}{3}\right)^{9}\left(\frac{2}{3}\right)=\frac{20}{59049} ;$ etc.

${ }^{3}$ The denominator of the eleven terms obtained by expanding $\left(\frac{1}{3}+\frac{2}{3}\right)^{10}$ is $3^{10}=59,049$. 
(highest ordinate) is $27 \mathrm{~cm}$. The arithmetical mean is $r, 574,640: 59,049=26 \frac{2}{3} \quad \mathrm{~cm}^{1}$ This does not represent any existing prism. For the naturalist the second definition of the mean is not applicable.

A second difference exists between a curve of errors (\$ I08) and the variation curve of the prisms ( $\S$ II5) with reference to the significance of the extreme values (limits). In a curve of errors the limits are indefinite and of secondary importance, because it is always possible that a new error exceeds the greatest error previously committed. ${ }^{2}$ In the variation curve of the compound prisms, on the contrary, the extreme values are strictly definite. The minimum is $a^{10}\left(20 \mathrm{~cm}\right.$.) and the maximum $b^{10}$ $(30 \mathrm{~cm}$.). If one succeeds in finding these values by observation (extracting prisms from the urn), they are determined once for all : it is impossible to find in the urn any prism $<20$ or $>30 \mathrm{~cm}$.

In the example of the prisms and in all similar cases the extreme values may be defined as being the direct measure of the maximum and the minimum effects produced by the acting combined causes. In other words, using biological language, the maximum corresponds to the optimal conditions of growth of the species (compound prism), whereas the minimum corresponds to the most unfavourable conditions-the pessimal conditions. Both extreme values are constants, between which variation fluctuates.

We shall see below (§ II8-IIg) that the extremes (especially the maximum) deserve still better the name of constants when variable properties of animals and plants are measured. The method which I propose for the measurement of constants, the description of species and the identification of specimens is based upon the determination of the extreme values.

REMARK : In § IOI (Table $\gamma$, p. I27), we have seen that in the series of $f a c i a l$ values obtained by casting two dice the extreme values ( 2 and I2) are definite. Other examples of definite extremes are mentioned in $\S$ I02, examples (A) (p. I28) and (B) (p. I29) ; experimental verification in § I03. In § II3, Fig. I9, the maximal value is definite.

§11\%.-EIGHTEENTH EXAMPLE: EXPERIMENTS WITH CARDS. MEAN VALUE AND EXTREME VALUES. -First Experiment: I ascribe to each card of an ordinary pack

1 The value $1,574,640 \mathrm{~cm}$. is the total length of the 59,049 prisms.

2 In the example in $\S 108$ (measurement of a density) I have put down $n=10$, supposing that the combined causes were ro in number. This is arbitrary : I was compelled to adopt a definite value for $n$ because I am using the arithmetical method. By doing so I have arbitrarily fixed two limits of error $\left(a^{10}\right.$ and $\left.\mathrm{b}^{10}\right)$. In reality, $\boldsymbol{n}$ is an indefinite number. Instead of being combined ro by 10, the causes which bring about errors may be combined II by 11,12 by $12, \ldots$. I 100 by roo, etc. (See note, p. 147.) 


\section{THE QUANTITATIVE METHOD IN BIOLOGY}

(52 cards, 4 suits) the following facial values (without distinguishing the suits):- whole numbers I to Io ; Knave =II ; Queen $=\mathrm{I2} ; \mathrm{King}=\mathrm{I} 3$.

Drawing from a complete pack 4 cards simultaneously at random, I ascertain the sum of their facial values (example : ace $+7+9+$ queen $=29$ ). This experiment is repeated a number of times. (After each drawing the 4 cards are put back into the pack and this is shuffled before the next drawing.)

If we take only the compound facial values into account (the suits being overlooked), all the possible compound events (combinations of 4 cards) are reduced to 49 events, measured by the whole numbers from 4 ( 4 aces) to 52 (4 kings). Each of both extreme values may be realized only in one way.

The 49 different values may be looked upon as representing 49 kinds of specimens of a certain species, variable in a certain property, which is measured in each specimen (4 cards) by the facial value. The variation curve is symmetrical: its hump (most frequent value) coincides with 28 , which is also the arithmetical mean.

In this example the range of variation is very wide and the probability of discovering the extremes by a series of measurements (drawings) is small. Therefore the experimental discovery of the extremes is more difficult, I think, than in the majority of the living subspecies or monotypic species. I have carried out 1200 drawings of 4 cards divided into three series of 400 successive drawings each. Result (facial values) :

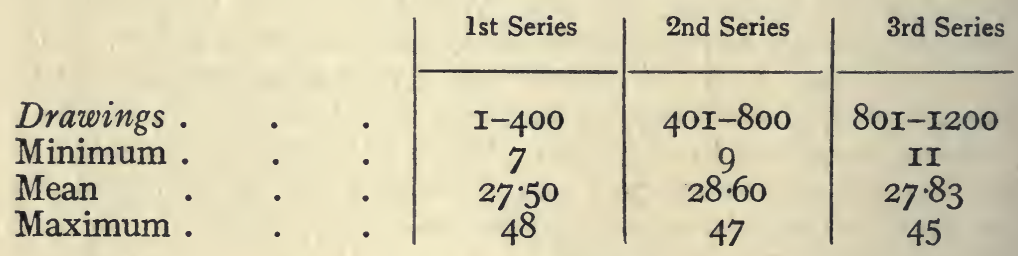

$\begin{array}{lcccc}\text { Ist }+ \text { 2nd }+3 \text { rd series (I200 drawings) : } \\ \text { Minimum : } & \text { Observed } 7 & \text { Calculated } & 4 \\ \text { Mean: } & \text { " } & 27 \cdot 98 & \text { " } & 28 \\ \text { Maximum : } & \text { ", } & 48 & \text { ", } & 52\end{array}$

Second Experiment: Similar to the first, the cards I, 2, I2 and I3 of each suit being suppressed. The cards are drawn simultaneously 4 by. 4 . The extreme facial values (4 cards) are I2 $(4 \times 3)$ and 44 (4 knaves). Curve symmetrical. Arithmetical mean, 28. Result : 


\begin{tabular}{|c|c|c|c|c|c|}
\hline & & & 4th Series & 5th Series & 6th Series \\
\hline Dra & & & $\mathrm{I} 20 \mathrm{I}-\mathrm{I} 600$ & I $60 \mathrm{I}-2000$ & $200 \mathrm{I}-2400$ \\
\hline Minimum & & & I5 & & \\
\hline $\begin{array}{l}\text { Mea } \\
\text { Max }\end{array}$ & & & $28 \cdot I 6$ & $28 \cdot 83$ & $27 \cdot 69$ \\
\hline $\mathrm{Ma}$ & . & & 43 & 42 & 42 \\
\hline
\end{tabular}
$4^{\text {th }}+5^{\text {th }}+6$ th series (I200 drawings): $\begin{array}{lcccc}\text { Minimum : } & \text { Observed } & \text { I } 4 & \text { Calculated I2 } \\ \text { Mean : } & \text { ", } & 28 \cdot 23 & \text { " } & 28 \\ \text { Maximum : } & \text { " } & 43 & \text { " } & 44\end{array}$

Third Experiment: Similar to the first, with I3 cards of one suit. Cards drawn simultaneously 4 by 4 . The extreme facial values are Io $(=I+2+3+4)$ and $46(I 0+I I+I 2+I 3)$. Curve symmetrical. Arithmetical mean, 28. Result (facial values) :

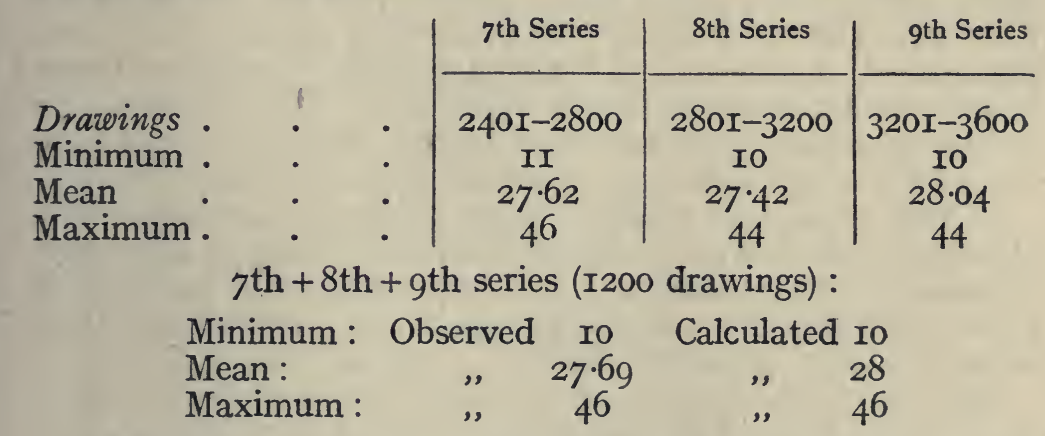

REMARKS : In each series of I200 drawings and even in almost all the series of 400 drawings the mean value has been discovered in a satisfactory way.

With regard to the extreme values, the result is unsatisfactory in the first experiment (this was expected, the frequency of the extremes being very small); the approximation is closer in the second experiment. In the third experiment both extremes have been found exactly. The exceptional wide range of variation in the first experiment being taken into account, we may conclude from the above result that the discovery of the extreme values, with a sufficient degree of approximation, is practically within the reach of observation.

§ 118.-NINETEENTH EXAMPLE. VA R I A T ION CURVE OF A PROPERTY OF A LIVING SPECIES (BIOLOGICAL VARIATION CURVE).--Starting from a very simple example (sphere, §9I) in which all the possible effects of chance are reduced to one event, we have been brought step 


\section{THE QUANTITATIVE METHOD IN BIOLOGY}

by step to very complicated cases, in which chance brings about a large number of events, the diversity of which is expressed by a curve of errors (Fig. I8, p. I46), or by a variation curve (dice, § IOI ; prisms, § II 5 ; cards, § II7).

Let us now suppose that we have measured a variable primordium in numerous specimens belonging to a subspecies or a monotypic species; for instance, the length of the adult spike of a certain race (subspecies) of rye.

Each observed figure is the measure of an object (individual, spike) which is in a state of equilibrium. The equilibrium is brought about by a series of reactions which take place in the course of the development of the measured object. (See $\S 45$, growth of a petal.) In these reactions two groups of causes are operative: (I) specific causes, which depend on the living substance of the species under consideration; (2) external causes, which are numerous ; for instance, temperature, light, water, food, etc. (See $\S$ IIg.) Each cause has an influence upon the observed values. The causes are combined in many different ways according to the laws of chance ; their resultant is different from one specimen to another. The figures of the measured property, considered as a whole, are represented by a variation curve which is governed by chance.

It has often (not always) been observed that the curve obtained is one humped and symmetrical (or nearly so), corresponding to the expression $\left(\frac{1}{2}+\frac{1}{2}\right)^{n}$ (see note, p. I47) and similar to the variation curve of the prisms in $\S$ II 5 and the curve of errors in $\S$ I08. (See QUETELET, § II6, p. I6r.)

What is the significance of the mean value and the extremes in a variation curve of a property of a living species-in other words, in a BIOLOGICAL variation curve?

We have seen in $\S$ Io8 that in a curve of errors the mean value is the measure of something independent of chance. If the combined causes (chance) were not operative while we are determining the specific weight of a solid ( $\S$ I08), no errors would be committed and in each determination a value would be obtained equal to the mean. In an inorganic variation curve (for instance, the curve of the compound prisms, $\S$ II5), on the contrary, each specimen is brought into existence by the very same causes which result in variation by their various combinations. If these causes (components of chance) were not operative, ${ }^{1}$ no mean value would be obtained, for the simple reason that no specimens (compound prisms) would exist. Therefore the mean value is an indirect expression of a complicated something. (Compare $\S$ II6, p. I62.)

A mean value calculated from a biological variation curve

1 The causes alluded to were acting and varying continually while we were extracting the simple prisms from the first urn. 
seems to have the same significance as in an inorganic variation curve. The length of the adult spike of the rye being taken as example, the external causes (temperature, water, food, etc.) which bring about variation by their combinations are in reality the causes of the development of the spike. ${ }^{1}$ Without heat, water, food, etc., no spike would come into existence, and no mean value would exist.

There is, however, between both cases (inorganic and biological) a fundamental difference.

\section{§ 119.-BIOLOGICAL AND INORGANIC VARIATION} CURVES (continued):-Among the external causes (factors) which have (or may have) an influence upon the development of the living beings, the following may be mentioned :-

(I) Temperature.

(2) Light (source of energy and stimulant).

(3) Water.

Food, which consists of a number of substances; for instance, (4)-(I5) :

(4) Carbon (tension of $\mathrm{CO}^{2}$ ).

(5) Nitrogen.

(6) Phosphorus.

(7) Sulphur.

(8) Chlorine - (Br., I.).

(9) Potassium.

(I0) Sodium.

(II) Calcium.

(I2) Magnesium.

(I3) Iron.

(I4) Oxygen (food and respiratory comburant; tension of oxygen in the atmosphere).

(I5) Silica.

(I6) Electricity.

(I7) Radio-activity.

(I8) So-called catalysts (manganese, lead, uranium, etc.).

(Ig) Other living beings (parasitism, symbiosis properly so called, etc.).

(20) Thc space available for the development of the individual.

Each of the mentioned causes (the list is rather incomplete) has its proper influence upon each living specimen considered as a whole and upon each of its primordia. These causes are the CONDITIONS OF EXISTENCE.

In the course of the development of a living specimen the

1 Without the external factors the (internal) specific causes would not be operative. 


\section{THE QUANTITATIVE METHOD IN BIOLOGY}

above-mentioned factors are continually varying; their variable values are combined in an unlimited number of ways:

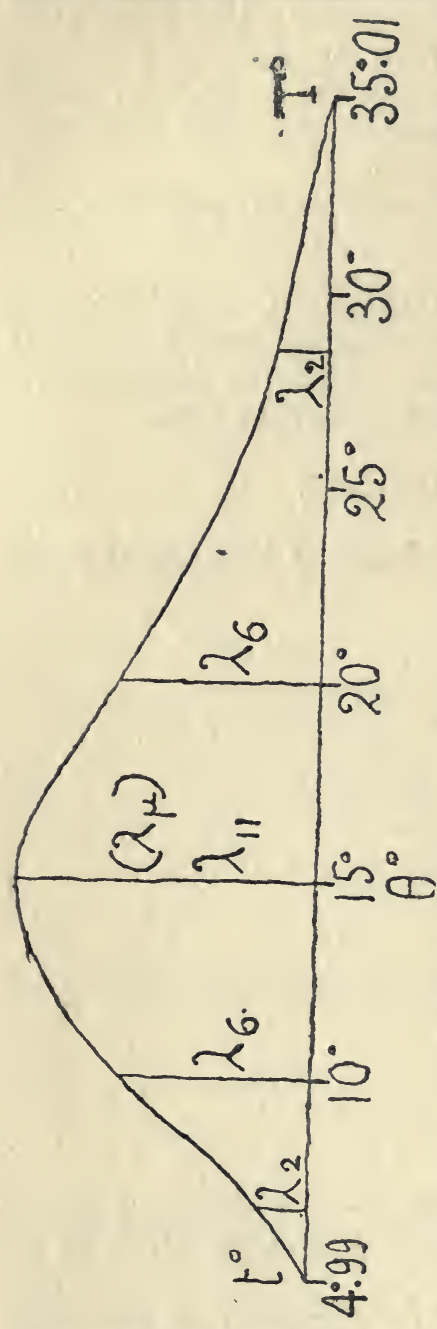

FIG. 25.-The curve is an approximate expression of the relation between temperature $\left(t^{\circ}-T^{\circ}\right)$ and length $\lambda$ of the spike; $\lambda \mu$, maximal length of the spike; $\theta^{\circ}$, optimal temperature. (See text.) they are the COMPONENTS OF CHANCE. The prevailing combination is different for all the specimens of a given species.

I take the influence of temperature upon a given primordium (for instance, the length $\lambda$ of the spike of a given subspecies of rye) as example. We know from experience that the growth of any living object whatever is possible only within two limits of temperature. I call the lowest limit $t^{\circ}$ and the highest limit $T^{\circ}$. Let us suppose that, in the case of the spike, $t^{\circ}=+5^{\circ} \mathrm{C}$. and $T^{\circ}=35^{\circ}$ C. (or thereabout). Between $t^{\circ}$ and $T^{\circ}$ every variation of temperature results in a variation of the intensity of growth and therefore of the value $\lambda$. Starting from $t^{\circ}$, every increase of temperature brings about an increase of $\lambda$ till a certain temperature $\theta^{\circ}$ (I suppose $I 5^{\circ}$ C.) is reached. Every further increase from $\theta^{\circ}$ to $T^{\circ}$ results on the contrary in a decrease of $\lambda$. The temperature $\theta^{\circ}$ (intermediate between $t^{\circ}$ and $T^{\circ}$ ) is the optimal temperature, which coincides with the maximal effect.

The relation between cause and effect is roughly represented by Fig. 25. Below $t^{\circ}$ and above $T^{\circ}$ the length $\lambda=0$, for the simple reason that no spike may come into existence.

The limits $t^{\circ}$ and $T^{\circ}$ are, of course, critical temperatures. Therefore I take, in Fig. 25, limits which are a little below $t^{\circ}$ and a little above $T^{\circ}$.

Suppose that a series of specimens have been cultivated at all possible temperatures between $t^{\circ}$ and $T^{\circ}$, the other conditions of development being the same for each and all. The adult spikes being measured, a series of values $\lambda_{1}, \lambda_{2}, \lambda_{3} \ldots \lambda_{\mu}$ is obtained. The highest value 
$\lambda \mu$ coincides with the optimal temperature $\theta^{\circ}$. It is impossible to obtain a spike longer than $\lambda \mu$, whatever may be the temperature (the other conditions of existence being the same). Therefore $\lambda \mu$ is a constant. If we compare two or several subspecies of rye, each of them has its own value $\lambda \mu$.

The maximal value of a primordium is the exact expression of a constant property of each species (specific form), just as the density of a given substance is the exact expression of a constant property of that substance.

REMARK: The influence of temperature upon the primordium under consideration is comparable to the influence of temperature upon the density of water. The existence of liquid water is possible between $t^{\circ}\left(=0^{\circ} \mathrm{C}\right.$. $)$ and $T^{\circ}\left(=100^{\circ} \mathrm{C}\right.$. $)$. If a series of specimens of water were taken at all possible temperature between the limits $t^{\circ}$ and $T^{\circ}$, and if their density were measured, a series of values $d_{1}, d_{2} \ldots d \mu$ would be obtained. The highest value $d \mu$ would coincide with $+4^{\circ} \mathrm{C}$., which is $\theta^{\circ}$. This 'value $d \mu$ has been adopted as a fundamental physical constant.

§ 120.-BIOLOGICAL AND INORGANIC VARIATION CURVES (continued).-I suppose that we find, in the state of nature, an unlimited number of specimens which have been developed at all possible temperatures between two limits (which are not necessarily $t^{\circ}$ and $T^{\circ}$ ): a large number-for instance, I024 adult spikes-are measured. ${ }^{1}$ The temperature of development of each specimen depends on a combination (resultant) of a number of natural accidental causes. The frequencies of these combinations are governed by the laws of chance, and therefore the frequencies of the various observed values of $\lambda$ (length of the spike) are governed by the same laws.

The variation curve (curve of frequency) of temperature being represented by $\left(\frac{1}{2}+\frac{1}{2}\right)^{10}$ (see Fig. I8, p. I46), what will be the variation curve of $\lambda$ ?

I take two eventualities as examples and expound the subject by means of figures, supposing that all other conditions of existence are the same for all the specimens. (The following Tables and calculations are merely approximate, owing to the use of the arithmetical method.)

First Eventuality: The most frequent temperature is $\theta^{\circ}$ (optimum). Suppose the limits of temperature have been $10^{\circ}$ and $20^{\circ}$, the optimum $\left(\theta^{\circ}\right)$ being $15^{\circ}$. The following Table $\left[(a+b)^{10}\right]$ gives the curve of frequency of temperature expressed

${ }^{1}$ In order to eliminate the variation produced by gradation (see Part VIII.) in each plant only the spike of the first bud generation is measured. This is, in the case of the rye, ordinarily the longest spike of each plant. 


\section{THE QUANTITATIVE METHOD IN BIOLOGY}

by the number of measured specimens developed at each temperature :-

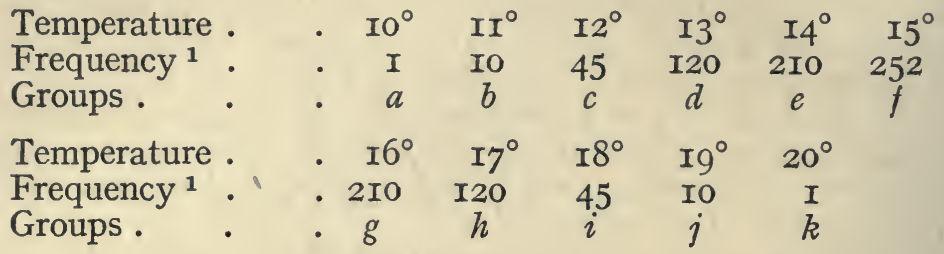

Suppose, on the other hand, that the relation between the length $\lambda$ and temperature (between $10^{\circ}$ and $20^{\circ} \mathrm{C}$.) is expressed by the following table ${ }^{2}$ :-

Length $\lambda_{6}$ (for instance, $10 \mathrm{~cm}$.) coincides with $10^{\circ}$ and $20^{\circ} \mathrm{C}$.

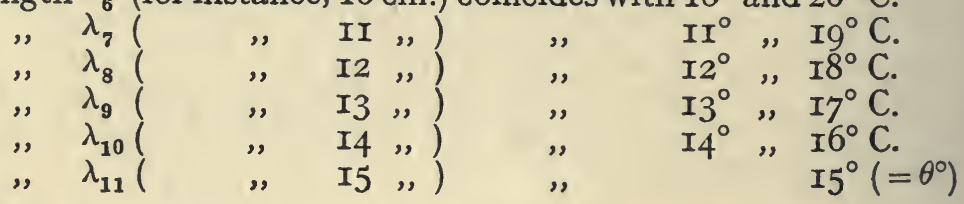

From the above figures the following variation curve (curve of frequency) of $\lambda$ is deduced :-

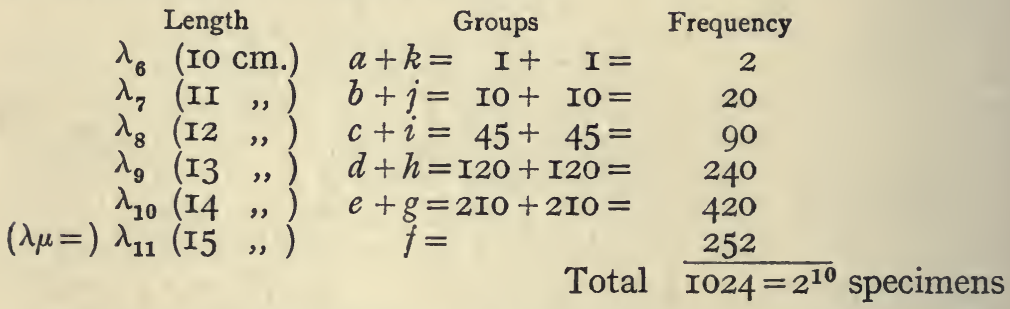

This curve is asymmetrical: the most frequent value $\lambda_{10}$ $\left(I_{4} \mathrm{~cm}\right.$.) is the length of the spikes which have been developed either at $14^{\circ}$ or at $16^{\circ} \mathrm{C}$. The arithmetical mean of $\lambda$ is 13.77 $\mathrm{cm}$. It may be possible to express (in a rather complicated way) the relations between the mean value and the data. The latter are: (I) the variation curve of temperature (absolute values and frequencies); (2) the values $\lambda_{6}, \lambda_{7} \ldots$ and the curve which expresses the relation between these values and the temperatures between $10^{\circ}$ and $20^{\circ} \mathrm{C}$.

In the present state of biological science, however, the problem is insoluble, because we have no exact information

${ }^{1}$ Number of specimens (total I024).

2 Proceeding in Fig. 25 from both limits $t^{\circ}$ and $T^{\circ}$ towards the highest ordinate, we meet on each side successively the values $\lambda_{1}, \lambda_{2} \ldots \lambda_{11}$. The length $\lambda_{1}$ (practically o) coincides with the critical temperatures $t^{\circ}$ and $T^{\circ}$. The length $\lambda_{2}$ coincides with two temperatures (see Fig. 25) which are nearer the optimum $\left(\theta^{\circ}\right)$, etc. The length $\lambda_{11}(=\lambda \mu)$ coincides with $\theta^{\circ}$. 
about the data. The figures which I have taken are more or less approaching to reality; they are, however, arbitrary. In any case, the arithmetical mean is here, for the biologist, an empirical value.

Second Eventuality: The limits of temperature are supposed to be $\mathrm{II}^{\circ}$ and $2 \mathrm{I}^{\circ} \mathrm{C} .\left(\theta^{\circ}=I 5^{\circ}\right)$. The frequencies of temperature are given by the following curve (according to $\left.\left(\frac{1}{2}+\frac{1}{2}\right)^{10}\right)$ :-

\begin{tabular}{|c|c|c|c|c|c|c|}
\hline Temperature & - $\mathrm{II}^{\circ}$ & $\mathrm{I} 2^{\circ}$ & $13^{\circ}$ & $14^{\circ}$ & $15^{\circ}$ & $\mathrm{I} 6^{\circ}$ \\
\hline Frequency ${ }^{1}$ & & IO & 45 & $\mathrm{I} 2 \mathrm{O}$ & 210 & 252 \\
\hline Groups . & & $c$ & $d$ & $e$ & $t$ & $g$ \\
\hline $\begin{array}{l}\text { Temperature } \\
\text { Frequency }\end{array}$ & $17^{\circ}$ & $18^{\circ}$ & $19^{\circ}$ & $20^{\circ}$ & $2 I^{\circ}$ & \\
\hline $\begin{array}{l}\text { Frequency }{ }^{1} \\
\text { Groups. }\end{array}$ & ${ }_{h}^{2 I O}$ & $\mathrm{I}_{i}$ & ${ }_{j}^{45}$ & $\begin{array}{l}\text { IO } \\
k\end{array}$ & $\begin{array}{l}\mathrm{I} \\
l\end{array}$ & \\
\hline
\end{tabular}

The variation curve of the primordium $\lambda$ is given by the following Table (the relation between $\lambda$ and temperature being the same as in the first contingency, and the length of the spike at $2 \mathrm{I}^{\circ}$ being $\lambda_{5}=9 \mathrm{~cm}$.) :-

$$
\begin{aligned}
& \text { Length } \\
& \begin{array}{lll}
\lambda_{5} & (9 \mathrm{~cm} \text {.) }
\end{array} \\
& \text { Groups } \\
& l= \\
& k= \\
& \lambda_{7} \text { (II ") } b+j=\mathrm{I}+45 \\
& \lambda_{8} \text { (I2 ",) } c+i=10+\mathrm{I} 20 \\
& \lambda_{9} \text { (I3 ") } d+h=45+2 \text { IO }
\end{aligned}
$$

The curve is asymmetrical, yet distinctly different from the preceding one. Arithmetical mean of $\lambda=13.52 \mathrm{~cm}$.

The remarks about the mean value in the first eventuality are also applicable here.

It is easily seen that an unlimited number of eventualities are possible, since the most frequent temperature and the extremes may coincide, in each peculiar case, with various temperatures between the limits $t^{\circ}$ and $T^{\circ}$. The form of the variation curve of $\lambda$ (hump, mean value, etc.) depends, in each series of measurements, on the prevailing conditions. ${ }^{2}$ The observed figures (values of $\lambda$ ), and also the mean value, are an indirect expression of the conditions of development (temperature). One single figure is invariable: this is the maximal value of $\lambda$ (I have supposed $\lambda \mu=15 \mathrm{~cm}$.). ${ }^{3}$ This value will be

\footnotetext{
1 Number of specimens (total 1024).

${ }^{2}$ In certain cases a unilateral curve might be obtained.

${ }^{3}$ About the minimal value of $\lambda$, see below.
} 


\section{THE QUANTITATIVE METHOD IN BIOLOGY}

discovered as often as the conditions under which the measurements are made are various enough to include $\theta^{\circ}$. It is a constant of the race.

I have taken temperature as example. The same rule holds, in general, ${ }^{1}$ for the various factors mentioned in the list, p. I67. For each factor there are two limits and an optimum. We know from experience, for instance, for the substances nitrogen, phosphorus, potassium, etc., that the development of an organism is impossible when they are not available in sufficient quantity and that, on the other hand, too high a dose becomes detrimental and even poisonous. Every gardener knows that the development of many species (for instance, a number of ferns) is impossible in a sunny place or in a place which is too dry, and also when the intensity of light is too weak or the watering too abundant; etc., etc.

The absolute values of the minimum, optimum and maximum (values $m-0-M$ ) of each factor (with reference to each primordium and to the individual considered as a whole) are the expression of properties of each living species. They are, however, variable within the limits of one species. The chief cause of this variability is the fact that the values $m-0-M$ of each factor are more or less modified by the variation of other factors.

We know, for instance, that the optimal value of the tension of carbon dioxide in the atmosphere depends on the intensity of light. The $m-0-M$ of temperature are modified (in an intricate way) by the available quantity of water. Potassium, calcium, phosphorus, etc., are absorbed by each species in certain proportions: if the available quantity of one substance $a$ (for instance, potassium) is modified, the absorption of the others $b, c \ldots$ is modified in its turn, and one would therefore expect that any variation of $a$ would result in a variation of the $m-0-M$ of $b, c$. . . Although our knowledge of the relations alluded to is still incomplete, we may assume that they are very numerous and intricate. Therefore the exact experimental determination of the values $m-o-M$ of a given cause (factor) with regard to a given primordium of a given species is an exceedingly complicated problem. ${ }^{2}$

In each specimen the numerous factors enumerated (p. I67) are combined in a certain way. The diversity of the combinations brings about variation of the primordia, each primordium being variable according to its specific energy.

1 Perhaps with certain restrictions, which are unimportant for our subject.

${ }^{2}$ Physicists and astronomers are faced with questions which are almost as involved as the biological problems alluded to. I recall the numerous corrections which have to be made in order to deduce from the height of the mercury in a barometer the exact pressure of the atmosphere. This is a comparatively simple example. 
We know that when a large number of causes (factors) are combined under the influence of chance, the intensity of each factor being variable according to the law of chance (see temperature, p. I70), ${ }^{1}$ and when no cause is predominant, the frequency of the combinations is, when all is said and done, governed by the law of chance which also governs the errors of observation and finds its expression in the curve of errors (Fig. I8, p. I46).

When a certain primordium is measured in a number of specimens of a given species taken at random in the state of nature, each figure is the expression (the measure, as it were) of a certain combination (resultant) of ALL the factors which are the components of the conditions of development. It may therefore be expected that the observed variation would be expressed by a one-humped symmetrical curve similar to a curve of errors (or the variation of the prisms, Fig. 24, p. I6r). This is actually often (not always) the case. ${ }^{2}$

In a biological variation curve (whatever its form may be) the arithmetical mean is not a constant of the species. It is, just as any of the observed individual values, a physiological measure of a certain combination of factors. It is not the expression of a simple something. It is impossible to decompose each observed value into a constant \pm an error. The very same causes which produce variation bring the measured primordium into existence. (Compare $\S$ I08, p. I47, and $\S$ Ir6, p. I62.)

It is, moreover, impossible to determine exactly the $M E A N$ $V A L U E$ of a variable property of a species. I take as example Poa annua and suppose that I wish to determine the mean length of the axis of its panicle. If a number of specimens are collected from a dry, waste place, a wood (shadow), the banks of a stream (humid and sunny), walls or rocks, etc., a different mean value is obtained from each series. A comparison between the mean values is simply a comparison between the crnditions of existence in the mentioned localities. If an arithmetical mean were calculated from all the series considered as a whole, the obtained figure would depend, of course, on the number of specimens of each series; it would be an arbitrary and undecipherable something which would be modified by each new observation.

The MAXIMAL VALUE is, on the contrary, a strictly deter-

${ }^{1}$ In the case of living beings each factor is not only variable from one specimen to another, but also continually varying through the whole period of development of each specimen.

${ }^{2}$ Asymmetrical curves in which the mean does not coincide at all with the hump are common. When certain values of the measured primordium are more easily realized than others because of a certain specific energy, the variation ourve deviates from the typical form. (Sec Part VII., variation steps.) 


\section{THE QUANTITATIVE METHOD IN BIOLOGY}

mined specific constant. Suppose the panicles of a number of specimens, collected from various places, have been measured, and that the longest one has a length of $\operatorname{Irg} \mathrm{mm} .^{1}$ This value is the measure of the greatest possible length which the living mixture of Poa annua is able to produce when the combination of all the external factors is as favourable as possible ; in other words, when the resultant of the combined factors is optimal. Since the maximal effect of each factor (considered separately) does not coincide with its maximal value, but with its optimum, the effect of any combination whatever cannot exceed a certain determined maximum.

This conclusion is confirmed by daily observation.

We know from experience that a given property of a given species never exceeds a certain value. The length of a leaf of Quercus pedunculata, the number of marginal teeth of a leaf of Castanea vesca, the number of cells of a hair on the leaves of Primula sinensis, the length of the tibia of a horse or the tail of a cow, the weight of a potato, the breadth of a petal of Ranunculus acris never exceed a certain figure, however favourable the conditions of existence may be, whatever may be the efforts of the gardener or the breeder.

When a vegetable species is brought under CULTIVATION it often happens that the new combination of external factors is, on the whole, nearer the optimum (with regard to a given property) ${ }^{2}$ than the combination which is the most frequent in the state of nature. The mean value may therefore be augmented, and it is also possible that the highest observed value becomes greater. I think, however, that if numerous wild specimens collected from a wide area and developed under various conditions had been measured, the obtained maximum would be hardly or not inferior to the maximum which might be obtained from cultivated specimens. In this question, any conclusion drawn from a mere impression must be distrusted: it is only by measuring each primordium separately that exact information can be obtained. (Compare § 23.)

When the maximum of a primordium has been determined by the measurement of numerous (wild and eventually cultivated) specimens, it is possible that a higher maximum is found by more observations. In this occurrence the specific constant is to be corrected, and this may be repeated several times. Many physical and chemical constants have also been corrected step by step. After each correction of a biological constant we are brought nearer exactitude, and the probability of a new correction and its probable importance become smaller. ${ }^{3}$ At

1 This is the figure I have found. According to J. D. HOOKER, the maximum is 3 in. $=76 \mathrm{~mm}$.

${ }^{2}$ It is possible, of course, that the reverse happens if the conditions of existence are less favourable under cultivation than in the state of nature.

${ }^{3}$ Because we are approaching more and more the extremity of the curve of frequency (Fig. 24). 
the end the error will be as small as the unavoidable errors of measurement.

In order to discover the extreme values (maximum and minimum) of a primordium it is not always necessary to measure very numerous specimens. The value of many primordia may be roughly estimated without any instrument. In all such cases we may content ourselves with collecting and measuring, among a large number of individuals (in each locality or spot), the specimens which approach the limits.

\$120A.-MINIMAL VALUES.-The minimal value of a primordium may be looked upon, with certain restrictions, as being a constant of the species. The lowest value of a primordium $p$ coincides with the most unfavourable (pessimal) combination of external factors under which its existence is possible. The resultant of the pessimal combination is, of course, a critical value, just as the limits of each factor considered separately. (See p. I68.) On the other hand, the value of $p$ at the beginning of its development is ordinarily very small, practically not different from zero. If the prevailing combination of factors is only a little better than the pessimum, the growth of $p$ is stopped in a very early state, when its value hardly exceeds $o$. If the combination of factors is more unfavourable than the pessimum, $p$ does not come into existence, which is expressed by the value o. In both cases the value of $p$ is practically $o$. This value being the same for very numerous primordia of innumerable species, the minimal value of a primordium is, in general (no restrictions being made), deprived of any specific significance.

This conclusion is confirmed by the observation of facts. I take as FIRST EXAMPLE the length of the limb of the leaf in Castanea vesca, Fagus silvatica and Betula alba. The maximal values are distinctly different and characteristic of each species. In the three mentioned species the limb of the smallest leaves is very short, and since the three minimal values converge towards the same limit (which is 0 ), these values are not characteristic. ${ }^{1}$

I take the height $h$ of the stem of the rye as SECOND EXAMPLE. In the ripe seed $h$ is, as it were, infinitely small (compared with its maximal value, which is 2 metres or thereabout). In the course of the germination and later on $h$ increases, passing through a series of successive values $h_{1}, h_{2}, h_{3}$. Its growth may be stopped in any state whatever of its development, when the value $h_{1}$, or $h_{2}$, or $h_{3} \ldots$ is reached. Since many (practically all) other Gramineo (for instance, Poa

1 The smallest leaves are to be looked for a short time after the buds have expanded because they often disappear later on. 


\section{THE QUANTITATIVE METHOD IN BIOLOGY}

annua, Phleum arenarium, etc.) behave in the same way, the minimal value of $h$ converges towards the same limit (practically o) in each and all, just as in the above example of the leaves. Therefore the terms minimal height of the stem, without more, represent an indeterminate notion.

Remark : The facts alluded to may be actually observed as often as a limited area is crowded with seeds of the same species. The growth of the young plants is stopped when their stems are still very short (and sterile). The same experiment being carried out with several species (each of them separately), no perceptible difference is observed with regard to the minimal value of $h$. I have carried out the experiment with rye, Poa annua and Phleum arenarium.

Certain CONVENTIONS (restrictions) being made, however, the minimal value of a primordium may be looked upon as being a characteristic specific constant.

The aspect of the question is changed, indeed, if we take a given primordium under certain definite conditions; for instance, the height hf of the fertile stem of a grass. The existence of a fertile stem is only possible when the variation of the conditions of existence (combined factors) is included within certain limits which are different according to the species, and narrower than the limits between which the development of a stem in general is possible. Therefore the minimum of $h f$ is not the minimal height of a stem in general, but the peculiar minimum which may occur when the conditions of fertility of the species are prevailing. Therefore the minimum of $h f$ is a specific constant.

In a similar way the minimal values of various primordia of animals and plants are specific constants.

Examples: The length, breadth and other primordia of the longest leaf of a fertile stem of an acrocarpic moss; the length and other primordia of the longest petal of a flower; the number of flowers of an inflorescence; the length of an antenna, a wing and other parts (segments) of an insect; the primordia of an animal or a vegetable embryo in a state of development coinciding with a given value of the leading property (see $\$ 49$ ), etc.

§ 120B.-RELATION BETWEEN MEAN VALUE AND VARIATION STEPS.-The arithmetical mean of a series of measurements has, in general, only an empirical significance. It may happen, however, that a mean value coincides with one of the terms of a series of variation steps. In this case the mean value is the expression of a characteristic state of equilibrium, and is really a constant of a peculiar kind. (See Part VII., especially § I27.)

\section{§ 121. -USEFULNESS OF MEAN VALUES FOR COM-} PARING TWO OR MORE SERIES OF MEASUREMENTS.One single mean value, taken alone, is a rather vague piece of information; if we ascribe to it a definite significance we 
are in danger of being deceived. In certain cases, however, a comparison between two or several mean values obtained under definite conditions may render good service.

Example: Wheat is cultivated on two fields $A$ and $B$, all the conditions of existence being as exactly as possible the same for both ${ }^{1}$-in such a way that the variation curve of any given property of the wheat would be the same on $A$ and $B$. A certain quantity of potash manure is added to $B$. When the wheat is ripe, one of its properties-for instance, the length of the spike-is measured. If any difference exists between the mean values of $A$ and $B$ it may be considered as an indirect measure of the influence of the added potash.

In general, it may be said that a comparison between two or several mean values gives useful information as often as the series of measurements have been collected under conditions which were different only with regard to one factor.

According to this principle, I use the mean values for the investigation of the gradation curves, the varying factor being here a social cause. (See Part VIII.) In a similar way I have used mean values for the investigation of the growth of certain properties of a mixture ( $\$$ II4, pp. I55 and I57), the varying factor being here the age of the measured specimens.

1 In other words, the same series of combinations of factors with the same frequencies prevailing on both fields. 


\section{PART VII}

\section{VARIATION STEPS}

§ 122.-EXAMPLES OF VARIATION STEPS: PEDIASTRUM, PERISTOME OF MOSSES.-In Pediastrum (§ 64) the segments (cells) of an adult specimen (canobium, Fig. 3, p. 79) are $2,4,8 \ldots 2^{n}$ in number. The same series of values is observed in the number of teeth of the peristome of the mosses. These values are the expression of certain states of equilibrium (see, for instance, $\S 66$ ), which are more probable (more stable ?) than the intermediate values. I call them variation steps.

Although attention has been repeatedly called to this subject, especially by LUDWIG and also, among others, by DE BRUYKER, WASTEELS, DE VRIES, VERSCHAFFELT and myself, its importance has not yet been realized by the great majority of the biologists.

In general, when a given property passes through a series of values, if certain values $a^{\prime}, a^{\prime \prime}, a^{\prime \prime \prime}$ are observed more frequently than the intermediate values, the terms $a^{\prime}, a^{\prime \prime}, a^{\prime \prime \prime} \ldots$ are variation steps. Between the values $a^{\prime}, a^{\prime \prime}, a^{\prime \prime \prime}$. . certain arithmetical relations exist.

\section{§ 123.-DIVERSE SERIES OF VARIATION STEPS.-} Several series of variation steps have already been discovered. I limit myself to five examples ${ }^{1}$ :

(I) The Fibonacci series (discovered and thoroughly investigated by LUDWIG), which consists of the terms I, 2, 3, 5, 8, I3, $2 I, 34$. . . Each term is the sum of the two preceding terms, the first terms being I and 2. Examples are very numerous; for instance, the number of marginal florets in many species of Corymbiferous Compositæ. This series seems to exist also in the animal kingdom (LUDWIG); for instance, in certain properties of the shells of many Mollusca (Pecten, VAN DER GUCHT ; Scalaria, MACLEOD and WASTEELS, etc.).

(2) The series $3,5,7 \ldots$ (uneven numbers). Example: the number of leaflets of digitate leaves in many plants; for instance, in Trifolium pratense quinquefolium (discovered by DE VRIES).

(3) The series 5, Io, I5 ... (multiples of 5). Example:

${ }^{1} \mathrm{My}$ notes are not within my reach. 
the number of styles in a race of Geranium with numerous styles (discovered by DE VRIES). (See $\S$ I3I.)

(4) The series 3, 6, 9 (multiples of 3). Example: the number of stamens in many Monocotyledons; for instance: Iris, 3 ; Lilium, 6 ; Butomus, 9. The values I, $2 \ldots 4,5 \ldots 7,8$ ...IO, II ... are uncommon, rare or very rare in the androecium of the Monocotyledons.

(5) The series 2, 4, 8, 16, $32 \ldots$ (powers of 2). Examples: number of cells in Pediastrum; number of teeth of the peristome of the Mosses.

REMARK: Certain values belong to more than one series; for instance: the value 3 belongs to the series 1,2 and 4 ; the value 5 belongs to the series $\mathrm{I}, 2$ and 3 ; the value 8 belongs to the series $\mathrm{I}$ and 5 . (See $\S \mathrm{I26}$.)

§ 124.-VARIATION STEPS OF THE FIRST, THE SECOND AND THE THIRD DEGREE.-Several degrees are observed in the frequency of the characteristic terms of a given series of variation steps compared with the frequency of the intermediate values. I discern three degrees of frequency, between which all possible transitions exist :

Variation steps of the first degree.-The characteristic terms of the series under consideration exist alone, the intermediate values being very rare (or practically never observed). Example: genus Senecio. In Senecio nemorensis, subspecies (?) pentaglossa (ordinary form, province Luxemburg, Belgium), the marginal florets are 5 in number. In a subspecies (?) which I have found in Belgium, and which might be called Sen. nem., subsp. triglossa (if not yet described), the number is $3 .^{1}$ In Sen. nem., subsp. (?) octoglossa (mentioned in Switzerland) the number is 8. In Senecio jacobaa (Flanders) the number is I3. In these examples the observed figures $(3,5,8,13)$ belong to the Fibonacci series. According to my (very numerous) observations, the above-mentioned figures 3,5 and 13 are almost invariable in each of the corresponding specific forms, and, according to floristic data this is also the case with figure 8 in subsp. octoglossa. ${ }^{2}$ The figures $2,4,8,16 \ldots$ in the peristome of the Mosses, the step values 3, 6, 9 in the andrœcium of many Monocotyledons are probably almost always of the first degree. (That is to say, invariable or almost invariable in a given specific form.)

Variation steps of the second degree.-The transitory values

1 This subspecies is very abundant in a wood about $\mathrm{I}$ kilom. north from the station Poix St Hubert (province Luxemburg), east from the railway.

2 In the British Islands, the number of marginal florets varies in $S$. nemorensis between 5 and 8 (seldom more than 6 or 7). (BENTHAM, British Flora, 1866, pp. 254-256.) According to LUDWIG (Botan. Centralblatt, vol. Lxiv., r895, p. 100) the typical values in the mentioned species are 3 and 5 , the figure 5 being predominant. 


\section{THE QUANTITATIVE METHOD IN BIOLOGY}

between the variation steps are rather common, but distinctly less frequent than the characteristic step values. Examples: number of leaflets in Trifolium pratense quinquefolium: the figures $3,5,7 \ldots$ are predominant; leaves with $4,6,8, \ldots$ leaflets being less numerous, although not uncommon (DE VRIES). In Chrysanthemum segetum (number of marginal florets) the Fibonacci terms I3 and 2I are much more frequent than the transitory values (DE VRIES). This is also the case with the number of marginal florets in many other Composite (LUDWIG). For instance, in Chrysanthemum carinatum the terms 5, 8, I3 and $2 \mathrm{I}$ are distinctly predominant (DE BRUYKER and myself).

Variation steps of the third degree.-Here the limits of variation coincide more or less exactly with two characteristic terms of a series, the most frequent value being one of the transitory values. Example: the number of marginal florets in the terminal flower-head of Centaurea cyamus ${ }^{1}$ : the most frequent value is about Io or II (under ordinary conditions of existence). Starting from this maximum the frequency of the flower-heads decreases in the positive and in the negative sense till the values 8 and $\mathrm{I} 3$ are reached. Below and above these limits there is a sudden decrease in the frequency: flower-heads with >I3 marg. florets are uncommon and such with $<8$ marg. florets are rare. The variation of the property under consideration oscillates, as it were, between two limits which coincide with two variation steps. I think that numerous examples of the third degree will be discovered as soon as more attention is paid to this subject.

§ 125.-SYMMETRY AND VARIATION STEPS.-Many biologists look upon the Fibonacci terms and the other series mentioned in $\S$ I23 as being merely the expression of certain states of symmetry. (This view is not a sufficient reason to overlook the whole subject.)

In the case of Pediastrum and Euastropsis (number of cells : series $2,4,8 \ldots 2^{n}$. See $\$ 65$ ) the observed figures are not a consequence of symmetry, since they are determined before the cells meet one another, thus before any symmetry exists with regard to their relative position. In a bicellular specimen of Euastropsis the bilateral symmetry is a state of equilibrium which depends on the fact that two independent cells meet each other. Similarly in Pediastrum tetras, the radial symmetry depends on the fact that four cells meet each other and are united into a system of equilibrium which has the form of a

1 Specimens with blue flowers collected in ryefields in Flanders. Specimens with blue and specimens with purplish flowers (subspecies atropurpurea) raised from seed which was obtained from HAAGE and SCHMIDT in Erfurt. 
rectangular cross. In these examples, the observed symmetry is secondary, the number of segments is primary.

Between symmetry and variation steps certain relations may exist and probably really exist. In certain examples symmetry may be the cause of the variation steps; in other examples symmetry is rather the effect, the variation steps being the cause. It is impossible to express the relations alluded to in one short sentence.

This subject is in relation with very delicate morphological problems. Morphological homology, mechanical concordance (\$ 65) and variation under the influence of external causes (plasticity) ought to be taken into account; the distinction between hereditary possibilities and observable properties must be borne in mind.

§ 126.-THE SIGNIFICANCE OF AN OBSERVED VALUE DEPENDS ON THE SERIES TO WHICH IT BELONGS.In Senecio nemorensis, subsp. octoglossa, the marginal florets are 8 in number. Here the number 8 is a term of the Fibonacci series, for other terms of this series are observed in other species of Senecio ( $\$$ I24) and in other Compositæ. In Epilobium and Fuchsia 8 stamens exist; here the number 8 is a term of the series 2, 4, $8 \ldots 2^{n}$, for this series is observed among the Onagracea (Circcea, Lopezia, 2 stamens; Eucharidium, Isnardia, 4 stamens; Hauya, Clarkia, Enothera, Epilobium, Fuchsia, 8 stamens). From these examples (see also § I23, Remark) it may be concluded that the significance of a given value depends on the series to which it belongs, as often as variation steps are at play.

In other words, the series of steps through which the value of a given property passes is the quantitative expression of a certain specific energy of this property. Therefore the value 8 is the expression of different specific energies in Epilobium and Senecio.

This is of the highest importance with regard to the study of heredity and variation. (See $\S \mathrm{I} 3 \mathrm{I}$.) See, in $\S \mathrm{I} 32$, the methods for discovering the series of variation steps to which a given value belongs.

\section{§ 12\%,-A MEAN VALUE WHICH COINCIDES WITH A} VARIATION STEP MAY BE LOOKED UPON AS BEING A CONSTANT.-In a biological curve a mean value which does not coincide with a variation step has not the significance of a constant. It is not the measure of something which has an independent existence, and it is therefore quite different from the mean value of a curve of errors. (See $\S$ ro8.) Such a biological mean is merely an indirect measure of the conditions 


\section{THE QUANTITATIVE METHOD IN BIOLOGY}

of development of the measured specimens. A comparison between two mean values is, in reality, a comparison between the conditions of existence of two groups of specimens. (See $\S$ I20.)

EXAMPLE: In Mnium hornum the length of the longest leaf of the fertile stem varies between 5.17 and $8.06 \mathrm{~mm}$. These figures are specific constants. If a certain number of specimens collected from one spot are measured, the extremes may be, for instance, $5^{\circ} 50$ and 7.00 , the mean being $6.25 \mathrm{~mm}$. A second series of specimens, collected from a second spot (even in the same locality) may give : extremes 6 and 7.50, the mean being $6.75 \mathrm{~mm}$., etc. Since no variation steps exist in the property under consideration, the mean values obtained (and also the extremes in each series) depend on the conditions of existence. These conditions are more or less variable from one spot to another.

When, on the contrary, a biological mean coincides with a variation step, it is really the measure of a definite something, of a specific energy which exists in the measured property, independently of any external cause. Such a mean value is (for the naturalist) comparable with the mean of a curve of errors : it is a constant.

EXAMPLES: Variation steps of the first degree. In Senecio jacobcea the number of marginal florets is almost always 13 (Fibonacci term); the figures $\mathrm{I}_{2}$ and $\mathrm{I}_{4}$ are very rare. Series of specimens collected from various spots and various localities always give the mean I3. This mean is a constant. $I \bar{t}$ may be surmised that many properties of animals and plants, which are practically constant in a species or a genus, are in reality variation steps of the first degree of a certain series.

Variation steps of the second degree. I have cultivated Chrysanthemum carinatum in several series under various conditions of existence. In one of the series, the variation curve was comparatively symmetrical, the most frequent value (hump of the curve) being 21 (Fibonacci term). The mean value was, approximately, $2 \mathbf{r}$. Such a coincidence between the mean and a variation step is rather rare when the steps are of the second degree. Ordinarily the mean coincides approximately with one of the transitory values between two steps. In Chrysanthemum segetum, DE VRIES obtained the following variation curve (number of marginal florets of the terminal flowerhead ${ }^{1}$ ) :

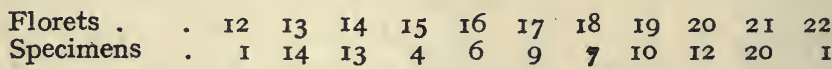

The arithmetical mean is 17.5 . The curve is two-humped (dimorphic) : the humps coincide with the variation steps 13 and $2 I$ and represent therefore constants, whereas the mean has no definite significance. (See also § I29.)

Variation steps of the third degree. In Centaurea cyanus (under ordinary conditions of existence) the variation curve of the number of marginal florets of the terminal flower-head is one-humped, the hump coinciding with the values 10 or $I I$, the mean coinciding almost exactly with the hump. In reality, the mean is intermediate between two variation steps 8 and 13 , which are indicated by a sudden falling of the curve between 7 and 8 and between I3 and 14. The mean does not represent a constant: it is, however, influ-

${ }_{1}$ Archiv für Entwickelungsmechanik, Bd. II., p. 52, 1896. (Quoted after VERNON, loc. cit., p. 50.) I have obtained several similar curves for Chrysanthemum carinatum. Unfortunately the figures are not at my disposal. 
enced in a certain degree by the existence of the variation steps. The curve is governed not only by the laws of chance; it is also under the influence of the specific energy which finds its expression in the variation steps.

If we compare the examples given in this paragraph, we see that in the case of Mnium the mean is merely a product of chance; in Senecio the influence of a specific energy is quite predominant; in Chrysanthemum the latter influence is less important; in Centaurea ${ }^{1}$ it is still more in the background. It is, moreover, quite thinkable that variation steps might be still more concealed than in the case of Centaurea, their influence upon the mean and upon the form of the curve being still smaller. In the present state of science, we must content ourselves with a rough estimation of the influence alluded to. We may, however, anticipate the possibility of calculating it exactly.

However skilful and subtle the mathematical methods used in biometry may be, biological errors may be committed in the interpretation of a mean value if the eventual existence of variation steps is not taken into account.

OTHER EXAMPLES: Professor PEARSON counted the number of stigmatic bands on the 4443 seed capsules obtained from I 76 Shirley poppies growing in a single garden, and found the following frequencies (Pearson, Grammar of Science, 2nd Ed., p. 443. Quoted after Vernon, p. 89):-

$\begin{array}{llrrrrrrrr}\text { Bands } & . & 5 & 6 & 7 & 8 & 9 & 10 & \text { II } & \text { I2 } \\ \text { Frequency } & . & \text { I } & \text { II } & 32 & 56 & \text { 148 } & 363 & 628 & 925 \\ \text { Bands } & . & 13 & \text { I4 } & \text { I5 } & \text { 16 } & \text { I7 } & \text { 18 } & \text { 19 } & \\ \text { Frequency } & . & 954 & 709 & 397 & \text { I55 } & 51 & \text { I2 } & \text { I } & \end{array}$

Professor PEARSON counted the segments on 3212 fruits of Nigella hispanica, and found the following frequencies (loc. cit.):-

$\begin{array}{lrrrrrrrrrr}\text { Segments } & \text {. } & 2 & 3 & 4 & 5 & 6 & 7 & 8 & 9 & \text { 10 } \\ \text { Frequency } & \text { ir } & \text { 10 } & 7 & 20 & 303 & 412 & 534 & \text { 1552 } & 223 & 59 \\ \text { Segments } & \text { II } & \text { I2 } & \text { I3 } & \text { 14 } & \text { I5 } & \text { 16 } & \text { I7 } & \text { 18 } & 19 & 20 \\ \text { Frequency } & 35 & 43 & 6 & - & - & 6 & - & - & - & 2\end{array}$

In both curves the material is not homogeneous. Terminal fruits and lateral fruits of successive order being brought together, the influence of gradation (social cause, see $\S$ I28) has been overlooked. In other words, there is no social equivalence among the material.

In spite of that, the most common form coincides in each curve with a variation step (respectively 13 and 8 ) which belongs here to the Fibonacci series. Therefore the hump of each curve may be looked upon as being a constant.

The mean values (12.51 and $\left.74^{\circ 6}\right)$ coincide approximately with the most frequent values. In reality, however, the mean values (if not compared with the humps) are here a vague expression of the conditions of existence of the examined plants. According to my observations, the number of stigmatic bands in Papaver (poppy) is very variable according to the conditions of life, and this is undoubtedly also the case in Nigella.

\section{§ 128. - RELATION BETWEEN THE VARIATION STEPS AND THE CONDITIONS OF EXISTENCE. TRANS-}

${ }^{1}$ By counting the ribs of the shell of Scalaria communis (more than 1000 specimens, Flemish coast) a variation curve was obtained more or less similar to that of Centaurea cyanus (MACLEOD and WASTEELS). 


\section{THE QUANTITATIVE METHOD IN BIOLOGY}

FORMATION OF A MONOMORPHIC CURVE INTO A DIMORPHIC OR A POLYMORPHIC ONE BY EXTERNAL CAUSES. - When variation steps exist in the series of possible values of a certain property $p$, it may happen that a monomorphic (one-humped) curve is obtained under certain conditions of existence, whereas the curve is dimorphic or polymorphic under other conditions without any change in the hereditary properties.

EXAMPLE: I have cultivated Chrysanthemum carinatum in several groups, the conditions of existence being more and more unfavourable from the first group to the last one ${ }^{1}$ : the first group under ordinary conditions in a garden, the intervals between the specimens being rather large; the second group in the same soil, the intervals being too small to allow a full development of each specimen, etc.

The marginal florets of the terminal flower-head were counted in all the specimens. ${ }^{2}$ In the first group the variation curve was somewhat regular, with a distinct hump coinciding with the value $2 \mathrm{I}$. In the second group the hump coincided with I3; in the next groups the summit passed through the values 8,5 . ... In certain groups two humps (belonging to the series 3,5 , $8,13 \ldots$. .) were observed, with a depression between both. In this experiment the variation of the measured property and the succession of the steps (Fibonacci terms) was, of course, a consequence of plasticity. There was no specific hereditary difference between the groups.

The specimens of the first group produced a number of flowering branches; flowers were abundant for a period of about ten weeks. About a fortnight after the terminal flowerheads had been investigated, a second group of flower-heads produced by lateral branches were observed in their turn, and so on, several successive groups of flower-heads being taken with intervals of about a fortnight. The successive curves were different from each other in the same way as the curves of the terminal flower-heads of the groups cultivated under different conditions. The successive summits coincided with the Fibonacci terms, the order of decrease being 2I (terminal heads), $13,8,5,3$ from the beginning to the end of the flowering period. In certain curves two humps coinciding with two successive terms were observed. The successive appearance of the Fibonacci humps depends here on a social cause-i.e. gradation. (See Part VIII.)

1 This experiment was carried out in the Botanic Garden at Ghent with the collaboration of J. V. BURVENICH. The seeds were obtained from HAAGE and SCHMIDT, Erfurt. The subspecies cultivated was characterized by simple flower-heads; marginal florets white, central florets brownish.

2 The property mentioned here is of the second degree. 
Similar experiments were carried out by DE BRUYKER, on the whole with similar results.

In the Corymbiferous Composite the number of marginal florets may pass through a long series of values, let us say from 0 to I0o (and still more). When the variation of this property is observed :

(I) Within the limits of a complex species (Senecio nemorensis, $\S$ I24) or a genus (Senecio, $\S$ I24);

(2) In one monotypic species under the influence of plasticity ;

(3) In one monotypic species under the influence of gradation, the rule is always the same. The Fibonacci terms are always predominant (if they are of the first or the second degree), coinciding with the humps of the curves.

Adopting the view that any value whatever of the property under consideration corresponds to a state of equilibrium ( $\$ 43)$ I conclude that the Fibonacci terms are the expression of states of equilibrium which are more stable ${ }^{1}$ than those expressed by other values. The Fibonacci terms are, therefore, the expression of a certain mechanical predisposition which is a specific energy of the property. This conclusion is applicable on any series of variation steps whatever. (See $\$$ I23.)

Two more conclusions may be drawn from the above observations :

(I) The existence of a two- (or more) humped variation curve does not give proof of the existence of different subspecies (races) in the material ( $\$$ I30). In other words, dimorphism or polymorphism of a curve may depend on the existence of variation steps without any complexity. This remark is applicable on certain curves, from which the coexistence of different subspecies or races has been deduced, without any information about the specific energies of the measured property.

(2) A monomorphic (one-humped) variation curve may be transformed into a dimorphic (or polymorphic) one by a simple change in the conditions of existence-if variation steps are at play. Therefore, when the variation curve of a given property of a given species is one-humped in a first country (or locality), and two-humped in a second country (or locality), we are not allowed to conclude without more information that the species is monotypic in the first case and complex in the second case.

In Primula elatior the number of flowers of the so-called umbel is very variable, with distinct variation steps which coincide with the terms $3,5,8 \ldots$ (Fibonacci series). Dr DE BRUYKER has observed that specimens collected from dry spots give a variation curve in which the lower terms ( 3 or 5 , or both) are predominant, whereas specimens collected from wet spots in the same locality show a distinct predominance of the

${ }^{1}$ I discern three degrees of stability (\$ 124$)$. 


\section{THE QUANTITATIVE METHOD IN BIOLOGY}

higher values ( 5 or 8 , or both). Here the influence of the conditions of existence is as indubitable as in the above-mentioned experiments with Chrysanthemum carinatum.

LUDWIG $^{1}$ has studied the variation of the number of marginal florets in Chrysanthemum leucanthemum. Series of specimens collected from certain localities showed the I3-floret form to be the commonest, whereas the 34 -floret form was predominant in other localities. It would be premature to conclude from these facts, without more information, that two different subspecies (hereditary races) exist among the material collected by LUDWIG ( $(30)$.

\section{§ 129. - INFLUENCE OF SELECTION UPON THE} VARIATION STEPS IN CHRYSANTHEMUM SEGETUM. -DE VRIES sowed the mixed seed of Chrysanthemum segetum obtained from twenty different botanic gardens. The terminal flower-heads of each of the ninety-seven healthy plants obtained were examined, and were found to contain the following numbers of marginal florets ${ }^{2}$ :-

$\begin{array}{lrrrrrrrrrrr}\text { Florets . } & \text { I2 } & \text { I3 } & \text { I4 } & \text { I5 } & \text { I6 } & \text { I7 } & \text { I8 } & \text { I9 } & 20 & 2 \text { I } & 22 \\ \text { Specimens } & \text { I } & \text { I4 } & \text { I3 } & 4 & 6 & 9 & 7 & \text { I0 } & \text { I2 } & 20 & \text { I }\end{array}$

This two-humped curve (Fibonacci series of the second degree) resembles certain two-humped curves of Chr. carinatum obtained under unfavourable conditions or by examining flower-heads of lateral branches. According to DE VRIES, the observed discontinuity indicated the presence of two forms, a I3-ray form and a 2I-ray form. The seeds from I2- and I3ray specimens were collected and sown next year, the terminal flower-heads obtained therefrom having the following numbers of florets ${ }^{3}$ :-

$\begin{array}{llllrrrrrrrr}\text { Florets } & . & . & . & 8 & 9 & \text { I0 } & \text { II } & \text { I2 } & \text { I3 } & \text { I4 } & \text { I5 } \\ \text { Specimens. } & : & : & : & 2 & \text { I } & 0 & 7 & \text { I3 } & 94 & 25 & 7 \\ \text { Florets } & : & : & : & \text { I6 } & \text { I7 } & \text { I } 8 & \text { I9 } & 20 & 2 \text { I } & 22 & \\ \text { Specimens. } & : & . & . & 7 & \text { I } & 2 & 0 & 3 & 0 & 0 & \end{array}$

"That is to say, all trace of the 2I-ray form had been eliminated and a nearly pure I3-ray form obtained. That this was so was proved by sowing the seed of some of the I2-rayed plants obtained on this occasion in the following year. It was then found that the frequencies of occurrence of flowers with various

${ }^{1}$ Quoted after H. M. VERNON, loc. cit., p. 47.

2 Archiv für Entwickelungsmechanik, Bd. II., p. 52, 1896. (Quoted after VERNON, loc. cit., p. 50.)

It is worth noting that in this curve the limits coincide approximately with two variation steps, just as in Centaurea cyanus. (See \& 127, P. I82.)

${ }^{3}$ Here the limits coincide once more almost exactly with two variation steps. 
numbers of rays remained practically unchanged " (VERNON, loc. cit., P. 5I). ${ }^{1}$

On the other hand, DE VRIES, "starting in I 896 with plants which had 2I-ray florets occurring most frequently in their capitula, and none of which had more than 23 florets, picked out each year the two or three plants richest in florets for breeding with, and sowed their seed the following year. In I897 a single flower was obtained, having 34 florets, but the 2I-floret form was still the commonest. In I898 one of the flowers had 48 florets, the commonest flowers now having 26 or 34 florets. In I899 one had 67 florets, the commonest form having 26 or 33 to 35 florets, and in Igoo one had ror florets, the commonest form having 47 florets." (VERNON, loc. cit., p. 63.)

I think it would be premature to conclude from the above very important experiments that two hereditary forms (subspecies ?, pure lines ?) were mixed in the original group of 97 specimens. It may be surmised that the results of selection have been influenced by the existence of variation steps-i.e. by a specific energy of the examined property.

The differences between the 97 original specimens were probably produced by two groups of factors: (I) differences in the conditions of existence (of the specimens) which are unavoidable (plasticity); (2) differences in the quantitative composition of the living mixture $(\$ 8 \mathrm{~A}) .^{2}$

Selection being carried out, specimens of different quantitative composition have been picked out and isolated, the differences being increased (within certain limits) by continued selection. The progress (in respect of the observable property), instead of being gradual (by impalpable changes) has been very rapid, proceeding, as it were, by jumps, because of the existence of variation steps.

In other words, in this example each of the figures I3, 2I, 34, etc., considered in itself is not an hereditary property of the species or of one or another subspecies (race, form, etc.), but what is transmitted by inheritance is the specific energy, expressed by a Fibonacci series of the second degree.

§ 130.-VARIATION STEPS, DISCONTINUOUS VARIATION AND SPECIFIC DIFFERENCE.-Two given species (subspecies, etc.) are always strictly different by the qualitative composition of their living mixture and therefore by their

1 Taking ONLY the figures into account, it may be remarked that selection has resulted here in a change of the curve similar to the changes produced in Chr. carinatum by modified conditions of existence or by gradation (ई 128$)$.

2 The latter differences being themselves a consequence of differences in the conditions of life of the parents, for the seeds were obtained from twenty botanic gardens, thus from various countries. 


\section{THE QUANTITATIVE METHOD IN BIOLOGY}

hereditary possibilities (possible primordia). In the variation of a given primordium continuity or discontinuity may exist within the limits of a complex group of specimens (including two or more specific forms), just as within the limits of a monotypic group (including one specific form only). In §2I I have called attention to this fact. (See also § I28.)

Here a distinction must be made between primordia with variation steps and primordia in which no variation steps exist.

I take as first example the length of the longest leaf of the fertile stem in Mnium serratum, spinosum and undulatum. These three species (Acrocarpic Mosses) are distinctly different and easily recognizable. I have measured the mentioned primordium in a number of specimens collected from several localities. No trace of variation steps could be discovered. The limits of variation were (in $\mathrm{mm}$.) :

$$
\begin{aligned}
& \begin{array}{c}
\text { Minimal } \\
\text { length }
\end{array} \quad \begin{array}{c}
\text { Maximal } \\
\text { length }
\end{array} \\
& \text { Serratum . . . . } 2 \cdot 49 \quad 4 \cdot 7 \text { I } \\
& \text { Spinosum . . . . 5.OI 8.IO } \\
& \text { Undulatum . . . } \quad \text {. } 6.93 \quad \mathbf{I} 55^{8}
\end{aligned}
$$

According to these figures, which are specific constants, ${ }^{1}$ absolute discontinuity exists probably between serratum and spinosum (the difference between $4.7 \mathrm{I}$ and $5.0 \mathrm{I}$ is, however, too small to be decisive) and certainly between serratum and undulatum. Between spinosum and undulatum continuity exists, for $6 \cdot 93<8 \cdot$ Io.

The aspect of the question is completely changed when we limit the comparison to series of specimens collected from given localities.

We may find, for instance, in a locality $\mathbf{A}$, for spinosum: limits 5.20 and $7 \cdot 60$, mean 6.40 ; for undulatum: limits 9 and I3, mean II. Between both variation curves discontinuity is absolute.

In a second locality, $\mathrm{B}$, we might possibly find, for spinosum limits 6.93 and $8 \cdot 10$, mean 7.52 ; for undulatum the same figures. Here both curves are identical.

Between identity and absolute discontinuity all possible transitions may occur.

In a third locality, $\mathrm{C}$, indeed, the figures may be, for spinosum: limits 5.50 and 8 , mean 6.75 ; for undulatum: limits 7 and ro, mean 8.50. Here transgressive variation exists ; in other words, both curves overlap one another. This results in partial discontinuity.

In a fourth locality, D, we may find for spinosum: limits 6.30

1 It is possible that these constants will be corrected later on, but this is of no importance for our subject. 
and 8.10, mean $7 \cdot 20$; for undulatum: limits 6.93 and $9 \cdot$ Io, mean 8.02 . Here the difference between both curves is small.

Suppose now that the two species under consideration were 'doubtful (critical) species, and that for each locality the collected specimens were confused in one series of measurements, the result would be : in A, two separate curves; in $\mathrm{C}$, a two-humped curve; in $\mathrm{D}$, a one-humped asymmetrical curve; and in $\mathrm{B}$ a regular, symmetrical one-humped curve. If we limit ourselves to one series collected from one locality, we are in danger of being completely deluded: the curves obtained from the localities $\mathrm{B}$ and $\mathrm{D}$ point to the existence of one species, whereas the existence of two specific forms seems to be demonstrated by the figures obtained from $A$ and $C$. If the curves obtained from the four localities were compared, we might perhaps be tempted to believe that transitory forms between two species exist.

In reality, the differences between the four localities depend merely on differences in the conditions of existence. Compare Mnium hornum in $\S 127$, p. I82.

From the above examples (and many others which may easily be found) it may be concluded that continuity and discontinuity in various degrees may be observed in the variation of any primordium whatever in a given group of specimens, and that any conclusion about the existence of one or several species among the observed material is questionable, if not verified by other methods.

When variation steps exist in the investigated primordium we are still more in danger of being deceived if we draw any conclusion from a supposed relation between continuous variation and specific identity or between discontinuous variation and specific difference, for a monomorphic (one-humped) curve may be easily transformed into a dimorphic or a polymorphic one by a simple change in the conditions of existence or under the influence of gradation. See the examples of Chrysanthemum and Primula in $\S \mathrm{I28}$, pp. I84 and I85.

Many attempts have been made in order to discover, by means of the biometrical method, whether a given critical species consists of one or several specific forms, and also in order to find characteristic differences between two or more allied critical species or between specimens of a given species collected from various countries or localities. In the researches alluded to much importance has been ascribed to the mean values, the correlation constants and the form of the variation curves. ${ }^{1}$ Several authors are tempted to believe that a sufficient degree of discontinuity in the variation curve of a given

1 This subject is expounded and illustrated by a number of examples in VERNON, loc. cit., chaps. ii. and $\mathrm{x}$. Examples are also found in the review Biometrika, passim. 


\section{THE QUANTITATIVE METHOD IN BIOLOGY}

primordium indicates the existence of two specific forms. Unfortunately, little attention, if any attention at all, has been paid to the variation steps and the specific limits of variation (minimal and maximal values).

I think that the application of the followed method to the difficult problems under consideration is fruitless or at least premature.

Scientific progress is obtained by proceeding from the simple to the complicated. Very numerous specific forms of animals and plants are easily recognizable : it is possible to investigate them quantitatively, determining the constants (limits of variation) and eventually the variation steps of numerous properties for series of (not critical) allied forms ; for instance, for series of species of one genus or allied genera.

In the higher forms of life, numerous measurable properties exist which have been hitherto completely or almost completely overlooked. Examples: Dr FRIEDRICH HEINCKE 1 has examined a number of so-called local races of the herring in respect of about 25 different characters, and some in respect of over 50 characters. I have measured 38 properties (characters) in 90 species of Carabus and Calosoma-a dozen of properties of the leaves of the mosses of the genus Mnium (see Part IX.)-and more than 25 properties of the fertile stem, the leaves and the flowers of more than 25 species of Graminec. (See Part IX.)

A complete and exact description of the species which are DISTINCTLY CHARACTERIZED is, in the present state of science, an attainable object of the quantitative method. It may be expected that the description of a few hundreds of species by means of figures will be sufficient to demonstrate the value of the quantitative method for descriptive science. The collected data will afford a base of comparison for the investigation of the critical species, the local races, etc. We will be, however, very often compelled to have recourse for critical specific forms to the experimental method (see $\S \mathrm{I} 7$ ), the results of the experiments being expressed by measurement.

\section{§ 131.-RELATION BETWEEN THE VARIATION STEPS AND CERTAIN QUESTIONS OF PHYLLOTAXIS. PRIMULA OFFICINALIS, MYOSOTIS, GERANIUM, ROSACEA.-In $\S \mathrm{I} 26 \mathrm{I}$ have called attention to the fact that the significance of a given value depends on the series of varia- tion steps to which it belongs. In certain cases exact informa- tion about the variation steps might perhaps throw any light upon certain phyllotaxic and other morphological problems. \\ In Primula and Myosotis the corolla consists of five petals and is ordinarily looked upon as being cyclic (verticillate). In Geranium the gynæcium is also pentamerous and described as cyclic.}

${ }^{1}$ Quoted after VERNON, loc. cit., p. 322. 
Let us see what information may be obtained from the variation steps.

LUDWIG has counted the petals of II70 flowers of Primula officinalis which were all obtained from a single meadow (near Wieda). ${ }^{1}$ The number varies from I to 22 . The variation curve has five humps, corresponding to 3,5 (predominant), 8 , Io $(5 \times 2$ ?) and 13 ; the superior limit coincides almost exactly with 2I. From these observations it may be concluded that the number 5, which is practically constant in the species, is here a term of the Fibonacci series, and it may therefore be surmised that the corolla of Primula is, in reality, spiral, the divergence being ordinarily $2 / 5$.

REMARK : For the observed facts three explanations are $a$ priori possible : (I) In the meadow where the flowers were collected certain peculiar conditions of existence prevail by which a number of unusual reactions (expressed by the humps of the curve) have been produced instead of the ordinary reaction which results in the number 5-thus a modification similar to the changes which I have observed in Chrysanthemum carinatum (\$ 128, p. I84)-and in general, similar to modifications produced by cultivation. It may be surmised, moreover, that not only the number of petals, but also the angle of divergence has been modified. (2) In the locality mentioned a peculiar subspecies exists, characterized by the fact that the Fibonacci series of the first degree observed in the ordinary form (the term 5 being invariable just as in Senecio jacobaca) has been transformed into a series of the second degree (comparable to Chrysanthemum carinatum and many other Compositæ). (3) In the mentioned meadow a mixture of several subspecies (pure lines?, races) occurs. I look upon the latter explanation as being very improbable, because it implies about half-a-dozen mutations in a single property.

In a certain species of Myosotis ${ }^{2}$ a form exists which has more than 5 petals ; the number is variable, the figure 8 being predominant. Since 8 is a Fibonacci term we may conclude that the ordinary figure 5 is also a Fibonacci term, and it may be surmised that the corolla of Myosotis is spiral (divergence 2/5).

REMARK: The form of Myosotis alluded to may be looked upon as being probably a subspecies because its characteristic feature is hereditary, even when the plants are cultivated in a country very distant from their original locality.

In a certain form of Geranium examined by DE VRIES, the number of pistils was very variable : the predominant numbers were 5 , ro, $15 \ldots$ (multiples of 5 ). It may therefore be surmised that the gynæcium of Geranium is really cyclic, the deviating specimens having two, three or more pentamer cycles of pistils.

Number of stamens in the Rosacea: in this property, a series of variation steps coinciding with the multiples of 5 exists. In

1 Ber. deut. Bot. Gesellsch., xiv., r896, p. 204. (Quoted according to VERNON, loc. cit., p. $4^{8}$.)

2 I think $M$. alpestris. The seeds (from which plants were raised in the Botanic Garden at Ghent) were obtained from Germany. I don't remember the name of the tradesman. (My notes are not within my reach.) 


\section{THE QUANTITATIVE METHOD IN BIOLOGY}

Prunus spinosa, for instance, the number 20 prevails. In the neighbourhood of Leipzig, DIETEL found in this species a variation curve in which the figure $2 \mathrm{I}$ was predominant (LUDWIG). ${ }^{1}$ In Cratcegus coccinea LUDWIG found a variation curve with a distinct hump coinciding with the value 8 . According to LUDWIG it may be surmised that in the mentioned examples the ordinary cyclic disposition of the stamens is transformed into a spiral one.

By the above examples an interesting line of research is indicated.

§ 132.-METHODS FOR THE DISCOVERY OF VARIATION STEPS.- Several methods for the discovery of variation steps may be followed. I give here six methods and I suggest a seventh one.

FIRST METHOD: When a two-humped (dimorphic) or multi-humped (polymorphic) variation curve is obtained, it may happen that the humps coincide with variation steps. This may be considered as very probable if a certain arithmetical relation exists between the values which coincide with the humps. In such a case it is advisable to verify the obtained conclusion by carrying out a second series of measurements or by applying another method. (See below.)

SECOND METHOD: In a one-humped (monomorphic) curve the existence of variation steps may be surmised, as often as a sudden decrease of the ordinates (frequencies) coincides with two values between which certain arithmetical relations exist, and also when arithmetical relations exist between both extreme values, or between the most frequent value (hump of the curve) and one of the extreme values or both extreme values. In such cases verification is, of course, necessary. (Example: Centaurea cyanus, § I24, p. I80.)

THIRD METHOD : Variation steps may be discovered by comparing the value of a property in several subspecies, species, genera, etc. ; in other words, by examining the variation of a given property through a long series of specific forms. From the predominance of certain figures the existence of variation steps may be deduced. (Examples: the predominance of the figures $3,6,9$ in the number of stamens of the Monocotyledonsthe predominance of the Fibonacci terms in the number of rays of the umbella of the Umbelliferæ, etc.)

FOURTH METHOD : Variation steps may be rendered observable by cultivating plants (or breeding animals) under conditions of existence as various as possible, or by observing them in the state of nature under different conditions. EX-

1 Prof. Dr F. LUDWIG, Ueber Variationskurven und Variationsflächen der Pflanzen. Botan. Centralblatt, 1895, vol. Ixiv., pp. 103-105. 
AMPLES : Chrysanthemum carinatum, p. I84. In the number of flowers of the inflorescence of Primula elatior a Fibonacci series of the second degree is observed. According to DE BRUYKER, in the state of nature, the predominance of a given term depends on the conditions of life (for instance, on the quantity of water in the soil).

FIFTH METHOD : Variation steps may be discovered by observing the variation produced by gradation. (See Part VIII.) EXAMPLE: the Fibonacci terms are rendered observable in Chrysanthemum carinatum by comparing the flowerheads of the successive lateral branches. (See p. I84.)

SIXTH METHOD: SELECTION. In certain cases the successive terms of a series of variation steps have been brought into evidence by selection. DE VRIES, starting with two specimens of Trifolium pratense, which had a few leaves with 4 leaflets, obtained by selection a form with numerous leaflets, the most frequent values being $3,5,7 \ldots$ (series of the uneven numbers). (See also the example of Chrysanthemum segetum, § I29.)

From this method the discovery of new series of variation steps and the elucidation of the true significance of certain values ( $\S$ I26, I3I) may be expected.

SEVENTH METHOD : CURVES OF DEVELOPMENT. In the course of the individual development many primordia pass through successive values till the definitive value is reached. Ordinarily the increase seems to be gradual (continuous). It may be expected, however, that in the development (growth) of a primordium in which variation steps exist, jumps may occur, the passage from a term (step) to the next one taking place suddenly, or more rapidly than the passage between two transitory values.

It may be anticipated that in such cases the variation steps might be indicated by abrupt changes in the direction of the curve of development (see $\$ 49$ ), these turning points of the curve being more or less distinct according as the series of steps under consideration belongs to the first, the second or the third degree. (See § I24.) Therefore the use of curves of development for the discovery of variation steps may be suggested.

§ 133.--SERIATION OF THE PRIMORDIA ACCORDING TO THEIR DEVELOPMENT. EMBRYOLOGICAL SERIES. - Since each term of a series of variation steps represents one of the states of equilibrium of a primordium, the arithmetical relations between the terms of a series correspond to more or less complicated mechanical relations, and very probably in many cases to morphological relations, and also to embryological relations. (See $\S 132$, Seventh Method.) 


\section{THE QUANTITATIVE METHOD IN BIOLOGY}

It happens very often that distinctly different primordia follow one another in the course of the individual development according to a certain order $a, b, c \ldots$ the primordium $c$ being produced by a metamorphosis of $b$, and $b$ by a metamorphosis of $a$. The primordia $a, b, c \ldots$ may then be looked upon as being successive terms of a series, which I call an embryological series. Certain series of variation steps very probably represent successive states of development ; but between a series of steps by which the successive states of one primordium are represented, and an embryological series, which indicates the developmental relations between several different primordia, a fundamental difference exists.

In Myosotis palustris the colours white, rose, blue ( $\$ 46$, p. 54) are the terms of an embryological series which is observed in many Boraginacea. In the blue Centaurea cyanus a similar series exists, consisting of the terms white, rose-purplish and blue $(\S 47)$.

In Myosotis versicolor the terms are white, yellow, blue. This series recalls the embryological series of colours observed in the subspecies of Viola tricolor mentioned in $\S 38$.

The transformation of a given term of an embryological series into the next one may take place in different ways. In Myosotis palustris the metamorphosis of rose into blue proceeds in such a way that irregular blue spots appear on the rosecoloured petals. These spots (the limits of which are rather vague) coalesce more and more till the petal is blue. In Centaurea cyanus, on the contrary, the metamorphosis of rosepurplish into blue begins at the extremity of the petals and proceeds gradually and regularly towards their base (gradation; see Part VIII.).

The available information about the relations alluded to in the present paragraph is hitherto fragmentary. Further investigation of this subject is desirable. A more complete acquaintance with the developmental relations between different primordia and between the different values (variation steps) of a given primordium might throw some light upon the relations between the terms of a given pair of properties in the hybrids, ${ }^{1}$ and upon other biological problems.

§ 134.-THE DIFFERENCES BETWEEN THE TERMS OF AN EMBRYOLOGICAL SERIES MAY BE EXPRESSED QUANTITATIVELY.-In Myosotis palustris the primordia white, rose and blue being chemical properties, they may be represented by chemical formulæ, which are the expression of quantitative notions.

1 Strict segregation or transitory values (goneoclinie); dominant and recessive, etc. 
From another standpoint the differences between the primordia under consideration may be expressed by measurement. The rose colour appears at a certain moment, let us say after $n$ hours ; the blue colour after $n^{\prime}$ hours. A petal stopped in its development before the moment $n$ is white ; if stopped before the moment $n^{\prime}$ it is rose ; if stopped in its development after $n^{\prime}$ it is blue. The curve of development being constructed, the differences may be reduced to the terms of time. ${ }^{1}$

§ 135.-PARALLEL VARIATION.-The term analogous or parallel variation has been used by DARWIN to indicate that similar properties occasionally make their appearance in several "varieties" or "races" descended from the same species and more rarely in the offspring of widely distinct species. DARWIN points out that the majority of the observed cases (occasional appearance of black wing bars in the various breeds of pigeon, and of stripes on the legs of the ass and of various races of the horse, etc.) are evidently due to reversion. Other examples are regarded by many biologists (for instance, by H. M. VERNON, loc. cit., p. 96) as being probably mere coincidences and of no scientific value.

EXAMPLES (mentioned by DARWIN) ${ }^{2}$ : many trees belonging to quite different orders have produced pendulous and fastigiate varieties. A multitude of plants have yielded varieties with deeply cut leaves. Several varieties of melon resemble other species in important properties. Thus one variety has fruit so like, both externally and internally, the fruit of the cucumber, as hardly to be distinguished from it. In animals we find feather-footed races of the fowl, pigeon and canary bird. Horses of the most different races present the same range of colour. Many "sub-varieties" of the pigeon have reversed and somewhat lengthened feathers on the back parts of their heads, and sub-varieties of the fowl, turkey, canary, duck and goose all have either top-knots or reversed feathers on their heads. It is a common circumstance to find certain coloured marks persistently characterizing all the species of a genus, but differing much in tint. The nectarine is the offspring of the peach, and the varieties of peaches and nectarines offer a remarkable parallelism in the fruit being white, red or yellow fleshed; in being cling-stones or freestones; in the flowers being large or small; in the leaves being serrated or crenated, furnished with globose or reniform glands, or quite destitute of glands.

At least three different groups of facts are confounded under

1 Or to the terms of the value of a leading property ( $\$ 49)$.

2 See CH. DARWIN, The Variation of Animals and Plants under Domestication, second edition, 1875 , vol. ii., p. 340. See also VERNON, loc. cit., p. 96. 


\section{THE QUANTITATIVE METHOD IN BIOLOGY}

the term parallel variation and are therefore confounded in our mind.

I place in a first group the cases in which two or more subspecies, species, genera, etc., resemble one another in certain properties, without more. Examples: fasciated and twisted stems, ascidiform leaves, eye-shaped spots on the wings of butterflies and the feathers of birds. In certain Coniferce (Pinus silvestris, etc.) certain insects (Chermes) bring about cecidia, which resemble a strobilus by certain properties, etc. Such resemblances are the expression of similar states of equilibrium: they ought to be called mechanical concordances. They are comparable to the examples given in $\S 65$, in which this subject is expounded.

In other cases a SERIES of primordia, observed in a species (genus, etc.) $A$ is met with again in a second species (genus, etc.) $B$. Examples: the above-mentioned horses of different races which present the same range of colour.

If there is no relation between the properties which belong to such a series, ${ }^{1}$ the term parallel variation ought to be avoided: the resemblances under consideration are mechanical concordances and belong to the first group.

Second Group.-It may happen, however, that the properties under consideration are terms of an embryological series (§ I33). I bring such cases in a second group under the name embryological parallelism. Example: in the species Myosotis palustris three subspecies exist: white, rose, blue. In other species of Myosotis and in several species of other genera of the same family (Echium vulgare, etc.) a similar series of subspecies exists. The primordia white, rose and blue are terms of an embryological series : therefore we may say that embryological parallelism ${ }^{2}$ exists between the different series of white-roseblue subspecies.

In a third group of so-called parallel variations, the properties under consideration correspond to determined values, $a, b, c$ ... of one primordium and coincide with variation steps. Here the existence of the terms $a, b, c \ldots$ in several subspecies, species, genera, families, etc., depends on a mechanical concordance of a peculiar kind which I designate by the term parallel variation steps. Examples: the series $2,4 \ldots 2^{n}$ is repeated in Pediastrum (number of cells, $\S$ I22), the Onagracece (number of stamens, $\S$ I 26 ), the Mosses (teeth of the peristome, $\S$ I22). The Fibonacci series is found in many Compositce (number of marginal florets) and Umbelliferce (number of rays

1 I don't know whether any relation exists between the colours of the horses.

${ }^{2}$ The term embryological parallelism is based upon the constatation of a fact and quite independent of the phylogenetic relations between the subspecies alluded to. 
of the umbella, LUDWIG), in Primula and Myosotis (number of petals?, § I3I) and very probably in certain properties of Mollusca and other animals. Etc.

Examples of mechanical concordance, embryological parallelism and parallel variation steps are innumerable. It is by discerning and measuring the primordia-in the adult state and in the course of the individual development-that it may become possible to classify the facts and to establish their biological significance.

In this subject, as in many others, DARWIN has been the pioneer. If, however, we go on talking continually and indiscriminately about analogous or parallel variation, reversion, ancestral characteristics, convergent adaptation (see $\S 65, \mathrm{p} .8 \mathrm{I}$ ), etc., further progress will be rather slow. 


\section{P A R T V I I I}

\section{GRADATION}

§ 136.-COMPARISON BETWEEN LIVING BEINGS AND CRYSTALS.-Attempts to establish a comparison between living beings and crystals have been made repeatedly and often discussed in biological literature. The remarkable regularity of a number of forms of life ${ }^{1}$ has probably been the origin of such attempts. Along this line, however, no results of any real value have been hitherto attained, because the attempted comparisons have been merely based upon similitudes of the exterior forms. The real nature of the crystals, which depends on their internal constitution rather than on their external aspect, has been overlooked, and this has rendered fruitless the attempts under consideration. Moreover, the universal occurrence in the living beings of curved lines which are never observed in crystals seemed until now to be an insuperable obstacle, and no attention has been paid to gradation, which is the key to the whole subject ( $\$$ I39).

In the comparison which I advance in the following paragraphs, there is no question of external similitudes.

\section{§ 13\%.-THE AXES OF THE CRYSTALS ARE LINES} OF STABILITY.-A crystal is a system of material parts which are in a certain state of stability. In each crystal we discern a certain number of imaginary straight lines or axes (ordinarily three, sometimes four) which may be called lines of stability or equilibrium. The constitutive parts or units (molecules, particles) of a given crystal are all alike and arranged in a certain way according to the axes. All the successive points of a given axis are identical. The value of any property whatever of a crystal is invariable along each of its axes.

I take, for instance, an orthorectangular prism ${ }^{2}$ : in such a crystal we discern three axes, $a, b$ and $c$, each of which is perpendicular to the plane of the two others. The crystal may be compared to a society of individuals (units) associated into a rectangular triaxial system. (See § 88.) If we divide the crystal into successive slices (sections) parallel to the plane $b c$

1 Diatoms, polyhedric cells in many animals and plants, tetrads, prismatic stems ; Echinids, etc.

${ }^{2}$ A straight prism, the base of which is a rectangle. 
and following each other in the direction of the axis $a$, and if we measure in those sections any physical property (dilatability, conductibility, compressibility, refraction, specific gravity, etc.) we obtain the same value for each and all. The same constancy is observed along the axes $b$ (slices parallel to the plane $a c$ ) and $c$ (slices parallel to the plane $a b$ ).

All the crystals are governed by the same law.

§ 138.-THE AXES OF THE LIVING BEINGS ARE ALSO LINES OF STABILITY.-I consider now a living being, limiting myself to the pluricellular animals and plants. Here we also distinguish axes which are lines of stability. ${ }^{1}$ Each pluricellular specimen is a society consisting of a certain number of individuals (segments or biological units; cells, etc. See § 54) associated into a certain state of equilibrium and ordered according to the axes.

When the axes of the living beings are looked upon as being lines of stability and ordonnance, they are no longer arbitrary or abstract conceptions. They acquire the same mechanical significance as the axes of a crystal, and a comparison between both is founded upon real analogy.

§ 139.-DIFFERENCE BETWEEN THE AXES OF THE LIVING BEINGS AND THOSE OF THE CRYSTALS. GRADATION.-A fundamental difference between the axes of the living beings and those of the crystals depends on Gradation. In a plant or an animal the value of a given property, measured successively at different places along a given axis, is variable instead of being constant as in the crystals. Its variation is regular; that is to say, ruled by a geometrical law, which is to be discovered by measurement in each peculiar case and may be represented by a gradation curve. ${ }^{2}$

ई 140.-EXAMPLES OF GRADATION. FIRST EXAMPLE: THE FERTILE STEM OF POA TRIVIALIS (A GRASS).-I call this stem a specimen or individual of the first order; it is a uniaxial system. It consists of two segments (individuals or units) of the second order-viz.: (I) the basal (proximal) segment or stem properly so called; (2) the terminal (distal) segment or inflorescence (panicle, the lateral branches of which are neglected here). Both segments are distinctly different by a number of properties (differentiation).

1 See on the different systems of axes which are observed in the living beings (uni-, bi-, triaxial systems, etc.), $\$ \$ 54,77,88$.

See on the axes of unicellular beings, $\$ 60$ (egg of Spirogyra). See on curved axes, which consist of a succession of straight simple axes, $\$ 84$.

${ }^{2}$ In the crystals, the gradation curve of any property is always a straight line parallel to the axis. Therefore we may say that gradation does not exist. 


\section{THE QUANTITATIVE METHOD IN BIOLOGY}

Each of the above segments consists in its turn of a number of units of the third order called internodes. All the segments or units (of the second and the third order) follow each other in the direction of one straight line, which is the axis. The whole system (specimen) is therefore a uniaxial system.

The axis is a line of ordonnance. It is characterized by three facts: it is a line of: (I) segmentation; (2) differentiation; (3) gradation.

With reference to the latter point I measured the primordium (simple property) length of the successive internodes from the base to the summit (the terminal spikelet being excluded) of two flowering stems taken at random. ${ }^{1}$

The figures are given in the folloving Table:

Length of the successive internodes of two flowering stems of Poa trivialis. The terminal spikelet is excluded. The internodes are numbered (I., II. . . .) from the base to the summit. The limit between the stem properly so called and the inflorescence is indicated for each stem by ] [ Length in $\mathrm{mm}$.

\begin{tabular}{|c|c|c|c|c|c|c|c|c|}
\hline $\begin{array}{l}\text { Internodes } \\
\text { Length ist stem } \\
\text { Length 2nd stem }\end{array}$ & $\begin{array}{l}\text { I } \\
7 \\
5\end{array}$ & $\begin{array}{l}\text { II } \\
\text { I6 } \\
\text { I0 }\end{array}$ & $\begin{array}{r}\text { III } \\
27 \\
25\end{array}$ & $\begin{array}{l}\text { IV } \\
33 \\
39\end{array}$ & $\begin{array}{l}V \\
36 \\
3 I\end{array}$ & $\begin{array}{l}\text { VI } \\
62 \\
44\end{array}$ & $\begin{array}{l}\text { VII } \\
126 \\
60\end{array}$ & $\begin{array}{l}\text { VIII } \\
\text { I } 87] \\
\text { I02 }\end{array}$ \\
\hline $\begin{array}{l}\text { Internodes } \\
\text { Length ist stem } \\
\text { Length 2nd stem }\end{array}$ & $\begin{array}{cc}\text {. } & \text { IX } \\
\cdot & {[32} \\
\cdot & 178]\end{array}$ & $\begin{array}{l}X \\
23 \\
{[23}\end{array}$ & $\begin{array}{r}\mathrm{XI} \\
\mathrm{I} 8 \\
\mathrm{I} 7\end{array}$ & $\begin{array}{l}\text { XII } \\
\text { I5 } \\
\text { I4 }\end{array}$ & $\begin{array}{l}\text { XIII } \\
\text { I5 } \\
\text { II }\end{array}$ & $\begin{array}{c}\text { XIV } \\
\text { I0 } \\
9\end{array}$ & $\begin{array}{c}\mathrm{XV} \\
6.5 \\
6\end{array}$ & $\begin{array}{c}\text { XVI } \\
5 \\
45\end{array}$ \\
\hline $\begin{array}{l}\text { Internodes } \\
\text { Length ist stem } \\
\text { Length 2nd stem }\end{array}$ & $\begin{array}{c}\text { XVII } \\
\text {. } \\
3 \\
\text {. }\end{array}$ & $\begin{array}{c}\text { XVIII } \\
3 \cdot 5 \\
2 \cdot 2\end{array}$ & $\begin{array}{l}\text { XIX } \\
\text { I } \\
2\end{array}$ & $\begin{array}{c}\mathrm{XX} \\
2 \\
\mathrm{I} \cdot 8\end{array}$ & $\begin{array}{l}\mathrm{XXI} \\
I^{*} 2 \\
2 \cdot 2\end{array}$ & 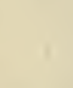 & & \\
\hline
\end{tabular}

Each of the above series of figures represents an individual gradation curve (specimen curve). By means of the figures of each series (I take the first stem as example) we may draw the curve (Fig. 26), in which the axis (stem) is represented by a horizontal line, the length of the successive internodes being represented by equidistant vertical ordinates. Such a curve is merely a graphic representation of facts without any calculation.

It is seen that in both stems the value of the primordium under consideration increases from the base ${ }^{2}$ till a maximum is reached and further diminishes towards the summit. The curve has thus an ascending-descending form. The slight irregularities which occur at several places (for instance, and stem, internode IV.) are brought about by accidentál causes (chance). ${ }^{3}$

1 It happened that the total number of internodes was the same in bothviz. 21 . This is not always the case.

${ }^{2}$ The value $y$ of any ordinate depends on the distance comprised between its base and the origin $I$. In other words $y=f x$.

${ }^{3} \mathrm{~A}$ number of similar curves have been described by PERCY GROOM in his interesting paper on "Longitudinal Symmetry in Phanerogamia," Phil. Trans. Roy. Soc., London, ser. B., vol. cc. (I908), pp. 57-I I5, with numerous figures. 
There is a distinct breach of continuity (discontinuous gradation) in each of the above curves between the longest ordinate and the next one. This breach is a quantitative expression of the differentiation of the stem (individual of Ist order) into two segments (individuals of and order : vegetative part of the stem and panicle). The longest internode is the upper internode of the basal part; the next one is the first internode of the panicle. I have measured the length of the internodes of numerous stems belonging to a number of species of Gramineæ: the general (ascending-descending) form of the gradation curve is the same in each and all. An exact comparison between two given stems, ${ }^{1}$ in respect of the primordia

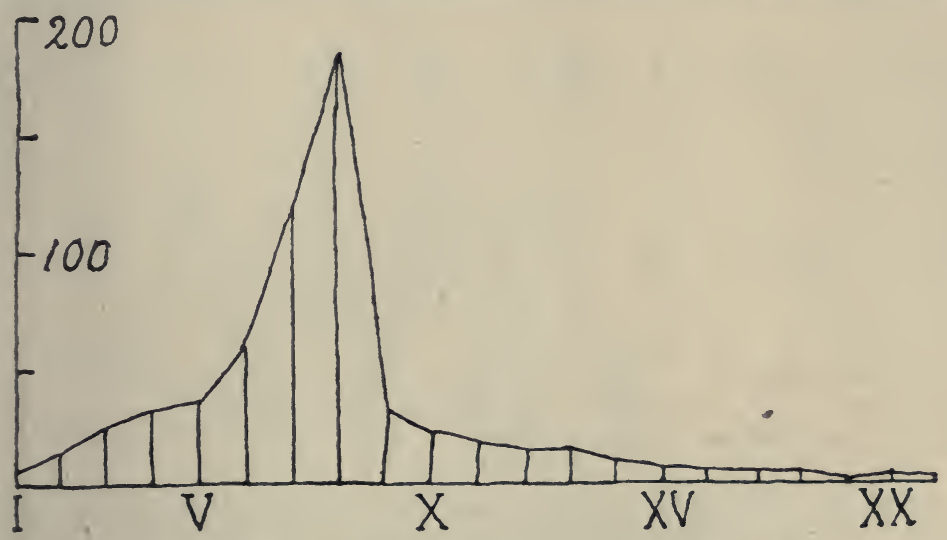

FIG. 26.-Poa trivialis. Gradation Curve of the length of the internodes of one fertile stem. $I$, Base of the stem; $I, V, \ldots$ successive internodes. Scale in $\mathrm{mm}$. See the figures, p. 200 , Ist stem.

(length, etc.) of their internodes is easily obtained by comparing the longest internode and the first internode of the panicle of both stems. The compared internodes are socially equivalent and they represent the maximal value of the length in each of the segments of 2 nd order. ${ }^{2}$

SECOND EXAMPLE: THE FERTILE STEM OF HOLCUS MOLLIS (A GRASS). - This object has the same constitution as the first example. I have measured the following primordia, which are all ordered along the longitudinal axis of the stem :

(I) The length of the internodes from the base to the summit (the terminal spikelet being excluded);

1 Belonging to the same or different species.

2 It may be remarked that each of the above series of figures is a bertillonage that is to say, a quantitative description of a specimen complete enough to enable us to distinguish it from any other fertile stem of any grass whatever, because the same combination of figures practically never occurs a second time. 


\section{THE QUANTITATIVE METHOD IN BIOLOGY}

(2) The length of the sheath of the successive leaves taken in the same order;

(3) The length of the blade (lamina); and

(4) The breadth of the blade of the successive leaves (measured at the place of their greatest breadth).

The figures are given in the following Table : ${ }^{1}$

Gradation in a flowering stem of Holcus mollis. Four primordia have been measured : length of the internodes, length of the sheaths, length and breadth of the blades of the leaves. The internodes are numbered (I., II., . . . ) from the base to the summit. The figures of each leaf are in the same vertical column as the figures of the internode at the base of which it is inserted. The limit between the stem and the inflorescence is indicated by ] [. The lowest leaves were faded and could not be measured exactly. Dimensions in $\mathrm{mm}$.

\begin{tabular}{|c|c|c|c|c|c|c|c|c|c|c|}
\hline Internodes & • & I & II & III & IV & V & VI & VII & VIII & IX \\
\hline Length internodes & - & I'5 & 12 & 8 & 7 & 7 & 3 & 7 & I5 & 8 \\
\hline Length sheaths & $\bullet$ & - & - & 一 & 1 & - & - & 44 & $5^{8}$ & 68 \\
\hline Length blades & & - & - & - & 一 & 一 & 一 & 52 & 90 & $12 \mathrm{I}$ \\
\hline Breadth blades & • & - & - & - & 一 & - & - & $x \cdot 8$ & 24 & 32 \\
\hline Internodes & & $\mathbf{X}$ & $\mathrm{XI}$ & XII & XIII & XIV & XV & XVI & XVII & \\
\hline Length internodes & . & 45 & 52 & 44 & $4 I$ & 43 & 49 & $146]$ & {$[7 \cdot 4$} & \\
\hline Length sheaths & & 75 & 72 & 55 & 45 & 36 & 35 & 72 & & \\
\hline Length blades & & I3I & I39 & 142 & II6 & $9 \mathrm{r}$ & 75 & 15 & & \\
\hline Breadth blades & & 4 & 5 & $6 \cdot 2$ & 74 & & 6.4 & $2 \cdot 6$ & & \\
\hline Internodes & - & \multicolumn{2}{|c|}{ XVIII } & XIX & \multicolumn{2}{|c|}{$\mathrm{XX}$} & XXI & \multicolumn{2}{|c|}{ XXII } & \\
\hline Length internodes & . & \multirow{2}{*}{\multicolumn{2}{|c|}{$\begin{array}{c}9 \\
\text { XXIII }\end{array}$}} & 8 & & & $5 \cdot 5$ & \multirow{3}{*}{\multicolumn{2}{|c|}{5}} & \\
\hline Internodes & - & & & XXIV & & XV & XXVI & & & \\
\hline Length internodes & 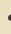 & $2^{\circ}$ & & $3^{\circ} 1$ & & $I$ & 3 & & & \\
\hline
\end{tabular}

With regard to the length of the internodes the remarks made about Poa (first example) are also applicable to Holcus. Here, however, the humps observed in the internodes II. and XI. seem to be something more than fortuitous deviations. We know that the internodes I.-XVI. (stem properly so called) have been formed successively in acropetal order; therefore they represent a period of growth. In the course of this period something has happened by which the regular progress of growth has been disturbed two times: this has produced two secondary humps (internodes II. and XI.) in the gradation curve. In other words, several secondary waves of growth have followed each other.

I have observed similar facts in the fertile stems of certain Mosses. ${ }^{2}$ In Mnium subglobosum and $M n$. punctatum, two waves occur rather frequently in the ascending portion of the gradation curves (length and breadth of the leaves). Here the limit between the waves is more conspicuous than in the above bertilloned ${ }^{3}$ stem of Holcus; it is really a distinct breach of

${ }^{1}$ A similar example is given in my paper on Mnium, p. 14, Fig. 3 .

${ }^{2}$ See p. 33 in my paper on Mnium mentioned in the present book on p. 69.

${ }^{3}$ From the French verb bertilloner. See note 2, p. 201. 
continuity by which two successive periods (waves) of gradation are disjointed.

The existence of secondary humps (or breaches of continuity) in a gradation curve of a given specimen depends probably very often on a temporary change in the external conditions (temperature? supply of water? etc.) in the course of the period of growth. In certain species, however, the existence of more than one period is observed in all the specimens ${ }^{1}$ and is therefore characteristic of the species. This is the case with the gradation of the primordia length and breadth of the leaves of the fertile stem in Cinclidium stygium Sw. (a moss allied to Mnium).

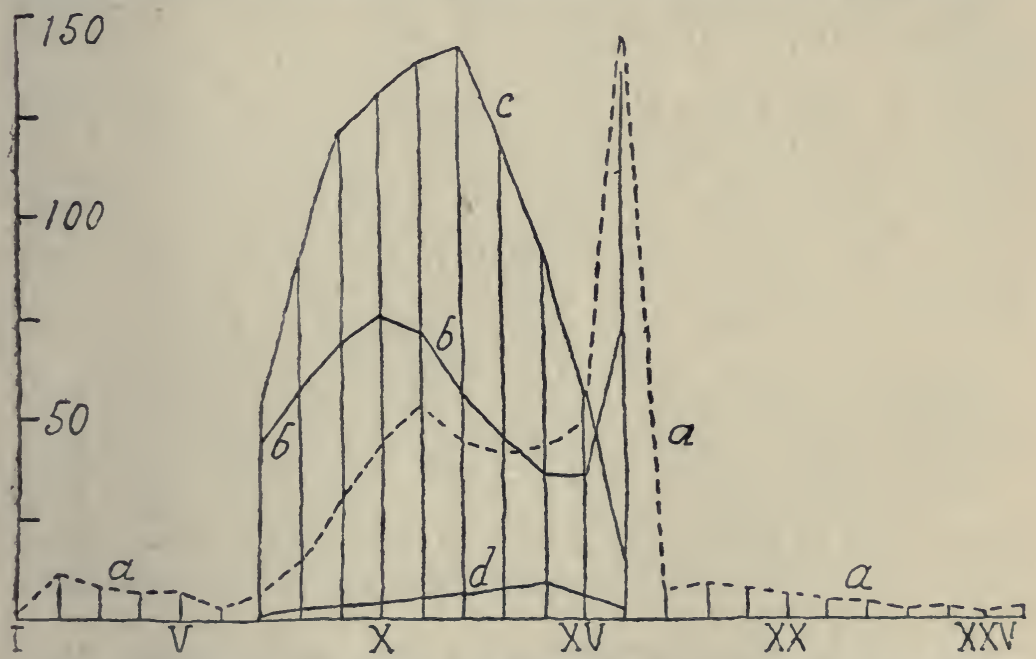

FIG. 27.-The curves represent the figures on p. 202. $a$, length of the internodes; $b$, length of the sheaths; $c$, length of the blades; $d$, breadth of the blades ; $I, V, \ldots$ successive internodes. Scale in millimetres

Further investigation (by measurement !) of this subject may bring, I think, an explanation of a number of facts in the structure of living beings which have been hitherto overlooked or looked upon as being mere curiosities.

In the gradation curve of the length of the sheath (Holcus) one observes a distinct maximum (hump) in the upper leaf (internode XVI.) and a secondary hump in internode $\mathrm{X}$. The latter did not exist or was hardly perceptible in other stems of the same species. The gradation curves of the primordia length and breadth of the blade have a rather regular ascendingdescending form, their summits coinciding respectively with the ordinates XII. and XIV.

The gradation curve of the property under consideration being simple (one-humped) in allied species. 


\section{THE QUANTITATIVE METHOD IN BIOLOGY}

Comparing the four curves in Fig. 27, it may be concluded that the gradation of each primordium is independent of the gradation of the others. The study of several examples of gradation in other Phanerogamia (internodes and leaves in Ilex, Ulmus, etc.) and in animals (shells of Molluscs, etc.) has brought me to the same conclusion. In my paper on Mnium referred to above I have given the gradation curves of a dozen of primordia of the leaves along the axis of the fertile stem in ten British species of that genus : here, also, the curves were found to be in general independent of each other, although in certain cases two curves have the same form or thereabout.

The independence of the gradation curves of different primordia along a given axis seems, therefore, to be a general rule.

THIRD EXAMPLE: GRADATION IN A LEAF.-The blade of a leaf (in preference an entire oblong, lanceolate, oval or oboval leaf) is an individual (unit) of a certain order (order $x$ ), the longitudinal axis (axis NS) of which is indicated by the midnerve. We know that the successive parts (I do not use here the term segments) which follow one another along the axis have been developed successively, ordinarily in basipetal order. If we measure the breadth of the blade at a certain number of equidistant places from the base to the summit of the leaf we obtain a series of figures which represent a gradation curve.

The margin of a leaf is, on each side, a curve of the gradation of the primordium breadth ${ }^{1}$ drawn by nature itself. Very often, even in leaves which seem to be exactly symmetrical, a difference between both margins (right and left) is discovered by measurement.

In certain leaves (or other phylloms), which are narrowed about their middle, two periods (waves) of gradation exist (marginal curve two-humped). (See my paper on Mnium, p. 33.)

The margin of a leaf is curved; it consists of a series of successive, straight, simple axes. The curvature is a secondary form brought about by gradation ( $\$ 84$ ).

$\S$ 141.-COMPARISON BETWEEN GRADATION CURVES AND EMBRYOLOGICAL CURVES. INDEPENDENCE OF THE PRIMORDIA.-When we compare the different values of a given primordium along a given axis, each value coincides with a certain state of development in which the growth of the primordium has been stopped. (See length of a petal, $\S 45$.$) For instance, in the first stem of Poa trivialis,$ mentioned p. 200, internode V. has been stopped in its growth

1 The dimension of one-half of the leaf in the direction of the transversal axis (axis EW). 
(has reached its final state of equilibrium) with reference to the primordium length when the latter was $36 \mathrm{~mm}$., whereas the growth of the length of internode VII. has been stopped when the value I $26 \mathrm{~mm}$. was reached. Therefore a gradation curve may be compared to a curve of development. Especially in those numerous gradation-curves in which the increase is continuous from one extremity to the other (without waves or secondary humps), the successive ordinates represent, as it were, a series of individuals (segments) measured in successive states of development (example: internodes I.-VIII., first stem, p. 200).

The above comparison is, of course, only applicable when each primordium is taken separately, as an independent something. The aspect of the question is completely changed if we consider each individual (specimen or segment) as a whole. When we compare, for instance, in Holcus mollis (p. 202), leaf VIII. with leaf XIII., we see that XIII. is comparatively juvenile (in an embryonal state) in respect of the length of the sheath, whereas the same leaf XIII. is further advanced in its development (comparatively senile) in respect of the length and the breadth of the blade. (Compare colour and length of the corolla in Centaurea cyanus, p. 58; see also p. 52.) One may find numerous similar examples in my paper on Mnium.

In the study of gradation, as well as in the study of embryology, each primordium must be measured at first separately in order to obtain EXACT information. The gradation curves of several primordia being plotted down into the form of one diagram (Fig. 23, p. I58, and Fig. 27, p. 203), exact notions about each individual taken as a whole become attainable.

The notion of padogenesis and the terms padogenetic form, juvenile state, embryonal form, etc., when applied on individuals, have been often the expression of vague conceptions. ${ }^{1}$ When applied on species, genera, families, etc., those conceptions have been the cause of erroneous conclusions and many contradictions. The fruit of laborious phylogenetic researches, carried out for half-a-century, has been partly spoiled because we have overlooked the FUNDAMENTAL PRINCIPLE OF THE INDEPENDENCE OF THE PRIMORDIA. (See § 33: MENDEL.)

$\S 142$.- In the present book attention has been repeatedly called to the importance of gradation, and several curious and even unexpected consequences of gradation have been mentioned. In this paragraph I wish to recall the most important passages in which gradation is alluded to :

(I) $\S 38$ (p. 43): Segregation of properties produced by

1 For instance, with reference to the comparison between male and femalo individuals of the same species (sexual and secondary sexual characters). 


\section{THE QUANTITATIVE METHOD IN BIOLOGY}

gradation. Comparison between the effects of Mendelian dissociation, plasticity, gradation and individual development. Example of segregation by gradation : the primordium downy in the sheaths of the leaves of Holcus (p. 45). A similar example is described in my paper on Mnium, p. 20, Remark IV.

(2) $\S 49$ (6) (p. 6I) : Comparison of the curves of development of several primordia according to the method foliowed ( I40, second example, and § I4I) for the comparison of gradation curves.

(3) $\S 52$ (fifth example, p. 68) : Influence of gradation on certain properties of the leaves of Mosses. (See also my paper on Mnium.)

(4) $§ 7 I$ (p. 86) : Any axis is a line of segmentation, differentiation and gradation. Gradation in the erect branches of Pseudochate gracilis, in an egg of Spirogyra, in a hair.

(5) $\$ 79$ (p. 96): Alteration of a chess-board system by gradation.

(6) $\S 82$ (p. Ioo): Gradation in a chess-board system in the direction of the axes NS and EW ; complicated effects (Fig. I3, p. IOI).

(7) $\S 83$ (p. Ior): Continuous and discontinuous gradation (differentiation). Antenna of Carabus. Epidermis of Allium porrum.

(8) $\S 84(p$. I04) : Curvature of compound axes a consequence of gradation.

(9) $\S 85$ (p. I07) : Gradation a cause of disorder in biaxial systems. 


\section{PART IX}

\section{APPLICATION OF THE QUANTITATIVE METHOD-}

THE DESCRIPTION OF SPECIES

\section{§ 143.-VARIOUS APPLICATIONS OF THE QUAN-} TITATIVE METHOD.- In this book I have pointed to a number of possible applications of the quantitative methodfor instance :

(I) The construction of embryological curves, based upon the measurement of a sufficient number of primordia in successive states of development.

(2) The investigation of the structure of animals and plants by means of gradation curves based upon the measurement of primordia along the axes.

(3) The quantitative investigation of the influence of external conditions of existence (plasticity).

(4) The quantitative description of the results of experiments.

(5) The quantitative description of species.

(6) And, in general, the determination of constants, by which it becomes possible to replace terms by figures in any description whatever and to obtain exact expression of observed facts.

In my paper on Mnium (mentioned, p. 69) I have applied the method to the description of species and also to the description (bertillonage) and the identification of specimens, replacing the classic dichotomous tables by tables of constants. I have taken as example ten British species of the genus Mnium. I have applied the same method on the species of the genus Carabus and on the GRAMINEÆ of the Manchester district. ${ }^{1}$ From the fact that the adopted method gives satisfactory results in each of those three widely different groups of living beings, one may conclude that it is applicable to all animals and plants. In certain cases, however, measurements are rendered difficult by practical obstacles-for instance, by the contractility of certain animals (Polypes, Bryozoa, Molluscs, etc.), by the astonishing plasticity of certain plants (many lower Fungi, etc.), a.s.o. It may be hoped that such technical difficulties will be surmounted one after another.

§ 144.-BREACH OF CONTINUITY IN THE DEVELOPMENT OF BIOLOGICAL SCIENCE.-I wish to emphasize

1 The total number of measurements which I have hitherto carried out in the three mentioned groups may be estimated at more than 300,000 . 


\section{THE QUANTITATIVE METHOD IN BIOLOGY}

that the quantitative description of specific forms is only one of the numerous possible applications of the method described in this book, because many biologists take little interest in the systematic part of their science. From the fact that I have applied the quantitative method especially to systematics, they might be tempted to conclude that this method is good for specific description only and is of no importance for other subjects.

There has been a breach of continuity in the historical development of Biological Science. The classical work of LINNÆUS, the DE JUSSIEUS, LAMARCK, LATREILLE, R. BROWN, the DE CANDOLLES, DESHAYES, LINDLEY, BERKELEY, REICHENBACH, VON MARTIUS, W. and J. D. HOOKER and other masters of descriptive science, who tried to inventory and to classify the specific forms, has made hardly any substantial progress for half-a-century. It has been, as it were, interrupted when the doctrine of the constancy of species was replaced by the idea that specific forms are transformed one into another by the accumulation of impalpable changes (DARWIN): It is true, many new species (or so-called species) have been discovered and described, but the new material has been studied almost entirely according to oldfashioned methods. The specific and generic descriptions of Vertebrate and Articulate animals, Molluscs (recent and fossil shells), Phanerogams, etc., which are published every year in a number of memoirs and books, are on the whole drawn up in the same way as half-a-century or even a century ago. ${ }^{1}$

On the other hand, scientific research along new lines has obtained more prominent positions: much progress has been achieved in anatomy, cytology, embryology, physiology, hybridization, heredity, variation, biology properly so calledthat is to say, in those parts of zoology and botany which might be called laboratory science.

Unfortunately systematic science, being almost entirely confined to museums and private collections, did not avail itself of the progress of laboratory science. On the other hand, numerous biologists, who are working in laboratories or experimental gardens, have almost forgotten the existence of systematics. They limit themselves to a rather small number of forms, which are, on the whole, nearly the same in all the universities and laboratories of Europe. They no longer realize the astonishing

1 Compare, for instance, the Flora of the Paris District, edited in 1857 by COSSON AND GERMAIN, or GEORGE BENTHAM'S Handbook of the British Flora (New edition, I866) with the new floras which have been published in Europe and other parts of the world in the last twenty years. As far as the method is concerned, several of the new works are rather inferior to COSSON AND GERMAIN or BENTHAM. 
diversity of the forms of life ; they become rather indifferent to the splendour of living nature.

When they are told that in a certain collection 5000 species of birds are brought together, they do not realize what that means. They know the anatomy and the embryology of the chicken; they have an idea of the duck and the pigeon; they know the peculiarities of the skeleton of the ostrich. Is that not enough? Why should they waste their time with 5000 variants of the type bird? When the laboratory botanist reads in a book that in Greece, Italy and Spain, thousands of Phanerogams are found which are unknown in Central Europe, his curiosity is not awakened. He knows the most important forms of temperate Europe; why should he bother about their Mediterranean representatives ? I was myself in that state of mind for years.

The majority of the biologists of the modern school take from an unlimited forest a few branches which they investigate thoroughly, but they hardly know the trees the branches of which they are studying, and they have not a clear idea of the immensity of the forest, although they believe they have. The systematists walk and travel through the forest, but they do not know what is found within a branch.

Such a state of things is detrimental to the progress of our science. It is not with impunity that we have disunited the right and the left hand. The one-handed method has given us, on the rohole, what it possibly could give. On many sides our science seems to be at a standstill, because we are faced with fundamental problems which will remain insoluble as long as we do not combine the use of both hands.

§ 145.-VAGUENESS AND INCOMPLETENESS OF SPECIFIC AND GENERIC DESCRIPTIONS.-The living beings are described in our floras and faunas by means of terms. Unfortunately the terms are often vague; there is even something mysterious in their use. We are told, for instance, in one of our best floras, that the leaves of Deschampsia flexuosa (a grass) are short, with a long sheath. According to my measurements the length of the leaf (blade) varies in this species between 8 and II $2 \mathrm{~mm}$., and the limits of variation of the length of the sheath are 37 and $I 75 \mathrm{~mm} .{ }^{1}$ What is long and what is short? According to the book a sheath of $50 \mathrm{~mm}$. is long and a blade of Ioo $\mathrm{mm}$. is short. The imperfection of the descriptive method is obvious.

When figures are given they are often hardly approximate, or quite inexact. We find in a classic book that in Phleum pratense the length of the inflorescence varies between 25 and $100 \mathrm{~mm}$. ( $\mathrm{I}-4$ inches); the limits I have found are 8 and $194 \mathrm{~mm}$. ! We are told in the same book that in Triodia decumbens the upper empty glume is 3-nerved. This is given

II have limited myself to the upper leaf of the fertile stem. 


\section{THE QUANTITATIVE METHOD IN BIOLOGY}

as a characteristic of the genus. I have found the following variation curve :-

$$
\begin{array}{cccccccc}
\text { Number of nerves: } & 3 & 4 & 5 & 6 & 7 & 8 & 9 \\
\text {, , glumes: } & \text { I } & 0 & \text { I2 } & 3 & \text { I } & \text { I } & \text { I }
\end{array}
$$

It is seen that the primordium under consideration is very variable; that the figures 5 and 6 are predominant, and that 3 is a rarity!

Similar examples are found in UNLIMITED NUMBER in the best systematic works in which Phanerogams, Fungi, Algæ, Fishes, Birds, Articulate animals, Shells, etc., are described. ${ }^{1}$ As soon as we measure a few primordia in a sufficient number of specimens of a species ${ }^{2}$ and compare the result with the information given in a flora or a fauna, we discover vagueness, inexactitude and even manifest errors. (See § 52.)

I point out here a serious evil which seems to have been hitherto overlooked. ${ }^{3}$ The systematists, confined in an antiquated routine, are the first victims of their deplorable method. Since the great majority of the existing specific and even generic descriptions are superficial and unfinished to such a degree that the exact identification of a specimen is simply impossible, the systematists discover continually and describe under new names so-called new species, which have already been described either once or even several times. The result is a complicated synonymy and a discouraging disorder. When anyone tries to make a catalogue of the flora or fauna of a given area, he is faced with inextricable difficulties. If he takes the pains of travelling from one museum and private collection to another in order to examine and to compare the types, he discovers that numerous descriptions have been based upon one or two specimens, or even upon a fragment, and he is again and again disappointed. ${ }^{4}$

Moreover, the existing descriptions are ordinarily very incomplete. Only a few characters are mentioned, according to a sort of conventional scheme, which would possibly have been sufficient (or thereabout) a century ago, when the number of known species was comparatively small, but which does not answer the needs of modern science. The fruits and the seeds

1 See other examples in my paper on Mnium.

2 Taking a species the identification of which is beyond any doubt.

${ }^{3}$ See C. G. LLOYD, The Myths of Mycology, Part I. Cincinnati, $O$. (December, r9I7). I6 pages.

The author of this paper has illustrated, by a number of examples, the almost incredible imperfection of many well-known works on fung $i$ and the deplorable disorder which prevails in this department of descriptive botany.

4 I repeat here in a few words what I was told by TH. DURAND, one of the authors of Conspectus Flore Africance. 


\section{APPLICATION OF THE QUANTITATIVE METHOD 211}

of many plants are simply ignored or hardly mentioned. ${ }^{1}$ As a consequence of the spirit of routine, microscopical characters are still almost entirely excluded from the systematic description of Phanerogams, Vertebrate animals, shells, etc. Although microscopes of modern type were brought into general use between 1830 and 1840 , at the time being many entomologists have not yet realized that the descriptive work they are carrying out without the microscope will have to be done over again.

By means of the method expounded in this book, it becomes possible to describe exactly any primordium whatever, however variable it may be. Using the microscope for the discovery and the measurement of primordia we are enabled to go far beyond the usual scheme. For the description of the higher forms of life ${ }^{2}$ there are practically no limits to the number of primordia which may be used. (See p. I90.) Following the variation of a given primordium through a long series of specific forms, interesting and unsurmised resemblances and differences are discovered. (See p. 68.) By means of tables of constants the innumerable observed facts may be set in order. (See my paper on Mnium.) Following this method we grow accustomed to exactitude and we learn to use the terms with more accuracy. Moreover, we find now and then that a given peculiarity, which was quite unknown and seems to be a futile detail, is a characteristic feature of one species, with the consequence that a decisive diagnosis of that species may be reduced to five or six words with one or two numbers. ${ }^{3}$

§ 146.-IMPORTANCE OF SYSTEMATICS.-It would be a mistake to disdain the work of the classic school. The talent of observation of the masters of systematic science is marvellous. They had exactly distinguished and classified an enormous number of species with poor technical means, at a time when optical instruments and laboratory science had not yet emerged from childhood. They have been the pioneers of our science. They were almost all enthusiastic collectors. Their collections of objects have been collections of ideas: let us follow their example. They were chiefly guided by a sort of instinct, which enabled them to distinguish and to recognize the species by their habitus (facies). The high value of that instinct, acquired and developed by experience, should be impressed upon the mind of many modern biologists, who cannot realize how it is possible, for instance, to recognize thirty or forty horticultural sorts of Azalea indica by a glance at the plants without flowers.

1 The study of the fruits and the seeds of exotic Angiosperms, and even of many European species, is for the investigator an unlimited field full of promise.

2 And even for the description of many Thallophytes and lower animals.

See my paper on Mnium, Table XXXIX. More examples will be given in a paper on Grasses which I hope to edit later on. 


\section{THE QUANTITATIVE METHOD IN BIOLOGY}

Unfortunately the methods of description which came down to us from the past do not enable us to make a useful inventory of the forms of life. It may be hoped that the quantitative method will render possible further development of the work of the pioneers.

§ 147.-SYSTEMATICS AND COMPARATIVE METHOD ; MORPHOLOGY AND PALÆONTOLOGY. IMPORTANCE OF COLLECTIONS.-The Comparative Anatomy of CUVIER is the real fundament of modern morphology : it has been built up by the comparison of numerous species. This would have been impossible without collections. CUVIER and his contemporaries were, in a certain sense, one-handed : they limited themselves to the comparison of adult specimens. They could not do otherwise; embryology was almost entirely beyond their reach, because there were neither microtomes nor good microscopes. We are also one-handed: in morphological science we have universally adopted the embryological method, but we are not concerned with collections and we overlook the importance of the comparative method. We have forgotten that our science has been created by the latter and has taken birth in museums.

Why do not we combine both methods? Because of the breach of continuity I have already alluded to. Comparison is, in reality, impossible without systematics and collections. Both are disdained by many modern morphologists, because they have been too often disappointed by the imperfection of the antiquated methods still followed by the collectors and in the museums.

Numerous biologists overlook the importance of palæontology. Here embryology is of little use ; it is only by the comparative method that we can investigate the majority of the fossil plants and the innumerable fossil animals. The bulk of the palæontological material consists of shells, carapaces (Echinids, etc.), polypiers, teeth, leaves, etc., which are, as a rule, disdained by the laboratory biologists. Since there is a gap between museum and laboratory, between the comparative and the embryological methods, palæontology is hampered in its progress. Fossil Molluscs, Echinids, polypiers, etc., are, as a rule, still investigated according to the methods of DESHAYES, D'ORBIGNY and other pioneers of the past. ${ }^{1}$

The quantitative method, applied on systematics, enables us

1 GEORGE HICKLING, D.Sc., F.G.S., "The Variation of Planorbis multiformis Bronn," in Memoirs and Proceedings of the Manchester Literary and Philosophical Society, vol. lvii., Part III. ; 24 pages with 2 plates and 6 figures (rgr3). This interesting memoir is an exception to the ordinary rule: the author has applied the modern biometrical method to the study of the variation of the fossil species mentioned in the title. 
to discover in the shells and the carapaces numerous unsuspected peculiarities, ${ }^{1}$ which may afford new, wider means of comparison between fossil and recent species. (See § I48.)

§ 148.-IMPORTANCE OF MINUTE DETAILS.-The tables of constants given in my paper on Mnium, the tables which are given below ( $\$$ I50), and many examples mentioned in the present book, might bring about the impression that I am concerned with unimportant details.

In Biological Science there are no unimportant subjects. MENDEL and his followers have taken a certain number of simple things or primordia and studied their hereditary transmission. They have discovered a new world by the investigation of colours, wrinkles, hairs, prickliness and smoothness of fruits, presence or absence of glands on the leaves, branching or unbranched habit, presence of starch or sugar in the albumen, dimensions (tallness or dwarfness) and other details which are ordinarily considered unimportant.

The intricate problems of heredity have been brought nearer their solution by dividing them into simple components.

The most intricate morphological structures consist of a combination of primordia, each primordium being a simple something, a detail. Comparing compound structures, the morphologists try to discover the relations between large groups (orders, classes, families) of living beings, but they are less concerned with the relations between smaller groups, such as genera, species, subspecies. Here the relations are simpler, because the differences depend on a smaller number of primordia, but the fundamental morphological laws are the same. In the simple, as well as in the complicated cases, everything depends on the primordia and on the specific energy of each of them.

We should bear in mind that the best method is to proceed from the simple to the complex. It would be profitable, I think, to pay more attention to the relations between genera, species and subspecies: this would pave the way for the study of more intricate relations. When we apply the quantitative method on systematics, investigating, for instance, a number of primordia in a series of species of Carabus, Mnium or Graminea, we are studying minutiæ, it is true, but we may hope to discover general rules which govern the more complex combinations of primordia. A consequence of our disdain for systematics is that we sometimes attack insoluble problems, putting the cart before the horse.

In the shells, carapaces, polypiers and other similar objects, we also discern a number of primordia. Here the combinations 


\section{THE QUANTITATIVE METHOD IN BIOLOGY}

are comparatively simple, and we enjoy the inestimable advantage of having at our disposal not only recent species but numerous series and innumerable specimens of fossil species from all the geological periods. By means of tables of constants the facts may be set in order. Here we must, of course, begin with the investigation of the recent forms, in order to pave the way for the study of their fossil analogues. ${ }^{1}$

The history of the progress of physics and chemistry teaches us an important lesson : here the quantitative method has been applied more and more to the study of minutiæ. The constructors of instruments have been asked continually for more perfection in their balances, thermometers, goniometers, galvanometers, thermostats and other implements, in order to penetrate deeper into the quantitative knowledge of small things which were previously neglected. Along this road marvellous discoveries have been made. In a similar way much progress may be achieved in biology by the measurement of minutiæ which are primordia. By the work of the Mendelian School and by the application of the quantitative method to systematics, the road is opened.

$\S 149$. -THE NOTION OF SPECIES.-This notion is in reality the corner-stone of biological science. In Part I. I have expounded a hypothesis according to which the notion of species is a chemical notion, and each species is strictly different from all others. Adopting the latter principle, I deviate from the Darwinian doctrine of the continuity of the forms of life which is still accepted by the great majority of the biologists. I am, however, not alone.

It may be remarked, at first, that DARWIN himself, especially in some of his later works, has repeatedly pointed to the occurrence of sudden variations or sports, by which a specific form might possibly be transformed into a new one (saltation).

"... GALTON (I889) is of the opinion that the aberrant or discontinuous variations generally known as sports may be of considerable significance in evolution. Because evolution may proceed by minute steps, he considers that it does not by any means follow that it must so proceed.

"Again, within recent years the orthodox view (continuity) has been ably combated by BATESON in his book on variation

1 For instance, the study of the fossil Brachyopods, Pectens, Cardiums or Echinids should be preceded by the quantitative investigation of the primordia of the recent species of the same groups, because it is possible to obtain about the latter information in respect of individual development (embryological series, see p. 194 ; embryological curves, see p. 61 and $15^{8}$ ), conditions of existence (plasticity) and even hybridization. Beginning with the fossils, we would, I am afraid, put once more the cart before the horse. 
(I894). In this work he has collected a very large number of instances of discontinuous variation, or variations in respect of certain organs or parts, which have suddenly arisen in a complete and perfect state, without, as a rule, the occurrence of any intermediate stages. If, therefore, argues BATESON, such instances of discontinuous variation undoubtedly occur, is it not possible that the discontinuity of species which is so striking a fact among living organisms is a consequence and expression of this discontinuity of Variation ?" 1

In his theory of mutation HUGO DE VRIES has emphasized the principle of discontinuity of species; he promulgated the view that one species arises from another by a distinct step or jump (mutation; saltation).

Many facts discovered by the MENDELIAN SCHOOL seem to be inconsistent with any theory (Darwinian or NeoLamarckian) about the origin of species based upon the principle of continuous transformation. In a number of examples, indeed, primordia (characteristics) are transmitted independently from one another, being in turns observable or latent through successive generations, without intermediate forms (plasticity being taken into account).

And moreover, as far as I know, it has been hitherto impossible, by means of ARTIFICIAL SELECTION, to modify a species beyond a certain limit and to obtain the gradual transformation of a species into another one.

The doctrine of the constancy of species, which prevailed in pre-Darwinian times, can no longer be accepted. There are, however, very serious reasons to adopt the principle of the independence of species, which has the same significance for practical purposes, although it is different from a theoretical standpoint.

Suppose that we wish to study the numerous indigenous species of Ranunculus, Vicia, Veronica or Graminea. We collect specimens and try to identify them by means of the best modern floras: in those books the given information is vague, often hardly approximate, or even erroneous. ${ }^{2}$ Since we are continually hesitating we are tempted to believe that a species is really an artificial something and that all our Veronicas or Vicias are simply variants of one type. One day perhaps a friend may identify our specimens. We persevere; we look at the specimens rather than at the books. Observing the plants under various conditions of existence, we become aware of the importance of plasticity. We acquire step by step a certain degree of instinct, and the result is that we become capable of

1 See H. M. VERNON, Variation in Animals and Plants (London, 1903), p. 52. See also, in the present book, p. 36 , note 1 .

${ }^{2}$ See $\$ 145$. 


\section{THE QUANTITATIVE METHOD IN BIOLOGY}

distinguishing the species, recognizing them at first sight. Now we realize that the authors of the floras knew the species and even certain subspecies ${ }^{1}$ on the whole very exactly. We believe that the initial difficulties have been a result of our ignorance. Do we realize that they were, above all, a consequence of the hopeless insufficiency of the descriptions?

In certain critical genera, such as Rosa, Rubus, Hieracium, and also Salix, Carex and others, it is true, the difficulties seem to be insuperable. Here the notion of species seems to be really artificial. Let us try to discover the origin of that state of things.

The prevailing disorder has taken birth in former times, when the disentanglement of the specific forms of the mentioned genera was an insoluble problem. Here the instinct was not a sufficient guide because of the extreme variability. Our predecessors had no clear notions about the different sorts of variation. They have described indiscriminately species, subspecies, variants, ${ }^{2}$ hybrids and bud-variations. ${ }^{3}$ Since the descriptions were drawn up in the ordinary defective way, it is impossible to find in their writings the exact expression of the observed facts. In more modern times, the same method being still followed, the disorder has been continually augmented by the publication of more memoirs, monographs, and critical revisions. It became still more fearful when we began to talk about Jordanian species: the sluice gates were opened more widely than ever before. ${ }^{4}$ The subject has been spoiled.

A similar disconcerting result would be attained if a number of mineralogists, ignorant of the MODERN METHODS of investigation of their science, began to write memoirs on the composition of all sorts of sand collected from various parts of the world.

The investigation of the critical genera of animals and plants should be started afresh. The existing literature should be provisionally thrown aside, the best floras and faunas being used, however, for general orientation and for the discovery of primordia $(\$ 52)$. A sufficient number of primordia should

1 Certain forms, described as varieties, are simply variants. (See p. I I.)

${ }^{2}$ Numerous species of Carex and Salix are more or less amphibious: it is well known that amphibious species are in general very plastic.

${ }^{3}$ Hybrids and bud-variations may be multiplied indefinitely by asexual propagation. (See $\S 20$, p. I6.) The latter is widely spread in the genera under consideration.

FR. CRÉPIN, who devoted more than thirty years of his life to the study of the genus Rosa, has called attention to the fact that many so-called species of that genus have been based upon one specimen, or upon one bush (buisson) consisting of specimens which were all produced by vegetative propagation of a single one. Such species are represented in numerous herbaria by branches, which were distributed by exchange clubs or exsiccata. CRÉPIN called this method buissonomanie.

A similar method has been probably applied on Rubus, Salix, Carex, etc.

4 Investigation of the Jordanian species ought to be carried out by means of the quantitative method initiated by JOHANSEN for the pure lines in his experiments with beans. 
be exactly determined and measured, gradation being taken into account. Seedlings and cuttings should be compared and cultivated under various conditions of existence, and we should have recourse as often as possible to hybridization.

In this way, it may be hoped that light will be thrown upon that foggy department of systematic science.

Whatever the theory may be, it is a matter of fact that critical species are a small minority and that the independence of species is the ordinary rule among living organisms. One may ask whether the belief that the notion of species is artificial has not its origin rather in the vagueness of the existing descriptions than in the living objects.

The quantitative method is independent of any theory : it may be applied immediately to the description of the very numerous species of animals and plants which are, in fact, independent, whatever the explanation of that independence may be. And, moreover, the constants of those complex species which include critical subspecies may be established, each species being taken as a whole. The constants of the subspecies may be eventually determined later on. Since they are, of course, included within the limits of the species, their determination does not affect the latter. ${ }^{1}$

§ 150.-EXAMPLE OF APPLICATION : THE QUANTITATIVE DESCRIPTION AND IDENTIFICATION OF GRAMINEÆ.-In my memoir on Mnium I have given a first example of application of the method to systematics. Here I give a second example.

I have applied the method to the Graminea of the Manchester district. Since the number of primordia (characters) is practically unlimited in those plants, a choice must be made. I have measured about 25 primordia of the fertile stem (including inflorescence, spikelets and flowers). For each primordium in each species I have determined the limits of variation-that is to say, the lowest and the highest value, which are specific constants.

In order that we might find the limits without being compelled to measure an excessive number of specimens, the MATERIAL IS COLLECTED in the following way :-I try to find specimens of a given species under conditions of existence as various as possible : on dry and wet, sunny and shady spots, on rich and poor soil, on walls and rocks and on the banks of rivers and streams, in forests and gardens and on cultivated

1 In the memoir on Gramine which I intend to publish later on, I hope to discuss the notion of species (and subspecies) in relation with specific constants, and also to suggest an explanation of the so-called adapiation of the RACE to the conditions of existence, independent of the direct influence of the surroundings and without the intervention of natural selection. 


\section{THE QUANTITATIVE METHOD IN BIOLOGY}

fields, on the heath, in waste places, in meadows, etc. ${ }^{1}$ From each spot I collect the largest and the smallest specimens ${ }^{2}$ and measure them. In this way the work required for the discovery of the limits is reduced to a minimum. ${ }^{3}$

The description of a species consists of a table in which the constants of each primordium are given.

Remark: Those constants are something quite different from the limits of variation represented by the extremities of a variation curve constructed by the measurement of a series of specimens collected (according to the ordinary biometrical method) at random on one spot or in one locality. See pp. $182,188$.

EXAMPLE (here I content myself with nine primordia) :

Specific description of Alopecurus pratensis L. :

1. Length of the upper internode of the fertile stem : $129-678 \mathrm{~mm}$.

2. Length of the blade of the upper leaf of the fertile stem : 12-253 mm.

3. Length of the inflorescence : 24-183 $\mathrm{mm}$.

4. Length of the first empty glume: $3 \cdot 86-6 \cdot 42 \mathrm{~mm}$.

5. Breadth of the first empty glume: $1 \cdot 38-2 \cdot 20 \mathrm{~mm}$.

6. Number of nerves of the first empty glume: $3-3$.

7. Number of nerves of the second empty glume: $3-3$.

8. Length of the (first) flowering glume : $3^{\circ} 44^{-5} 97 \mathrm{~mm}$.

9. Length of the awn of the (first) flowering glume : $4^{*} 73-9 \cdot 99 \mathrm{~mm}$.

The ratio (length first empty glume) : (length first flowering glume) varies between 0.94 and I. 17 .

In the above table I give an example of a ratio, which is, of course, not a primordium but an empirical value calculated arbitrarily from two primordia. We might also take arbitrarily the sum, the product, the square root of the product, etc. (§ I02). Such empirical values may render in certain cases good services, although their biological or mechanical significance is very vague. The constants of the primordia are, on the contrary, figures which have been obtained by direct measurement without any calculation. They are the expression of observed facts.

TABLES OF IDENTIFICATION are constructed in the following way, limiting myself in one or another way. I take, for instance, all the species of a genus, or the species of a family which are indigenous in a given country or district, etc. For each primordium a table is drawn up in which the minimal and maximal values of each species are given. In the following example I content myself with four primordia, one ratio and six

1 The possible conditions of life are very varied for the majority of the species, although many of them are ordinarily found under certain definite conditions. In LEO GRINDON'S Flova of Manchester (1857) the ordinary surroundings of each species are exactly indicated.

${ }^{2}$ And, as much as possible, those specimens which are conspicuous by one or another peculiarity, for instance by very long or short leaves, very large or small spikelets, etc.

${ }^{3}$ And it may be added that many interesting observations are made in the field. 
species of grasses. This is enough to give an idea of the method. I take Agrostis alba as a whole, and bring under this name $A$. alba L., A. vulgaris With. and their so-called varieties, adopting provisionally the view of BENTHAM (Handbook of the British Flora, 1866, p. 533). Dimensions in millimetres:

\section{TABLE I}

Length of the blade of the upper leaf of the fertile stem

Minimum

Alopecurus pratensis

Agrostis alba

Glyceria fluitans

Festuca pratensis Huds.

Melica uniflora

Bromus asper
I2

I7

27

33

33

I25

Maximum

Melica uniflora

Glyceria fluitans

I75

203

Agrostis alba

224

Alopecurus pratensis

253

Festuca pratensis Huds. 264

Bromus asper

$4 \mathrm{I} 6$

TABLE II

Length of the first empty glume (awn excluded)

Minimum

Glyceria fluitans

Agrostis alba

I.6

I.8

Festuca pratensis Huds. $2 \cdot 0$

Melica uniflora

Alopecurus pratensis

Bromus asper
$2 \cdot 7$

$3 \cdot 8$

$4 \cdot 0$

Maximum

Agrostis alba

$3 \cdot 2$

Glyceria fluitans

$4^{\circ} \mathrm{O}$

Festuca pratensis Huds.

Melica uniflora

Alopecurus pratensis

Bromus asper

$4 \cdot 3$

$5 \cdot 5$

$6 \cdot 5$

$7 \cdot 6$

TABLE III

Length of the first flowering glume (awn excluded)

Minimum

Agrostis alba

Melica uniflora

Alopecurus pratensis

Glyceria fluitans

Festuca pratensis Huds.

Bromus asper
Maximum

I.4 Agrostis alba

3.2 Melica uniflora

3.4 Alopecurus pratensis

4. $\quad$ Glyceria fluitans

4.7 Festuca pratensis Huds.

8.7 Bromus asper

$2 \cdot 3$

$5^{\circ} 0$

$6 \cdot 0$

$7^{\circ} 0$

$7 \cdot 6$ $13^{\circ} \mathrm{O}$

\section{TABLE IV}

Length of the awn of the first flowering glume Minimum

Glyceria fuitans

Mclica uniflora

Festuca pratensis Huds. o Agrostis alba Bromus asper 0.04

Maximum 


\section{THE QUANTITATIVE METHOD IN BIOLOGY}

\section{TABLE V}

Ratio (length Ist empty glume) : (length Ist flowering glume)

Minimum

Glyceria fluitans

Festuca pratensis Huds. 0.39

Bromus asper

Melica uniflora

Alopecurus pratensis

Agrostis alba
0.50

0.82

0.94

I.08

Maximum

Glyceria fluitans

Bromus asper

Festuca pratensis Huds. 0.65 Alopecurus pratensis

Melica uniflora

Agrostis alba
0.55

0.64

I'I7

$I \cdot I 9$

I.5I

USE OF THE TABLES OF IDENTIFICATION : Suppose that we want to identify a Grass $x$ with one or several fertile stems, and that we have no other information than that it belongs to one of the species mentioned in the Tables I.-V. The THREE METHODS of using the tables which I have given in my paper on Mnium are also applicable to the Grasses.

According to the FIRST METHOD I measure the primordia of one stem and of one spikelet of its inflorescence. The figures are (this example is taken at random):

\section{SPECIMEN $x$}

Length blade upper leaf

" first empty glume

" " flowering glume

awn first flowering glume

Ratio length (Ist empty) : (Ist flowering) glume
$70 \mathrm{~mm}$.

49

$5 \cdot 1$

7.5 "

I begin with Table I. : minimum, Bromus is excluded; maximum, no species excluded.

Table II.: minimum, no species excluded; maximum, Agrostis, Glyceria and probably Festuca excluded. (Since the constants are not definitively established, the difference between $4^{\circ} 3$ and $4^{\circ} 9$ is rather too small to be decisive.)

Table III.: minimum, exclusion of Bromus confirmed; maximum, exclusion of Agrostis confirmed, Melica probably excluded.

Table IV. gives a decisive answer: minimum, no species excluded; maximum, all the species excluded except Alopecurus. Here, however, the exclusion of Bromus is only probable (for the above given reason), but Bromus has already been excluded.

It may be concluded that $x$ is Alopecurus pratensis.

I measure in a similar way the primordia of one stem and one spikelet of a Grass $y$. The figures are : 


\section{SPecimen $y$}

Length blade upper leaf

first empty glume . • . I55 mm.

: . $377^{\circ}$

" . flowering glume . . 4. $4^{\circ}$ " awn first flowering glume : : 0 "

Ratio length (Ist empty) : (Ist flowering) glume 0.93 ",

The order in which the tables are used being arbitrary, I begin this time with:

Table V.: minimum, Agrostis probably excluded ; maximum, Glyceria, Bromus and Festuca excluded [here the practical utility of an empirical value (ratio) is obvious].

Table IV.: minimum, Agrostis again probably excluded; maximum, exclusion of Bromus confirmed, Alopecurus excluded.

Table III. : minimum, exclusion of Bromus and Festuca confirmed; maximum, exclusion of Agrostis confirmed.

Since five species have been excluded, $y$ is Melica uniflora.

I try now a third Grass $z$ and measure the primordia (one stem, one spikelet). The figures are :

\section{SPECIMEN $z$}

Length blade upper leaf . . . . $327 \mathrm{~mm}$.

" first empty glume . . . . $3^{2} 2$ ",

" $\quad$ flowering glume . . . $5^{\circ} 2$ "

awn first flowering glume : : I.7 ",

Ratio length (Ist empty) : (Ist flowering) glume 0.62 ",

I begin with Table I.: minimum, no species excluded; maximum, Melica, Glyceria, Agrostis, Alopecurus and Festuca excluded.

Table II. : minimum, Bromus excluded.

All the species being excluded, it may be concluded that $z$ does not belong to any of our six species. In order to verify this deduction, I take the tables in the reverse order, and begin with :

Table V.: minimum, Agrostis and Alopecurus excluded, Melica very probably excluded; maximum, Glyceria probably excluded.

Table IV.: minimum, Bromus excluded, exclusion of Alopecurus confirmed; maximum, exclusion of Melica and Glyceria confirmed.

Table III.: minimum, exclusion of Bromus confirmed; maximum, exclusion of Agrostis confirmed.

Table II. : no more species excluded.

Table I. : minimum, no species excluded ; maximum, exclusion of Melica, Glyceria, Agrostis and Alopecurus confirmed, Festuca excluded. 


\section{THE QUANTITATIVE METHOD IN BIOLOGY}

The above deduction is verified. The Grass $z$ is, indeed, a specimen (taken at random) of Dactylis glomerata. This example gives us an idea of the way in which it may be discovered whether a given species is new for the flora of a certain area or even new for science, if we have tables of constants at our disposal.

The SECOND METHOD is applicable as often as it is possible to measure the same primordia in two or several specimens which belong with certainty to the same species (in the case of the Grasses two or several stems of one plant or one patch). Example: I take (at random) three fertile stems of one patch of Alopecurus pratensis and measure the length of the blade of the upper leaf. The figures are $\mathrm{I}_{53}, \mathrm{I}_{32}$ and $47 \mathrm{~mm}$. Taking Table I., the values 153 and 132 do not give us any information, but by means of the figure 47 Bromus asper is excluded. Etc. See my paper on Mnium.

The THIRD METHOD is applicable if one specimen (in the case of the Grasses one inflorescence) affords opportunity of measuring certain primordia two or several times. Example: I measure in one inflorescence, $u$, the length of the awn of the first flowering glume of several spikelets. Among the examples which I have collected I choose one in which the figures were $5.7,6.2$ and $8.2 \mathrm{~mm}$. Taking Table IV., the figures 5.7 and 6.2 do not give decisive information, but from the value 8.2 it may be deduced that $u$ is Alopecurus pratensis.

In the above examples it has been possible to identify a specimen by means of a few figures. This happens more frequently than one would think. It is, of course, often necessary to measure a rather large number of primordia, especially when we want to make a choice between numerous species. (An example is given in my paper on Mnium, Table XXXIX.)

DESCRIPTION OF ONE SPECIMEN. BERTILLONAGE. -One figure, representing the value of one primordium of one specimen, has rarely any value as long as it is taken isolatedly. When a sufficient number of primordia of one specimen are measured, the combination of figures obtained is a bertillonage : it is a quantitative diagnosis of the specimen (compare $\S$ I 40 ). A bertillonage has been hitherto looked upon as being useful only for the identification of an individual among all the specimens of the same species. A bertillonage has, however, a much higher significance. The species itself is included in the combination of figures. (See the combinations of $x, y$ and $z$, pp. 220-22I.) I have tried a very large number of examples taken at random among species of Carabus, Mnium and Graminece. I never found an exception.

See my paper on Mnium, $\S I 8$ : the value of bertillonage for descriptive botany and zoology. 


\section{INDEX}

\section{A}

ABIoric substances and properties, 6, 70

Accommodation, 17, 5r

Adaptation, individual, 17, 51 ; of the race, 217 ; specific, 17

Adult, individual, 5 I ; primordium, 5 I Agrostis, 2 I9

Aira, 44

Ajuga, 17

Alkaloids, 4

Allen, J. A., 28

Allium, 96, 102, II2

Alopecurus, 218, 219

Alternative variation, $1 \mathbf{1} 7$

Alysarine, 6

Amaryllidaceæ, 92

Ammonites, II 3

Anagallis, 67

Ancylus, II 3

Anemone, constant hybrid, 39

Annelids, 97

Annuals, 92

Aphrophora, 19

A pocynacee, II I

Apple, 44

Arachis (oil), 4

Articulates, 97

Asclepiadacea, II I

A sperula, 6

Ass, 195

Axes, 86, 93, 95 ; compound, 103 ; of crystals, 198; curved, 103; of living beings, 199; oblique (false), ro8; optical, 74 ; simple, ro3 ; uniaxial system, $7 \mathbf{I}$

\section{B}

BALLS in an urn, 124, 125

Bateson, W., 32, 37, 38, 39, 42, 69, 214

Beech, 43. See Fagus

Bentham, I I, 208, 2 I9

Bertillonage, 27, 201, 222

Betula, 175

Biaxial system, 93

Binomium $(a+b)^{2}, 120^{\circ} ;(a+b)^{n}, 146$

Biology, breach of continuity in, 207

Biometrika, 31

Biometry, 27, 31

Bioproteins, 5
Bivalves, I 13

Bohr, Niels, viii

Bois, Dr De, 57

Boraginacea, 194

Bromus, 219

Bruyker, Dr de, $17,58,178, \mathbf{1} 85$

Bud-generations, 9 I

Bud-species, I6

Bud-subspecies, I6

Bud-variation, I 5

Bugs, 6

Buissonomanie, 216

Bulbous plants, 92

Burvenich, J. V., I3, 22, I 84

Butomus, I 79

Butter, 4, 5

Butterflies, I I ; scales, 8 I

Callitriche, $\mathbf{I}_{3}$

Calluna, 18

Calosoma, 62, 68, 97, 190

Campanula, 13, 43

Campanularia, 81

Canary bird, 195

Carabus, 62, 67, 102, 107, 190

Cards, experiments with, 163

Carex, 216

Cassis, 99, II 3

Castanea, I75

Cecropia, 91

Centaurea, 18, 21, 58, I80, 182, 194

Cephalopods, II 3

Certitude, expression of, 123

Chara, 6

Characteristics (chemical), 6, 70

Chelonide, 62

Chemical characteristics, 6, 70

Chemical variations, 70

Chermes, 196

Chess-board system, 94; alterations, 95: differentiation, IOI ; disorder, I05; gradation, 100

Chrysanthemum, 12, 58, 180, 182, 184, I 86

Cicindela, 6, 7

Cinclidium, 203

Circaa, I8I

Clarkia, 18r

Classification, I

Cleavage, 93, Iro

Coccinella, 6, 19 
Coefficient (equation), personal, 49

Cœnobium, 178

Coins, equilibrium of, I16, I19, 121, 122

Colchicacea, 99

Coleoptera, 97

Collections, importance of, 212

Collumbien, 13

Complex species, $I_{4}$

Complexity, II, I4

Compound properties, 40 ; decomposition of: in the course of individual development, 46 ; by gradation, 45 ; by hybridization, 40 ; by plasticity. 43

Concordance, mechanical, 79

Conifera, I96

Constants, biological, I74, I8I ; tables of, 218

Copper-beech, 43

Correlation, 56

Correns, 35, 37

Cortex, II 2

Cosson, 208

Crampton, H. E., II4

Cratcegus, 91, 192

Crépin, Fr., 216

Crimson Rambler (Rose), I3

Cucumber, 195

Cultivation, 17, 174

Curve, biological variation, 28, 165 167 ; dimorphic, 185; polymorphic, I8 5 ; of errors, 145 ; of growth, I53I58; inorganic variation, $158-167$; unilateral variation, I5I. See Embryological, Embryology

Cuttings, 90

Cuvier, 66, 80, 212

\section{D}

DACTYLIS, I8, 222

Darwin, 15, 16, 19, 45, 46, 49, 51, 60, I95, I97, 208, $2 I_{4}$

Darwinism, I7

Dautzenberg, $\mathrm{Ph} ., 24$

Davenport, C. B., 3 I

Deschampsia, 44, 209

Description of species, quantitative, 207,218 ; vague and inexact, 209, 216,217

Details, importance of, 213

Determiners, 4I

Die, equilibrium of a, 125, 127

Dietel, I92

Differentiation, 72, IOI, 201

Dipsacea, 6

Dipsacine, 6

Dipsacotine, 6

Dipsacus silvestris torsus, 22

Disorder, 105

Dissociation, in hybrids, 34. See Segregation
Dominant character, 33

Donax, II 3

Drosera, $8 \mathrm{I}$

Duck, I95

Durand, Th., 210

E

ECHINODERMS, 77

Echium, I96

Elementary species, 7, I I

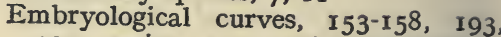
204; series, 193, I96; parallelism, 196

Embryology : curves of development, 61 ; variation in, 62 ; method, 50 , 80,212

Endodermis, II 2

Epidermis, 98, II I

Epilobium, 181

Equation, personal, 49

Equilibrium, 5I

Evica, 78

Eristalis, 19

Erodium, 87

Errors of observation, $\mathbf{I}_{45}$

Erythrca, 21

Euastropsis, 78, 180

Eucharidium, I8I

Evans, W. D., viii

Existence, conditions of, 167

Experiments (investigation of critical specific forms by), I4, 216; with cards, 163

External factors, 167

Eye, 49

Eye-shaped spots, 196

\section{F}

FACTORS, hereditary, 4 I

Fagus, II, 43, 56, 88, I 75

Fasciation, 20

Fats, 2

Fertilization, self and cross, 49

Festuca, 219

Fibonacci numbers, 178

Ficaria, 17

Fossils, 212, 214

Fowl, 195

Frequency, I 8

Fritillaria, 99

Frontignan (grape), 16

Fuchsia, 18I

Fumaria, 89

G

Galton, Francis, 30, 3I, 214

Gamophyllous corolla, calyx, 89 
Gasteromycetes, 79

Gauss, I 47

Genista, 67

Geranium, I79, I9I

Germain, 208

Gladiolus, 16

Glyceria, 2 I9

Glycerides, 2

Goose, 195

Gradation, 100, 198, 205 ; discontinuous, 201,203 ; in a leaf, 204, 205

Grafts, 90

Graminea, 92, 217

Grape, I6

Grasses, 217

Grindon, Leo, 218

Growth, I 54

Gryllotalpa, 81

Gucht, van der, 178

H

HAECKEL, 50

Hamburger, 49

Häuy, 64

Häuya, 181

Head or tail, II 6

Heincke, Dr Fr., I90

Heredity, 7 ; two kinds of, 8

Herposteiron, 84

Herring, 190

Hickling, Geo., 212

Hickson, S. J., II4

Hieracium, 216

Holcus, 18, 45, 48, 201, 205

Homology, 79

Hooker, J. D., 67, I74

Horse, 195

Horticultural species, 16

Hybridization, 32,134 . See Hybrids

Hybrids, 21 ; constant, 38, 39, I 41 ; dissociation, 34; dominant characters, 33 ; intermediate, 37,38 ; Mendelism, 32; Enothera, 38 ; recessive characters, 33 ; segregation, 34 ; vegetative multiplication, 16 Hydrodictyon, 83

Hyoscyamus, 37

Hypericum, 19
Infantile state, 52, 59, 205

Intermediate, 36 ; units, 96 ; specific forms, 39

Interposed specific forms, 39

Iris, 92, II 2, 179

Isnardia, I8I

JANCZEWSKI, 39

Johansen, I 5, 3I, 216

Jordanian species, 216

Juvenile state, 52, 59, 205

K

KNIGHT, I6

Koelreuter, 35

L

LABORATORY science, 208

Lamarckism, 8, I 7, 81

Lang, W. H., vii

Latreille, 27, 66

Lavoisier, 64

Law, rule, 40

Leading property, 6r

Leaf, gradation in a, 204, 205

Leguminosa, 91

Leibnitz, 55

Lelewell, 80

Leontopodium, 9

Ligneous vessels, 112

Liliacece, 92

Lilium, I79

Lines, pure, I5, 31

Linnæus, 27

Linseed (oil), 4

Linum, 4, 8, 47

Living substance, 2, 70 ; variation of, Lizard, 97

Lloyd, C. G., 2 10

Lopezia, I81

Ludwig, I78, I79, I86, 191, 192, 197

Lychnis, 17

Lycoperdon, 8I

\section{M}

$m$-o- $M$ values, 172

MacIntosh, D. C., 29

MacLeod, 40, 69, I78, I 83

Mariotte, 35

Maximal value, I73

Mayer, A. G., 28

Mean deviation, 30 
Mean error, 30

Mean value, 29, 147, 16r, 166, 173 ; use of, 176 ; relation with variation steps, $176, \mathbf{1} 81$

Mechanical concordance, 196

Melandrium, 17

Melica, 219

Melon, 195

Mendel, Gregorius, 21, 32, 65, I I 5, I34, 139

Mendelism, I34, 2 I 5

Mentha, 2 I

Meristic variations, 69

Miers, Sir Henry Alexander, I

Mimosa, 78

Minimal value, 175

Mixtures, 4

Mnium, variation in, $28,69,182,188$, 190, 202

Mobilis atas, 57

Monocotyledons, I 79

Monotypic species, I4

Morus, 91

Mosses, ro4, 106, 108, 109, 178

Muscle, contraction of a, 50

Mutation, 7, 8, 16, 14I, 215

Mycology, 2 Io

Myosotis, 191, 194, 196

Myxomycetes, 79

\section{$\mathrm{N}$}

NAEGEII, 35, 79

Narcissus, II 2

Nautilus, I 13

Nectarine, 195

Nicotiana, 6

Nigella, 183

Nucleus, 5

\section{O}

Obliquangular system, I09

Oblique (false) axes, 108

Enothera biennis, 21, 38; constant hybrid, 38

Oils (fixed), 2

Onagracea, $18 \mathrm{I}$

Ophiocama, 29

Opium, 4

Optimum, r68

Orchids, 78, 8I, 92

Owen, R., 66

$\mathbf{P}$

Pexpogenesis, 205

Pædogenetic state, 52, 59, 205

Palæontology, 212

Papaver, $4,57,183$

Partula, II 4

Patella, II 3

Pea, 32, I34
Peach, 195

Pearson, Karl, 31, I 83

Pecten, 109, 178

Pediastrum, 78, 178, I80

Pelecypods, II 3

Percy Groom, 200

Perennials, 92

Personal equation (coefficient), 49

Phajus, 73

Phallus, 6, 7

Philodendron, 12, 43

Phleum, 18, 20, 176, 209

Phloem, II 2

Phyllotaxis, 48, 190

Pigeon, 195

Pinus, 196

Pisum, 32

Planorbis, 212

Plasticity, 9, 52, 58

Plastids, 5

Plateau, Josef, 49

Pleurococcus, 94, 97

Plum, I6

Poa, II2, I75, 199, 204

Polygonum, 10, 44, 48

Polyps, 77, 79, 81

Poppy, 183

Possibilities, 9, 26, 36

Potato, 16

Potentialities, 9, 26, 36

Potentilla, 17

Prasiola, 97

Priestley, 64

Primordia, 40; classification, 66, 69, $74,87,89$; classified according to their development, 55 ; accrescent, 56 ; arrested, 54; awakening, 53 ; caducous, 54 ; deciduous, 54 ; metamorphic, 53 ; original, 53 ; transitory, $54 ;$ independence of, 204 ; leading, $6 \mathrm{I}$

Primula, 13, 18, 55, 185, I9I

Primulacea, 67

Probability, II 8

Probable error, 30

Progressive mutation, 59

Properties, combination (co-existence) of, 47 ; possible and observable, 9, 26 ; simple and compound, 40. See Primordia

Proteins, 3, 5

Prunus, 16, I92

Pseudoch cete, 84

Pseudoclytia, 28

Puccinia, 103

Pure lines, I5, 3I, 2 I6

Pyrus, 91

$$
\text { Q }
$$

Quantitative method, 26, II 5, I44 ; various applications, 207 


\section{INDEX}

Quercus, 88, 90

Quetelet, 28, 31, 70, I I 5

R

RACE, adaptation of the, 217

Radial system, 77

Ramification, 89

Rana, 19

Ranunculus, 10, 21

Recessive character, 33

Reptiles, scales, $8 \mathrm{r}$

Reseda, 89

Retina, II 4

Retrogressive mutation, 59

Rhododendron, 9, 78

Root, primordia, I I2

Rosa, I3, 2 I 6

Rosacea, 191

Rubia, 6

Rubus, 216

Rule, law, 40

Rye, I7

S

Saccharomyces, 78

Salicornia, 21

Salix, 216

Saltation. See Mutation

Scalaria, 178, 183

Sciurus, 28

Secale, 17, 175

Seed rarely produced in many species, I 7

Seed-fixed properties, I6

Seed-species, 16

Segregation, 34, 38 ; in hybrids, 34, 35,40 ; by gradation, 45 ; in the course of individual development, 46 ; by plasticity, 43

Selaginella, 78

Selection, 7, 8r, 215, 217

Senecio, 12, r79, I8I, 182

Sensations, duration of, 49

Sensitive period, $56,75,82$

Serrure, 80

Sertularia, 8r

Sexual characters, 205 ; secondary, 60

Shells, collection of Ph. Dautzenberg, 24; of molluscs, 98, I 13

Shrubs, 92

Simple properties, 40

Skin, human, 98

Social: cause, difference, environment, 73 ; equivalence, 9r ; relations, 91

Solanum, nigrum, 8, II ; potato, 16

Soldanella, 9

Solidago, 92
Species, constancy of, 215 ; description of, 207, 209, 217; independence of, 215 ; Jordanian, 216 ; notion of, I, 2I4; monotypic, I4; complex, 14 ; horticultural, 16 ; bud-, 16 ; seed-, 16 ; origin of, I4I

Specific, energy, I16, I29, I81, 187 ; constants, 174, 176, 218

Specimen, 7I

Sphere, equilibrium on a plane, I 16

Spirogyra, 70

Sport, 7,8

Sprengel, Chr. K., 35

Spurs, 92

Steinbrink, 74

Stellaria, 18

Stomates, 102

Subspecies, 7, I I, I4

Substantive variation, 69

Symmetry, relation with variation steps, 180

Symphoricarpus, 91

Systematics, importance of, 2 I I

$\mathbf{T}$

TABLES, of constants, 218 ; of identification, 218

Tail (head or), I I6

Talpa, 8I

Teleutospores, 77, 103

Tellina, 109

Tetrahedral system, 78

Thistles, I I

Thorpe, Edward, 2, 3, 4

Trees, 88, 92

Triaxial system, $\mathrm{r}$ IO

Trifolium, 89, 178, 180, 193

Triodia, 209

Tschermak, 35

Tulostoma, 81

Turkey, 195

Types (specimens), 2 10

\section{U}

Ulmus, 204

Units, biological, 7I, 84 ; intermediate, 96

Unwin, G., viii

V

VAlUE, maximal, 173; $m-0-M, 172$; minimal, I75; optimal, 168. Sce Mean Value

Vanda, 99

Vandevelde, A. J. J., 107

Variants, ro

Variation curves, 29, 160, 165 
Variation: alternative, I5I ; complexity, II ; continuous, discontinuous, $17,150,153,185,187$; index of, 30 ; meristic, 69 ; parallel, 195 ; plasticity, 9; substantive, 69: under cultivation or domestication, I 7

Variation steps, I78; gradation, I84; methods for the discovery of, 192 ; parallel, 196; plasticity, 184 ; relation with mean value, I76, I81; relation with phyllotaxis, 190; relation with symmetry, I80; selection, 186 ; specific difference, 187

Varieties, II, I5

Vernon, 28, 182, I86, 195, 215

Verschaffelt, E., 107, I78

Vertebrates, 97

Vexillary marks, 98 , 108

Viola, 46, 194

Vitis, 16

Volvox, 83
Vries, Hugo de, II, 16, 22, 35, 38, 49 , $57,178,182,186$

\section{W}

WALIACE, $3 I$

Wasteels, I 78, I 83

Weiss, F. E., vii. 69

Weldon, W. F. R., 3 I

West, G. S.; 78, 83, 84, 93

Wheat, I 77

Wille, N.; 97

$\mathrm{x}$

XYLEM, II2

Z

ZENITH-NADIR, IIO

Zygnema, 70 



\section{PLEASE DO NOT REMOVE CARDS OR SLIPS FROM THIS POCKET}

\section{UNIVERSITY OF TORONTO LIBRARY}




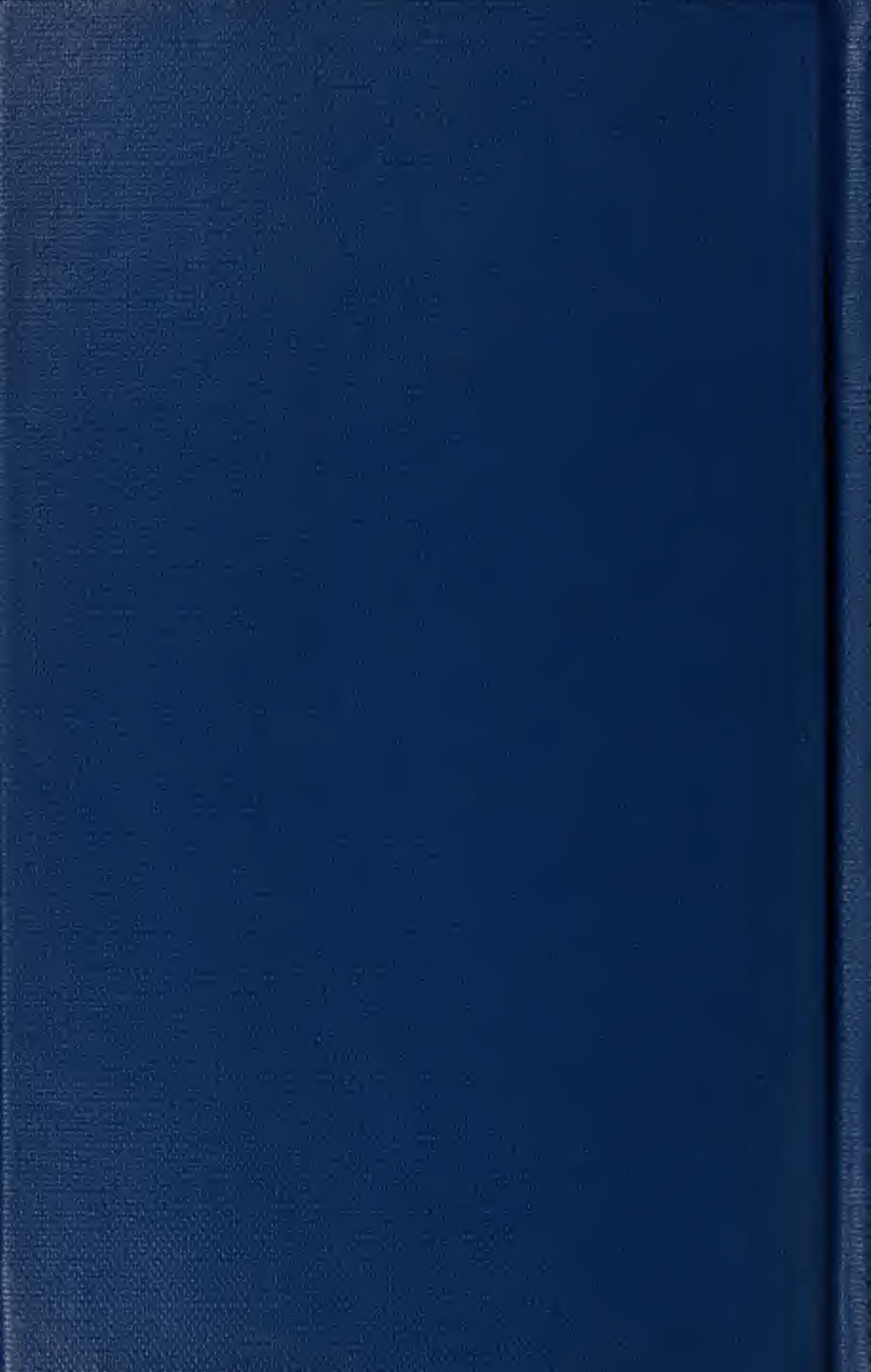

